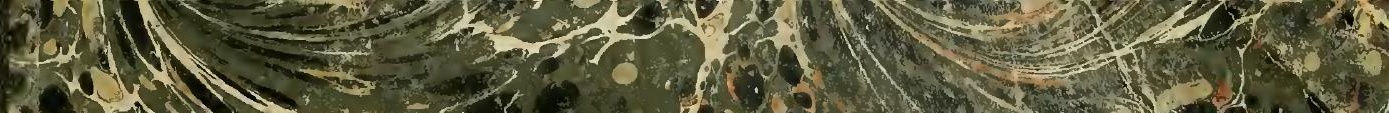

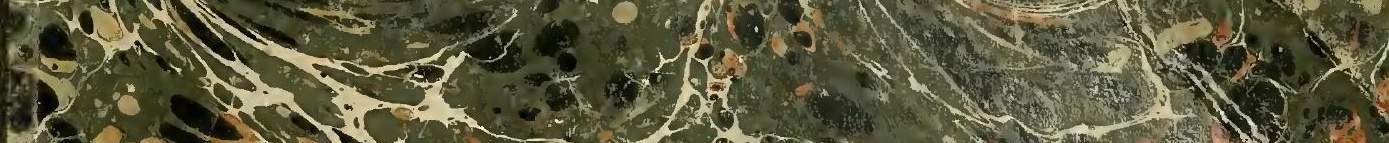

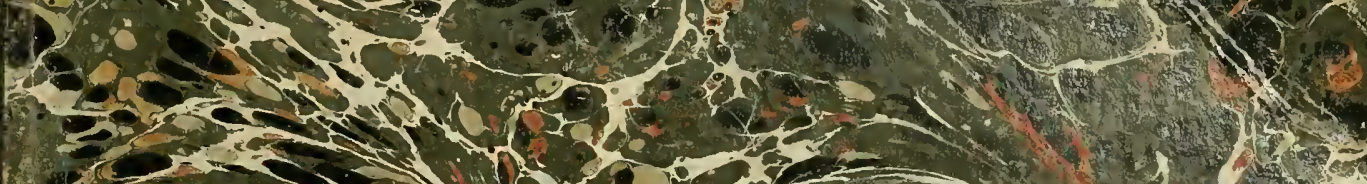

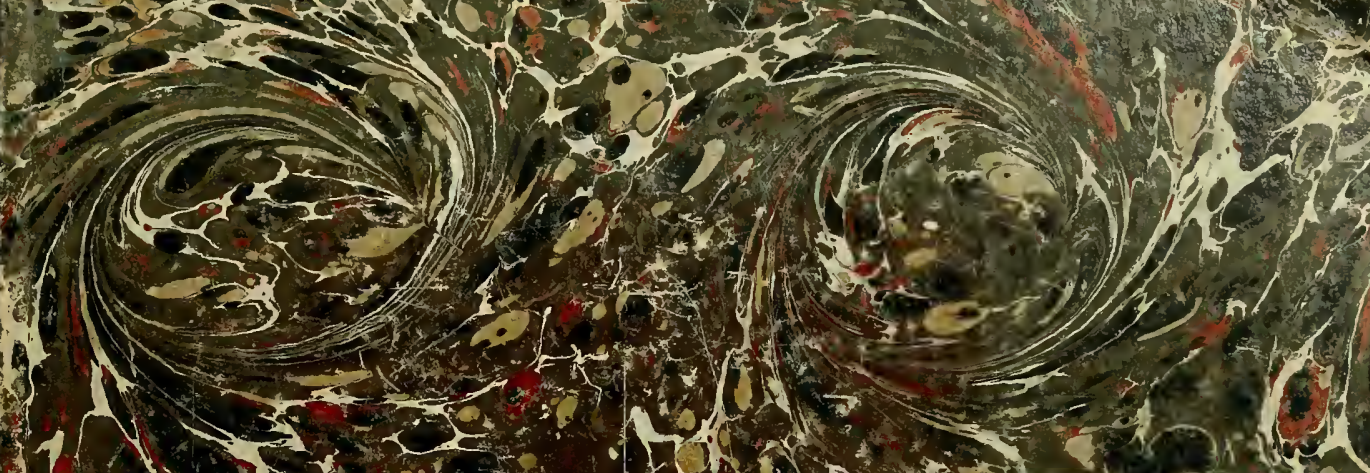

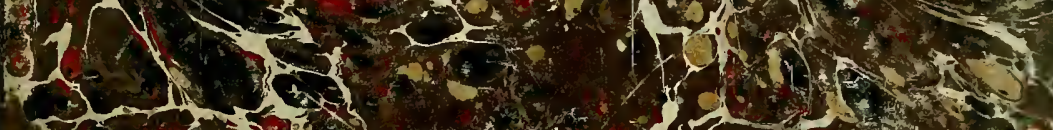

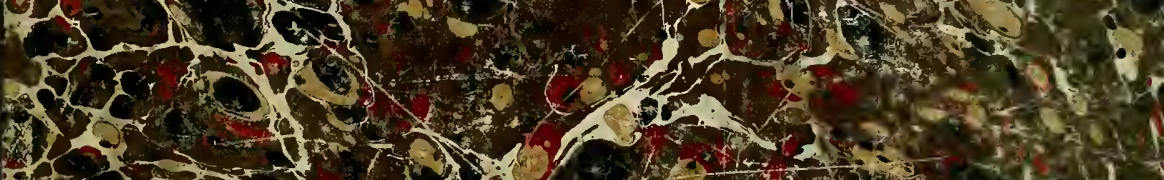

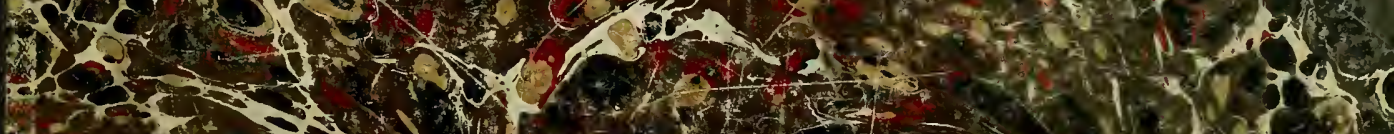

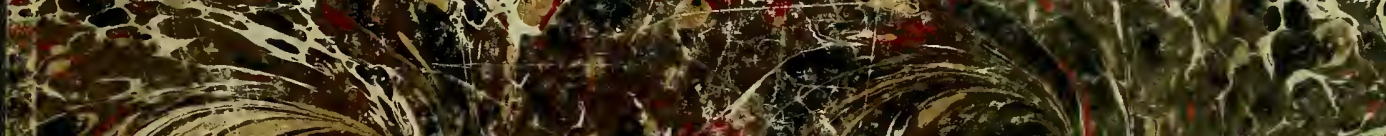

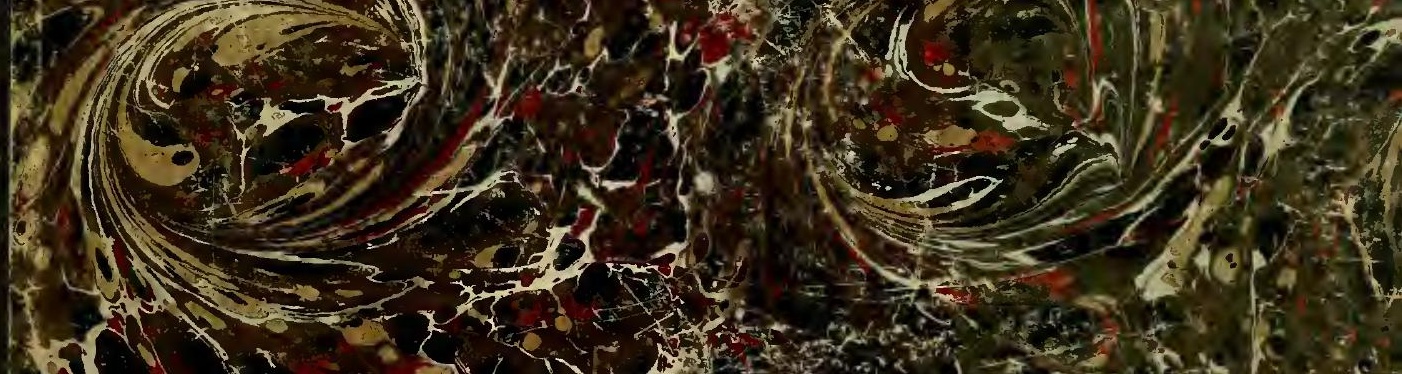

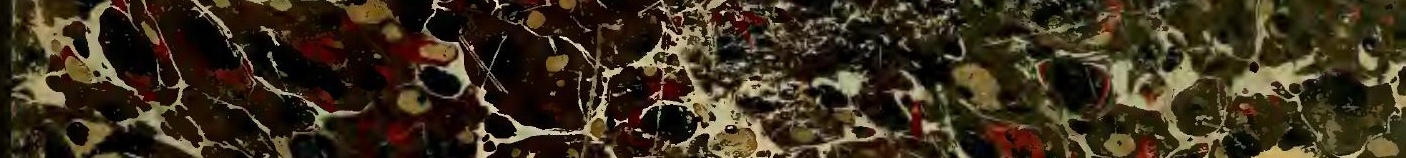

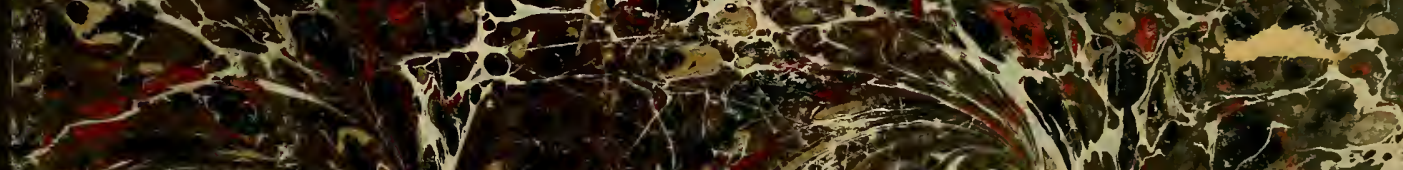

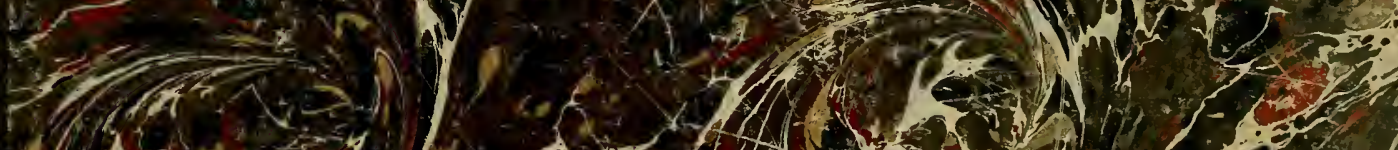

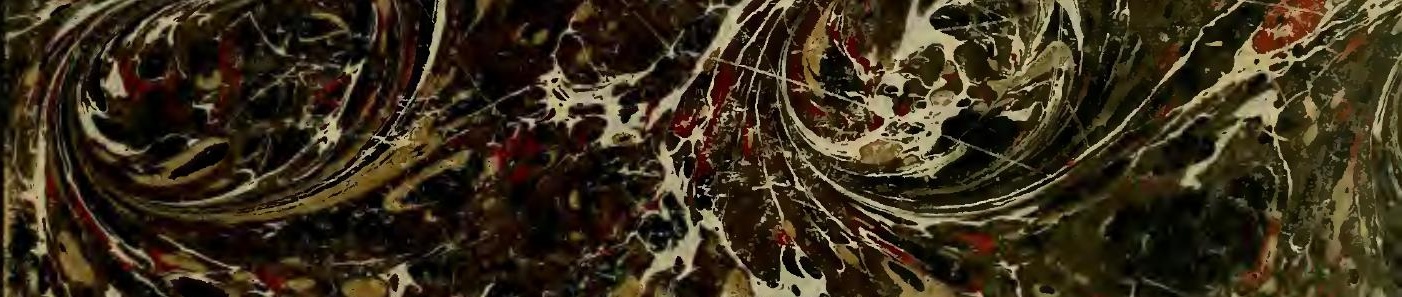

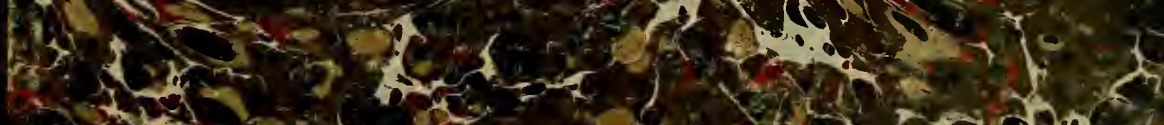

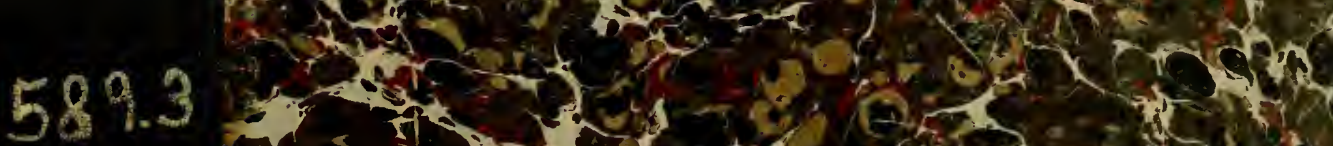

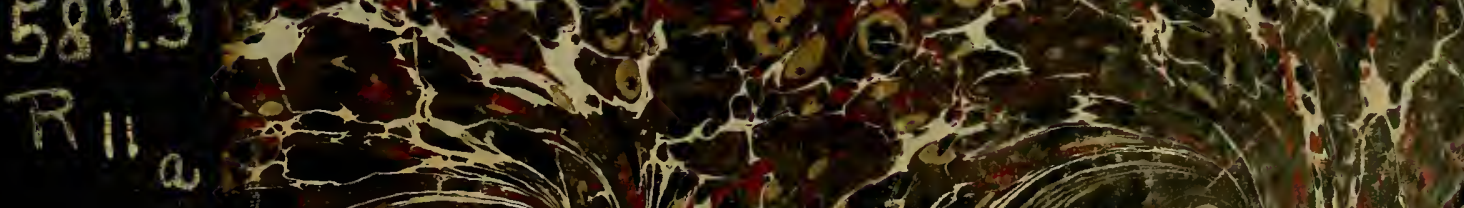


Dr rer. nat.

c. Schomente. 


DIE

\section{SÜSSWASSER-DIATOMACEEN.}

(BACILLARIEN.)

\section{FC̈R FRECNDE DER MIKROSKOPIE}

BEARBEITET

\section{L. RABENHORST.}

IIT ZEHN LITHOGRAPHIRTEN TAFELN.

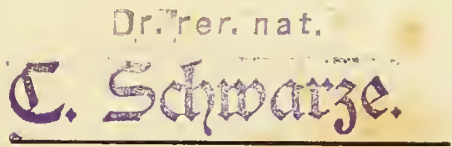

LEIPZIG,

E D U A R K I II M R. 



\section{VORWOR'T.}

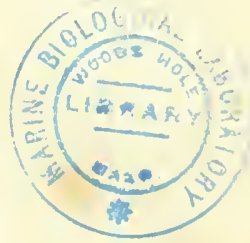

Zu dem reichen Material, welches ich seit mehreren Jahren sowohl in Sachsen, wie auf Reisen in und ausser Dentschland, zumal aber 1847 in Italien gesammelt hatte, kamen in den jüngst vergangenen Jahren mit dem Begimn neiner Bacillarien-Hefte. Beiträge ans allen Gegenden Dentschlands, Süd- und Nord-Europas; und noch weiter hinaus: im Orient, in Amerika, in Südpersien, Labrador, Grönland u. a. O. erschlossen sich mir Quellen, die viel des Interessanten und Nenen lieferten. Es sind zmmal folgende Herren, denen ich mich dankbar verpflichtet fühle:
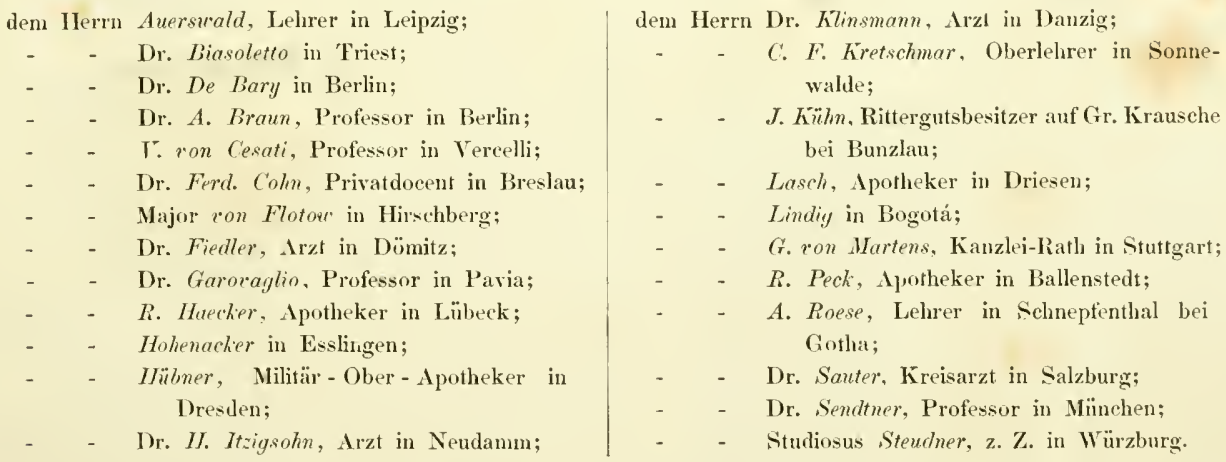

Durch mehrere der elen genannten und rülmbichst bekannten Männer, zumal aber durch Herrn Hohenacker, Herrn Bischof Brentel, Herm Lindig in Bogotá und Herrn Lechler in Chile sind nir anch für die nächste Zukunft die schönsten Anssichten anf reiches Material erüfnet. Doch anch schon das vorhandene schien ansreichend, eineu nicht unwïrdigen Beitrag zm Kenntniss und Verbreitung dieser zierlichen Organismen zn geben, und so war ich im Begriff, ihn der Oeffentlichkeit zu übergeben, als man mich ron mehreren Seiten aufforlerte, die sämmtlichen Süsswasserformen als ein geschlossenes Ganze kurz und fasslich für. Freunde der Mikroskopie, denen diese Wesen so häufig begegnen, zu bearbeiten. Ich erkannte die Nützlichkeit und das Bediurfniss, indem die Literatur nichts Aehnliches bietet, und so entschloss ich mich sehr leicht, das Bekamnte nachzutragen, dahingegen die nenen Meeres-Finmen, sowie die fossilen aber zu einer andern Arbeit zurïckzmnehmen.

So sind diese Blätter entstanden und so äbergebe ich sie zunächst den Fremden der Mikroskopie mit lem Wunsche, dass sie ihnen den Nutzen gewähren mögen, den sie davon erwarten. Doch nicht ansschliesslich für sie, auch fü̈ die Wissenschaft werden sie 
nicht nutzlos voriberziehen, indem ich zu wesentlich andern Resultaten gelangt bin, als alle meine Vorgänger.

Noclı labe ich zu benerken, dass die Vergrösserungen fast ohne Ansnahne $=\frac{300}{1}$ sind. Die (rössen sind nach Millimeter (Mm.) angegeben um zwar deshalb, weil eine solche Mikrometertheihng sich ein Jeder leicht anschaffen und bei jerlem Mikroskope anwenden kam. Herr $C$. Zeiss in Jena liefert ein solches lnstrunent für 4 Thaler. hch nuss hierbei aber daranf anfuerksam machen, dass die Objecte mit solchem Glasmikrometer nur trocken gemessen werden können, inden die Theilstriche im fenchten Znstande nicht sichthar sind. Ein Schranben-Mikrometer, das $\frac{1}{100, n 00}$ par. Zoll noch angiebt und wonnit ich gewöhnlich arbeite, ist sehr thener und nur bei einem Instrumente erster Construction anweudbar, ich labe deshalb hier keinen Gebrauch davon gemacht, habe aber bei einigen Arten, die mir nicht genau bekannt sind, der Vollständigkeit wegen aber doch mit erwähnt werden mussten, ihre Grössen nach den Hessungen (mit Schraukemmikrometer) der Antoren in Linien ("“) angegeben.

Alle Citate habe ich remieden, dafür sehliesst sich ein Synonymen-Register mit Angabe der Literatur an, wobei freilich die Grenzen der Süsswasserformen nicht immer innegehalten werden konnten und durften.

Dresden im Februar 1853.

\section{Rabenhorst.}

Sinnstörende Druckfehler.

Scite 8. Zeile 16. v. u. statt in Mitte lies: in der Mitte.

- 11. - 15. v. o. statt Fäden lies: Faden. - Das dahinter befiudliche Komma streiche.

- 37. - 12, v. o. statt Fasiola lies: Fasciola. 


\section{SACHREGISTER.}

\begin{tabular}{|c|c|c|c|c|c|c|c|c|c|c|c|c|c|c|}
\hline \multirow{2}{*}{\multicolumn{3}{|c|}{ Achnantheae Fam. IV. Charakteristik }} & \multicolumn{4}{|r|}{ Seite } & & & & & & \multicolumn{3}{|r|}{ Seite } \\
\hline & & & & & 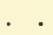 & 25 & striatus Ehrenb. & - & te & & & & & 13 \\
\hline Zahl der bekannten Arten & . & & & & 25 & 64 & Surirella Ehrenb. . & . & 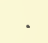 & & & & & - \\
\hline Achnanthes Bory (T. VIII.) & . & & & & • & 25 & Ceratoneis Ehrenb. (T. IX. & 5.). & . & & & & & 37 \\
\hline . & . & & & & . & 26 & amphioxys . . . . & . . & & s. & & & & \\
\hline crista & . & & & & 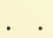 & - & . . . & . & . & & & & & \\
\hline . . . . & . & & & & . & - & Fasciola . . & . . & . & & & & . & \\
\hline a Kitz. . . . & . & & & & - & - & gracilis Bréb. . . & . . & . & . & & & . & \\
\hline Ka Ktz. . . . & . & & 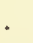 & . & . & 25 & laminaris. . . . & . . & 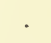 & . & & & . & . \\
\hline . . & 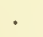 & & & & . & 26 & Cocconeideae Fam. V. Chara & akter & ristik & & & & & \\
\hline enb. . . & . & & & & & - & flanzung & .. & & 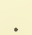 & & & 0 & \\
\hline n Kitz. (T. VIII.) & . & . & . & . & . & 25 & Zahl der bekannten $A$ & Arten & n & . & & & & \\
\hline aeg. . & . & . & & • & • & - & Cocromeis 1 & & & . & & & & \\
\hline lum Kitz. . & - & & & & & - & Cocconeis & c) & & & & & & . \\
\hline otrantinum Rabenl. . & - & & & & & - & b. & . & . & . & & & & \\
\hline ciculares & & & & & & & i $\cdot$ & - & & - & & & & . \\
\hline & & & & & & 9 & abenh. & . $\cdot$ & - & - & & & & . \\
\hline r. V.) & . & & & & . & 36 & ca Ehrenb. & - $\cdot$ & . & . & & & . & . \\
\hline nb & . & & & & . & - & Ehrenb. . & - . & . & . & & & . & . \\
\hline nb. (T. IX.) & . & & & . & . & 31 & . . & . . & . & . & & & & . \\
\hline . & - & & & & - & - & ta Ehrenb. · & . $\cdot$ & · & · & - & & . & . \\
\hline angusta & . & & & & & - & limbata Ehrenb. · & . . & . & . & . & & & \\
\hline aponi & & & & & & - & Ehrenb. & r & 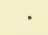 & . & & & & \\
\hline libyea 1 & . & & & & & - & a Ehrenb. & - & · & · & & & · & \\
\hline borealis Ktz. . . . & . & & & & & - & Ritz.) . . & . & . & . & & & . & \\
\hline coffeaeformis (Ag.) Kitz. & . & & & & & - & Pediculus Ehrenb. . & . & . & . & & & . & \\
\hline (18) & & & & & • & - & 1. . . & . & . & . & - & & & \\
\hline & . & & & & . & - & a Ehrenb. & . & . & . & & & & \\
\hline benh. & & & - & & • & - & 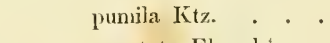 & $\cdot \cdot$ & - & - & & & - & . \\
\hline & & & & & & . - & punctata Ehrenb. . & - & . & . & & & . & \\
\hline & & & & & & $\ldots$ & ) . . & & - & . & & & . & \\
\hline & & & & & & & Ehrenb. & & & & & & & \\
\hline ares . & & & & & & $?$ & & & . & 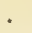 & & & & \\
\hline rcuatae . . . . . . & . & & • & · & . & 8 & striolata Rabenh. . . & . $\cdot$ & . & . & - & & & \\
\hline Calodiscus Rabenh. (T. III.) & . & . & & . & . & 12 & conema Ehrenl). (T. VI & I1.) & . & . & . & & & \\
\hline superbus Rabenh. . . . & . & . & & • & • & - & affine Kíz. . . . & 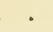 & . & . & & & & \\
\hline b. (T. 1I.) & . & & & & • & 13 & Arcus Ehrenb. & 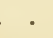 & • & - & & & & \\
\hline 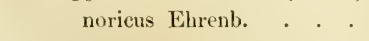 & . & & & & . & - & ii $x^{2}$ & - $\cdot$ & . & . & & & & \\
\hline radiosus E & & & & & & - & Cistula Ehrenb. & & & & & & & \\
\hline
\end{tabular}


cornutiam Ehrenb.

cymbiforme Ehrenl.

gihbum Elrenb.

Janceolatum Elarenb.

mexicanum Ehrenb.

saxunicum Rabenh.

sunuilum Jiréh.

Colletonema Brél).

eximinm (Thwates) kitz.

lacustro ( $\mathrm{lg}$.) Ktz.

virilulum Brél.

\section{Cuneatae}

Cyclotella kitz. ('T. II.)

meneghiniana Kitz.

operenlata ( Ig.) Kiz.

rectaugula lirél.

Cymbella Ag. (T. VII.)

aftinis kitz.

amphicephalat Nateg.

eurvata Rabenh.

delicattula Kitz.

Ehrenbergii Ktz. . . . . . . . . . 22

epithemoides Rabenh. . . . . . . . -

excisa Ǩ́tz. . . . . . . . . . . 23

flexella kiz. . . . . . . . . . -

fornicata Rabenlı. . . . . . . . 22

Fusidim (Ehrenb.) Rabenl. . . . . . 28

grustroides Ktz. . . . . . . . . . 21

gracilis (Elurenb.) Ktz. . . . . . . . 2.

helvetica Kíz. . . . . . . . . . - -

heteropleura (Elrenb.) . . . . . . -

Iepterceras Ehrenb. . . . . . . . -

Lmula (Ehrenb.) Rabenh. . . . . . 23

maxima Xaeg. . . . . . . . . 20

microstoma Rabenlı. . . . . . . . -

obtusiuscula Kíz. . . . . . . . . . 2:8

Orsiniana Rabent. . . . . . . . . -

pachycephala Rabenl. . . . . . . 22

porrectit Rabenh. . . . . . . . . -

rostrata Rabenh. . . . . . . . . -

truneata Rabenh.. . . . . . . . 2]

ventricosa Kt\% . . . . . . . . 2:3

Cymbelleae lam. III. Charakteristik . . . 21 Sticlbildung . . . . . . . . . Zahl der hekannten Arten . . . . 21. 61

Denticula Kitz. ('T. J.) . . . . . . . . : 32 acuta Rabenh. . . . . . . . . 33 constricta (Blarenb.) Ktz. . . . . . . crassula Niteg. . . . . . . . . . elegans kít.. . . . . . . . . . frigida litz. . . . . . . . . . . olitusa ( Ig.) Kt\%. . . . . . . . . - tenuis Kit . thermalis Ktz. . . . . . . . . 33

undulata (Ehrenb.) Ktz. . . . . . . 32

Diadesmis Ktz. (T. IX.) . . . . . . . . 51

confervacea Ǩ́tz. . . . . . . . . . -

Diatoma Dee. (T. II.) . . . . . . . 32. 35

cuneatum Rabenh.

Ehrenhergii Kíz. . . . . . . . . . -

elongatum $\lg$. . . . . . . . . , -

gracillinum Naeg. . . . . . . . . -

mesudun Kiz. . . . . . . . . . . -

meooleptum Ḱtz. . . . . . . . . . -

peetinale Kt\%. . . . . . . . . . -

tenu Kítz. . . . . . . . . . . . -

vulgare Kt\%. . . . . . . . . . -

\section{Diatomaceen.}

Charakteristik dersclben . . . . . . l

Experiment zur Unterscheidung derselben von verwandten formen

Die Sulstanz Jer Ilïlle und die Gestalt des Panzers untrügliche Kennzeichen der Diatomaceen

Beschatfenheit des den Diatomaceen eigenthümlichen Farbstotfes

Verschiedenartigkeit der Hïlle bei verschiedenen Gattungen

Dreifache Fortptlanzung: a) durch 'Theilung der Mutterzelle in zwei neue oder Tochterzellen; b) durch einfache oder dojpelte (inpulation; c) durch wirkliche linchtzellen

Jic" ansdicinend lreiwillige bewegung der freien, nicht angewachsenen Diatomaceen $3 \mathrm{f}$.

Ihr Vorkonmen . . . . . . . $4 \mathrm{f}$.

Art les Einsanmolus . . . . . . 5

Ihre Anfluewahrung . . . . . . . . -

Welche Instrumente zur Lntersuchng nothwentig sind . . . . . . . $5 \mathrm{f}$.

Wie die Untersuchung in Bezng anf Bestimmung anzustellen ist. . . . . $6 \mathrm{f}$.

Uebersicht der Familien und Galtungen, wobei die Gestalt der Individuen als leitendes Princip angenommen ist . . T-10

Discosire Rabeuh. (T. III.) . . . . . . 12 sulcata Rabeuh. . . . . . . . . . -Echinclla (T. IV. u. V.) 2. Untergattung der synechar . . . . . . . . . . 53

Ellipsoidea vill Ovoideate . . . . . . . 5 Encyonema Kiz. (T. VII.) wesentlich von den Cymbellen versehieden . . . . . 21. 24t Anerswaldii Rabenl. . . . . . . 24 caspitusum Ǩ. . . . . . . . . . gracile Rabeuh. . . . . . . . . 25 paradoxum Kitz. . . . . . . . $2 t$ prostritum Ralfs . . . . . . . . - 
Epithemia Bréb. (T. 1.) . . . . . . . 17 adnata liréb. (Vertagus Kítz.) . . . . . 18 alpestris Kiz. . . . . . . . . . angulata Perty . . . . . . . . Argus Ehrenb. (Kłz.) . . . . . . 19 gibba (Ehrenb, Kḱtz. . . . . . . 17 gibberula (Ehrenb.) . . . . . . . 19 Librile Ehrenb. . . . . . . 18 Lindigii Rabenh. . . . . . . . . 19 margaritifera Rabenh. . . . . . . 17 ocellata (Ehrenb.) Kítz. . . . . . . . 19 otrantina Ralenh. . . . . . . . quinquecostata Rabenb. . . . . . . Is reticulata Naleg. . . . . . . . . saxonica Kít.. . . . . . . . . . Sorex kítz. . . . . . . . . . . Textricula Ehrenb. . . . . . . 19 turgida (Ehrenb.) Kitz. . . . . . . 18 ventriensa lítz. . . . . . . . . 17 Westermani (Elirenb.) . . . . . 18 Zebra (Ehrenb.) Kiz. . . . . . . . zebrina Ehrenb. . . . . . . . -

Eunotia Ehrenb. (T. I.) . . . . . . . 15 alpina lítz. . . . . . . . . . 16 amphilepta Ehrenb. . . . . . . . . amphioxys Whrenb. . . . . . . 15 bidens Ehrenb. . . . . . . . 17 bigibba Kítz. . . . . . . . . . . Camelns Ehrenb. . . . . . . . . . corona Rabenh. . . . . . . . . . Crocodilus Ehrenb. . . . . . . 16 dectivis Ehrenb. . . . . . . . 17 depressa Ehrenb. . . . . . . . 16 Diadema Ehrenb. . . . . . . 17 Diana Ehrenl. . . . . . . . 16 Diodon Elurenb. . . . . . . . . dizyga Ehrenl. . . . . . . . . 17 Elephas Ehreub. . . . . . . . . . Hexuosa Brél. . . . . . . . . 16 Furmiea Ehrenl,. . . . . . . . . nodosa Ehrenb. . . . . . . . . . pachyceplala Kíz. . . . . . . . . paraltela Ehrenb. . . . . . . . . pracenta Elarenb. . . . . . . . . quaternaria Ehrenb. . . . . . . . 17 quínaria Elırenl. . . . . . . . . . Sella Elrenb. . . . . . . . . . septena Elrenb. . . . . . . . . . tridentula Ehrenb. . . . . . . . . mucinata Ehrenls. . . . . . . . 16 ventralis Ehrenb. . . . . . . . . . Zygodon Ehrenb. . . . . . . 17

Eunotiaceae Fam. II. Charakteristik

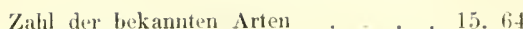

isolirt lebende. . . . . . . . 15

Familienwejose lebende . . . . . . -

Falcatella Riabeuh. (T. V.) . . . . . . 16 i

delicatula Rabenl. . . . . . . . -

lunata Rabenh. . . . . . . . . . -

neapolitana Rabenl. • • • . . . . -

romana lahenh. . . . . . . . - -

Fragilaria Lyngb. (T. I.) . . . . . . 32.33

aeuta Ehrenb. . . . . . . . 34

bipunetata Ehrenl. . . . . . . 33

eapucina Desmaz. . . . . . . . . -

eonstricta Ehrenl). . . . . . . . 34

corrugata Ktz. . . . . . . . . . -

diophthalma Whrenb. . . . . . . 33

rhabdosoma Ehrenb. . . . . . . . 3t

virescens lialfs . . . . . . . . 3:3

Fragilarieae fam. VII, Charakteristik . . 32

Fortptanzung . . . . . . . . . . -

Zahl der lekannten Arten . . . .32. 6it

isolirt Jebende Irten . . . . . $32 \mathrm{f}$.

zu Bändern verbunden . . . . . $33 \mathrm{f}$.

Bänder zickzackförmig anfgelöst . . . . 35

Frustulia Ag. ('T. VII.) . . . . . . . . 50

Haeckeriana Rabenh. . . . . . . . -

Ḱ̈̈tzingiana Rabenh. . . . . . . . -

minuta Rabenh. . . . . . . . . -

salina Ehrenly. . . . . . . . . 51

saxonica Rabent. . . . . . . . 50

forfacea A. Bram . . . . . . . -

Gallionella Ehrenb. . . . . . . . 1:

Gomphogramma, warum zu den Fragilarien ge-

z) gen und neben Dentienla gestellt. . 32

Charakteristik . . . . . . . . 33

G. rupestre A. Braun . . . . . . . . -

Gomphomella Rahenh. (T. IX.) . . . .57.61

angusta Rabenl.. . . . . . . 61

Lenormandi Rabenl. . . . . . . -

slivicea Rabent.. . . . . . . . . -

parvula Risbenh. . . . . . . . . -

Gomphonema $\mathrm{Ag}$. (Т. VIHI.) . . . . . 57.58

abbreviatum $\mathrm{Ag}$. . . . . . . . 5.5

acuminatum Ehrenb. . . . . . . 60

aftine Ktz. . . . . . . . . . . . 59

anglicum Whrenb. . . . . . . 60

Augur Ehrenb. . . . . . . . . . -

auritum 1. Braun . . . . . . . 59

Brébistonii lítz. . . . . . . . . 60

eapitatum Ehrenb. . . . . . . . . -

davatum Ehrenb. . . . . . . . 58

constrietum Ehrenh. . . . . . . 60

contractum Kitz. 
coronatum Ehrenb. . . . . . . . 60

crassum Rabenh. . . . . . . . . 59

erispatum Ralfs . . . . . . . . -

curvatum Kítz. . . . . . . . . . -

cuspidatum Rabenh. . . . . . . . -

Cygnus Elırents. . . . . . . . . -

discolor Elırenb. . . . . . . . . -

erosum Rabenl.. . . . . . . . . -

geminatum $\Lambda \mathrm{g}$. . . . . . . . . 60

giganteum Ehrenb. . . . . . . . -

gracile Ehrenl. . . . . . . . . . 59

hereynicum Rabenb. . . . . . . . -

intricatum Ktz. . . . . . . . . . -

Lagemula lítz. . . . . . . . . . -

lanceolatum Ehrenb. . . . . . . - -

laticeps Elurenb. . . . . . . . . 60

mieropus Kiz. . . . . . . . . . $5 \mathrm{~S}$

nasutum Elirenb. . . . . . . . . 60

persicum Rabenl. . . . . . . . 59

pulvinatum A. Braun . . . . . . . 58

rotundatun Elırenb. . . . . . . -

Śceptrum liabenh. . . . . . . 60

sphenelloides Rabenl.. . . . . . 58

subtile Ehrenb. . . . . . . . 60

tenellom litz. . . . . . . . . . 58

Vibrio Ehrenb. . . . . . . . . 59

Gomphonemeae Fam. X. Charakteristik . . . 57 ilure Fortpllanzung . . . . . . . -

Zahl der bekannten Arten. . . . 57. 64

Gyrosigma Hassall. (T. V.) . . . . . . . 46 acuminata Rabenh. . . . . . . 47 aestuarii Bréb. . . . . . . . . . Agellus Ehreub. . . . . . . . . apula Rabenl. . . . . . . . . attenuata Rahenh. . . . . . . . baltica (Elirenb.) . . . . . . . . curvula Rabenlı. . . . . . . . . . cuspidata kabenh. . . . . . . . - dubia Rabenh. . . . . . . . . IIassallii Rabenh. . . . . . . . Ilippocampus Ilassall. . . . . . . . l:umprocampa Rabenh. . . . . . . . Scalpellum Rabeuh. . . . . . . . . thuringiea Rabenh. . . . . . . . . -

Himantidinm Ehrenb. (T. I.) . . . . . 19 Arcus Elrenl). . . . . . . . . 20 attenuatum Rabenh. . . . . . . . 19 biceps Rabenh. (Eunotia biceps Ehrenb.) . 20 bidens Elirenb. . . . . . . . - exiguum lirél. . . • . . . . . 19 gracile Ehrenh. . . . . . . . . 20 gujanense Ehrenb. . . . . . . . IIalcyonellae Perty . . . . . . . . - minus Kt\%. . . . . . . . . . 19

monodon Ehrenl. . . . . . . 20

Papilio Ehrenb. . . . . . . . . . -

pectinale (Dillw.) Kłz. . . . . . . . 19

yuaternarium Elarenh. . . . . . 20

quinariun Ehrenb. . . . . . . . -

Soleirolii Kız. . . . . . . . . . 19

strictum Rabenh. . . . . . . . -

Tetraodon Bréb. . . . . . . . 20

veneris kítz. . . . . . . . . . -

Liparogyra Ehrenb. . . . . . . . . . 12

circularis Ehrenb. . . . . . . . . -

(spiralis) dendroteres Ehrenb. . . . . -

Lysigonium Link . . . . . . . . . . 13

Melosira C. Ag. (T. II.) . . . . . . . 13

atequalis $\mathrm{Ag}$. . . . . . . . . -

americana kíz. . . . . . . . . 1t

arenariat Hoore . . . . . . . . -

Binderiana kítz. . . . . . . . . -

crenulata (Ehrenb.) Ktz. . . . . . . -

listans Ktz. . . . . . . . . 13

garganiea Rabenl. . . . . . . . 14

Jürgensii Ḱtz. . . . . . . . . 13

orichalcea kítz. . . . . . . . . . -

Roeseana Rabenl. . . . . . . . -

salina Ǩ́tz. . . . . . . . . . -

subflexilis Kítz. . . . . . . . . -

valians $\mathrm{Ag}$. . . . . . . . . -

Melosireae Fim. I. Charakteristik . . . . 11

Zall der bekannten Gattungen und Arten 11. 64

Meridieae Fam. XI. Charakteristik. . . . 61 Zahl der bekannten Arten. . . .61. 64

Meridion Ag (T. I.) . . . . . . . . 62

circulare $\mathrm{Ag}$. . . . . . . . . . -

constrictum Ralfs . . . . . . . . -

panduriforme Ehrenb. . . . . . . -

Zinckeni Iítz. . . . . . . . . . . -

Nannema Elirenb. (T. VII.). . . . . . 5 I

americanum Ehrenb. . . . . . . -

amphioxys Ehrenb.

Naricula (Bory. T. V. u. VT.) . . . . . 37

Arten mit stumpten, niclit vorgezogenen

oder vorgestreckten Emlen . . . $37 \mathrm{ff}$.

Jrten mit seharf gespitzten Enden . . . 39

Arten nit mehr oder minder vorgestreekten

(kopfformigen) Euden

$39 \mathrm{f}$.

In der Mitte ansgeschweifte Arten, ron geigenförmiger Gestalt . . . . . $40 \mathrm{f}$.

Arten mit kuotig oder bauchig erweiterter

Nitte. . . . . . . . 41

Nav. acuta Kiz. . . . . . . . . . 39

affinis Elırenb. . . . . . . 40 
Nav, ambigua Ehrenb. . . . . . . . . 40

americana Ehrenb. . . . . . . . -

Amphigomphus Ehrenb. . . . . . 38

amphioxys Ehrenb. . . . . . . . . -

Amphirhynchus Ehrenb. . . . . . 40

amphisbaena Bory . . . . . . . . -

amphisphenia Ehrenb. . . . . . . 37

aponina Ktz. . . . . . . . . . . 39

appendiculata Kłz. . . . . . . . 38

Bacilum Ktz. . . . . . . . . . . -

liceps Ehrenb. . . . . . . . 40

binodis Ehrenb. . . . . . . . . 41

brachysira Bréb. . . . . . . . 39

Brébissonï Ktz. . . . . . . . . . 38

Carassius Elirenb. . . . . . . . 40

Cesatii Rabent. . . . . . . . . 39

crassula Naeg. . . . . . . . . 40

eryptocephala Ktz. . . . . . . . 39

cuspidata Ktz. . . . . . . . . . 37

Demerarae Ehrenb. . . . . . . 38

diaphana Ehrenb. . . . . . . . -

dilatata Ehrenb. . . . . . . . 37

Dirhynchus Ehrenb. . . . . . . 40

dubia Ehrenb. . . . . . . . -

duplicata Ehrenb. . . . . . . . -

eurycephala Rabenh. . . . . . . . -

exilis Ktz. . . . . . . . . . . . 39

Faba Ehrenb. . . . . . . . . 40

Formica Elrrenb. . . . . . . . 41

fulva Ehrenb. . . . . . . . . 37

gracilis Ehrenb. . . . . . . . 38

guttulifera Rabenh. . . . . . . . 40

Ilitchcockii Ehrenb. . . . . . . 41

inflata Ǩtz. . . . . . . . . . . -

Jürgensii ḱtz. . . . . . . . . 38

lanceolata Ktz. . . . . . . . . 39

latiuscula Ktz. . . . . . . . . . 38

leptocephala Rabenh. . . . . . . 39

leptogongyla Ehrenb. . . . . . . . 41

leptorhynchus Ehrenb. . . . . . . to

limbata Ehrenb. . . . . . . . . -

limosa Rabenl.. . . . . . . . . 41

lineolata Ehrenb. . . . . . . . 38

Lyra Elirenb. . . . . . . . . 40

mesolepta kihrenb. . . . . . . . . 41

mesotyla Elırenb. . . . . . . -

microstoma Ǩtz. . . . . . . . . 38

minutissima Rabenh. . . . . . . 39

mutica Ktz. . . . . . . . . . 38

nodosa Ehrenb. . . . . . . . 41

oblongella Naeg. . . . . . . . . . 39

obtusa Ehrenb. . . . . . . . 38

oralis Naeg. . . . . . . . . . 39

paradoxa Ehrenb. . . . . . . 40
Nav, persica Rabenh. . . . . . . . 41

polyonea Brél. . . . . . . . . -

Pupula Ǩtz. . . . . . . . . . . 38

pygnaea Ktz. . . . . . . . . . 39

rhombea Ehrenb. . . . . . . 38

rhomboides Ehrenb. . . . . . . . -

rhynehocephala Ktz. . . . . . . . 39

rostrata Ehrenb. . . . . . . 37

Schomburgkoram Ehrenb. . . . . . 39

scopulorum Bréb. . . . . . . . 41

Sernen Elirenb. . . . . . . . 38

seriaus Bréb. . . . . . . . . . -

Silicula Ehrenb. . . . . . . . 41

sphaerophora Ktz. . . . . . . . . 40

tenella Bréb. . . . . . . . . . -

Trabecula Ehrenl. . . . . . . 41

truncata Kłz. . . . . . . . . . . 39

tumidula Rabenh. . . . . . . $\$ 1$

undosa Ehrenb. . . . . . . . -

Velox Ktz. (ablonga Ehrenb.) . . . . 38

veneta Kitz. . . . . . . . . . . 39

viridula Ktz. . . . . . . . . 38

Naviculacea Fam. VIII. Charakteristik . . 36 Fortplanzung . . . . . . . . . -

Zabl der bekannten Arten. . . . 36. 64

Naviculares . . . . . . . . . . . 9

Nodosae . . . . . . . . . . 10

Odontidium Ktz. (T. II.). . . . . . . 32. 34

bogotánum Rabenh. . . . . . . . 32

capitatum Rabenh. . . . . . . . . -

chamocephalum Rabenh. . . . . . . -

glaciale Kız. . . . . . . . . . . -

grande (Ehrenb.) Rabenh. . . . . . 35

hyemale Ǩ́z. . . . . . . . . . 34

mesodon (Ehrenb.) Ktz. . . . . . . -

pinnatum (Ehrenb.) Ktz. . . . . . . -

salisburgense Rabenh. . . . . . . . -

striolatum (Ebrenb.) Ktz. . . . . . . -

turgidulum (Ebrenl.) Ktz. . . . . . . -

Oncosptienia Ehrenb. . . . . . . . 61

carpathica Ehrenl. . . . . . . . -

Ovoideae . . . . . . . . . . . 8

Pinnularia Ehrenb. (T. VI.) . . . . . . 42

Arten von nachenfürmiger Gestalt, mit stumpfen und zugerundeten Enden . . . . -

Arten mit stark verdünnten, fast zugespitzten Enden . . . . . . . . . .

Arten mit nicht ausgeschweiftem Rande, aber mit kopfförnig gestreckten oder eingeschnürten Enden . . . . 43 f.

Arten mit banchig- oder bucklig-aufgetrie-

bener Mitte. . . . . . . . $t 4 \mathrm{f}$. 
Arten mit ausgescliweifter oder zusammengeschürter Vitte, daluer geigenlörmig $4.5 \mathrm{f}$.

Pinn. acrosphaeria Rabenh. . . . . . . . 45 aequalis Ehrenb. . . . . . . . 44 ampliceros Ktz. . . . . . . . . . Amphigouplus Ehrenb. . . . . . 43 amphioxys Ehronb. . . . . . . Amphiprora Ehrenb. • . . . . . 46 Amphirhynchus Rabenh. . . . . . . 43 Apis Elntenb. . . . . . . . 4ti Bombus Hhrenb. . . . . . . . . borealis Ehrenb. . . . . . . 42 capitata labenh. . . . . . . . . . $4 t$ caraceana Ehrenb. . . . . . . . 42 chilensis Ehronl.. . . . . . . . . cocennoides Rabenl. . . . . . . 43 Conops Ehrenb. . . . . . . . . 46 costata Ehrenb. . . . . . . . 42 Cralno Ehrenb. . . . . . . . 46 Cyprimu Ehrenb. . . . . . . 44 Dactylus Ehreab. . . . . . . . 42 derurrens Elrenb. . . . . . . . 45 dicephak Ehrenb. . . . . . . . 44 didyma Ehrenb. . . . . . . . 46 diomphala Elırent. . . . . . . . 44 disciformis Rabenb. . . . . . . 42 displenia Ehresb. . . . . . . . 43 dissimilis Rabenh. . . . . . . . 45 Ehrenbergii Rabent.. . . . . . . 43 elliptica Rabenh. . . . . . . . 42 Esox Ehrenb. . . . . . . . . 45 garganica Rabeuh. . . . . . . . . 14 Gastrum Ehrenb. . . . . . . . gibba Ehrenb. . . . . . . . 45 gibberula Ktz. . . . . . . . . . Gigas Ehrenb. . . . . . . . 45 gracilis Ehrenb. . . . . . . . . 4:3 hemiptera Rabenh. . . . . . . . 42 inaegualis Ehrenb. . . . . . . . 49 inflata Rabenh. . . . . . . . . 4t interrupta Rabenh. . . . . . . . . Iridis Ehrenb. . . . . . . . . . 42 italica Rabenh. . . . . . . . . . Kefringensis Ehrenl. . . . . . . 45 lanceolata Elurenb. - . . . . . . 4:3 lata (Brob.) . . . . . . . . . 42 latimeula labenh. . . . . . . . 43 Legumen Elirenls. • . . . . . 45 libyca Ehronb. . . . . . . . . 43 limosa Rabeuh. . . . . . . . . 45 major Rabenl. . . . . . . . . . 42 mesogongyla Ehrenb. . . . . . . 45 Monile Elrenb. . . . . . . . . . nubilis Ehrenb. . . . . . . . 44
Pinn. ohlonga Rabenh. (macilenta Ehrenb.) . . 45 otrantina Rabenlr. . . . . . . . 44 pachycephala Rabenh. . . . . . . 43 pachyptera Ehrenb. . . . . . . 45 Parmula Brél). . . . . . . . - peregrina Elnenb. . . . . . . . 4s P'isciculus Ehrenb. . . . . . . . 44 Placentula Ehrenb. . . . . . . . porrectar Ehrenb. . . . . . . . 45 raliosa Rabenh. . . . . . . . . 43 rostellata Ktz. . . . . . . . . . 44 Sehombnrgkï Ehrenl. . . . . . . 43 sillinanorum Ehrenb. . . . . . . 44 suecica Ehrenb. . . . . . . . 42 Tabellaria Elnenb. . . . . . . . 44 Trabecula Ehrenb. . . . . . . . 45 Utriculus Ehrenb. . . . . . . 43 viridis liabenh. . . . . . . . . 42 viridula kabenh. . . . . . . . . 43 vulpina Rabenh. . . . . . . . . . -

Porocyclia Ehrenb. . . . . . . . 12 dendrophila Ebrenb. . . . . . . Pyxidicula Ehrenb. (T. 11.) . . . . . . . major Ktz. . . . . . . . . . . Scamularia Kítz. (T. IV.) I. Entergattung der symera . . . . . . . . 52

Sigmatella Kit\% (T. IV.) . . . . . . 56 Brébisonii Ktz. . . . . . . . italica Rabenh. . . . . . . . . Nitzsclii kíz. . . . . . . . . . tergestima Rabenh. . . . . . . . rermicularis kiz. . . . . . . . sphenella Kits. (1. VIII.) . . . . . . 57 argustata Kit\%. . . . . . . . 58 elongati Ktz. . . . . . . . . . . glacialis K1z. . . . . . . . . . . italica Rabenh. . . . . . . . . oltusata Kíz. . . . . . . . . . 57 parvinla Ktz. . . . . . . . . . 5s rostellata Kítz. . . . . . . . . . vulgaric К1\% . . . . . . . . . . Sphenosina Ehrenl. (T. VIII.) . . . . 57. 61

Catena Ehrenb. . . . . . . . 61 Stanrogramma Rabenl. (T. 1X.) . . . . . 50) persicum Rabenh. . . . . . . . Stanconeis lihrenb. (T. IX.) . . . . . 47 arroephata Rabenh. . . . . . . 4t amphicephala Kítz. . . . . . . . . amphilepta Ehrenl). . . . . . . . -anceps Elurenb. . . . . . . . . . Bendleyi Ehrenb. • . . . . . . . birostris . . . . . . . . . . constricta Ehrenb. . . . . . . . 49 dilatata Ehrenb. . . . . . . . - 
Staur. exilis Ktz. . . . . . . 48

Fenestra Ehrenb. . . . . . . . . -

gracilis Ehrenb. . . . . . . . . -

inflata Ktz. . . . . . . . . . . -

laneeolata Kítz. . . . . . . . . . -

linearis Ehroub. . . . . . . . -

lineolata Ehrenb. . . . . . . . . -

monogramma Ehrenb. . . . . . . . -

Phoenicenteron Ehrenb. . . . . . 47

phyllodes Ehrenb. . . . . . . . 48

platystoma (Ehrenb.) lítz. . . . . . -

polygramma Ehrenb. • . . . . . . -

pteroidea Ehrenb. . . . . . . . . -

Sieboldii Ehrenb. . . . . . . . . -

staurophaena Ehrenb. . . . . . . . -

ventricosa Ktz. . . . . . . . . 4!

Stauroptera Ehrenb. (T. IX.) . . . . . . ti

Achnanthes Ehrenb. . . . . . . - -

aspera Ehrenb. . . . . . . . . -

eardinalis Ehrenb. . . . . . . . . -

constricta Rabenh. . . . . . . . 50

dendrobates Ehrenb. . . . . . . 49

gibba Elrenb. . . . . . . . . . -

Ieostauron Ehrenb. . . . . . . . . -

Legumen Ehrerib. . . . . . . . . -

macrocephali Ktz. . . . . . . . . -

microstauron Ehrenb. . . . . . . . -

monogramma Ehrenb. . . . . . . 50

parva Ehrenb. . . . . . . . . 49

paucicostata Rabenh. . . . . . . . --

Peckii Rabenl. . . . . . . . . . -

punctata Kitz. . . . . . . . . 50

sealaris Ehrenb. . . . . . . . t9

truncata Rabenh. . . . . . . . -

Stephanodiscus Ehrenh. . . . . . . 12

berolinensis Elrenb. . . . . . . - -

Niagarae Ehrenb. . . . . . . . . -

Stephanosira Ehrenb. . . . . . . . . . 14

Epidendron Ehrenb. . . . . . . -

enropaea Ehrenb. . . . . . . . . -

Hamadryas Ehreub. . . . . . . . -

Surirelle Turpin.

Die Arten zerfallen in versehiedene Gruppen:

a) in der Mitte mehr oder minder zusammengeschnürt und dadureh geigenförmig . 2 es

b) länglich oder lanzettförmig . . . $29 \mathrm{f}$.

c) Nebenseiten keilförmig . . . . . . 30

d) verhogene . . . . . . $30 \mathrm{f}$.

Surirella Turpin. (T. III.) . . . . . . . 28

ambigua Kítz. . . . . . . . . . 29

angusta Ḱ́tz. . . . . . . . . . . -

anstralis Ehrenb. . . . . . . . -
Sur. IBreutchiana Rabenh. . . . . . . . 29

brevis Ehrenb. . . . . . . . 30

Campylodiseus Ehrenb. . . . . . . . -

C'raticula Ehrenb. . . . . . . . 29

decora Ehrenb. . . . . . . . . -

didyma Kitz. . . . . . . . . . -

elegans Ehrenh. . . . . . . . . 30

elliptica Bréb. . . . . . . . . . -

anglypta Ehrenh. . . . . . . . . -

Hcxuosa Ehrenl. . . . . . . . . -

ichthyoephala Rabenh. . . . . . . -

henneri IIans. . . . . . . . . . . -

microcora Ehrenb. . . . . . . . -

mimuta Bréb. . . . . . . . . - -

multifaseiata Ktz. . . . . . . . . 29

myodon Ehrenb. . . . . . . . 31

oblonga Ehrenl. . . . . . . . . 29

obtusangula Rabenh. . . . . . . . -

ovalis Bréb. . . . . . . . . 30

panduriformis Rabenl. . . . . . . 29

peruviana Ehrenb. . . . . . . . . 30

regula Elirenb. . . . . . . . 29

Solea Bréb. . . . . . . . . 28

spiralis Kiz. . . . . . . . . 31

splendida (Ehrenb.) Ḱtz. . . . . . . 30

striatula (Ehrenb.) Turpán . . . . . . -

tenella Kítz. . . . . . . . . . 29

umbonata (themalis Kitz.) . . . . . . -

Surirelleae Fam. VI. Charakteristik . . . 28

ihre Fortplanzung . . . . . . . . -

Zahl der bekanten Arten . . . 25. 64

Synedra Elirenb. (T. IV. u. V.) . . . . . 52

acicularis litz. . . . . . . . . . -

Acula Kitz. . . . . . . . . . . 54

\ens Kt\%. . . . . . . . . . 56

acuta khrenb. . . . . . . . . 55

aequalis Ktz. . . . . . . . . . . 54

alpina Naeg. . . . . . . . . . . -

amphicephala lítz. . . . . . . . . 53

amphishynchus Ehrenb. . . . . . . 55

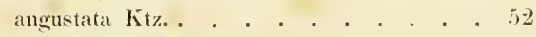

apiculata Rabenh. . . . . . . . 56

areuati Narg. . . . . . . . . . 54

Itomms Narg. . . . . . . . . . . 52

Biasolletiana Ktz. . . . . . . . . -

biceps Kitz. . . . . . . . . . . 55

bilunaris Ehrenb. . . . . . . . 54

eapitata Ehrenb. . . . . . . . . 55

curvula Ḱtz. . . . . . . . . . . 54

danica Kítz. . . . . . . . . . . -

debilis $\mathbf{K} t \% . \quad$. . . . . . . . . 55

dissipata Kitz. . . . . . . . . 53

Ehrenbergii Ǩtz. . $.06 \backslash \hat{C} A 4$. 54 
Syn. falcata Ktz. et Bréb. . . . . . . 54 fameliea Ktz. . . . . . . . . . . 53

familiaris Ktz. . . . . . . . . 56

fusidioides Rabenh. . . . . . . . 53

Fusidium Kłz. . . . . . . . . . -

gibba Ehrenb. . . . . . . . . . 54

gracilis ḱtz. . . . . . . . . . 5.3

gracillima Rabenh. . . . . . . . -

laevis Ehrenb. . . . . . . . . 54

lanceolata Ktz. . . . . . . . . . 55

longiceps Ehrenb. . . . . . . . . -

lunaris Ehrenb. . . . . . . . . 54

mesocampa Bréb. . . . . . . . . -

mesolepta Kítz. . . . . . . . . 55

minutissima Kítz. . . . . . . . 52

notata Ktz.. . . . . . . . . 55

oxyrhynchus Kíz. . . . . . . . . -

palea Kít. . . . . . . . . . . 53

parra Kitz. . . . . . . . . . . 56

parvula Kíz. . . . . . . . . . . 53

perpusilla Ktz. . . . . . . . . . 52

porrecta Rabenh. . . . . . . . 55

praemorsa Ehrenb. . . . . . . . -

pulchella (Ralfs) Ḱ́tz. . . . . . . 56

pusilla Ǩ́z. . . . . . . . . . . 52

radians Kiz. . . . . . . . . 53

rumpens kitz. . . . . . . . . . 56

saxonica Kítz. . . . . . . . . 54

sealaris Ehrenb. . . . . . . . 55
Syn. socialis Rabenh. . . . . . . . 56

spectabilis Ehrenb. . . . . . . . -

splendens Ktz. . . . . . . . . . 54

subarcuata Naeg. . . . . . . . . -

subtilis Ktz. . . . . . . . . . . 53

tenuis Ktz. . . . . . . . . . . . -

tenuissima Ḱtz. . . . . . . . . . -

Ulna Ehrenb. . . . . . . . . 54

valens Ehrenb. . . . . . . . 55

Vaucheriae Ktz. . . . . . . . . . -

ventricosa Rabenl.. . . . . . . 52

vitrea Ktz. . . . . . . . . . . . 55

Synedreae Fam. IX. Charakteristik . . $51 \mathrm{f}$. Zahl der bekannten Arten. . . . . 52. 64

Tabellaria Ehrenb. (T. X.) . . . . . .62. 63

fenestrata Ktz. . . . . . . . . 63

flocculosa (Roth) Ktz. . . . . . . . -

rentricosa Kítz.

Tabellarieae Fan. XII. Charakteristik . . . 62 ihre Fortpflanzung . . . . . . . . Zahl der bekannten Arten . . . . 63.64

Tabularia Kiz. 4. Untergattung der Synedra , 56

Terpsinoë Elurenb. (T. X.) . . . . . . 62.63 musica Ehrenb. . . . . . . . . 63

Tetracyclus Ralfs (T. IX.) . . . . . . 62. 63

lacustris Ralfs . . . . . . . . 63

I7naria Ktz. 3. Untergattung der Synedra . 54 


\section{EINLEI'TUNG.}

\section{A. CHARAKTERISTIK DER DIATOMACEEN,}

als Antwort auf die Frage: Was sind Diatomaceen?

Einzellige Organismen mit prismatischer Kieselhülle (Рanzer), einem eigenthümlichen, goldgelben oder bräunlichen Farbstoff. Fortpflanzung geschieht durch Theilung der Mutterzelle in zwei neue oder Tochterzellen.

Keine Klasse im organischen Reiche ist schärfer begrenzt, als die der Diatomaceen. Ihr starer, weder dureh Glühhitze noch durch Fäulniss zerstörbarer Kieselpanzer sondert sie scharf von allen bekannten Organismen ab. Treten in Bezug auf Gestalt verwandte Formen, z. B. unter den ihnen sebr nahe stehenden Desmidieen auf, so giebt ein einfaches Experiment sofort entsehiedene Auskunft und löst jeden Zweifel. Dies Experiment besteht darin, dass man ein Pröbehen auf Glimmer oder Platinblech über der Spiritısflamme glüht. Alles Organische wird dureh die Glühhitze zerstört, nm der Panzer der Diatomaceen nicht, er behält nicht nur seine Gestalt unverändert, sondern dureh Zerstörung seines organischen Inhalts treten seine Formen und sein Ban reiner und sehärfer hervor. Hierbei ist nur zu berïeksichtigen, dass keine Kali- oder Natronsalze zugegen sind, indem diese bekanntlich in der Glühhitze den Kiesel auflösen und mit ihm eine ehemisehe Verbindung eingehend das Glas darstellen.

Haben wir also hierin, in der Substanz der Hülle, ein untrügliches Kennzeichen für die Klasse, so finden wir noeh andere, fast nicht minder seharf hervortretende in Folgendem: Näehst der Substanz ist es die Gestalt des Panzers. Dieselbe ist nämlieh streng symmetrisch, rund, seheiben- oder walzenförmig, oder prismatisch viereckig, mit seharfen Kanten und gewöhnlieh ebenen Endfl̈̈chen. Die zwei gegenüberliegenden Flächen sind sich fast stets gleichgestaltig; in den Diagnosen sind daher in den meisten Fïllen nur zwei zu berẗcksichtigen und zwar die vordere (in fortschreitender Richtıng gedacht) oder die Hauptseite und eine der Nebenseiten. Diese Bezeichnung ist im entgegengesetzten Siune Kützing's.*) Bald sind es die Hauptseiten, bald die Nebenseiten, die mehr entwickelt sind und eine grössere Mannigfaltigkeit in Gestalt, Baı oder Zeiehmung zeigen,

*) In gleicher Weise haben Ėhrenberg und Kützing die Länge mit der Breite verwechsełl. Nehmen wí eine Walze, Faden oder Band und theilen dieselbe in die feinsten Querschnitle, so liegl die Länge jedes einzelnen Sclınittes immer noch in derselben Richtung, wie in dem zusammenhängenden Faden oder Bande. So verhält es sich augenfällig bei allen Diatomaceen, die auth nach dem Theilungsacle noeh mit einander verbunden bleiben. Nehnen wir aber Rüeksicht auf die Entwiekelung der isolirt lebeuden Arten, so verhält es sich eben so. Der längere Durehmesser ist dalıer ihre Breile oder Querdnrehmesser und der kürzere ihr lä̈ıgendurclımesser. Da es jedoch im Allgemeinen bequemer isı, sich den längern Durchmesser als die Länge zn denken und den kürzeren als die Breite oder Quere, und da es füglich ohne Nachtheil für die Systemalik isl, so werden wir Långe und Quere in dem Sinne Ehrenberg's und Kützing's beibehalten. 
und darum bieten bald diese, bald jene die wesentlichsten Charaktere für die Gattungen und Giruppen.

Auf seiner äussern Fläche ist dieser Panzer fast ohne Ausnahme glatt und eben, nach Innen aber zeigt er vortretende (drïsenartige) Verdickungen von der mannigfaltigsten Art. In ihnen liegen die Kieselpartikelchen weniger dicht wie an den spiegelglatten Stellen unl erscheinen als nabelförmige Knoten von bestimmter Gestalt (kugelrund, länglich, keil- oder trichterförmig') und werden von den Antoren nicht nur mit Oeffnungen bezeichnet, sonderu gradezu dafür ausgegeben, aus denen die Phantasie Aerme und Füsse hat heraustreten sehen: andere bilden kleine punktförmige Knötchen in regehmässigen Quer- oder Läugsreihen: wieder andere erscheinen als opake Quer- oder Längsstreifen, die man nach ihrer Stärke oder Breite mit Leisten, Rippen, Striemen oder Strichen bezeichnet; öfters sind diese wieder mit Knötchen besetzt oder eingefasst.

Der Panzer ist also auch in seiner Gestalt und Ban so eigenthümlich, dass sich ein Jeder bald so viel Uebung erwirbt, beim ersten Blick eine Diatomacee von jedem andern Organismus zu unterscheiden.

Dringen wir nun von dieser Kieselhülle nach Innen weiter vor, so berühren wir zunächst eine zarte Membran, die eigentliche Zellhaut, deren Produkt der Kieselpanzer ist. Sie umschliesst den Zellinhalt, der ans einer schleimigen Substanz besteht und von einem eigenthïmlichen hramnen oder goldgelben, vom Chlorophyll der Pflanzen durehaus verschiedenen Farbstoff gefärbt ist. Das Chlorophyll der Pflanzen ist nämlich durch Alkohol ansziehbar, wird dureh Alkalien nit gelbgrüner Farbe gelöst, durch Salzsäure smaragdgrün gefärbt, wälurend der Farbstoff der Diatomaceen in Alkohol unlöslich ist (mit der Zeit aber doch verbleicht), durch Alkalien unverändert bleibt und durch Salzsäure spangrün gefärbt wird.

Anfünglich, in der Jugend der Individuen, ist dieser Farbstoff gleichmässig vertheilt, nach kürzerer oder längerer Zeit aber gehen mit ihm, wie ïberhaupt im Innern der Zelle verschiedene Veränderungen vor: Der Farbstoff zieht sich zu den versehiedenartigsten. meist sehr regelmässigen, oft zierlichen Gestalten zusammen, man beobachtet die Ausscheidung orler Absonderung kleiner gekörnter Kägelchen, die Bildung feiner Bläschen, hïllloser Oeltröpfehen, Stäıkmehlkörnchen, mit Körnern erfïllter, wandständiger Bläsehen, die anfinglich festsitzen, sich dann ablösen und ähnlich den Schwärmzellen der Algen eine rotirend-schraubenförmige und schwärmende Bewegung im Lumen der Zelle zeigen. Auf Tafel IX Stauroneis F. 19 haben wir ein solches Bläschen dargestellt und den Weg durch Punkte bezeichnet, den es in stürmischer Bewegung durchlief. Eine weitere Entwickelung dieser mit besonderer Organisation versehenen Zellen kenmen wir jedoch bis jetzt nicht. Eineı eigentlichen Zellkern, wie wir ihn bei den Algen antreffen, haben wir niemals gesehen.

Das so gestaltete Individuum findet sich nun noch in einer Hülle oder Mantel, welcher gleichsam die Cuticula der höhern Pflanzen vertritt. Sie wird zumal durch die drüsenartigen Verdickungen der Kieselmembran abgesondert, ist von gelatinöser Beschaffenheit, bald mehr bald minder flüssig oder consistent, deshalb bald scheinbar fehlend, bald deutlich erkennbar, je nachdem ihre Ausseheidung durch die Kieselmembran eine allgemeine, ґ. b. auf der Oberfläche eine gleichmässig vertheilte, oder eine lokale, anf einem Punkte vorherrschende ist. Sie bildet in consistenterem Zustande formlose Gallertmassen, worin die Individuen mit oder ohne Ordnung zahlreich zusammengehäuft sind, so bei 
Frustulia, Naunema, Colletonema; sie erscheint röhrenförmig, worin die Individuen in regelmässigen Reihen liegen, so bei Encyonema. Bisweilen ist ihre Bildung an den Enden der Individuen vorherrschend und von besonders fester Substanz, sie bildet dann einen Stiel, der das Individum trägt, so bei Achnanthes, Gomphonema, Cymbella; in sehr seltenen Fällen findet mit der Stielbildung zugleich eine in entgegengesetzter Richtung statt, das Individum erscheint damn mit cin oder zwei hornartigen Spitzen, so bei Gomphonema anritum.

Geschlechtsuntersehiede sind noch nicht wahrgenommen worden, ihre Fortptlanzung geschieht:

a) dureh Theilung der alten oder Mutterzelle in zwei gleiche nene oder Tochterzellen, und zwar so: zum Akt der Theilung sondert sich der Zellinhalt in zwei, vom Primordialschlanch dicht umsehlossene und begrenzte Partien, worauf sich im Lumen der Zelle, die Axe der Mutterzelle unter einem rechten Winkel durchschneidend, eine Querwand bildet und somit das Bestehen der Mutterzelle aufhebt. Die beiden Tochterzellen bleiben nun entweder für die Daner ihres Entwickelıngskreises verbunden oder tremnen sich ganz oder theilwcise; im letztern Falle bleiben sie durch ein gallertartiges Zwischenglied (Hüllmembran) verbunden.

b) durch einfache oder doppelte Copulation: Die Kieselzellen zweier benachbarten Individuen spalten sich, der Inhalt, vom Primordialschlanch umselilossen, vereinigt sich entweder sofort $z u$ einem sogenannten Gonidium (die einfache C.), oder •er theilt sich erst in zwei Partien und vereinigt sich dann zu zwei Gonidien (die doppelte C.). Im ersteren Falle bilden zwei Mutterzellen nur eine Tochterzelle, im letzteren Falle zwei. Die Kieselhüllen der Mutterzellen werden abgestreift. Das copulirte Gonidium hat anfänglich eine kugelige Gestalt, geht aber durch schnelles Wachsthum bald in die typische Gestalt seiner Gattung über.

c) durch wirkliehe Fruchtzellen: Die Zelle sehwillt blasenartig anf und wird wälırend dem von mehr oder minder zahhreichen Brutzellen erfüllt, die anfangs unregelmässig gestaltet, später eine regelmässige länglich eiförnige Gestalt annehmen. Sobald sie dieselbe erreicht haben, tritt eine Strömmg in Lumen der Zelle, von der Rechten zur Linken ein (T. X. Suppl. F. 18.), die Mutterzelle spaltet sich, die Bruten strömen aus, in demselben Moment, wo sie austreten, werden an der vordern lichten Stelle zwei straffe Wimpern sichtbar, zeigen ein leichtes Schwärmen von sehr kurzer Dauer, setzen sich an und erreichen in kürzester Zeit die Grösse der Mutterzelle oder überragen dieselbe an Grösse. Die Existenz der Mutterzelle hört mit dem Zeugungsakt auf.

Ueber das Speciellere werden wir bei den verschiedenen Familien selbst beriehten. Eine Erscheinung, die zumal das Auge des Laien seln ergötzt, ist die anseheinend freiwillige Bewegung, welche fast alle freien, nicht angewachsenen, zumal aber die nachenoder spindelförmigen Individuen zeigen. Dieselbe ist von mannigfacher Art, bald ein ruhiges, gleichmässiges Vorrücken, bisweilen mit einem leichten Zittern an vordern und hintern Ende verbunden, bald ein stossweises Vor- und Zurückgleiten, hald ein Wenden, (Drehen um die eigne Axe) und daranf wieder puhiges Fortgleiten. Treten Hindernisse in den Weg, so wendet sich das Individuum und gleitet längs dem Gegenstande weiter, oder es hebt oder senkt sich mit dem vorderen Ende und ungeht gleichsam den Gegenstand. Bewegnngsorgane hat man bis jetzt noch nicht gefunden, die Bewegung ist in der 
Richtung ihres langen Durchmessers, also keine eigentlich vorschreitende, sondern eine seitwärts rückende und wird hervorgerufen durch den Ernährungsprozess, durch die Aufnahme und Ausscheidung (Endosmose und Exosmose oder auch Diffusion genannt) flüssiger Stoffe. Erfolgt die Aufuahme auf der rechten, die Ausscheidung auf der linken Seite, so ist die Bewegung nach reehts und so ungekehrt. Da nun physiologisch und morphologisch beide Hälften des Individumms vollkommen gleich sind, so kann auch die Aufuahme und Ausscheidung der Stoffe bald auf der linken, bald auf der rechten Seite stattfinden und daher die Bewegung bald eine vor- bald eine rückschreitende sein.

Ans dieser Charakteristik drïngt sich die Sehlussfolgernng nothwendig anf, dass die Diatomaceen sich dem Pflanzenreiche zunächst anschliessen.

\section{B. DAS VORKOMMEN, EINSAMMELN UND AUFBEWAHREN DER DIATOMACEEN.}

Ueberall, wo Feuchtigkeit herrscht, zumal im Frïhlinge, wo das Leben aller Organismen von Neuem erwacht oder angeregt wird, beginnen auch die Diatomacen aus dem Winterschlafe erwachend ihr harmloses Leben und erfüllen mit den zierlichsten Formen sowohl die oft anscheinend leeren Pfützen und Gossen, wie die krystallhellen Gewässer. Ihre Entstehung und Vermehrung ist oft überraschend schnell. Lässt man z. B. ein Glas Wasser einige Tage in Zimmer stehen, so zeigt sich früher oder später an Boden oder an den Wandungen des Glases ein grüulicher oder bräunlicher Anflug, der sich dann bald vergrössert und intensiver färbt. Der grüne pflegt aus Algen, der bräunliche immer, zuweilen beide aus Diatomaceen zu bestehen. Synedra Fusidium, S. Atomus, einige Naviculae wird man sicher darin finden. Die meisten Arten finden sich im Frühlinge gewölnnlich zahlreicher beisanmen, in Sommer und Herbst kommen die freien, nicht angewachsenen Arten mehr vertheilt und mit anderen gemischt vor; es ist nicht selten, in einer Schleinflocke 10-20 verschiedene Arten anzutreffen. So bilien sie dann brämnliche, grünliche oder schmutzig gefärbte Ueberzüge von schleimiger, häntiger oder breiartiger Beschaffenheit, oder fluctuirende Räschen oder Flocken, an Steinen, Holz, Halmen und andern Gegenständen unter dem Wasser festsitzend. Sie überziehen, gesellig mit Algen (zumal den einzelligen Algen und den Seytonemeen) ganze Felswände, Wasserleitungen, Wassertröge, Pumpen u. s. w. Sie finden sich frei herumschwimmend in den Rasen der Vancherien, Cladophoren, Conferven, Oscillarien u. dergl., oder sie leben anf den Algenfäden und Wasserpflanzen wie Schmarotzer, häufig in soleher Menge, dass die Gegenstände gauz und gar von ihnen bedeckt sind. Dies geschieht namentlich von den Cocconeis-, einigen Eunotia- und Epithemia-Arten, welche die Gegenstände wie die Schild- und Blattlüuse ïberziehen. Sie bilden auch öfters, wie die Odontidien, Fragilarien, mehrere Fuss lange braune Rasen, wie die Fadenalgen, unterscheiden sich aber sofort von diesen dadurch, dass sie, sowie man sie aufnehmen will, in ihre einzelnen Individuen oder Glieder zerfallen, gleichsam in sich zerfliessen; ja sie erfüllen oft ganze Lachen oder schleichende Wässer und erheben sich, oder werden viehmehr von den sich entwickelnden Gasarten als häutig-blasenartige oder schanmige Massen mehrere Zoll hoch über die Oberfläche des Wassers gehoben. Nur wenige Arten scheinen eine Auswall in den Lokalitäten zu treffen, die meisten nehmen so wenig hierauf Rücksicht, wie auf Temperatur-Differenzen. Viele Arten (Navieula Bacillum, N. arnphioxys, N. Silicula, Pinnularia borealis. Himantidium Areus, Eunotia gibba, E. anphi- 
oxys, Melosira distans, Synedra Ulna, Fragilaria capucina, F. rhabdosoma u. v. v. a.) sind auf der ganzen Erdoberfäche verbreitet, sie finden sich von den Polen bis zum Aequator, sie leben in dem Wasser der Gletscher, wie in den beissesten Quellen. Das Meer hat seine eigenthümlichen Formen, die sich streng von den Süsswasser bewohnenden unterscheiden. In salzigen Binnenwïssern trifft man meist Formen, die dem süssen Wasser angehören.

Man muss aber die Verbreitung der Diatomaceen noch weiter ausdehnen: man kann annelımen, dass sie sich in jedel. Staubmasse finden oder doch finden könuen. Und wenn dies Vorkommen freilich kein freiwilliges und gewähltes ist, so ist es unseres Bedünkens doch nöthig, dasselbe hier zu erwähnen. Denkt man daran, was Stürme für schwere Körper aufjagen und weit mit sich führen, so liegt es wahrlich auf der Hand, dass auch diese Organismen mit aufgerissen werden, und da sie meist weit kleiner als das feinste Staubkörnchen sind, auch lange Zeit, selbst dann noch, wenn wieder Ruhe in den Luftschichten eingetreten ist, schwebend erhalten werden. Ist die Atmosphäre nicht stark nit Wasserdämpfen geschwängert, so sterben sie natürlich bald ab, und man findet in dem aufgefangenen Staube nur noch ihre glashellen Panzer. Bei feuchtem Wetter habe ich sie nicht selten mit völlig gefärbtem Inhalt aufgefangen. Sind sie nun einmal von den Luftströmungen aufgenommen, so können sie sich natürlich auch ïberall da finden, wo sich sogenannter Staub ïberhaupt absetzt. Und so ist es: sie finden sich auf den liöchsten Thư' - und Bergspitzen, wie im Bücherstaube, auf Bäumen und Dächern, wie in Höhlen und Schlupfwinkeln.

Das Einsammeln ist höchst einfach und bedarf keiner eigentlichen Anleitung. Bei meinen Excursionen führe ich gewöhnlich $1-1 \% \frac{1}{2}$ Dutzend kleine, 1/2-1 Loth Wasser fassende, weitmündige Gläschen bei mir, die auf dem Stöpsel oder an einer beliebigen Stelle numerirt sind. Den Nummern nach bemerke ich den Standort in Notizbuch. Ausser den Gläsern benutze ich auch geöltes oder Wachspapier. Diese Papiere sind zunal auf Reisen oder zum Versenden frischer Exemplare sehr empfehlenswerth, indem sie durch Druck nicht leiden. Die Gläschen kann man in Papier gewickelt so in die Tasche stecken oder - was nett und beqnem ist - man lässt sich ein Kästchen von starkem Leder mit so vielen Räumen, als man Gläschen bei sich zu führen pflegt, fertigen und mit einem Riemen versehen, so dass man es gleich einer Patrontasche oder Cartouche um den Leib schnallen kann.

Die Untersuchung der gesammelten Gegenstände nimmt man allemal zu Hanse vor.

Die Aufbewahrung kann in Massen geschehen, oder man vertheilt etwas davon auf Glas oder Glimmer mit einigen Tropfen Wasser, lässt es abtrocknen, legt es in eine Papierkapsel, schreibt die nöthigen Notizen darauf, und ordnet diese nun systematisch oder alphabetisch, wie es beliebt, nur so, dass man jedes Objekt leicht wieder auffinden kann. Ich besitze auch eine Sammlung in Spiritus, und empfehle diese Methode deshalb ganz besonders, weil die Oljekte den Vorzug haben, dass sich der organische Inhalt fast unverändert erhält.

\section{DIE UNTERSUCHUNG DER DIATOMACELN.}

Zur Untersuchung, resp. Bestimmung der Diatomaceen ist ein Mikroskop von 250 bis 300 maliger Linear-Vergrösserung nothwendig. Diesartige Instrumente liefern die Herren Schiek in Berlin, Plössl in Wien, Amici in Turin, C. Kellner in Wetzlar. Aus diesen 
vier Werkstätten habe ich Instrumente in Gebrauch gehabt und habe sie zum Theil noch, und kann sie daher aus voller Ueberzengung empfehlen. Die Instrumente von Oberhaenser in Paris sind mir ebenfalls bekannt, seine Firma ist jedoch erlosehen. Die stärksten Wirkungen habe ich erreieht durch eine Combination der Schiek'schen Objektive mit Okularen von C. Kelher.

Wine ansführliche Anleitung zum Arbeiten kam man hier fïglich nicht erwarten; wer sich mit dem Mikroskop vertrant machen will, dem emptehle ich: H. von Mohls Mikrographie und das Mikroskop, und seine Anwendung von H. Sehacht. In diesen Büchem findet man ungefïh das, was zn wissen nöthig ist. Bemerken will ich jedoch, dass sich Nienand an gegebene Regeln und Vorschiften streng zu binden hat: wer Lust, Liebe und Beruf in sich fühlt, fleissig mit seinem Instrumente umgeht, ler wird in kïrzester Zeit auf Vortheile verschiedener Art selbst kommen. Es lïsst sich durchans nicht erwarten und vorschreiben, dass Einer wie der Andere arbeite, denn was dem Einen bequem ist, ist dem Andern unbequem.

Nur im Altgemeinen will ich erwähnen, dass man ansser dem Mikroskope noch eine gnte Lupe, einige Pinzetten, Glasstäbchen, Nadeln in einem Schaft, wie die Tamburir-Nadeh, einige dicke Harpinsel oder sogenannte Pilzwischer (die Fleischsubstanz des Hutes von Polyporns betulinus) zum Reinigen der Okulare besitzen muss. Zu Objektenträgem nehme man mässig starkes Spiegelglas und zn Deckglïsern geschliffene (nicht geblasene), 1/2 Zoll in Quadrat grosse, etwa $\frac{30}{100}$ Millimeter dicke Gläschen.

So ansgerïstet begimme man die Arbeit. Die Untersuchung in Bezug anf Bestimmmmg ist die einfachste und leichteste in der Mikroskopie. Es bedarf hiei keines kmstgerechten Schnittes, 1 m ein branchbares Präparat zı gewinnen, sondern nan nimmt mit der Pinzette oder dem Glasstabe ein Stïckehen, etwa nadelkopfgross, von der zu untersuchenden Masse, legt es mif den Objektenträger', rertheilt es mit etwas Wasser, deckt und schiebt es nnter das Mikroskop. Bein Decken hat man diranf zn achten, dass das Deckglas mit seiner ganzen Fläche gleichmässig anfliegt. Das wird öfters durch ein Sandkörnchen verhindert, odel die Masse ist nicht gut vertheilt; Beides lässt sich durch die Nadel leicht beseitigen. Eingesehlossene Luftblasen sind ebenfalls zu entfernen. Zum sicheren Erkennen und Bestimmen gehört duchans, dass die Gegenstände anch trocken, noch besser geglïht mutersncht werden, und dass man sie sofort zeichnet. Das Zeichnen halte ich für eine nnerlässliche Bedingung, um jedwede Tänschmng zn verhüten, oder, wo sie democh vorgekommen ist, sie leichter anfzufinden und berichtigen zu können. Beim Zeichnen mïssen die Einzelnheiten viel schärfer fixirt nnd anfgefasst werden, als das beim gewöhnlichen Betrachten mit einem ungeïbten Ange zn geschehen pflegt, and es ist viel leichter und sicherer, ein anf Papier entworfenes Bild mit der vorhandenen Abbildung zn vergleichen, als ein von den Simnen infigefisstes. Das Zeichnen mikroskopischer Objekte ist aher eine besondere Kumst, die nicht allein noth hent zu Tage so Manchen mberer nambaften Naturforscher, sondern anch dem geäbtesten Zeichner rom Fache fehlt. Die Kunst liegt nämlich in einer richtigen Anffassmg der relativen Grösse des mikroskopischen Bildes. Jeder, der seine Angen darin nieht geübt hat, wird das mikroskopische Bild nur oder kamm halb so gross zeichnen, wie er es eigentlich sieht. 1,h rathe daher Jettem, seine Zeichnungen mit dem Zirkel durch Doppelsehen (Sehen mit beiden Angen zngleich) zn kontroliren oder ïberhaupt die Grössen mit dem Zirkel zu bestimmen und anzulegen, oder sich der Camera lncida zn bedienen. Diese letztere Methode empfehle ich zumal dem., 
der keine Uebung im Zeichnen hat. Camera lucida (Zeichenprisma) zum Anfstecken auf die Mikroskopröhre, die bequemste Eiurichtung, liefert Carl Zeiss in Jena für 5 Thaler. Einige Schwierigkeiten, die sich heim ersten Gebranch derselben Jedem entgegenstellen, werden bei einiger Ansdaner leicht ïberwunden mol entschädigen den nicht fertigen Zeichner durch dentliche Anffissung der Gegenstände und korrekte, gleich grosse Zeichnung.

Die Schwierigkeiten sind 1) dass man den Kopf ganz ruhig, olne lie nincleste Schwankung hält, damit das Auge dicht an der kleinen Oeffnung der Blende gleichmässig und unverrïckt ruht: 2) dass man die Spitze des Griffels stets scharf sieht. Ein Umstand, der anfänglich viel Schwierigkeiten macht und nm durch eine zwecknässige liegulirung des Lichtes, welches auf das zn zeichnende Bild und Griffelspitze fällt, zn beseitigen ist. Man erreicht dies an leichtesten, wemn man das Mikroskop so stellt, dass der Zeichner mit dem Rüeken gegen das Fenster oder gegen das einfallende Licht steht und nur von der Seite so viel Licht auf das Bild und Griffelspitze fallen lässt, als nöthig ist. Durch Ausdaner wird man anch dies bald erreicht haben. Alles Uebrige, Reimbeit und Schärfe des Bildes, hängt von der richtigen Stellung des Prismas zmm Okular ab.

\section{UEBERSICHT DER FAMILIEN UND GATTUNGEN.}

Es kommt hier durchaus nicht darauf an, dass unsere Anordnung eine natürliche, d. h. eine in der Entwicklungsgeschichte der Gattungen nnd Familien begrïndete sei, sondern dass sie eine leicht fassliche und verständliche ist. Der Titel des Buches sagt es schon, für wen dasselbe zunächst bestimmt ist: es soll dem Laien und Dilettanten das Bestimmen dieser mikroskopischen Wesen erleichtern und ilım als Fülner dienen, um sich einigermassen zu orientiren in einer śchöpfung, die dem blossen Auge nicht zugänglich ist. Es setzt also keme Eingeweihten, überhanpt kein Studium voraus, und darum nun scheint es uns an Zweckmässigsten, die Gestalt der Individnen, da sie unwandelbar und ohne schärfere Beobachtung schon leirht und sicher erkennbar ist, als das leitende Princip an die Spitze dieser Eintheilung zn stellen.

\section{a) Almutares.}

FAM. I. MELOSIREAE.

Hauptseiten zirkelrund oder ringförmig; Nebenseiten rund, länglich oder walzenfürmig.

t Einzeln oder paarweise.

Cyclotella, mit ringförnigen, Hachen Hauptseiten.

Pyxidicula, mit gewölbten Hanptseiten.

Liparogyra, mit flachen Hauptseiten, am Rande gezahnt; Nebenseiten mit kammförnigen Spirallinien.

Porocyclia. Hauptseiten am Rande mit einem Kranz von tiefen Eindrücken; Nebenseiten ohne Spirallinien, aher mit Zirkel-Leisten.

Stephanodiscus, mit flachen Hamptseiten und einem randständigen Kranz von Zähnen. Calodiscus, mit flachen, nicht genan zirkelrunden Hauptseiten, einem breiten, quergestreiften Rande und strahlig gestellen, ungleichen Leisten.

Campylodiscus, mit verbogenen, nicht genau zirkelrunden Hauptseiten und strahlig gestellten Rippen. 
$+t$ Familienweise zu Fäden verbunden.

Discosira, mit leicht gewölbter Hauptseite, am Rande ein Zahnkranz, gegen das Centrum mit strahligen, aber gekrümmten Leisten.

Melosira, mit flachen Hauptseiten, aun Rande nackt, gegen das Centrum glatt oder strahlig gestreift.

Stephanosira, mit flachen, strahlig punktirten Hauptseiten, in der Peripherie mit einem Zahnkranz.

\section{b) Arcuatae.}

FAM. II. EUNOTIACEAE.

Hauptseiten flach, meist quergestreift, oder querrippig, in Umrisse erscheinen sie durch die gekrümmten Nebenseiten naclı oben gewölbt oder ein- oder mehr bucklig, unten mehr oder minder concav.

$$
\text { Einzeln oder parweise. }
$$

Eunotia, mit sehr zarten Querstreifen.

Epithemia, mit starken, rippen- oder leistenartigen Querstreifen.

Himantidium.

$$
+\dagger \text { Familienweise zu Bändern verbunden. }
$$

FAM. III. CYMBELLEAE.

Gekrümmt wie lie Eunotien, aber in der Mitte auf der Hauptseite dem untern Rande genähert mit einem drüsenartigen Knoten, der durch eine Leiste mit dem Endknoten verbunden ist.

Cymbella.

+ Frei schwimmende, stiellose Individuen.

Cocconema.

$$
+t \text { Auf einem einfachen oder verzweigten Stiel. }
$$

t† + In Längsreihen geordnet, von einer gelatinösen IIülle scheidenartig

Encyonema. umschlossen.

FAM. IV. ACHNANTHEAE.

Von den Nebenseiten geseben erscheinen sie gebogen und an der untern Seite in Mitte wie eingeknickt, an derselben Stelle zeigen sie eine nach Innen keilförmige Verdicliung.

Achnanthidium.

† Freie, stiellose Individuen.

Achnanthes.

$$
+t \text { Gestielte. }
$$

c) Onoideae s. eflipsoideae.

FAM. V. COCCONEIDEAE.

Ellipsoidisch schildförmig, meist platt aufliegend, mit mehr oder minder gewülbter (obern oder) Rückenfäche, auf der (untern oder) Báuchfläche in der Mitte init einer knutenförmigen Drüse.

Cocconeis.

FAM. VI. SURIRELLEAE.

Mit elliptischem oder eiförmigem Typus, bald schlank, bald dicker, zuweilen auch in der Mitte zusanmengeschnürt und dadurch geigenförmig, selten verbogen, ohne Centralknoten.

Surirella, auf den Hauptseiten mit einer durchgehenden Längsrippe.

Amphora, mit zwei in dex Nähe des Randes befindlichen kurzen Querbinden. 
FALI. VII. FRAGILARILAE.

Meist zu bandfürmigen Fäden verbunden oder zickzackförmig aufgelöst, seltner einzeln. Hauptseiten linealisch, länglich, lanzettich oder ellipsoidisch, glatt oder mit durchgehenden guerrippen oder Leisten.

$$
\dagger \text { Isolirte oder parweise verbundene formen. }
$$

Denticula, Hau,tseiten mit durchgehenden Querleisten, Nebuseiten mit zahnartig rortretenden Leisten.

Gomphogramma, Hanptseiten mit durchgehenden Querleisten, Nebenseiten tafelfömig, nit miterbrochenen, nach Innen keulig verdickten Striemen, an Rande nach Innen gezalnt.

Fragilaria, ganz glatt.

$$
+\dagger \quad Z u \text { bandförmigen Fäden verbunden. }
$$

Odontidium, mit Querleisten.

Diatoma.

$$
\div \div \div \text { Bänderzickzackförmig aufgelïst. }
$$

\section{d) Jinuicufares.}

\section{M i t nacbenförmigem Typus.}

FAM. VIII. NAVICULACEAE.

† Freie und anscheinend nackte Formen.

Amphiplenra, mit Längsstrienen, ohne knotige Verdickung.

Ceratoneis, an beiden Enden schnabelförmig verlängert, nit Centralknoten.

Navieula, glatt, in der Mitte und an den Enden nit drüsenatiger Verdicknng, die durch eine Strieme oder Leisten verbunden sind.

Pinnularia, wie Navicula, aber nit Qnerstreifen, Ripren oder Leisten.

Gyrosigma, wie Navieula, aber Sförmig gekrümmt.

Stanroneis, in der Mitte mit einer Qnerbinde.

Statroptera, mit mehreren Querleisten.

Staurogramma, mit nach Innen vorspringenden Knoten, die durch zarte Streifen krenzweise verbunden sind.

$\div \div$ Mit einem Ende auf einem polsterfärmigen Fuss festsitzend.

Falcatella, wie Navicula, aber sichelfömnig gekrümmt.

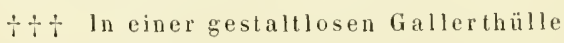

$$
\begin{aligned}
& \text { * ohne Ordnung zusammengehäuft. }
\end{aligned}
$$

Frustulia, ohne C'entralkuoten.

Sannema, mit Centralknoten.

Colletonema.

$$
\text { * Reihenweise geordnet. }
$$

$\div \div \div \div$ ohne Hülle, zu bandfürmigen Fäden verbunden.

Diadesmis, wie Fragilaria, aber mit Centralknoten anf den Hauptseiten.

\section{e) Incicutares.}

Linealisch, schlank lanzettlich oder nadelförmig, ohne Centralknoten.

Synedra, gestreckt mad gerarle.

FAN. IX. SYAEDREAE.

Sigmatella, leicht sförmig gekrïmmt. 
f) Cunentac.

Mit keilförmigem Typus.

FAM. X. GOMPHONEMEAE.

Nit Centralknoten.

sphenella.

+ Stiellose, isolirte Formen.

Gomphonema.

$+\div$ Gestielte.

sphenosira.

$$
\leftarrow+\dagger \quad Z \text { Fäden verbunden. }
$$

FAN. XI. MERIDIEAE.

Ohne Centralknoten, mit guerleisten.

Meridion.

\section{g) Jiotosne.}

In der Mitte stets, meist auch an den Enden stark gedunsen.

FAN. XIl. TABELLARIEAE.

Nehenseiten mehr oder minder grosse Tifelchen darstellend, mit durchgehenden oder unterbrochenen Querstriemen, bandförmig verbunden oder zickzackförmig aufgelïst.

$\doteqdot$ Bandfärmig verbunden.

Tetracyclus, mit durchgehenden Querstriemen.

$$
\div \div \text { Zickzackförmig aufgelïst. }
$$

Tabellaria, Nebenseiten hinealisch, schmal-tafelförmig, mit mterbrochenen Querstriemen. Terpsinoe, Nebenseiten breit und gross-tafelförnig. nit unterbrochenen, kenlig verdickten Querstriemen. (Gomphogramma.) 


\section{FAM. I. MELOSIREAE.}

Panzer gestreckt oder kurz-walzenfürnig oder rundlich-kuglich, isolirt oder durch ein melı oder minder entwickeltes Zwischenglied in Familien verbunden und Faden bildend; llaujtseiten zirkelrund. llach-scheibenfïmig oder gewölbt.

Die Melosireen zeichmen sich besonders dmeh ilne zinkelrunden Hanptseiten ans, und wo diese Zirkellinie nicht vollständig erscheint, ist sie meist nur scheinhar dureh eine Krïmmmg der Scheiben anfgehoben oder nuterbrochen. Viele leben einzeln oder nach dem Theilungsact anf knrze Zeit parweise, Andere viele Generationen hindhmed immer in Familien verbunden, aus 2, 4, 8, 16,32, 64 и. s. f. Zellen (Individuen) bestelıend, eimen perlschumförmiger oder kettenartigen Faden bildend. Sic sind stets mit einer änssern Schleimhïlle umgeben, welche bald so dïmflïssig ist, dass sie kamm wahruehmbar ist, bald consistenter und ganze Generationen röhrenförmig einschliessend. Bei fortschreitender Entwickelıng, wo die Zellen einzeh, meist pararweise ansemander rücken, zieht sich die Hülle uicht selten stielförmig znsanmen, bildet ein verengtes Zwischenglied, vermittelt den Zusammenhang der Generationen und der Fäden, erscheint lam perlsehnmförmig; so pflegt anch die Gattung Melosina durch enu anf' gleiche Weise gebildetes Stielchen sich an Gegenständen zu befestigen. Unter allen Diatomaceen ist Melosira diejenige, welche am hänfigsten wirkliche Fruchtzellen ansetzt; die Zelle schwillt kuglich anf mu entlüsst gleich oder in ähnlicher Weise, wie bei den Farlenalgen, Schwämsporen, die sich zn nenen Individnen entwickeln.

Es sind gegenwärtig 22 Gattungen mit gegen 163 Arten bekannt, von denen über die Hälfte mur noeh fossil vorkommen: 10 Gattungen mit etwa 31 Arten gehören den süssen Wasser an; hiervon mïssten freilich streng genommen noch die im Brack- mo Soolwasser vorkommenden abgezogen werden; die Zahl der Arten reducirt sich dam anf 28 . Ans dem Meere kennen wir 10 Gattımgen mit 37 Arten.

\section{CYCLOTELLA K'TZ. (T. II.)}

Einzeln oder paarweise, in einer gestaltlosen, gelatiuösen llülle. Hauptseiten genau zirkelrund, scheibenförmig-flach; von den Nebenseiten gesehen eine kurze (zweigliedrige) Walze darstellend.

1. C. operculata ( $\Lambda g$.) Kitz. (Fig. 1.) Hampts. $\frac{1-2}{100}$ Mm. im Durchmesser, am Rande mit punktförmigen Küü̈tchen; Nebenseiten mit stmmpfzugerundeten Eeken. Durch Dentschland, Frankreich. In stehenden Wassergräben unter Charen und andern Algen, eine schmutzig gelblichweisse Schleimmasse darstellend, die anfangs festsitzt, später an der Oberfläche des Wassers schwimmt.

2. C. rectangula Bréb. Wie die operenlata, aber anf den Nebenseiten mit scharfen rechtwinkligen Eeken. Bei Paris.

3. C. meneghiniana Ktz. (Fig. 2.) Hampts. $\frac{1 / 2-1}{100}$ Mm., mit strahlig-gestreiftem Rande. In Italien, Dentschland. Var. major, eine doppelt grössere Form. Bei Falaise von De Brébisson entdeckt. 


\section{PYXIDICULA EHRENBG. (T. II.)}

Einzeln, in Gestalt einer lïnglich-runden, zweiklappigen Büchse. Hauptseiten gewölbt.

1. P. major Kitz. Elliptisch, mit regelmässig rertheilten, punktförmigen Knoten. Nordamerika. Frankreich.

\section{LIPAROGIRA EIIRENBG.}

Panzer walzenfürmig, einzeln, an der innern Wand mit kammförmigen spirallinien.

1. I. (spiralis) dendroteres Ehrenbg. $\frac{1}{30}$ “ lang, mit 13 Spiralen; Hauptseiten am Rande gezähnelt. Anf Bammstämmen in den Urwäldern von Veneznela. Hat ganz den Habitus einer Spurogyra.

2. I. circularis Ehrenlig. $\frac{1}{30}$ "' lang, mit 13 ringförmigen Windungen. Ebendasellost. Beide anch in Rio Conigo in Brasilien.

\section{POROCYCLIA EHRENI3G.}

Ier vorigen Gattung ithnlich, ,es hat aber innere Zirkelleisten ohne Spirale und am Rande der scheibenförmigen Enden (Hauptseiten) sciner Zylinder-Glieder einen liranz von grossen Oeffnungen oder tiefen Eindrücken".

1. P. dendrophila Ehrenbg. $\frac{1}{27}{ }^{\prime \prime}$ lang, nur lalb so breit, glatt, mit 9 Zirkelleisten; Hauptseiten am Rande mit 12 Eindrücken, nach dem Centrum zu strahlig-punktirt und mit 5 Centralspitzchen. Auf Baumstämmen in Venezucla.

\section{STEPHANODISCUS EHRENBG. (Abbildung fehlt!)}

Eine Cyclotella mit einem randständigen Zahnkranz.

1. St. herolinensis Ehrenbg. Klein, scheibenfömig-flach, mit zarten, strahlenförnigen Streifen: Zahnkranz mit beiderseits (häntig 32) spitzigen Zähnen. Bei Berlin.

2. St. Niagarae Ehrenbg. Grösser, mit gekörnten (knotigen) (öfters 64) strahlenförnigen Streifen und (öters 64) spitzigen Zähnen. Im Niagara-Fluss.

\section{CALODISCUS RAJENH. (T. III.)}

Ungleich kreisrund, scheibenförnig-flach, in flüssig gelatinüser llülle. llauptseiten mit (ïfters 64) strahlenförmigen Leisten, von denen je zwei in dem breiten, gestreiften Rande durclı einen spitz zabnfürmigen Streifen mit einauder verbunden sind, im Centrum dunkellsaun getrübt und mit lichter quer durchgehender, einästiger Zone.

1. C. superbus Rabenh. (T. III.) Durchnesser $\frac{15-20}{100}$ Mm., der änssere Rand $\frac{1}{100}$ Mm. und darüber breit, mit dichten und scharfen Streifen. In der terra di Otranto (süd̈̈stliches Italien).

\section{DISCOSHAA RABENH. (T. III.)}

Walzenförmig, 4-6gliedrig, in einer dicktlïssigen Schleimhülle. Ilauptseiten genau zirkelrund, leicht gewölht, mit פด bis 33 lejcht gekrümmten, schief strahlenfümigen Leisten und einem hranz von $50-64$ Zühnen: im Centrum gleichmäissig punktirt.

1. D. suleata Rabenh. (T. III.) Walzenförmig, tiefgefurcht, $\frac{4-5}{100} \mathrm{Mm}$. im Durchmesser; die Furchen entsprechen den Zähnen der Hauptseite, jeder Zahm mit 7 kleinen, scharten Zähnchen, welche erst bei 800 bis 100 maliger Vergrösserung sichtbar werden. In Tümpehn, sogenannten Lagunen an der Ostküste Italiens (bei Manfredonia). 


\section{VHI. CAMPYLODISCLS EHRENB. (T. Il.)}

Einzehn, scheibenformig, verbogen, gerundet-elliplisch, mit strahlenförmigen Rippen.

1. C. rarliosus Ehrenbg. (T. I. F. 1.) Hanptseiten im C'entrum punktirt, nach dem Rande zu strahlig gestreift (nit fast 70 Strahlen). V'era Cruz.

2. C. noriens Ehrenbg. Fast kreisund, in Ceutrum glatt, gregen den Rand auf $\frac{1}{96}{ }^{\prime \prime} 7$ Strahlen, am lande schurf kammfömig-gekerbt. Bei Salzburg lebend, fossil aun Hoehsimmer.

3. C. Snrirella Ehrenbg. Gross, länglich, verbogen, in Centrun glatt, am Rande strahlig gestreift. In spanien.

4. C. striatus Ehrenbg. (T. II. F. 2.) Eine aus dem Ehrenberg (Verhr. in Amerika) kopirte, ms mbekannte Form, die auf keinen Fall zu Campylodiseus gehört, ohne Anschaumg natïrlicher Exemplare aber nicht weiter zu deuten ist.

\section{HELOSIRA C. AG. (T. II.)}

Kettenfïrmig verbunden zu confervenartigen Fäden und meist angewachsen. Die einzelnen Individuen walzen-, scheibenförmig oder kuglich, zweigliedrig, durch ein ringfürmiges Zwischenglied verbunden. Hauptseiten genau zirkelrund, scheibenförmig-flach, glatt oder strahlig-gestreift. Die üussere Hülle inehr oder minder deutlich entwickelt, röhrenfürmig, zieht sich am Grunde und da, wo die Glieder auseinander treten, stielfirmig zusammen.

\section{a. LXSIGONIUNI LINK.}

Gilieder kuglich oder elliptisch, gegen beide Enden gekielt.

1. M. salina Ktz. (Fig. 1.) $-\frac{1-2}{100} \mathrm{Mm}$. im Durchmesser. Bildet schleimige Ueberzüge in den Leitmgsrinnen und Gräben der Soolwässer, auch im Brackwasser der Küsten.

\section{b. GALLIONELLA EHRENBG.}

Glieder länglich - walzenförmig, nicht gekielt.

2. M. varians Ag. (F. 4.) $\frac{1 / 2-2}{100}$ Mm. im Uurchmesser, dicht verbunden, ohne stielförmiges Zwischenglied; Hauptseiten glatt. Sehr verbreitet, durch ganz Europa, Aegypten, Sïdpersien.

3. M. a equalis Ag. (F. 10.) Eine M. varians nit eonstant quadratischen Gliedern. Durch ganz Deutschland.

4. M. subflexilis Ktz. (F. 6.) Eine M. varians mit quadratischen oder walzenförmigen Gliedern, je zwei Glierler durch ein ku'zes und schmales Zwischenglied verbunden. Durch Dentschlancl.

5. M. oriehalcea Ktz. (F. 2.) ist der Mr. varians sehr verwandt, die Zelle imerhalb des Kieselpanzers ist hier aber zweimal leicht eingeschüirt; das hat sie wieder mit der M. Jürgensii gemein, von der sie sich dureh die flachen Hauptseiten unterscheidet. Sie ist ebenfalls sehr verbreitet.

6. M. Jürgensii Ktz. (F. 7.) Hauptseiten gewölbt. In Brackwasser an den Küsten.

7. M. distans Kt.z. (F. 9.) Bis $\frac{1}{100}$ Mm. dick, jerles Glied mit zwei Ringfurchen: Hauptseiten flach und glatt. Sehr verbreitet, sowohl lebend, wie fossil: Europa, Centralafrika (Ukamba), Südpersien, anch im Meteorstaub.

8. M. Roeseana Rabenh. (T. X. suppl. F. 5.) bis $\frac{2}{100}$ Mm. im Durchnesser: Glieder länger als breit, mit zwei breiten Ringfurchen, an den Gelenken gestreift; Hanptseiten strahlig gestreift. An fenchten Felsen eines Wasserfalles bei selmepfenthal in Thïringen. NB. Sie hat mit M. distans die Ringfurchen gemein, ist aber noch einmal bis 
doppelt so gross und ist an den Gelenken, wie auf den Hauptseiten gestreift. Sie repräsentirt die H. arenaria im verjüngten Maassstabe.

9. M. arenaria Moore (T. II. F. 5. áb. b.) Die grösste aller bekamnten Arten, $\frac{3-8}{100} \mathrm{Mm}$. im Durchnesser; Glieder walzenförmig, dicht verbunden, an den Gelenken gestreift; Hamptseiten strahlig gestreift, im Centrum punktirt. Sie ist in Deutschland (conf.' Rabenh. Bacill. exsice. N. 62.), England und Frankreich lebend beobachtet worden.

10. M. americana Ktz. (T. 11. F. 11.) $\frac{1-2}{1+0} \mathrm{Mm}$. im Durchmesser'; Glieder an den Gelenken gestreift; Hauptseiten gew ilbt und strahlig gestreift, mit sehr kleinem, pmiktirtem Centrum. Im tropischen Amerika.

11. M. crenulata (Ehrenbg.) Ktz. (T. II. F. 3.) Glieder bis $\frac{1}{100}$ Mm. im Durehmesser, 2-4mal länger, an den Gelenken gezahnt, Hauptseiten flach, am Rande mit punktförmigen Knötchen, die den Zähnen der Nebenseiten entsprechen, gegen die Mitte strahlig gestreift. Durch Europa, Nordamerika, sïdpersien.

12. M. Binderiana Ktz. (T. II. F. 12.) Gleich zarten Conferrentülen, sehr lang gegliedert, Glierler $\frac{1 / 6-\text { gegen } 1}{100}$ Mm. dick, 4-8mal länger, oft banchig gedunsen, an den Gelenken zart gestreift; Hauptseiten strahlig gestreift, die Streifen nach der Peripherie zn in ein Knötchen auslanfent. Bei Hambmrg ron Binder entdeckt, anch in Gräben bei Salzburg (Santer) und im sächsischen Erzgebirge.

13. M. garganica Rabenl. (T. II. F. 8.) Sehr schlank, Glieder $\frac{1 /}{100}$ Mm. im Durchmesser, 2-3̈mal länger, mit einem stark gednnsenen Zwischengliede und nndentlich gezälnt: Hauptseiten flach, in der Perjpherie knotig-pmetirt. In Lago s. Egidio in Gargano. NB. Nach dem Glïhen erimnert sie an die fossile M. tennis der lüneburger Heide.

\section{X. stepHANOSIRA EHRENBG. (Abbildung fehlt.)}

Hauptseiten scheibenfürmig, zart strahlig-punktirt, in der Peripherie mit einem Zahnkranz geziert.

Bildet durch unvollkommene Theilung walzenförmige Faden, wie Melosira, ist sonst dem

Stephanodiscus am Aehnlichsten.

1. St. Epidendron Ehrenbg. $\frac{1}{160}-\frac{1}{36}$ “. im Dnrelmesser; Nebenseiten mit junktirten Querdinien und Querfurchen. Auf Bäumen in den Urwäldern ron Venezuela, im Fio Conigo in Brasilien.

2. St. Hamadryas Elrenbg. $\frac{1}{60}$ ' im Durchmesser'; Nebenseiten glatt, am Raude der Glieder quergestreift; Hauptseiten nur am Rande strahlig-punktirt, in der Mitte mit wenigen zerstrenten Punkten. Auf Bämmen, wie die vorige.

3. St. enropaea Ehrenbg. Viel kleiner als die vorigen, lie Glierler hänfig breiter als lang, glatt, am Rande sehr zart gestreift (gewimpert?). Auf Bämmen unter Mloos bei Berlin. 


\section{FAI. II. EUNOTIACEAE.}

Panzer prismatisch-vierseitig, die beiden Hauptseiten gleichgestaltig, eben, ıuergestreift, bisweilen knotiggekïrnt oder pmoktirt, mit zwei durchgehenden Lüngsfurchen, die sich an den Enden erweitern; Nebenseiten: die untere schmaler als die obere, mehr oder minder eingebogen, die obere mehr oder minder gewölbt, bisweilen mit $2,3,4,5$ u. s. w. Buckeln.

Die Emotiaceen oder sogenannten Prachtschiffchen bilden eine gut in sich abgeschlossene Familie, die sich zumal durch die ungleichen Nebenseiten wesentlich anszeichnen: Die nntere meist gebogene ist schmaler als die obere, man nennt sie figürlich anch Banch oder Banchfliche: die isolirt lebenden Arten liegen wie die Cocconeiden damit auf und erscheinen so wie jene als wirkliche Schmarotzer; die entgegengesetzte oder obere Seite nennt man Rücken, sie ist immer gewölbt, selten niedergedrickt, üfters mit mehreren Buckehn oder Wellenlinien. Ihre Fortpflanzung geschieht ansser der einfichen Theilung durch einfache oder doppelte Copulation: der Panzer spaltet sich, der Inhalt zweier benachbarter Zellen, rom Primordialschlanch nuschlossen, vereinigt sich entweder sofort zu einem Gonidinm, das schnell zu einem Individum heranwïchst, oder der Inhalt jeder Zelle theilt sich erst in zwei Partien, und darauf erfolgt die Copulation zu zwei Gonilien. Die erstere, die einfache, ist der Grattung Hinanticlium eigen, die letztere ist bei Emotia und Epithemia beobachtet.

sie leben isolirt, frei orler anfsitzend, oder mit den Hauptseiten reihenweise neben einander liegend und durel die gelatinöse äıssere Hülle verbunden und bandfürmige Fäden darstellend. In letzterem Falle können sie von den Fragilarien und andern in gleicher Weise familienweise lebenden Arten sicher nur durch die Gestalt der Hauptseiten unterschieden werden. Ein veroleichender Blick auf die Tafeln wird die Unterschiede an Dentlichsten zeigen.

Wir kennen bis jetzt 95 Arten, die in drei Gattungen vertheilt sind. Sie gehören fast ausschliesslich dem süssen Wasser an: nur vier sind ans dem Meere bekannt. Die Gattung Himantidium ist im Meere noch nicht gefunden worden. In Europa sind einige 50 , ausser Europa 58 beobachtet, fossil überhaupt 42 gefunden worden. Einige Arten (Eunotia amphioxys, Epithemia gibba, Himantidimm Arcus) sind allgemein verbreitet, andere sind den verschiedenen Breitegraden oder den entsprechenden Höhen über der Meeresfläche, oder - wie es scheint - gewissen Lokalitäten eigenthümlich. Die drei Gattungen lassen sich ïbersichtlich so fassen:

\section{a) Isolirt lebende.}

Eunotia, mit äusserst zarten, oft scheinbar fehlenden Querstreifen.

Epithemia, mit starken oder breiten, öfters knotig punktirten Querstreifen.

b) Familienweise, zu bandfürmigen Faden verbunden lebende.

Himantidium, mit oder ohne Querstreifen.

\section{EUNOTIA EHRENBG. (T. I.)}

1. E. amphioxys Ehrenbg. (T. I. F. 1.) $\frac{2-2 \frac{2}{10}}{100} \mathrm{Mm}$. lang, grösste Breite $\frac{2}{5}$ der Länge, linealisch, mit leicht gewölbtem, glattem Rïcken und schwach eingebogenem, zart 
gestreiftem Banche, an beiden Enden plötzlich verdïnnt, etwas gestreckt und stumpflich abgerundet. In stehenden und fliessenden Wässern durch ganz Enropa, Amerika, Island, Centralafrika, Sïdpersien: anch im Meteorstube. Var. P) rostrata Ehrenbg. mit mehr gestreckten, schnabelförnigen Enden. Amerika, Centralafrika, in Meteorstanbe.

2. E. Dianae Ehrenbg: Wie E. anphoxys, aber grösser, an den Enden mehr gespitat und zurä̈ckgebogen; Querstreifen dentlich, 41 anf $\frac{1}{100}{ }^{\prime \prime}$. Bis jetzt nur bei Brandenburg an der llavel beobachtet.

3. E. Warallela Ehrenbg. Linealisch, gekrümnt, nit dentichen Gnerstreifen, einfach zugermdeten Enden. Nordamerika.

4. E. praerupta Ehrenbg. Verlängert, dentlich quergestreift, nit gewölbtem, gegen die erweiterten und gestutzten Enden nach und nach herablaufendem Rücken. Nordamerika, lsland.

5. E. a pina Kitz. (F. 2.) Meist paarig, linealisch, $\frac{1-2}{100}$ Mm. kam darïbur lang, nit stark gewölbten lïicken, flacher, in der Mitte leicht ansgeschweifter Banchtäche, an den Enden verdünnt und gestntzt. In den Alpen der Schweiz.

6. E. amphilepta Ehrenbg. Linealisch-viereckig, nit gewälbtem, glatten Rüicken mo leicht eingebogenem gestreiftem Banche, an den nach und nach zugespitzten Enden etwas zurückgekrïimmt. Länge $\frac{1}{39}{ }^{\prime \prime \prime}$. Auf Japan.

7. E. depressa Ehrenbg. (F. 4.) $\frac{4-5}{100}$ Mm. lang, mit platt niedergedröcktem Pürken, plützlich verdïnnten und zugerundeten Enden. Amerika (New-Iork, Brasilien, Bogotii).

8. E. Crocodilus Ehrenl,g. Gestreckt, gestreift, "1" lang; der gewillote líicken ist in der Mitte eingedrïrkt und in der Hitte des coneaven Banches findet sich ein kleiner Buckel; die Enden ziemlich seharf' zngespitzt nnd znrïckgekrümmt. Gujana, Senegambien, Centralafrika.

9. E. nodosa Ehrenbg. (F. 5.) Bis $\frac{10}{100}$ Mm. ling, gestreckt, in der Mitte oben und muten leicht gedunsen, an den Euden zugerunlet nud etwas abwäts gekriummt. Anerika: anch fossil.

10. E. Formica Ehrenbg. Wie E. nodosa, aber die Enden nicht gekrïmmt und gednusen. Amerikit.

11. E. ventralis Ehrenbg. ist nur am Banche etwas anfgeschwollen, der Rücken platt, die Enden sind gedunsen und gestreckt, wie bei der E. Formica. Nordamerika.

12. E. flexuosa Bréb. Genan linealisch, oben und menten 2-3mal wellig gebogen, an den leieht rerdickten Enden kopfförmig zngemurlet, $\frac{1}{15}$ “ lang. Frankreich.

13. E. pachycephala Ktz. Leicht gekrümmt, kaum gestreift, an den Enden in emen kenlenförmigen kopf erweitert; -1 "' lang. Frankreich.

14. E. uncinata Ehrenbg. Schmal linealisch, gekrümmt, unter den kopfförmigen Enden stark zusammengeschnïrt. Nordamerika.

15. E. Diodon Ehrenbg. (F. 10.) Kamm über $\frac{2}{100}$ Mm. lang, dentheh gestreift, mit flachem Banche und zwei-bnckligem Rü̈ken, an den Enden verdïnnt und zugerundet. England, Sarbsen. Früher nur fussil bekannt. NB. Hier schliessen sich die bis jetzt nur fossil bekannten Formen an, die nach der Zahl der Buckehn mnterschieden und benannt werden, als Triodon, Tetriodon, Pentodon, Heptodon, Oetodon, Enneodon, Decaodon u. s. w., nnd neben diesen finden sich noch parallel lanfende Formenreihen, deren Bnckel weniger hervortreten, die eine eine mehr oder minder flache Wellenlinie bezeichem, die andere mit fast stumpt' zahnartigen Höcker'n. 
16. E. bidens Ehreubg. Wi. E. Diorton, die Buckeln sind aber mehr zahmförmig, die Enden erweitert um abgestutzt. Amerika.

17. E. Zygodon Ehrenbg. (F. 12.) ist fluch huckhger als E. Diodon, mud die germuleten Enden sind geneigt. Gujana, Centralafika.

18. E. declivis Ehrenbg. (F. 26.) hat einen stärker gehobenen und eingedrïckten Rï̈ken, der gradlinig in die ziemlich spitzen Enden verläuft. Cayeme, Bogutá.

19. E. Camelus Ehrenbg: (F. 6.) Gestreift, mit zwei erhabenen Buckeh und verdïnnten, vorgestreckten stumpflichen Enden. Amerika.

20. E. Sella Ehrenbg. (F. 28.) Fast wie E. reclivis, der Riucken verläuft aber nicht grallinig, sondern bogig. Amerika; anch im Meteorstanl, und anf Flechten von Labrador.

21. E. bigibla Ktz. Hat ansser zwei Bnckeh an jedem Ende noch eine leicht bucklige Ansehwellung und ist ohne (Gnerstreifen. Bei Jever in Oldenburgischen.

22. E. Elephas Ehrenbg. (F. 27.) Sehr rohus, hreit, leicht gekrümnt, am Rücken mit drei wellenförmigen Erhabenheiten, an den Enden zngerundet. Brasilien.

23. E. dizyga Ehrenbg. (F. 30.) Kileiner und mit vier wellenförnigen Erhabenheiten. Cayenue.

24. E. tridentula Ehrenbg. (F. 16.) Schlank, mit drei stmmpen Zühnen, gedunsenen und etwas zurïckgeschlagenen Furlen. Amerika, Centralafrika, Sï̈lpersien.

25. E. quaternaria Ehrenbg. (F. 17.) Wie tridentula, aber mit rier stumpflichen Zälnuen. Cilyeme.

26. E. quinaria Ehrenbg. (F. 15.) Wie die vorigen, aber fünfzähnig. Cayenne, New-York, anch in Meteorstaube.

27. E. septena Ehrenlıg. Klein und schlank, siebenzähnig. Labrador.

28. E. Diadema Ehrenbg. (F. 34.) Bis über $\frac{5}{100}$ Mm. lang, $\frac{1}{100}$ Mm. breit, mit sechs wellenförnigen Erhabenheiten. Fossil in Amerika, Finnland und schweden. Wir fanden sie als leere Schalen in einem schwärzlichen Schlamme, ler von Herrn Lindig in einem stehenden Wassergraben lei Bogotá gesammelt wurde.

29. E. corona Rabenh. Fast so breit als lang, hoch gewölbt, fünfbucklig, die beiden seitlichen die eingeschmürten Enden überragend: Qnerstreifen convergirend, 8-9 auf $\frac{1}{100}$ Mm. Ostkïste Italiens, in Lagmenschlamm der terra di Otranto. Wir finden jedoch nur die leeren Kieselzellen, es ist deshalb zweifelhaft, ob sie überhaupt dem süssen Wasser angehört.

\section{XY. EPITHENIA DE BRÉB. (T. I. unter Emotia!)}

Die Querstreifen sind meist breit, leistenförmig.

E. gibba (Ehrenbg.) Ktz. (F. 3.) $\frac{6-15}{100}$ Mm. lang, gestreckt, am Rücken mit breitem Buckel. mit breit zngerundeten, bisweilen etwas geneigten Enden: anf den Nebenseiten (a.) in der Mitte stark anfgetrieben. Sehr verbreitet. Luropa, Amerika, Centralafrika, in kalten und heissen Quellen, Gräben, Teichen und Flüssen; auch fossil und im Meteorstaube.

2. E. ventricosa Ktz. (F. 22.) Bis $\frac{3}{100} \mathrm{Mm}$. lang, hucklig, mit stumpf zugerundeten Entlen, auf $\frac{1}{100} \mathrm{Mm}$. mit acht Querleisten. Sachsen, Piemont (bei Vercelli).

3. E. margaritifera Rabenh. (F. 32.) Bis $\frac{3}{100}$ Mm. lang, mit stark gehobenem Rïcken, der durch eine Wellenlinie in die verdümnten und gerundeten Enden verläuft; 
Qnerleisten etwas geneigt, auf $-\frac{1}{100}$ Nm. 4-5, anf jerler Randseite mit einer Reihe punktfömiger Knötchen besetzt: and" den Nebenseiten länglich-eifömig. mit vorspringenrlen Querteisten, an den Euden abgestutzt. Sürlpersien, in stehenden Wasser am Fusse des Berges ... Subst-Buschom".

4. E. reticulata Naeg. Leicht gekrimmt, $\frac{1}{40}-\frac{1}{25}$ " lang, an beiden Enden etwaw verdiunt und stumpf, nit durchgehenten Querleisten, 3-5 anf $-1{ }^{100}{ }^{\prime \prime}$, zwischen denselben regehü̈sig netzförmig gealert, an hande zart quergestreift. Schweiz.

5. E. adnata Bréb. (Vertagus Ktz.) (F. 24.) Lang. schlink, leielıt gekrïmmt und mit leicht gehobenem liücken, an den stmmpfich germoleten Eurlen zurïckgekrümmt. mit convergirenden Qnerleisten, 10 auf $\frac{1}{100}{ }^{-\prime}$, in den Zwischenräunen mit einer Reihe punktförmiger Kuötehen. Frankreich.

6. E. Librile Ehrenba. (F. 31.) Robust, mit niedergedrücktem und etwas eingedrücktem Räicken, gegen die Enden plötzlich rerdïmnt, stumpf und zur ïckgekrïnmt, die untere Seite leicht gekrümmt, Gnerleisten convergirend, nit einer lieihe punktfirminger Kü̈tchen wechsehn; Nebenseiten breit linealiseh. rechtwinklich abgestutzt. Mexiko.

7. E. turgida (Ehrenbg.) Kitz. (F. 11.) $\frac{5-10}{100}$ Mn. lang, mit ziemlich stark gehobenem Rücken, der in regehnässiger Bogenlinie gegen die stark verdïnnten, etwas vorgestreckten mul gestutzt-alggerundeten Euden verläuft: Querleisten 5-6 auf $\frac{1}{100}-\mathrm{Mm}$. durch ganz Europa, auf Vaucherien, (ladophoren schmarotzend.

8. E. Zebra (Ehrenbg.) Ktz. (F. 8.) $\frac{3-4}{100}$ Mm. lang, mit gleichmässig gewölbtem Rücken, stumpf zugerundeten, kam gestreckten Enden; Querleisten convergirend, 4-5 auf $\frac{1}{100} \mathrm{Mm}$. Durch Deutschland, Englanı, Frankreich, Italien (Ancona), Amerika (Bogotá).

9. E. zehrina Ehrenbg. Verlängert, mit gleichmässig gewälbten Rü̈ken, gegen die stumpfen Enden zusammengeschnït, zwischen den Querleisten mit einer Reilie punktfömiger Knötchen. Amerika, Island.

10. E. Westermanni (Lhrenbg. (F. 19.) $\frac{3}{100}$ Mn. lang, gekrümmt, mit gewölbtem Rïcken, verdïnnten, stumpflichen Enden: Querleisten kamm convergirend, 6-7 auf $\frac{1}{100}$ Mn. Durelı ganz Europa, Amerika.

11. E. angulata Perty (F. 18.) Mit lochgewölbtem Rücken, in der Mitte anf der nntem Seite ausgeschnitten, an den Euden stumpflich-spitz. Querleisten etwa 12 anf $\frac{1}{100}-$ Mu. In der Schweiz.

12. E. Sorex Ktz. (F. 7.) $\frac{1-11 / 2}{100}$ Mm. lang, mit stark gewölbtem Rïcken, spitzen und vorgestreckten Enden; Querleisten convergirend, $8-9$ auf $\frac{1}{100}$ Mm. Anf Fadenalgen schmarotzend, in Deutschland nicht selten. wahrscheinlich durch ganz Europa: anch in Kleinasien.

13. E. saxonica Ktz. (F. 9.) $\frac{1}{100}$ Mm. und darüber lang. gekriimmt, mit verdünnten, gerundeten Enden; Querleisten etwas convergirent, gewöhnlich 5-6: Nebenseiten linealisch-länglich, an den Enden stumpf zugerundet. In Deutschland, hin und wieder.

14. E. alpestris Ktz. (F. 23.) $\frac{3-6}{100}$ Mm. lang, bogig-gekrimmt, schmal, mit stumpflichen oder germoteten Enden; Querleisten 3-4 auf $\frac{1}{100}$ Mm.: Nebenseiten fast keilförmig, gestutzt. In klaren Bächen Salzburgs, der Schweiz, Frankreichs, Italieus (bei Subiaco).

15. E. quinquecostata Rabenh. (F. 35.) $\frac{3-4}{100}$ Mn. lang, mit bogig-gewölbtem Rücken und platt aufliegendem Bauche, schwach und nach und nach verdünnten, stumpf- 
lichen Enden; Querkeisten leicht eonvergirend, bei jeder Grösse mur stets 5 beobachtet. In sächsischen Erzgebirge.

16. E. ocellata (Ehrenby.) Ktz. (F. 25.) Mit thach bogig-gewälbtem liücken,

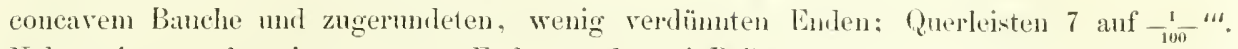
Nebenseiten oval, mit gestutzten Enden und zwei Reihen rundes Aeuglein (knotiger Verdickungen). In Peru: fossil in Griechenland.

17. E. Argus Ehrenbg. (Ktz.) (F. 33.) Nebenseiten länglich-quadratisch. Amerika; anch in Neteorstaube.

18. E. Textricula Ehrenbg. (F. 13.) Röeken bogig-gewöbt, nach und nach in die gerundeten, nicht zusammengeschnürten Enden äbergehend. mit entfernten, seitlichen Querleisten, in den Zwischenränmen mit Längstreifen. Mexiko, Island.

19. E. gibberula (Ehrenbg.) (F. 14.) $\frac{3}{100}$ Mm. lang, bogig-gekrümnt, mit spitzen Enden: Nebenseiten elliptisch: Querleisten 5-6 atuf $\frac{1}{100}$ Mn, sehr zart gekörnelt. Amerika; anch im baltischen Heere.

20. E. Lindigii Rabeuh. (F. 20.) Gegen $\frac{1}{100}$ Mm. lang, nit stark gewölbtem lïicken nnd wenig eingebogener Banchfläche: Enden fast scharf gespitzt: Querleisten entfernt, 6-7. Amerika. bei Bogotá gesellig mit andern Diatomaceen muter stagnirendem Wasser liegendes Holz als gelblich-grane Schleimmasse überkleidend (lindig).

21. E. otrautina Rabenh. (F. 29.) Nebenseiten $\frac{7-9}{100}$ Mm. lang, über $\frac{2}{100}$ Mm. breit, länglich, mit gestutzten Enden, beiderseits auf $\frac{1}{100} \mathrm{Hm}$. mit drei Querleisten, die sich an der Spitze zn einem runden Knoten verdicken. In der Otranto in den Lagunen an Chara crinita.

\section{HHANTHDUUM EllRENBg. (T. I.)}

Zu Bändern verbunden, auf den llauptseiten unmerklich von den Euwotien abweicliend und deren Formesreihen wahrscheinlich wiederholend.

1. H. pectinale (Dillw.) Ktz. (F. 1. a. b.) ${ }_{-100}^{5-6}$ Mm. lang, leicht gekrünmt, gestreckt, mit gerumleten, etwas zurïkgekrïmmten Enden, anf $\frac{1}{100}$ Nm. 9-10 Querrippen; Nebenseiten länglich-quadratisch, rechtwincklig, am Rande zart quergestreift. Durch ganz Europa.

2. H. strictum Rabenh. (F. 1. c.) Mit ganz glatter Banchtläche und fluchem Rï̈cken, an den Enden verdünnt und zugerundet; $\frac{1-5}{100} \mathrm{Nm}$. lang; Querrippen 8 auf $\frac{1}{100} \mathrm{Mm}$. Durch ganz Dentschland, in Baiern. Oestreich, Oberitalien.

3. H. attenuatum Rabenh. (F. 10.) $\frac{5-\pi}{100}$ Mu. lang, gekrïmmt, nit stark verdümnten, stmmpfen und leicht zurückgekrümmten Enden; Nebenseiten öfters keilförmig. mit stark entwickelten Zwisehengliedern, an Rande weit kürzern Querstreifen, als bei dem $H$. pectinale, dem es, wie anch dem H. Arens, allerdings sehr nahe steht. In der sächsischen schweiz.

4. H. mimus Ktz. (F. 2.) Gegen $\frac{2}{100} \mathrm{Mm}$. lang, mit flach gewölbtem Rücken und leicht eingezogener Banchfläche, an den gerundeten Enden kaun zurïckgekrümmt, ohne Querstreifen. Dentschland, Frankreich, Oberitalien.

5. H. exiguum Bréb. Klein, ohne Querstreifen, bogig-gekrümmt, mit rorgezogenen, stumpfen Enden. In Frankreich.

6. H. Soleirolii Ktz. (F.3.) $\frac{2}{100} \mathrm{Mm}$., anch darüber lang, linealisch, gekrümmt, glatt, mit stumpfen, etwas zurïickgekrümmten Enden; von den Nebenseiten betrachtet 
erschennt die Zelle nnter dem Kiesehyanzer länglich-elliptisch. Dentschland, Frankreich, ltalien.

7. II. Hlalcyonellae l'erty. $\frac{1}{40}-\frac{1}{32}$ “" lang, gekrümmt, mit ansgerandetem Rücken und stmmpten Enden. In Halcyomella fluviatilis, in der Schweiz.

S. H. veneris Ktz. (T. I. ohne Nummer, unmittelbar unter F. 4. c.) Ganz glatt, mit bogig-gewöl,ten Rücken und platter Banchflïche, an rlen Enrlen zugespitzt. Auf Trinitad im see..Tacarigua".

9. 1. Arens Ehrenbg. (F. 6.) $\frac{5-12}{100}$ Mm. lang, robust, gekrïmmt, qnergestreift, mit germuleten, ctwas zurükgekrümmten Enden. Sehr verbreitet: Europa, Amerika. Afrika, sïdpersien: anch fossil und in Meteorstanbe.

10. H. gracile Ehrenhg. (F. 5.) $\frac{4}{100}$ Mm., kamm darüber lang, sehr schlank, gestreift, gckrümmt, mit fast kopffömigen, zurïekgekrümmten Enden. Europa, Amerika; anch im Meteorstantie.

11. I1. gujanense Elıenbg. (F. 9.) Gestreift, mit stark niedergedrücktem, fast zweiluckligem lä̈cken, concarem Bauche und stumpfen, leicht zurïckgekrïmmten Enden. Cayenne.

12. H. monodon Ehrenbg. (F. 7.) Gestreift, leicht gekrümmt, mit stark gehobenem Rücken (dadurch einbucklig oder einzahnig), an den Enden breit zugerundet. Amerika; auch fossil und im Meteorstaube.

13. H. Tetraodon Bréb. (F. 11.) Mit vier Buckeln. Lebend in Italien, fossil in Frankeich und Finnland.

14. H. biceps Rabenh. (Ennotia biceps Ehrenbg.) (F. 12.) Bis $\frac{5}{100} \mathrm{Mm}$. lang, gekrïmmt, quergestreift, mit flach gewöbtem Pï̈ken und gerundeten, stark zurïckgekrümmten Enden. Frankreich, Amerika, auf den Inseln St. Kitts, Falkland.

15. H. bidens Ehrenbg. Plan-convex, gestreift, mit zwei stumpfen Zühnen und erweiterten, gestntzten Enden. Island, Nordamerika.

16. H. quaternarinm Ehrenbg. Sehmal, gestreift, gekrimmt, am Rü̈ken tief eingeschnitten, vierzahnig. In Californien.

17. H. quinarium Elırenbg. Wie die vorige, aber fünfzahnig. In Californien. NB. Hier schliesst sich das H. dentieulatum Bréb. an, das aber, da die Zahl der Zähne nicht angegeben ist, anch nicht nïher bezeiclmet werden kann.

18. H. Papilio Ehrenbg. (F. 8.) Kur, mit stark gehobenem, zweibuckligem Rücken, concarem Banche und kurz zugerundeten Enden. Amerika: auch im Meteorstaube. 


\section{FAM. III. CIMBELIEAE.}

Die Cymbellen sind in Gestalt den Eunotion sehr ähnlich, sie unterscheiden sich aber durch eine sogenannte Oeffinng in Centrum, welche sich in Gestalt eines schmalen Leistens nach beiden Enden ansdehnt und hier sich wieder knotig oder drïsenartig verdickt.

Es ist wahrscheinlich, dass alle, d. h. die eigentlichen Cymbellen einen Stiel entwickeh: doch findet man sie meist stiellos, frei umherschwimmend. Die Gattung Encyonema biłdet sich statt res Stieles eine gelatinöse röhrenfömige orler scheidenartige Hülle, worin sieh die Intividuen reihenweise anordnen. Bei den Cymbellen liegt die Absonterung des Hüllstoffes rorzugsweise in der Luddrïse, und zwar in der, mit welcher sie sich gerarle an Gegenständen festsetzen; so ist es amch bei Gomphonema und Achnanthes. Bei Encyonema hingegen ist die Absondernng des Hüllstoftes auf der ganzen Fläche der Kieselzelle eine gleichmässig vertheilte. Schon deshalb müsste Eneyonema von den Cymbellen getrennt werden, sie unterscheidet sieh aneh noch durch die Art und Weise, wie sich die Tochterzellen von einander trennen, wodureh sie sich den Cocconeiden anschliessen; da wir aber bei unserer Anordnumg die Form oder Gestalt als leitendes Prinzip und für Dilettanten als das verständliehste und ohne eigentliches Stulium schon begreifliehe an die Spitze gestellt haben, so komnten wir Encyonema nicht von den Cymbellen trennen.

Die Stielhildung geht in der Weise vor sich, dass die freien Individuen sich mit einem Ende festsetzen. An dieser Basis sondern sie nun rorzugsweise, scheinbar allein, einen ziemlich consistenten Hüllstoff ab und werden in dem Grade, wie diese Absonderung erfolgt, dureh denselben horizontal rorgeschoben, mittlerweile hat das Individuum seinen Lebenscyclus durblaufen, es erfolgt die Theilung. Die beiden Tochterzellen begimmen ihren Vegetationskreislanf, eine jede ron ihnen bildet sich auf dem Stiel der geschwundenen Mutterzelle ihren eigenen Stiel; so wie num auch sie ihr Lebensziel erreicht haben, tritt die Theilung ein, und so wiederholt sieh der Lebens- und Zeugungsprozess fort und fort. Hierdurch muss nothwendig eine ganz regehnässige Dichotomie des Stieles eintreten, und naeh der Zahl derselben ist dam anch die Zahl der verschiedenen Generationen leieht zu ermitteh. Stossen wir zuweilen anf eine Unregehmässigkeit in der dichotomen Verzweigung des Stieles, so liegt das in einer Störung der Eutwicklung, welche bei diesen zarten Organismen durch irgend eiuen äussel'n Einfluss leicht herbeigefïhrt werden kamn, in Bezug auf Systenatik aber keiner Berüeksichtigung bedarf.

Im Ganzen kennen wir 52 Species, von denen nur 4 dem Meere angehören; 9 sind fossil und im Meteorstaube gefunden worden; 19 sind aus Amerika, Afrika, Persien bekannt.

\section{CYMBELLA AG. (T. VII.)}

Stiellose Individuen.

1. C. gastroides Ktz. (F. 2.) $\frac{7-12}{100}$ Mm. lang, grösste Breite bis auf $\frac{2}{100}$ Mm., gekrïmmt, in der Nlitte gedansen, an den Enden stumpf zugerundet; Querstreifen undeutlich gekörnt, 9 auf $\frac{1}{100} \mathrm{Mm}$. Durch ganz Europa gemein.

2. C. truneata Rabenh. (F. 3.) (C. gastr. $\beta$. Ktz.) $\frac{6-10}{100} \mathrm{Mm}$. lang, bis $-\frac{2}{100}$ breit, 
in der Mitte gedunsen, an den Enden breit abgestutzt; Querstreifen stark gekörnt, 8-9 auf'-1- Mm. Durch ganz Europa, Bogotí in Ameriki.

3. C. mierustoma Rabenh. (T. X. suppl. F. 3.) Bis $\frac{5}{100} \mathrm{Mm}$. langr, leicht gekriummt, mit nierlergedrücktem Rücken und breit abgestutzten Enden, im C'entrum mit sehr kleinem Nabel; Querstreifen glatt, $7-8$ a nf $\frac{1}{100}$ - Mm. Dalechi (Sürlpersien).

4. C. Ehrenbergii Ktz. (T. VII. F. 1.) $\frac{3-b}{100} \mathrm{Mm}$. lang, stark gerlunsen, mit rorgestreckten gestutzten Enden; Querstreifen gekörnt, 8-11 auf $\frac{1}{100}$ Mn. Durch England, Frankreich, Dentschland, Italien. Eine sehr rerwande Form ist die Pinnularia inatequalis Ehrenberg, unter welchem Namen Ehrenberg selbst irrig zwei Formen verenigt, die getrennt werden müssen.

5. C. amphicephala Naeg. Ungleich elliptisch, glatt, mit kupfoürnig rorgestreckten Enden, $\frac{1}{90}-\frac{1}{80}{ }^{\prime \prime}$ lang. Schweiz.

6. C. heteroplenra (Ehrenbg.) mit leicht znsammengesthürten, breiten stumpfen Enten. Norlamerika.

7. C. helvetica Kitz. (F.4.) Bis $\frac{5}{100}$ Mm. lang, schlank, leicht gekrümmt, an der untern Seite banchförnig gedmsen, an den Enclen stmmptlich zngespitzt: Guerstreifen seh" fein gekörnt, $11-12$ anf $\frac{1}{100}$ Mm. Frankreich, Schweiz, Salzburg, Baiern.

8. C. maxima Naeg. $\frac{1}{15}-\frac{1}{11}$ "“ lang, schlank, in der Hitte banchig, an den Enden verdümnt, stmmptlich; Querstreifen 16 anf $\frac{1}{100}{ }^{\prime \prime}$. Schweiz.

9. C. rostrata Rabenh. (F. 5.) $\frac{2-3}{100}$ Mn.. hoch rewölbt und dickbanchig, mit sehmabelförmig verdünnten, stmmpflichen Enden: Qnerstreifen convergirend, gekörnt, 12-13 auf $\frac{1}{100} \mathrm{Mm}$. Italien, in den pontinischen Sïmpten. Stelit der fossilen C. erspirdata sehr nahe.

10. C. porrecta Rabenh. (T. X. suppl. F. 10.) $\frac{8-10}{100}$ Mm. lang, nit flach gewölbtem Rücken, dickbänchig, weit rorgestreckten. stmmptlichen Enden: Querstreifen leistenartig breit, kamm convergirend, 6 anf $\frac{1}{100}$ Mm. Italien: in einer Hähle an Monte Comero in schlemigen Ueberzügen mit Scytonemeen.

11. C. fornicata Rabenh. (T. X. suppl. F. 9.) $\frac{i-5}{100}$ Mm. lang. bis $\frac{2}{100}$ Mm. breit, mit sehr hoch gewölbtem Rücken, leicht gedunsenem Bauche, rorgestreckten, kopfförnig abgermdeten und etwas zurïckgebogenen Enden: Querstreifen zart, glatt, 7 - 8 anf $\frac{1}{100}$ Mm. Sïdpersien, an Kiıh-Danëa.

12. C. epithemoides Rabenh. (T. VH. F. 16.) Bis $\frac{4}{100}$ Mm. lang, wie eine Epithemia, aber mit einem Nabel in der Mitte, schön bogig gewölbt, mit rorgestreckten. stumpfen, zurückgekrümnten Enden; Querleisten wenig convergirend, 6 anf $\frac{1}{100} N_{m}$. Unter Conferven bei Salzburg, durch Dr. Sauter mitgetheilt.

13. C. pachycephala Rabenh. (F. 10.) $\frac{3-4}{100}$ Mn. lang, mit bogig gewölbtem Rücken, gednnsener Bauchtläche, stark eingeschü̈rten, germndet-dickkopfförmigen Enden; Qnerstreifen schön knotig-gekörnt, wenig convergirend, $7-8$ auf $\frac{1}{\text { ton }} \mathrm{Mm}$. Unter Clodophora glomerata in Serbien.

14. C. graeilis (Ehrenbg.) K tz. (F. 12.) Bis $\frac{3}{100}$ Mm. lang, schlank, leicht gekrïmmt, mit leicht gedmusener, fast platter Banchfäche und stmmpflich zugerundeten Enden; Querstreifen zart, 13-14 anf $\frac{1}{\mathbf{1 0 0}}$ Mm. Sïd-und Westenropa, in Nord- und Centralanerika, Südpersien. NB. Bisweilen mit undentlichen Querstreifen: C. laevis Naeg. in der Schweiz.

15. C. leptoceras Ehrenbg. (F. 14. a.) $\frac{2}{100}$ Mm. und darüber lang, leicht gedunsen, gegen die Enden nach und nach verdünnt und zugerundet; Querstreifen zart, 
12-13 auf $\frac{1}{100}$ Mın. In Deutschland, Frankreich, Italien, Amerika; auch im Passatstaube und im Meteorstaub in C'hina.

16. C. culvata liabenl. (F. 14. b.) $\frac{2}{100}$ Mm. lang, glatt, hogig gewölbt, mit fast aingezogenem Banche und stmuptlich zugespitzten Enden. ln einem Bach der Apenninen bei lieti.

17 C. affinis Ktz. (F. 13.) $\frac{1}{100}$ Nu.. kam darïber lang, mehr oder minder hoch gewölbt. mit platter orler leicht gedunsener Banchfläche nud stmmpflich-spitzen Einden; Querstreifen zart, 14-15 auf -1 - Nm. In Dentschland, Frankreich und Amerika lebend; ancli fossil.

18. (. Fusidium (Ehrenbg.) Rabenh. (F. 8.) $\frac{1}{100}$ Mm., kaum darïber lang, dickbanchig, bogig hochgewölbt. mit stmupf-einwärts gekrïmuten Enden: Querstreifen zant, $12-13$ anf $\frac{1}{100} \mathrm{Mm}$. Anerika: anch in: Meteorstaube.

19. C. Lunula (Ehrenbg.) Rabenh. (F. 11.) Bis $\frac{3}{100}$ Mm. lang, hochgewölbt, mit platter oder leicht eingezogener Banchfläche und stumpflichen Enden; Qnerstreifen zart, 12-13 auf $\frac{1}{100}$ Mu. Durch ganz Emopa, Amerika, Central-Afrika (Zawo-Fluss), Südpersien: auch im Heteorstaube.

20. C. obtusiuscula Ktz. (F. 6.) Elliptisch-lanzettförmig, mit stmmpflichen, nicht vorgezogenen Enden: Querstreifen zart, 18-20 auf $\frac{1}{100}{ }^{\prime \prime}$. Auf Wangerooge.

21. C. ventricosa Kitz. (F. 9.) $\frac{1-2}{100}$ Mm. lang, mit melır oder minder hochgewölbtem Rücken, platter Bauchflïche und gestutzten orler stumpflichen Enden; Querstreifen sehr zart, fast fehlend. Durch Deutschland.

22. C. excisa Kitz. (F. 7.) Klein, wie die vorige, mit hochgewölbtem Rücken, an der Bauchfäche in der Nitte wie ausgeschuitten, an den Euden gestreckt, stumpf und zurïckgekrïmmt: Querstreifen 16 anf $\frac{1}{100}{ }^{\prime \prime}$. 'Triest. Falaise nach Kïtzing, mns unbekaunt. Bei Falaise.

23. C. delicatula Ktz. Ungleich und schmal lauzettlich, glatt, $\frac{1}{100}-\frac{1}{70}{ }^{\prime \prime}$ lang.

24. C. flexella Ktz. (F. 15.) Glatt, elliptisch- fast Störmig gekrünmt, mit wenig vorgezogenen. stmmpfen Enden; am Rücken gewölbt, an der Banchı̈lühe in der Mitte wie ansgeschnitten. In der Schweiz, Frankreich.

25. C. Orsiniana Rabenl. (Frustulia Ors. Menegh.) Ein eben sich festgesetztes, noch stielloses Cocconema gibbum.

\section{COCCONEMA EHRENBG. (T. VII.)}

Gestielte Formen.

1. C. cymbiforme Ehrenbg. (F. 1.) $\frac{4-7}{100} \mathrm{Mm}$. lang, mehr oder minder schlank, flach bogig gekrümum, bisweilen in der Mitte gedunsen, an den Enden zugerundet; Querstreifen zart, $10-12$ anf $\frac{1}{100} \mathrm{Nm}$. Durch Europa, Amerika.

2. C. lanceolatum Ehrenbg. (F. 3.) $\frac{5-10}{100} \mathrm{Mm}$. lang, mit stark gehobenem Rücken und platter Bauchfläche, an den Enden stumpf abgestutzt: Nebenseiten lanzettförmig, an den Enden gestutzt; Querstreifen dicht und zart, 12-15 auf $\frac{1}{100}$ Mn. Deutschland, Frankreich, Bogotá, Californien.

3. C. Bremii Naeg. Schlank, $\frac{1}{15}-\frac{1}{10}$ "' lang, halbmondförmig gekrümmt, an den stumpfen Enden rerdünnt; Querstreifen zart. In der Schweiz an Steinen in langsam fliessenden Gräben. 
4. C. mexicanum Ehrenbg. $\frac{1}{10} "$ lang, dick, mondfömig gekrümmt, mit leicht gedunsener Batuhtläche, an den Euden vorgestreckt, stmmpf: Querstreifen schön gekörut. 18 auf $\frac{1}{96}{ }^{\prime \prime}$. Mexiko, Californien.

5. C. cornutum Ehrenbg. Gross, quergestreift, mondförmig gekrümmt, auf der Banchfläche nach der Mitte zu nach nur nach gerlunsen, mit hornartig weit vorgestreckten, rerdünnten und stumpfen Enden. In Nordamerika.

6. C. Arens Elırenbg. Gekrümmt, nit nicht gedmnener Banchfläche, quergestreift, an den Enden stumpf. New-York.

7. C. saxonicum Rabenh. (T. 10. smpll. F. 11.) Bis $-\frac{2}{100}$ Mm. lang, mehr oder minder hoch bogig gewölbt, an der Banchfläche platt oder leicht eingezogen, an den Enden gestutzt: Querstreifen sehı zart, 16-18 auf $\frac{1}{100}$ Mm. Sächsisehe Schweiz.

8. C. Cistula Elnenbg. (F. 4.) Bis $\frac{3}{100} \mathrm{Mm}$. lang, bogig gewölbt, mit leicht eingekı̈ummter Bauchflïche und stumpfen Enden; Querstreifen 8-10 anf $\frac{1}{100}$ Mm. Durch Deutschlanı, Frankreich, Italien; Südpersien.

9. C. gibbum Ehrenbg. (F. 2.) $\frac{2}{100}$ Mm. lang und darüber, mit hochgewöllitem Rücken, platter oder leicht eingebogener Banchfl̈̈che, stark veriünnten, etwas vorgestreckten und gestutzten Enden; Querstreifen zart, $14-15$ auf $\frac{1}{100} \mathrm{Mm}$. Durch Deutschland, Italien sowohl lebend, als auch fossil.

10. C. affine Ktz. Die gestielte Cymbella affinis (conf. F. 13.). In Frankreich.

11. C. tumidum Bréb. $\frac{1}{50}-\frac{1}{40}$ "' lang, mondförnig, mit etwas rorgezogenen, stumpfen Enden; Querstreifen 16 auf $\frac{1}{100}{ }^{\prime \prime}$. Frankreich.

\section{ENCYONEMA KTZ. (T. VII.)}

Die Individnen von Gestalt der Cymbellen liegen in einer röhrenfömigen, gelatinösen Hülle und sind so geordnet, dass ihre Axe die Axe der Hïlle nnter einem rechten Winkel schneidet. Nach der Theilmg liegen die beiden Tochterzellen übereinander (siehe F. 2.), die obere sehiebt sich über die untere hinweg und ordnet sich so in die Reihen ein. Ein ähnlicher Vorgang fudet auch bei Coceoneis statt, nu mit dem Unterschiede, dass diese sich nicht reihenweise ordnet; Eneyonema zeigt dadurch eine nicht unwesentliche Verwandtschaft mit jener und entfernt sich dadurch von den Cymbellen. Nur ilne Gestalt hat uns bestimmt, sie hier einzuschalten.

1. E. paradoxum Ktz. (F. 3. und F. 4. Copie ron Kützing.) $\frac{2}{100}-$ Mm. lang, bogig gewölbt, mit gednnsener Banchfläche, an den Enden stumptlich; Qnerstreifen 15-16 anf $\frac{1}{100}$ Mn.; Scheiden dicht anliegend. In Dentschland, Frankreich, Italien.

2. E. caespitosum Ktz. (F. 5.) Kaum über $\frac{1}{100}$ Mm. lang, stark gedunsen, an den Enden fast gestutzt; Querstreifen sehr zart, 16-17 anf $\frac{1}{100} \mathrm{Mm}$; Scheiden locker, fast verfliessend. Jütland, Piemont, Florenz.

3. E. Anerswaldii Rabenh. (F. 2.) $\frac{3}{100} \mathrm{Mm}$. nnd darüber lang, mit stark gehobenem, fast bnckligem Rücken, leicht gedunsener Bauchfläche, an den Enden fast zusammengeschnïrt und kopffömig abgerundet; Querstreifen $11-12$ auf $\frac{1}{100}$ Mm.; Scheiden sehr erweitert. Bei leipzig.

4. E. prostratum Ralfs (F. 1.) Noch grösser als das vorige, flach bogig gewölbt, an den Enden mehr oder minder deutlich schnabelartig einwärts gekrümmt. In England, der Schweiz. 
5. E. gracile Rabenh. (T. X. suppl. F. 1.) $\frac{1-1 / \frac{1}{10}}{10 m}$. lang, sehr schlink, in der Mitte gedunsen, an den Enden gestutzt, undeutlich gestreift; Scheiden enge, leicht verschlungen. Salzburg, am Rande eines Moorgrabens gesellig nit Spirogyren, Ulothrix variabilis, Palmogloea macrococea. Mitgetheilt von Dr. Sauter.

\section{FAM. IV. ACHNANTHEAE.}

Nebenseiten schmal oder breit linealisch, mehr oder minder gekrümmt, an der Bauchfläche eingeknickt und mit einer keil-oder trichterfürnigen sogenannten Oeffnung, in der Mitte mit einer hroiten, längsgestreiften Binde, am Rande quergestreift. Irie Hauptseiten länglich eifïmig, mit stumplen oder gerundeten Enden, mit Guerstreifen, sie gleichen denen der Gattungen Diatoma und Odontidium.

Die Achnantheen sind äusserst zierliche Gestalten, sie leben einzeln, frei schwimmend oder mit einen stiele angewachsen und bilden dureh einfuche 'Theilung und unvollkommene Tremnung mehr oder minler lange, vielgliedrige liconvexe Bänder. Die Stielbildung ist in Wesentlichen zwar dieselbe, wie wir sie bei Coeconema largestellt haben, aber dadureh versehierlen, dass del Mntterstiel mverändert derselbe bleibt unl allen folgenden Generationen als Stïtze dient, und zwar dadurch, weil er selbst nicht Theil an der Theilung nimmt nud diese mur ene unvollkommene ist.

Wir kennen nu 20 Arten, ron denen über die Hälfte dem Meere angehören. Verzeichnet haben wir hier 10, woron aber ㄹ nicht dem sïssen, sondern dem Brackwasser zukommen; mo eine $\lambda \mathrm{rt}$ ist bis jetzt fossil gefunden worden, und selbst diese ist noch als hierher gehörend zweifelhaft. Ansserhalb Europas hat man erst 5 Arten beobachtet.

Wir tremen amch hier wieder die gestielten und ungestielten Formen.

\section{ACHNANTHIDIUII K'T\%. (T. VIII.)}

Verläil sich zu Achunthes, wie Cymhella zu Cocconema, unl ist deshalb als wirkliche Gattung eben so wenig stichhaltig.

1. A. microcephalum Kiz. (F. 2.) Gegen $\frac{1}{100}$ Mus. lang, schlank, lanzettlich, an den Enden kopftörmig vorgentreckt. Dureh ganz Europa.

2. A. cryptocephalum $\mathrm{Naeg}$. Lineal-lanzettlich, an den Euden undentich kopfförmig, $\frac{1}{120}-\frac{1}{100}{ }^{\prime \prime}$ laug. In der Schweiz.

3. A. otrantinum Rabenh. (F. 1.) Bis $\frac{7}{100}$ - Mm. lang, in der Mitte mehr oder minder stark gehoben orler eingeknickt, an Rande zart quergestreift, an den Enden gestutzt. In der terra di Otranto wiederholt gefunden, aber immer stiellos, dennoch halte ich es fïr eine gestielte Achnanthes, die wahrscheinlich dem Neere angehört.

NB. Die von Kützing noch anfgeführten Arten gehören unseres Bedïnkens nicht hierher.

\section{ACHNANTHES BORY. (T. VIII.) \\ Gestielte Intividuen. \\ + Togestreifte Formen.}

1. A. minutissima Ktz. (F. 2.) $\frac{1}{2}$ bis über $\frac{1}{100}$ Mm. lang, ohne Streifen, lanzett- 
lich, anf kurzem, sehr zartem stiele. Durch ganz Europa gemein. Stiellos erhielt ich sie von Bogotí dureh Herru Lindig.

2. A. exilis Ktz. (F. 1.) Gegen und fast äber $\frac{2}{100}$ Mn. lang, sehr schlank, streifenlos, gestutzt; Hauptseiten lanzettlich, an den Enden stark verdüunt und stumpf; Stiel oft sehr verlïngert. Dnreh ganz Viropa.

\section{$\div \div$ Gestreifte Formen.}

3. A. subsessilis Ktz. (F. 3.) $\frac{2-5}{100}$ Mn. lang, gekrïmmt, in der Mitte leicht gedunsen: Hauptseiten länglich-elliptiseh, an den Enden gerundet: Stiel sehr kurz, bisweilen fust fehleul: Querstreifeu 9-11 anf $\frac{1}{100} \mathrm{Mm}$. Europa, Amerika; anch in salzigen Binuenwässern. NB. Die Individnen leben öfters nur parweise, bisweilen aber anch zahleeich zu langen bandfömgen Fälen rerbunlen.

4. A. intermedia Ktz. (F. 5.) $\frac{1-2}{100}$ Mm. lang, in der Mitte gedunsen, an den Enden keilförmig verdïmnt und stmmp,f zngerundet, kurz gestielt: Qnerstreifen $15-16$ anf $\frac{1}{100} \mathrm{Nm}_{\mathrm{m}}$. In Deutsehland wohl allgemein.

5. A. brevipes Ehreubg. (F. 4.) Bis $\frac{6}{100}$ Mn. lang, linealisch oder lanzettlich, mit mehr oder minder keilförung verdünnten Linden, anf kurzem, dicken Stiele; Qnerstreifen feinknotig: $12-15$ anf $\frac{1}{100} \mathrm{~N}_{11}$. In Sool- unr salzigen Binnenwässern.

6. A. cristata Rabenh. (F. 7.) $\frac{2-3}{100} M \mathrm{~m}$. lang, länglich-elliptisch: Querstreifen leicht gekrümmt, knotig-kammförmig, fast entfernt, $9-10$ auf $\frac{1}{100} \mathrm{Mm}$. In den Gräben der pontinischen sïmpfe.

7. A. turggens Ehrenlg. (F. 6.) Dreimal Jünger als breit, lünglich-lanzettfürmig, mit stumpfen Euden. Amerika.

\section{FAM. Y. COCCONEIDEAE.}

Panzer platt-oder leichtgewölbt-schildfirmig. Hauptseiten elliptisch, mit der untern platt anfliegend, die obere mehr oder minder gewölbt, glatt oder verschiedenartigg gerippt, anch knotig-gekïnt; im Centrum auf der untern seite mit einem drüsenartigen knoten (einer sogetuanten Oeffnung) und grewöhnlich mit einer Längsleiste; Nebenseiten genau linealisch oder wie die Seitenansicht einer planconvexen Linse. Aenssere schleimhülle besonders zur Zeit der Theilung stark entwickelt, zur andern Zeit minder stark, hisweilen doch wohl nur scheinbar - fehlend, bei einigen Arten (C. limbata) dunkelhraun gefirbt and die Basis unsiumend. Die Fortpflanzung erfolgt durch einfache Theihung; Copnlation, und Fruchtzelsen-Bildung ist noch nicht beobaclitet.

Sic leben isolirt, fiei schwimmend ofler heerdenweise anf- und festsitzend, sowohl auf Fadenalgen, wie anch anf grösseren Diatonaceen.

Diese Familie ist nur durch eine Gattung mit 39 Arten rertreten. Wir haben 21 Arten aufgeführt, von denen jedoeh nur 14 als Süsswasser-Bewolner, 7 als dem Brackund salzigen B̉imenwasser angehörend zu betrachten sind; 18 gehören dem Veere ansschliesslich an; 8 sint fossil gefumlen. 


\section{xVII. COCCONEIS EHRENBERG. (T. III.)}

1. C. Pediculus Ehrenhg. (F. 1.) $\frac{2}{100}$ bis gegen $\frac{3}{100}$ Mur. lang, elliptisch, oben etwas gewölbt, unten etwas concav, fast plan-convex, mit zarten Längsstreifen (sind in der Zcichnung nicht ansgedrïickt), von den Nebenseiten gesehen genan linealisch, platt aufliegend oder lejeht gekrïmmt. Durch ganz Europa genein, gewöhnlich festsitzend, aber anch frei schwimmend.

2. C. Placentula Elurenbg. (F. 3.) $\frac{1-2}{100}$ Mn. lang, kamm gewöbt, Galitt, mit quer durehgehendem Leisten, der in der Mitte knotenartig rerdickt ist. Dureh ganz Europa, Amerika, lsland, Südpersien: aneh fossil. F. a. eine sehlanke Form von Brindisi (südöstliches Italien) an Zamichellia pedunculata.

3. C. Sentellum Ehrenbg. (F. 4.) Rundlich-elliptisch, leicht gewölbt, nit Leisten mol pmoktirten Qnerstreifen, die jedoch nach dem Glïhen erst deutlich sichtbar werden (F. 15.). Meeresbewohner, aber in Brackwasser der Küisten, in den Lagunen der Ostkiiste Italiens fast allgemein verbreitet.

4. (! pumila Kitz. (F. 10.) Gegen $\frac{1 / 2}{100}-$ Mn. lang, glatt, leieht gewölbt, ohne Centralknoten und Leisten. Durch gimz Emopil.

5. C. longa Ehrenbg. Linealisch, an beiden Enden gerundet, glatt. Island.

6. C. limbata Ehrenbg. (F. 14.) Eine C. Placentula mit stark entwickelter samartiger Ilïlle. Neeresbewohner, anch in den Lagmen mo im Lago di Salpi auf der Ostkiiste Italiens. Hierher gehört anch die persische anf T. X. suppl. F. 2. dargestellte Form, von etwas schlankerel Gestalt und mit ziemlich regelmässig gezahnt-gesehweiftem samme. Salzsee .Nemek-Derja* bei sichiras.

7. C. punctata Ehrenbg. (F. 2.) Elliptisch, beiderseits des Centralknotens nit 8 zart punktirten Längsstreifen. Amerika.

8. C. persica Rabenh. (F. 5.) Gross elliptisch-eiförmig, $\frac{3}{300}$ Mm. und darïber lang, $\frac{2}{10}$ Mm. breit, leicht gewölbt, beiderseits des in der Mitte und an den Enden erweiterten Längsleistens mit 23 knotig-punktirten Qnerstreifen. Sïdpersien im Salzsee Nemek-Derja.

9. C. salina (Ḱtz.) (F. 8.) Ueber $\frac{1}{100}$ Mm. lang, kamm gewölbt, mit 12 zarten Qnerstreifen, die aus einem randständigen Kunoten entspringen nnd gegen den Nittelleisten verschwinten. In salzigem Bimenwasser.

10. (C. depressa Ktz. ist eine ganz verflachte und kleinere Form der C. salina. In sïssem Wasser durch ganz Emropa.

11. C. borealis Ehrenbg. Klein. elliptisch, sehr verlängert, quergestreift. Amerika: anch fossil und in Bernstein bei Königsberg.

12. (' mexicana Ehrenbgg. (F. 11.) Rhomboidalisch, klein, nit etwas rorgezogenen, stmmpf zugermndeten Emlen und zart punktirten Qnerstreifen. Mexiko.

13. C. americana Ehrenl,g. Ton Gestalt der C. mexicana, aber olne Qnerstreifen. Mexiko.

14. C. striata Ehrenbg. (F. 12.) Länglich-elliptisch, mit etwas convergirenden Querstreifen. Nord- und Central-Amerika.

15. C. minor (K tz.) Bis $\frac{1}{100}$ Mn. lang, anf jeder Seite der Längsleiste mit 3-4 zarten Längsstreifen. In salzigem Binnenwasser (Salzsee bei Eisleben). 
16. C. fasciata Ehrenbg. (F. 7.) Elliptisch, gross, nit Längsstreifen, die durch eine Querbinde in der Mitte muterbrochen sint. Pern.

17. (C. striolata Rabenh. (T. X. smppl. F. 8.) Bis $\frac{2}{190}$ Mm. ling, mit zarten, dichten Längsstreifen. Im Salzluugisehen.

18. C. brundusiaca Rabenh. (F. 16.) Siehr gross, $\frac{3-5}{100} \mathrm{Mm}$. lang, $\frac{2-\text { fast } 3}{100} \mathrm{Mm}$. breit, stark gewölbt, nit breitem, nur in der Mitte etwas erweitertem Längsleisten, jederseits mit 22-2-4 sehmalen, etwas convergirenden, knotigen Qnerleisten. Brindisi, in dem kleinen Ilafen, der durch den Kanal (Süsswässer) gespeist wirl, aber nicht frei vom Meerwasser ist.

19. (. concentrica Ehrenbg. (F. 13.) Breit elliptisch, mit seln breit zugerundeten Enden, mit concentrischen Längsstreifen. Amerika.

20. C. decussita Ehrenbg. (F. 6.) Breit elliptisch, gross, breit zugerundet, rauh (\%), mit kienzständigen Querstreifen. Cuba.

\section{FAM. VI. SURIRELLEAE.}

Panzer prismatisch, elliptisch oder eifirmig, an den Enden gestutzt wler zugespitzt und dann den Xaviculis sehr ïhnlich. Die Nehenseiten minder entwickelt, breit linealisch, bisweilen keilfürmig, an den Enden stumpf- oder rechtwinklig abgestutzt. Yon den Naviculis untersclieiden sie sich durch den Nangel des Centrakknotens. Amphorit hat in jeder Seitr cine kurze leistenartige Binde.

Sie leben immer isolirt: als Fortpflanzung ist nit sicherheit nur die einfache Theilnng bekannt. Eimnal sahen wir bei smirella bifrons eine Anschwellung, die sich wohl zur Fruchtizelle entwickeln moehte, doch komben wir den Vorgang nicht verfolgen und deshall, zu keiner Gewissheit gelangen. Kurz vor der Theilnug sondert die Mutterzelle reichlichen Hüllstoff ab und nugiebt sich damit mantelförnig, nach der Theihug wird derselbe aber so dïnnflüssig. dass er bei den jungen lndividuen, die sich bald vollständig tremen, zn fehlen scheint. Bewegnng ist selten wahruehmbar und nie so leblaft, wie bei den Naviculis. Die Upsadele liegt wohl in den stark gestutzten Enden, mit denen sie den Wirlerstand des $1 \mathrm{asser}$ schwerel oder gar nieht ïberwinden.

Im Ganzen sind 92 Arten bekimit, ron denen $43 \mathrm{im}$ sïssen Wasser, 34 in Meere leben, und 15 warten fossil gefumten.

\section{SURIRILLLA TURPIN. (T. III.)}

Elliptisch länglich, regelmïsig oder verschieden gestaltig, mit gucrippen, einem querdurchgehenden lichten Streifen, Leisten oder Binde; Yebenseiten genau linealisch oder gogen ein oder beide Enden keilfürnig verschmilert, an den Enden recht-oder stmmpfwinkelig abgestutzt.

Die Arten zerfallen nach der vorherrsehenden Gestalt in versehiedene Gruppen, als a) in der mitte meln oder minder zusammengeschnürt und addurch geigenfirmig.

1. S. Solea re Bréh. (Nar. Librilis Ehrentg.) (Fig. 7.) $\frac{10}{100} \mathrm{Mm}$. und darïber lang, hald schlank, bald robust und danach an den Enden bald mehr. bald ninder ver- 
dïnnt, gestutzt oder stmmpf: Quel'streifen zart, 8 anf $\frac{1}{19 m}$ Mm.; Nebenseiten genau linealisch, an Rande quergestreift und mit einem durehgehenden, wellig gebogenen Leisten. Durch ganz Europa.

2. S. regula Ehrenbg. (F. 6.) ist auf den Nebenseiten ehenso gezeichnet, wie die vorige Art, die Hauptseiten sind aber linealisch, nicht eingeschnürt und an den Enden spitz-keilförmig verdünnt. Mexiko. Frankreich.

3. S. didyma Ktz. (F. 8.) Gegen $\frac{2}{100}$ Mn. lang, genan geigenföruig, an den Enden gestutzt, an liande mit knotigen Punkten. In halbsalzigem Wasser auf der Insel Wangeroog.

4. S. panduriformis Rabenh. (F. 9.) Wie die vorige, aber etwas grösser und robuster, an liande mit 6 Querstreifen auf $\frac{1}{100} \mathrm{Mn}$., die von einem knotigen randständigen Punkte entspringen: Nebenseiten ei-lanzettförmig, mit gestntzten Enden. Ostkïste Italiens (Lago di sialpi).

5. S. umbonata (themalis Kr z.) (F. 10.) Schlank, $\frac{5-7}{100} \mathrm{Mm}$. lang, äusserst zart, fast undentlich quergestreift, an den Enden gerundet oder zugespitzt: Nebenseiten verlängert-lanzettlich, mit germdeten Enden. In den warmen Quellen zu Karlsbad, Aqua santa, Ischia.

b) Länglich oder lanzettförmig.

6. S. Craticula Elrenbg. (F. 16.) $\frac{6-8}{100} \mathrm{Mm}$. lang, an den Enden zugespitzt; Querleisten divergirend, 4 auf $\frac{1}{-100}$ - In. Bei Berlin und in Amerika lebend; anch fossil and in Meteorstaube.

7. S. multifasciatak Kt. (F. 11.) $\frac{6-7}{100} \mathrm{Mm}$. lang, schlank lanzettförmig, an den Enden ziemlich scharf zugespitzt, mit sehr zarten, undentlichen Querstreifen. In Deutschland, Frankreich, Ttalien, Schweden (bei Stockhohn).

8. S. decora Ehrenbg. Schmal-lanzettlich, zugespitzt, mit zarten Querstreifen, $4-5$ anf $\frac{1}{100}{ }^{\prime \prime \prime}$. Amerika.

9. S. australis Ehrenbg. (F. 15.) Nur als Fragment bekannt. Falklandsinseln.

10. S. oblonga Ehrenbg. (F. 14.) Nit stumpfem Ende, an Rande buchtig-gezahnt. Fragment! Amerika.

11. S. ambigua Ktz. (F. 12.) Länglich, sehr breit, an den Enden gestutzt; Querleisten gerade, 4 anf-1-“". In dre Schweiz.

12. s. Brenteliana Rabenh. (F. 13.) $\frac{5}{100} \mathrm{Mm}$. lang, an den Enden breit zugerundet, nach hnen breit gerandet, durch 5 Querleisten wie zusammengeschnürt mnd dadurch buchtig-gezahnt. Insel St. Kitts.

13. S. obtusangula Rabenh. (F. 27.) Bis über $\frac{2}{100}-\mathrm{Mm}$. lang, lanzettförmig, mit keilformig verdïnnten, stumptlichen Enden; Nebenseiten oblong, breit zugerundet; Querleisten kurz. 6 auf $\frac{1}{100}$ Mn. Sachsen.

14. S. angusta Ktz. (F. 17.) Bis $\frac{2}{100}$ Mm. lang, linealisch-länglich, nit keilförmig verdünuten, stmmpf zugerundeten Enden; Querstreifen zart, $9-10$ anf $\frac{1}{100}$ Mm. Dentschlant. Frankreich; Bogotá in Amerika.

15. S. tenella Ktz. Länglich-lanzettförmig, mit stmmpf zugerundeten Enden; Querstreifen 5 auf $\frac{1}{100}{ }^{\prime \prime}$. Bei Northansen.

16. S. bifrons Ehrenbg. (F. 21.) $\frac{\text { s-16 }}{100}$ Mn. lang. an den Enrlen stumpt: Tebenseiten länglich-quadratisch, mit gestutzten Enden und stumpfen Ecken; Qnerleisten breit, 3 anf $\frac{1}{100}$ Hm. Durch Enropa, Amerika; anch fossil. 
17. S. Jenneri Hass. (F. 20.) Länglich, vierflüglich, wie der Querdurchsehnitt F. 20. b. zeigt, an den Enden zngermudet: an Rande mit kurzen, zahnförmigen Leisten. Englant.

18. S. peruviana Ehrenbg. (F. 19.) Sehr gross schmal elliptisch-lanzettformig, mit stumpfen Enden un sehr verkiirzten, zahnartigen Randleisten. Pern.

19. S. microcora Ehrenbg. (F. 26.) Klein, elliptisch-lanzettförmig, mit stumpflich-spitzen Enden, am Rande mit zahnfömigen Qnerleisten. Amerika.

c) Nebenseiten keilförmig.

20. S. splendida (Ehrenbg.) Ktz. (F. 22.) Länglich eiförmig, $\frac{11-15}{100}$ Mm. lang, grösste Breite bis und äber $\frac{5}{100} \mathrm{Mm}$., mit breiten convergirenden Qnerteisten, $3-4$ anf $\frac{1}{100}$ Mm.; Nebenseiten breit linealisch, gegen das eine Ende schwach keilfömnig verdümnt, beide Enden gestutzt-zugerundet. Durch ganz Dentschland, anch in Frankreich.

21. S. striatula (Ehrenbg.) Turpin (F. 23.) ${ }_{-5-7}^{5-7}$ Mn. lang, breit eiformig in eine keilförnige, stmm,te spitze verlanfend, nit gekrümmten Querleisten; Nebenseiten breit keilförmig, an den einen Ende gestntzt, an dem andern breit zngerundet: Querleisten anf den Nebenseiten kurz, zahnfömig, 4-6 auf $\frac{1}{100}$ Mn. Dureh ganz Dentschland, Frankreich, Oberitalien; fossil in Böhnen.

22. S. brevis Ehrenbg. Wie die rorige Art, aber schlanker mnd nit bis 12 Querstreifen anf $-\frac{1}{100}$. Mm. Kundistan.

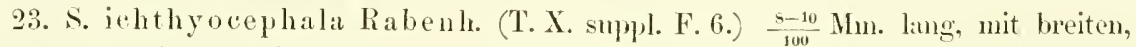
gekrümnt-convergirenden Querleisten, 3 aut-100 Mm.; an einem Ende breit zngermudet, an dem andern anf die Hälfte rersehmälert. Ostküste Italiens (in Gräben bei Ancona).

24. S. elliptica Bréb. (cophaena Ehrenbg.) (F. 18.) Wie die rorige, aber wellig gefaltet mod mit randständigen Zïhnen ( 6 auf $\left.\frac{1}{100} “\right)$. Frankreich, Nexiko.

25. S. ovalis Bréb. (F. 24.) Elliptisch-eiförnig, an dem einen Ende breit zngermudet, an lem andern verdïmnt, stmmpf-abgestutzt, am Rande mit kurzen zahnförmigen Leisten; Nebenseiten länglich, stumpf-keilförmig; Quteleisten rerküıt, s anf $\frac{1}{100}$ Mm. Frankreich; Amerika (Bogotá).

26. S. englypta Ehrenbg. (F. 25.) Länglich-eiförmig (fast spatelfürnig): Nebenseiten keilförnig, an einem Ende breit zugerundet, an andern abgestutzt, am Rande mit kurzen Querleisten, 5 anf $\frac{1}{100}$ Mm. Amerika.

27. S. minnta Bréb. (F. 28.) $\frac{1-2}{100} \mathrm{Mm}$., kaum darüber lang, eiförmig, an Rande mit knrzen Querleisten (6 anf $\frac{1}{100}$ Mur.); Nebenseiten breit keilförnig, an beiden Enden abgestıtzt, nach Innen gerandet. Deutschland, Frankreich.

d) Verbogene.

Die hierher gehörenden Formen kïnnten füglich eine besondere Gattung bilden; ich lıabe jedoch noch nicht Gelegenheit gehabt, sie lebend zu beobachten.

28. S. Campylodiscus Ehrenbg. (F. 4.) Eiförmig-elliptiseh, an beiden Enden zugerundet, anf die Art wie Campylodiscus verbogen, an Rande gestreift: Streifen 10-12 anf $\frac{1}{100}$ '“. In Nexiko; nach Küitzing auch in den warmen Quellen der Apenninen.

29. S. flexnosa Ehrenbg. (F. 3.) Grösser als 1. Querstreifen 4-5 auf_'”- "“ Mexiko; nach Krïtzing anch in Frankreich.

30. S. elegans Elrenbg. (F. 2.) Nur als Fragment bekannt; Querstreifen 4 auf ${ }_{100}^{\prime \prime \prime . ~ M e x i k o: ~ n a c h ~ K u ̈ t z i n g ~ a n c h ~ i n ~ D e n t s c h l a n d ~ b e i ~ H i l d e s h e i m . ~}$ 
31. S. spiralis Ktz. (F. 5.) Nebenseiten linealisch und spiralig gedreht, am Rande punktirt: anf $\frac{1}{100}$ “ $5-6$ Punkte. In einer Eisenquelle bei Nordhausen. Von Kiitzing nur eimmal beobachtet.

32. S. myodon Ehrenbg. (F. 1.) Hauptseiten schmal, verlïngert, leicht rerbogen, an dem einen Ende zngerundet; Querstreifen leistenartig, $6-7$ anf $\frac{1}{100}{ }^{\prime \prime}$. In Mexiko. Nur als Fragment bekannt.

\section{AMPHORA EHRENBG. (T. 1X.)}

Eiformig, ungleich, an den Enden gestutzt, isolirt lebend, in den Seiten mit einem randständigen Mittelknoten.

1. A. ovalis Ktz. (F. 1.) $\frac{1-5}{100}-1 \mathrm{~m}$. lang, bis $\frac{3}{100}$ Mm. breit, an Rande zart quergestreift, bisweilen scheinbar glatt. Durch ganz Europa; anch in Afrika, Sïdpersien (F. 1. b.). Dieselbe Form anch in Baiern.

2. A. bibyca Ehrenbg. (F. 3.) Gegen $\frac{2}{100}$ Mm. lang, mit gewölbtem Rüicken und concaver Banchfläche, am Raude gestreift, innerhalb mit punktförmigen Künötchen. In Lybien, Amerika, Island.

3. A. affinis Ktz. (F. 4.) $\frac{1-3}{100}$ Mm. lang, am Rande mit Längsstreifen. In Frankreich bei Falaise.

4. A. lineolata Ehrenbg. (F. 9. und 10.) $\frac{5-8}{100}$ Mn. lang, an Rande mit starken, in der Nitte mit zarten längsstreifen. Bei Ber.lin (F. 9. ('opie nach Ehrenberg), Sachsen (F. 10.), in tropischen Amerika und in den Lagunen von Venedig.

5. A. Hohenackeri Rabenh. (F. 11.) Ueber $\frac{1}{100} \mathrm{Mm}$. lang, länglich-eiförnig, jederseits mit drei Längsippen. Sïdpersien.

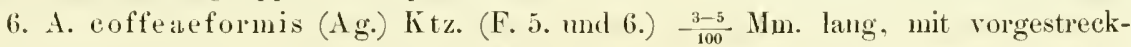
ten, stmmpf abgerundeten Enden, in der Mitte mit sehr zarten Längsstreifen, am Rande mit 4 Längsriplen. Durch Dentschland, sowohl in sïssem, wie anch im Soolwasser; auch in dem Mineralwassel zu Karlsbad.

7. A. Fischeri (F. 7.) $\frac{2}{100}$ Mn. lang, in der Mitte stïrker gedmusen, als die vorige Art: an den Enden rorgestreekt und breit abgestutzt. in der Mitte undentlich gestreift, am Rande nit 3 Längsstreifen.

8. A. aponina Ktz. (F. 8.) $\frac{1-2}{100} \mathrm{Mm}$. lang, nit vorgezogenen mol gestutzten Enden, olune Längsitreifen. In den warmen Qnellen der Apeminen.

9. A. gracilis Ehrenbg. (F. 2.) Schlank, nur leicht gedunsen, am Rande quergestreift. Amerika: anch im lleteorstube und im Bernstein.

10. A. angrusta Ehrenbg. ist der A. gracilis ähnlich, aber noch schlanker. In Spanien lebend, kommt anch fossil vor.

11. A. borealis Ktz. (F. 12. in verschiedenen Lagen). Bis $\frac{1}{100} \mathrm{Mm}$. lang, länglieh-lanzettfömig, gestutzt, auf den andern Seiten zugespitzt. An fenchten Felsen auf Helgoland. 


\section{FAM. VII. FRAGILARIEAE.}

Panzer prismatisch-vierseitig; Hauptseiten elliptisch oder lanzettförmig, glatt und eben oder mit durchgehenden Querleisten; Nebenseiten linealisch, länglich ‘uadratisch oder tafelfïnig, seltener

keilförmig, glatt oder am Pande gezahnt.

Die Fragilarien im engern Sinne mufassen die Gattungen Fragilaria, Odontilinm und Diatoma. Sie unterscheiden sich durch die Entwickehng zn bandförnigen Füden, eine unvollständige Theilung viele Generationen hindmeh, d. h. die Theilung erfolgt zwar, die gelatnöse Hüllmembran nimmt jerloch daran nicht Theil nnd erhält den Zasammenhang der Individnen; bei Diatoma überwinden die Individnen zwar die Henmumg zmm Theil, die Hüllmembran zieht sich dann stielartig an einer der Eeken znsammen und rerbindet je zwei Individnen; es entstehen dardurch die zickzackfömigen Fäden. Die Gattmgg Denticula, welche immer isolirt und frei orler während thes Theilnugsaktes parweise anftritt, ist ein vermittehrles Glied, welches sich an die surirellen anschliesst. Die Stellung der nenen Gattung Gomphogramma neben Dentienla findet ilure Rechtfertigung nur in der Gestalt und Bildnng der Hamptseiten, den stark entwickelten Nebenseiten nach ist sie den meerbewolnenden Striatellen sehr verwandt mol mïsste hier zn den Tabellarien gezogen werden, wo sie sich unmitelbar an Terpsinoe ansehliessen wünde, wie dem ïberhanpt in der Entwiekelung der Fragilarien und Tahellarien viel Verwanltes liegrt. Hätten wir msere systematische Eintheihmg und Ameihnug nach den Entwickehngsgeschichten der Fanilien entworfen, so würden die Fragilarien mit Ansschhss der Gattungen Denticnla und Gomphogramma unter die Tabellarien gestellt worden sein.

Ansser der Fortptlanznng dureh Theilung kennen wir anch (bei Fragilaria virescens) die durch doppelte Copulation, welche in gleicher Weise erfolgt, wie wir sie bei Hinantidimm mitgetheilt haben.

Die Gesammizalıl der bis jetzt bekannten Fragilarien beträgt 76 , von denen 38 als Sïsswasser-Bewohner hier rerzeichnet sind und zum Theil ïber die ganze Erdoberflïche verbreitet zu sein schemen. Denticnla leht in den heissesten Qnellen, wie in den Bächen der Gletscher. Odontidimm findet sich vorzugsweise in Gebirgsgegenden, während Fragilaria mo Diatoma anch durch das ganze Flachland rerbreitet sind. Ans dem Meere sind nur 8 Arten bekannt, und 30 Arten, von denen 3 mit noch lebenden identisch sind, wruden fossil gefunden.

$$
\text { + Isolirt lebende Arten. }
$$

\section{XX1. DENTICULA KT\%. (T. I.}

Einzeln und nach dem Theilungsakt noch kurze Zeit paarweise verbunden. Hauptseiten schlank lanzettförmig, länglich oder breit ellipsoidisch, mit durchgehenden querleisten; Nebenseiten durch die vortretenden Querleisten der Hauptseiten am Rande mit kurzen, zahnartigen oder keulig verdickten Querleisten.

1. D. undulata (Ehreuhg.) Ktz. (F. 1.) $\frac{5-10}{100}$ Mm. lang, Hauptseiten bis $\frac{5}{100}$ Mm. breit, breit ellipsoidisch, nit hreit zugerumdeten Enden; Nebenseiten lineal-länglich, mit rechtwinkligen Enden md wellig-gebogenem Rande. Bei Berlin, Dresden mnter schwinmenden Oscillarien auf Regenutüitzen. 
2. D. constrieta (Ehrenbg.) Ḱtz. (F. 2.) Bis $\frac{10}{100}$ Mm. lang, breit linealiseh, in der Mitte etwas zusammengezogen, an den breit zngerundeten, fast gestutzten Enden wiedler erweitert: Nebenseiten läuglich, in der Nitte stärker zusammengezogen als die Haup,tseiten: Querleisten 4 auf $\frac{1}{-100} \mathrm{Mm}$. Bei Berlin, Sidmeptentlal in Thüringen.

3. D. thermalis Kit. (F. 3.) Bis $\frac{2}{100}$ Mm. lang. schlank- oder elliptisch-latzettförnig: Querleisten 6 anf $\frac{1}{100} \mathrm{Mm}$. In heissen Quellen Italiens (Bataglia, Euganeen miter Prasiola mesenteriformis, Aqua santa).

4. D. elegans Kitz. (F. 4.) Bis $\frac{1-2}{100}$ Mnr. langr, lineal-lanzettförmig, stumptlich; Querleisten 4-5 auf $\frac{1}{100}$ Mm. In Bädıen Deutschlands, Salzburgs, Pienont: zwischeu Moosen (Orthotrichen) auf Bäumen bei Dresden.

5. D. tenuis Ktz. (F. 4.) Bis $\frac{1}{100}-\mathrm{Mm}$. ling, schlank lanzettlich, zugespritzt; Querleisten 8 auf $\frac{1}{100}$ Mn. Dureh Deutschlanr, Frankreich, Italien, Bosnieu.

6. D. frigida Ktz. (F. 6.) Bis $\frac{\%}{100}$ - Mm. lang, lineal-lanzettlich; Querleisten 8-9 anf $\frac{1}{100} \mathrm{Mm}$. In Bergwässern der Schweiz, Tyrols, Frankreichs.

7. D. acuta Rabenh. (F. 7.) Gegen $\frac{2}{100}$ Mur. lang, schlank lanzettförmig. zugespitzt: Nebenseiten meist keilförmig: Querleisten $6-7$ auf $\frac{1}{100} \mathrm{Mm}$. Südpersien (bei Persepolis).

8. D. obtusa ( $\Lambda$ g.) Kitz. (F. S.) Bis $\frac{4}{100}$ Mn. lang, lanzettförmig, mit stumpfen Euden; Querleisten 9 auf $\frac{1}{100}-\mathrm{Mm}$. Durch Europa.

9. D. crassula Naeg. Elhptisch; Querleisten zart, $8-9$ auf $\frac{1}{100} \mathrm{Mm}$. In der Schweiz.

\section{GOMPHOGRAMIA A. BRAUN. (T. IX.)}

Einzeln oder paarweise; Hauptseiten minder entwickelt als die Nebeuseiten, eltiptisch-lanzettföruigr, mit durchgehenden Querleisten; Nehenseiten tafelföıuig, mit unterbrocheuen, keulig verdickten Querstriemen, an Piande nach lonen gezalint.

Diese sehöne Gattung zeigt von den Nebenseiten betrachtet eine auffallende Aehmliehkeit mit Terpsinoe, sie kam aber wegen ihrer Hauptseiten von Denticula, Odontidim mor Diatoma nicht getremit werden.

1. G. rupestre A. Braun in litt. c. icone. $4-5$ Querleisten auf $\frac{1}{100} \mathrm{Mm}$. An massen Felswänden bei Freiburg im Breisgau (am Hirschenspruug in der Hölle).

$$
+\leftarrow \text { Zu Bändern verbunden. }
$$

\section{FliAGILARIA LYNGB. (T. I.)}

Lanzeltlïrmig, mit zugespitzten oder stumpfgerundeten Enden; Nebenseiten genau linealisch, länglichrechtwinklig quadratisch, zu mehr oder minder langen, geraden oder gekrümmten, biconvexen Bändern verbuuden.

1. F. virescens Ralfs (F. 1.) $\frac{2-3}{100} \mathrm{Mm}$. lang, an den Enden verdünnt, vorgestreckt und zugerundet; Nebenseiten bisweilen keilfürmig. Dureh ganz Emropa gemein.

உ. F. capucina Desmaz. (F. 2.) $\frac{2-3}{100} \mathrm{Mm}$. lang, schlank lanzettlieh, zugespitzt. Ueber die ganze Erde verbreitet.

3. F. dioplithalma Ehrenbg. (F. 7.) Kaum über $\frac{1}{100} \mathrm{Mm}$. lang, ei-lanzettföruig, zugespitzt. Selur rerbreitet.

4. F. bipunctata Ehrenl)g. (F. 8.) Kamm über $-\frac{2}{100}$ Mm. lang, schlank lanzettlich, zugespitzt; Nebenseiten sehr schmal linealisch. Durch Europa, Asien. Amerika: in Südpersien. 
5. F. acnta Elrenbg. (F. 3.) $\frac{1-2}{100}$ Mn. lang (selten dariber), linealisch, an den Enden spitz keilfömug. In Dentschland, Italien.

6. F. rhabdosoma Elorenbg. (F. 6.) Bis $\frac{3-5}{100}$ Mn. lang, schlank lanzettlich, an den Enden plötzlich kopftërmig verdickt. Durch Europa, Amerika, Afrika, Sïdpersien.

7. F. comstricta Ehrenbg. (F. 5.) lanzettich, in der Mitte zusammengeschnürt, an ten Enten spitz keilförmig. Amerikı.

8. F. сон'ngata Ktz. (F. 4.) (iegen $\frac{1}{100}$ Mm. lang, lineal-lanzetteïrnig, an den Enden schaf zugenpitzt; auf den Nebenseiten je zwei der Individuen zusammengezugen. Deutschland, Siaburg, Piemont.

\section{ODONTHUIUA KTZ. (T. II.)}

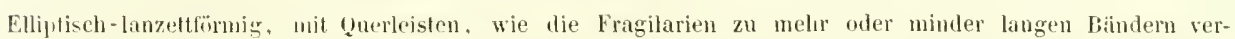
bunden; auf den Nebenseiten am Rande gozahnt und sowolıl daturch, wie auch durch die vorerwähnten !uerleisten der folgenden fiallung liatoma zunächst rerwandt.

1. O. mesodon (Elurenbg.) Ktz. (F. 2.) $\frac{1-3}{100}$ Mm. lang, in der Mitte gedunsen mul nit 3-5 Querleisten. in den Enden verdïnnt, vorgestreckt, stmmpf: Nehenseiten Inadratisch oder länglich quadratisch, an Rande mit vortretenden Zä̈hnen, die den Querleisten der Hanptseiten entsprechen. Durch ganz Europa.

2. O. turgidulum (Ehrenbg.) Ktz. (F. 6.) Bis $\frac{2}{100}$ Mm. lang, der vorigen fast gleichgestaltig, die Querleisten aber nicht anf die gedunsene Mitte beschränkt, sondern vertheilt, $4-5$ anf $\frac{1}{100}$ Mn. Dureh Emopa.

3. (). pinnatum Elbenbg. (Ktz.) (F.3.) Länglich, an den Enden abgrerundet; Qundeisten vertheilt, 15 anf $\frac{1}{100}{ }^{\prime \prime}$. Anf lskmd, in Imerika; auch fossil.

4. O. striolatum (Ehrenhg.) Ktz. (F.9.) 3-6mal länger als breit, unter den stumpfen linden kopffömig zusammengeschü̈rt: Querleisten strichförnig, 14-15) anf $\frac{1}{100}$ Hn. Durch Dentschliund.

5. O. capitatum láabenl. (T. X. suppl. F. 17.) $\frac{1}{100}$ Mm. und darüber lang, banchig, mit vorgestreckten, dicken kop,fömigen Eulen, 7 (unerleisten auf $\frac{1}{100}$ Mn. sïdpersien.

6. O. chanocephalum Rabenh. (T. X. suppl. F. 16.) $\frac{2}{100}$ Mm. lang, kamm darïber, an den stmnpfen Eurlen kopförmig eingeschnïrt, 6 Querteisten anf $\frac{1}{100}$ Mm. Amerika (bei loggotí).

7. (1. hyemale Kiz. (T. I1. F. 4.) Von seh" versehiedener Grösse, $\frac{1-6}{100}$ Mm. lamg, alliptisch-lanzettförmig, mehr oder minder selılank, an den Enden mehr orler minder versehmälert, stumpf orler abgermudet: Querleisten 6 anf $\frac{1}{100}$ Mm. In Gebirgsbächen sehr verbreitet: alch mu Bogotá in Amerika, F. c. rotmodatmm Rabenh. zwischen Moos am grossen Winterberog in der sächsischen schweiz.

8. (). glaciale Ktz. (F. 5.) Länglich-elliptiseh, an den Enden stumptlich: Nebenseiten trapezoidisch; Querleisten 4-5 anf $-\frac{1}{100}$ Mm. In den Bächen der Alpen.

9. O. bogotánum Rahenh. (F. 8.) Selr klein, länglich, mit zugermoleten Enden, 3 (rerhältnissmäissig) sehr breiten Querleisten. Bei Bogotá in Amerika.

10. O. salisburgense Rabenh. (F. 7.) Sehr klein, trapezoidisch, mit spitzen Enden, sehr schwachen, fast undentlichen Querleisten: Nebenseiten quadratisch, am Rande vielzähnig. Bei Salzhurg nuter Algen. Ob O. mininum Naegeli hierher gehört, lässt sich ans der Diagnose in Kützing's spec. Alg. nicht mit Sicherheit schliessen, indem die Gestalt der Hauptseiten nieht angegeben ist. 
11. O. grande (Ehreubg.) Rabeuh. (F. 1.) Sehr gross, lanzettförmig, mit stumpfen Enden: Querleisten 8-9 anf $\frac{1}{100}$ Mn. Bei Berlin, Spandan n. s. w.

to Bäuder zickzackfiirmig aufgeläst.

XXV. DIATONA DEC. (T. II.)

Ein Odontirlimn, dessen Glieder oder Indivihuen sich vollständig trennen, aber dureh Hëlhnembran, welche sich stielförmig zusammenzieht und gleichsam ein Zwischenghlied bildet, abwechselnd an dem obern und untern knde resbunden bleiben und dadureh eine zickzackförnige liette billen.

1. D. vulgare Ktz. (F. 6.) $\frac{2-5}{100}$ Mn. lang, länglich-elliptisch orler lanzettlich, an deu stumpfen Euden etwas zusammengeschü̈rt Querleisten $7-8$ anf $\frac{1}{100} \mathrm{Mm}$. Jureh ganz Europa gemein, in Nordafriki nud sïdpersien.

2. D. mesodon Ktz. (F. 3.) $\frac{1-2}{100}$ Mn. laug. lanzettfümig, in der Mitte bauhig: Querleisten nur in der banchigen Erweiterung. 3-4: Nebenseiten länglich-quadratisch. Durch ganz Deutschland, Savoyen, Piemont, anf der Ostabdachung der Apeminen, bui Bogotá in Ameriki.

3. D. tenue Ktz. (F. 5.) Sehr verümlerlich in Ciestalt und Grösse $\left(\frac{1 / 2-3}{100} \mathrm{Hm}\right.$. lang), lanzettförmig, mit 9-10 Qnerleisten anf $-\frac{1}{100}$ Hm.; Nebenseiten quadratisch, länglich-quadratiseh, linealisch oder keilformig, danach F. a. intermedium, b. cuneatum, c. uormale, d. moniliforme, e. dimotmm. Durch ganz Europa, sowolu in sïssem Wasser, wie in salzigen Bimnen- und Soolwässeen: in Ostindien, Sïdpersien, ant den Canarischeu Inseln, anf St. Kitts, in Mexiko miter Moos n. s. w.

4. D. mesoleptum Ktz. (F. 8.) Lauzettörmig, $-\frac{2}{100}$ Mu. und darüber lanı, 7-9 Querleisten anf $\frac{1}{100}$ Mn. Tebenseiten ans einer schlanken Vitte gegen die gestutzten Euden erweitert. Durch ganz Europa.

5. D. cuneatum Rabenh. (F. 4.) $\frac{1}{100}$ Mm. lang. elliptisch-lanzettförmig. nur in der Mitte mit 3-4 Querleisten: Nebenseiten constant keilförmig, an beiden Enden gestutzt, an Rande in der Mitte mit 3-4 keilförmigen und geneigten Zähnen. In Sachsen, Salzburg, Italien.

6. D. Elıenbergii Ktz. (F. 7.) $\frac{3-4}{100}$ Mm. und darüber lang, lineal-lanzettlich, vor den kopfförmig gerundeten Enden verdünnt; Querleisten zart, $9-10$ anf $\frac{1}{100} \mathrm{Mm}$. Nebenseiten linealisch, ans verdünnter Mitte gegen die rechtwinklig-abgentutzten Euden erweitert. Durch Enrola.

7. D. elongatum Ag. (F. 1.) Bis $\frac{5}{100}$ Mn. lang, sehr schlank, linealisch, an den germudeten Euden kopfförmig verdickt; Querleisten 6 auf $\frac{1}{100}-\mathrm{Mu}$.; Tebenseiten wie bei dem vorigen, aber schlanker. Dureh ganz Europa.

8. D. gracillimum Naeg. Sehr schlank, linealiseh, bis $\frac{1}{25}$ "' laug, ohne quelleisten, an den Enden kopffömig gedunsen: Nebenseiten fast wie bei D. elongatum. In der Schweiz.

9. D. pectinale kitz. (F. 2.) Bis $\frac{1}{100} \mathrm{Mm}$. lang, schlank lanzettfömig, glatt, mit gespitzten Enden; Nebenseiten rechtwinklig-länglich oder fast quadratisch. In Deutsehlaud, Frankreich, England. 


\section{FAM. VIII. NAVICULACEAE.}

Panzer auf den Hatpt- und Tebenseiten genau symmetrisch, erstere nachenförmig, gewöhnlich mit Centralknoten oder einer (buerhinde (nur in wenigen Fïllen olne diese), freischwimmend, aufgewachsen oder in einer fallerthïlle. Nebenseiten meist genau linealisch, an den Enden stumpfoder rechtwinklig abgestatzt.

Die Navienleen haben als Typus die Nachen-oder Spindelform, in der Mitte (anf den Ilanptseiten) einen drüsenartigen Knoten, ron den ans nach beiden Enden zu sieh ein Streifen oder Leisten zieht, der sich an den Enden oder kn\% vor denselben wieder knotenförnis verdickt oder erweitert (Natvicula): bisweilen zeigt der Panzer ansserdem nod, Querrippen und Streifen, so bei Pimularia. In wenigen Fällen verläıern sich die Enden schnabelförmig. wie bei Ceratoneis; ofter aber zeigt die Nachenform eine sfömige Krïnmung, so bei Gyrosigma. Der Centralknoten fellt mitunter, der Längsleisten ist dam in der Mitte unterbrochen, und die Mitte erscheint vollkommen glatt, so bei Frustuliat, Amphiplenra: oder es findet sich statt des Centralknotens eine breite Querbinde, die entweder von einem liande zum andern sich erstreckt, oler sie erreicht die Ränder nicht ganz. so bei Stanoneis, mit iln zugleich treten Qnerleisten auf, bei Stanroptera, oder die ganze innere Fläche ist bis anf die Gnerbinde und Längsleisten nit Knoten besetzt, welehe durch zarte Streifen krenzweise verbunlen sind, so bei stanogramma.

Ihre Vermehrmg gesehieht durch einfache, meist vollstïndige Theilung: hei einigen Neeresbewolnern, z. B. bei Schizonema und Mieromega, sind Fruchtzellen nachgewiesen.

Die grösste Zalıl lebt frei und isolirt, weil ihre Theilung eine vollstündige ist und die Hüllmemblan in demselben Moment ihrer Ansscheidmug wieder anfgelöst wird: alle diese zeigen eine öfters sehr lebhafte Bewegung. Nu bei wenigen ist die Hüllnembran comsistent und gallertartig, sie muliullt dam ganze Colonien, deren Individuen entweder ohne Ordnmg dureheinander liegen, so bei Frnstulia nud Nannema, oder sie sinu in regehnässigen Reillen geordnet, wie bei Colletonema. In nur einem bekannten Falle ist die Theilung eine nurollkommene, die Individnen bleiben, wie die Fragilarien, zn bandfömigen Fäden verbunden, so bei Diadesmis; chenso selten bildet die Hüllmembran einen gelatiösen Fuss, mit dem sich das Individum an Fadenalgen mo andern Gegenständen festsetzt (bei Falcatella).

Wir keunen 383 Arten, von denen 131 dem Meere aussehliesslieh angehören: 37 Arten sind fossil gefunden, von denen aber mehrere anch noch lebend vorkommen.

\section{XXYI. AllPHIPLEURA KTZ. (T. V.)}

Der Panzer zeigt nur Lïngsstriemen, in der Mitte eine lichte Stelle ohne knotige Verdickung.

1. A. pellucida (T. V.) Die cinzige bekannte Art des siissen Wassers. Sie findet sich meist gesellig unter andern Diatomacen, Oscillarien u. s. w. durch ganz Europa. 


\section{CERATONEIS EllRENBG. (T. IX.)}

Eine Navicula uit schmabelfürmig veflängerten, iffers zurückgekrümnten Euden, einem starken Centralknotru, an Rande öfters zart gerippt.

1. C. Areus (F. 1.) Durch ganz Europa verbreitet, anch in Nineralwässern. Sie ist sehr veränderlich in der Grösse, aber immer sicher zu erkennen an dem nach Aussen vorspringenden Centralknoten: die Enden sehr verlüngert, mehr oder minder zurïckgekrïmmt.

2. C. laminaris (F. 3.) ist lneit lanzettöpmig, gestreift mul kn\%-greschnäbelt. Bis jetzt nur ans llexiko bekinut.

3. C. amphioxys (F.4.) int nen. lah keme sie ans melneren Gegenden Deatsehlands: sie ist riemlich constant in ihrer Grösse mol wirl selten äher $\frac{3}{100}$ Mn. lang.

4. C. Fasiola (F. 2.) ist eigentlich ein Mceresbewohner; findet sich aber anch an den Kïsten in sogenannten Brackwasser. Eine anffallende nul interessinte Art durch die sehr verlängerten, un die eigene Axe gerhehten Enden.

5. C. gracilis Bréb. ist eine schlanke, Störmig gekrïmmte Form mit leicht rerdünnten und stmmpflichen Enden. Bisher nur in Frankreich beobachtet.

\section{XXVil. NAVICULA (BORY.) (T. V. und VI.)}

Bory re St. Vincent stellte 1822 diese Gattung anf mit ganz heterogenen Formen. Ehrenberg behielt 1838 in seinem grossen Infusorienwerke nicht nur die Gattung unverändert bei, sondern bereicherte sie noch mit ganz fremlartigen Elementen. Einige Jahre später trennte derselbe jedoch nehrere Gattungen ab, die zum Theil von Kützing 1844 wieder zusammengeworfen wurden.

Wir zichen zu dieser Gattung nur diejenigen Formen, welche eine regelmässig nachenförmige Gestalt anf den Hauptseiten, eine linealisch-viereckige anf den Nebenseiten, mit gerundet-stmmpfen Ecken besitzen, eine querdnchgehende Längsrippe, bisweilen noch einige schwächere Seitenrippen, in der Mitte, wie an treiden Enden eine stake, nabeloder knotenförmige Verdickmng zeigen, sonst aber spiegelglatt erscheinen.

Die Tebenseiten zeigen im Allgemeinen wenig Eigenthümlichheiten, sie sind deshab in den meisten Fällen zur Bestimmmg der Art entbehrlich.

$\div$ Arten mit stumpfen, abgerundeten, nicht vorgezogenen oder vorgestreckten Enden.

1. X. fulva Ehrenbg. (T. V. F. 17. und T. VT. F. 62.) Breit lanzettförmig, meist $\frac{8}{100}$ Mm. lang $\left(\frac{1-2}{100} \mathrm{Mm}\right.$. länger oder kürzer), anf den Nebenseiten mit etwas verschmälerten Enden. Wahrscheinlich über die ganze Erde verbreitet.

2. N. cuspidata Ktz. (T. V. F. 16.) ist der fulva sehr ähnlich, erreicht aber niemals jene Grösse, ihre Gestalt ist fast rhonboidalisch, die Nebenseiten sind genan linealiseh, an den Enden zugerundet. Sie ist ebenfalls sehr verbreitet.

3. N. amphisphenia Ehrenbg. ist eine cuspidata mit länglichem Centralknoten. Gujana.

4. N. rostrata Ehreubg. (T. VI. F. 52.) Breit lanzettfömig, schlank zugespitzt, mit stumpfen Enden. In Italien lebend und fossil.

5. N. dilatata Ehrenbg. Elliptisch-lanzettfömnig, mit stumpfen Enden und zarten Seitemippen. Nordanerika. 
6. N. rhombea Ehrenbg. (T. V. F. 14.) ist rbomboidalisch gestaltet mul hat ansser der Hamptrippe noch Nebempipen.. In Amerika.

7. N. Demerarate Ehrenbg. unterseheidet sich von der N. rhombea nur rum etwas vorgezogene, fast schnabelförmige Enden.

8. N. rhomboides Ehreubg. (T. V. F. 15.) ist anch romboilaliseh, aber schlanker und ohue Tehenrippen. Amerika, Frankreich.

9. N. Velox Ktz. (oblonga Ehrenbg.) (T. V. F. 12.) $\frac{2}{100}$ Mm. lang. Bekannt ans Mexiko, von der Insel Wamgerooge, Sïhpersien (Salzsee ,Nemek-Derja” bei Schiras).

10. N. Semen Ehrenbg. (T. V. F. 2.) $\frac{1}{100}$ Mm. breit, $\frac{2-21 / 2}{100} \mathrm{Mm}$, lang, wie gedunsen, mit breiten stumpfen Enden. Amerika, in Meteorstanbe, anch anf Bämnen in den Urwäldern ron Venezuela.

11. N. Amphigomphus Ehrenlyg. (T. VT. F. 47.) $\frac{6-7}{100}$ Hnl. lang, fast $\frac{2}{100}-M_{m}$. breit, mit fast keilformigen Emlen. Amerika.

1․ X. lineolata Ehrenbg. (T. VI. F. 8.5.) $\frac{3-5}{-100}$ Mn. lang, mit stmmptlichen Enden Amerika.

13. N. serians Brél. (T. VI. F. 51.) ist der N. lineolata sehr verwandt, ist aber bei gleicher Länge viel schlanker und wird his $\frac{7}{100}$ Hm. lang. Frankreich. Piemont, Italien.

14. N. amplioxys Ehrenbg. (T. VI. F. 63.) Schlank, schmal lanzettfömig, $\frac{21 / 2-i}{100} \mathrm{Mm}$. lang, nit stumpfen, bisweilen geschärften Enden. In Europa, Amerika, Afrika (Mosambik), Sïdpersien beobachtet, funlet sich anch im Bernstein eingeschlossen.

15. N. gracilis Ehrenbg. (T. VI. F. 64.) ist der X. amplioxys sehr ähnlich, sie ist bei gleicher Länge aber stets etwas stäker. Auf der ganzen lirde verbreitet, wird anch fast überall fossil gefunden.

16. N. viridula Kitz. Lanzettfömig, ${ }^{3-5}{ }^{-50}$ Mn. lang. Durch ganz Europra.

17. X. mierostoma Ktz. (T. V1. F. 53.) Breit lanzettë̈mig, in der Mitte gedunsen, ansser der Hauptrippe noch Nebenrippen, $\frac{6-8}{100} \mathrm{Mm}$. lang. Im westlichen Europa.

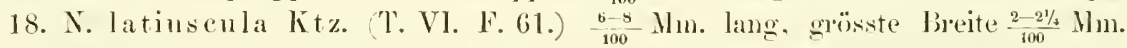
mit starker Rippe und seln starken Centralknoten. In Europa sehr verbreitet.

19. I. mutica Ktz. (T. VI. F. 81.) Elliptisch-lanzettfömig, kanm über $\frac{1}{100}$ Nm. lang. Insel Wangerooge.

20. N. appendiculata Ktz. (T. VI. F. 87. und 78.) länglich, vicht unter $\frac{1}{100}$ und selten über $\frac{2}{100} \mathrm{Mm}$. lang, mit schön abgermuleten, hisweilen vorgezogenen Enden. wodureh sie zu Grupe $\dagger \dagger \dagger$ himeigt. Der Centralknoten stark entwickelt. Durh ganz Enropa, anch in den heissen Quellwïssern.

21. X. Jurgensii Ktz. (T. VI. F. 79.) Länglich, nit undentlichen Centralknoten. In salzigen Bimenwässern.

22. N. obtusa Ebrenbg. ist eine No. 16. und 17. verwandte, uns nielut nïher bekannte Form aus Nordameriki.

23. X. Brébissooii Ktz. (I'. VI. F. 54.) Länglich-elliptisch, mit wenigg verschmälerten, germoteten Enden, $\frac{4-5}{100}-1 m$. lang. In Gräben und Teichen durch das mittlere, sïdliche und westliche Europa; in Amerika mir bisher nur von Bogotá bekant.

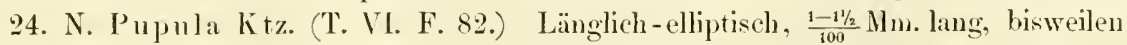
nit etwas zusammengezogenen, aber stets germdeten Enden. In Europa ziemlich verbreitet.

25. N. diaphana Ehrenbg. $\frac{1}{16}$ “' lang, lanzettförmig, mit stmmpf-zngernudeten Enden und zwei Seitemrippen. Gujana. 
26. N. Schomburgkornm Ehrenbg. ist $\frac{1}{15} "$ lang nud hat drei Seitenripent. Gujana.

27. N. Bacillum Ehrenbg. (T. VI. F. 76.) Linealisch, mit einfach zugerundeten Enden, $\frac{3}{100}$ Mn., anch etwas darïber lang. Norl- mul Centralamerika, Südpersien (auf dem Kuh-Daëna in der Nähe des ewigen Schnees). in der heissen Quelle des Rio Taentaflusses in Afrika; anch im Meteorstambe un im Bernstein.

28. N. "blongella Naeg. Länglich-eiföming. $\frac{1}{160}-\frac{1}{130}{ }^{\prime \prime}$ lang. In ded Schweiz.

29. X. ovalis Xateg. Elliptisch-eifomign, $\frac{1}{60}-\frac{1}{50} "$ lamg. In dev Sohweiz.

30. N. Pygmatea Ktz. Länglich-elliptisch, mit sehr kleinen Centralknoten, $\frac{1}{150}-\frac{1}{120}$ "' lang. Frankreich.

31. N. truncata Ktz. (I'. VI. F. 67.) Linealisch, mit zugerundeten Enden, nach Innen wellig geraudet. In Dentschland und des. Sohweiz. Mir muckannt, scheint nicht hierher zu gehören.

\section{t+ Arten mit scharf gespitzten Enden.}

32. X. aponina Ktz. (T. Y. F. 11. und T. VI. F. 88.) Lanzettlich, $\frac{1-2}{100} \mathrm{Mm}$. lang, die Nebenseiten mehr orler minder genau linealisch und an den Enden gestutzt. In kalten und heissen Quellen des südlichen und westlichen Europas.

33. N. brachysira Bréb. (T. V. F. 11. e. l. e.) unterscheidet sich von der N. aponina nicht wesentlich, sie bleibt nach der Theilung nu länger als die typische Form verbunden mol erscheint dann eine Zeit lang in kuren bänlern, wie das anch öfters bei der N. serians der Fall ist. De Brébisson hat sie bei Falaine berbachtet.

34. N. Cesatii Rabenh. (T. VI. F. 89.) Fast wie N. aponina aber weit schlanker und $\frac{2-21 / 2}{100}$ Mnt. lang: die Nebenseiten zwar genan linealisch, aber immer breiter und an den Eurlen abgerundet. In Piemontesischen.

35. N. acuta Ktz. (T. VI. F. 73.) $\frac{3}{100}$ Mm. und dariber lang, dabei ziemlich schlank, die Enden der Nebenseiten stark abgestutzt, ohne zugerundete Ecken.

36. N. lanceolata Ktz. (T. V1. F. 77.) Lanzettë̈mig, zugespitzt, in Gestalt der X. acuta sehr ähnlich, aber nicht lis $\frac{3}{100}$ Mm. lang. Durch ganz Europa, Amerika, in sïdpersien bei selinas.

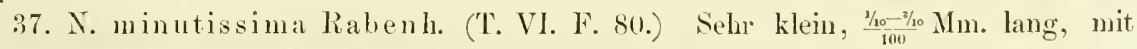
deutlichem Centralknoten. Sïrpersien, am Sabst Buschom.

$\div \div+$ Arten mit mehr oder minder vorgestreckten (kopfförmigen) Enden.

38. N. cryptocephala Kitz. (T. VI. F. 71.) Salmal lanzettförmig, $\frac{11 / 6-21 / 2}{100} \mathrm{Mm}$. lang. mit dentlich eingeschnïrten, aber wenig hervortretenden Enden, anf den Nebenseiten genau und sehmal linealisch. Durch ganz Enropa.

39. N. rhynchocephala Ktz. (T. VI. F. 68.) Sehr schlank, mit weit rorgestreckten Enden, $\frac{3-1}{100} \mathrm{Mm}$. lang. Durch das mittlere, südliche und westliche Europa.

40. N. exilis litz. (T. VI. F. 84.) Mit wenig rorgestreckten Eurlen, $\frac{1-1 \frac{1}{2}}{100}$ Mm. lang. Dentsehland.

41. N. leptocephala Rabenh. (T. VI. F. 69.) $\frac{5-6}{100}$ Mm. lang, mit rorgestreckten, schlanken, fast kenlig verdickten Enden. In Gebirgswässeru Dentschlands.

42. X. veneta Kitz. (T. VI. F. 83.) Ist eine eryptoceplala, aber kürzer und stärker. Im botanischen Garten zı Venedig. 
43. N. erassula Nateg. Elliptisch, mit kopfförmigen Enden, $\frac{1}{80}-\frac{1}{60} "$ lang, auf den Nebenseiten breit linealisch, abgestutzt. In der Schweiz.

44. N. affinis Ehrenbg. (T. VI. F. 58.) $\frac{-3-4}{100} \mathrm{Mm}$. lang, mit breiten, stumpfen, wenig vorgestreckten Enden. Enropa, Amerika: anch in Meteorstanbe und in Bermstein.

45. N. Dirhynchus Ehrenbg. (T. TT. F. 48.) $\frac{11 / 2-2}{100}$ Mm. lang, sonst der N. affinis sehr ähnlich. Amerika, Frankreich.

46. N. Leptorhyuchus Ehrenbg. mit weit rorgestreckten, fast gespitzten Enden.

47. N. ambigua Ehıenbg. ('T. VT. F. 59.) länglich, banchig, mit stumpfen Enden. Amerika.

48. N. limbata Ehrenbg. (T. V1. F. 75.) Linealisch, mit plützlich znsammengezogenen um abgestutzten Enden, nath fumen breit geraudet. Westamerika.

49. N. dubia Ehrenbg. ('T. VI. F. 60.) Der ambigna und affinis sehr ähnlich, aber kleiner und etwas schlanker. Siminam.

50. N. bieeps Ehrenbg. (T. VI. F. 49.) Breit lanzettömig, mit breiten, stumpfen Enden. Amerika, Frankreich, Piemont.

51. N. Carasius Ehrenbg. (T. VI. F. 57.) Stark bauchig, mit stark zusammengeschnürten, fast zugespitzten Enden. Gujama, Frankreich.

52. N. Anpliphynchus Ehreubg. (T. V1. F. 50.) $\frac{4-5}{100}$ Mm. lang, breit-lanzettfömig, mit stak eingeschnürten und gestntzten Enden. Lebend in Europa und Amerika, fossil in Italien.

53. N. sphatrophora Kitz. (T. VI. F. 65.) $\frac{5-7}{100} \mathrm{Mm}$. laug, $\frac{11 / 2-2}{100}-\mathrm{M}_{\mathrm{m}}$. breit, mit stark eingeschuïrten, gestutzten oder kopfförmig abgerundeten Euden, $3-4$ zarten Seitenripuen. Durch ganz Europar.

54. N. amphisbatua Bory. (T. VI. F. 66.) Ei-lanzettfömig, mit mehr oder minder stark eingeschnïrten, kopfömmigen Enden. Europa, Asien.

55. N. Lyra Ehrenhg. (T. V. F. 15. Bruelstrick, Copie nach Ehrenberg). Falklands-lnseln. Die Rippen zeigen die merkwürdige Gestalt einer doppelten Lyra.

56. N. guttulifera Rabenh. (T. VI. F. 74.) Linealisch, schlank, mit scharf eingeschü̈rten, fast kugehrunden Enden, die gleich emer Glasperle aufgesetzt zu sein seheinen: $\frac{4-8}{100}$ Mm. lang. Sürpersien.

57. N. enrycephala Rabenh. (T. V1. F. 70.) Selu gross und robust, $\frac{10-15}{100}$ Mm. lang, mit leicht eingeschü̈rten, dann erweiterten, breit abgestutzten Enden; Nittehrippe und Centralknoten sehr stark entwickelt. Erinnert an Stauroneis platystoma, der Centralknoten ist aber abgerundet, nicht bindenartig breit. Im sächsischen Erzgebirge.

$\div+\div+$ In der Milte ausgeschweifte Arten, von geigenfirmiger Giestall.

58. N. paradoxa Ehrenbg. (T. V. F. 1.) Längheh, in der Mitte leicht ansgeschweift, mit 4 längsstriemen und fast keilförmigen, stmmptén Enden. Pelu.

59. X. tenella Bréb. Schnal lanzettlich, mit spitzen Enden. Frankreich.

60. N. americana Ehrenbg. Länglich, mit breitgerundeten Enden. Nordamerika.

61. N. Faba Ehrenbg. Gedunsen, länglich, mit germudeten Enden und drei Nebenrippen. Am Tajo.

62. N. duplicata Ehrenbg. (T. V. F. 4.) $\frac{1-1 \frac{1}{10}}{100}$ Mu. lang, an beiden Enden zugerundet. Amerika (Bogotá, Cuba), St. Kitts. 
63. N. binodis Ehrenbg. (T. V. F. 5.) Schlank, in der Mitte und muter den zugespitzten Enden stark zusammengeschnïrt. In Tïmpeh uml Regenffützen: anch fossil im Bergnehl yon Santatiora.

$$
\text { †ナナナ† Arten mit knotig oder bauchig erweilerter Mille. }
$$

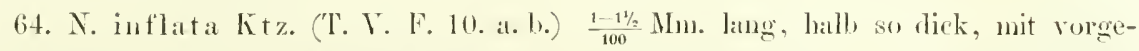
zogenen, stum,fen Enden. Wentschland, Italien; wahrscheinlich dureh ganz Europal; anch fossil.

65. N. polyonca Bréb. Verlängert, dreiknotig, der Mittelknoten banchig anfgetriehen, an den Enden kopffömig zugerumlet: $\frac{1}{40}-\frac{1}{30}{ }^{\prime \prime}$ lang. Frankreich.

66. N. Hiteheockii Ehrenbg: Länglich, zweinal zusammengeschnït, dahreh dreiwellig, mit plötzlich keilförmig verdïnnten, fast spitzen Enden. Amerikis.

67. N. Formica Ehrenbg. Schmal linealisch, viermal zusammengeschnürt, die einzelnen Abgherlenungen Iänglich. Amerika.

68. N. mesotyla Ehrenbg. ('T. V. F. (i.) Schmal und schlank linealisch, in der Mitte fast sphärisch aufgetrieben, an beiden Enden stumpf zugemudet. Ameriki.

69. N. seopulorum Bréb. (T. V. F. 7.) Schlanker, als N. mesotyla, lie Mitte weniger stark gerlumsen nul beiderseits gegen die gerundeten Enden verlanfend. An der Kïiste ron Frankreich wurle sie ron de Brébisson entrleckt: sie kommt aber anch im Brackwasser, in den Lagnnen Italiens ror, und ich habe sie zum Theil deshalb, zmm Theil aber anch ihrer grossen Aehnlichkeit mit der $\mathrm{N}$. mesotyla wegen hier aufgefïhrt.

70. N. leptogongyla Ehrenlyg. (T. V. F. 8.) Ist bei gleicher Länge nit den vorigen noch eimmal so dick, die Vitte, wie anch die gerundeten Enden leicht gedunsen. In den Bäichen höherer Gebirge, der Mpen Emopss, und in Nordanerika.

71. N. tumidula Rabenh. ('I. V. F. 9.) Bis $-\frac{5}{100}$ Hn. lang, in der Mitte stark gedunsen, nit sehr starkem ('entralknoten, gegen die gerundeten Enden leicht verdickt. Stockholn unter (onferven. Sie ist der fossilen $\mathrm{X}$. ventrieosa sehr ähnlich.

72. N. Silicula Ehrenbg. In der Mitte und an den Enden sturk gedunsen (dreiknotig), ganz stmmpf abgermelet. Nordanerika. In Meteorstub und auf Bämmen in den Urwïllern von Venezuela.

73. N. nodosa Ehrenbg. (T. VI. F. 86.) $\frac{3-4}{100}$ Hn. lang, in der Mitte stark gednnsen und dureh eine Wellenlinie in die verdünten und stumpfen Enden verlaufend. Enropa und Amerika, sehr verbreitet.

74. X. Trabecula Ehrenbg. ist eine schlanke Pinnularia gibba ohne Qnemippen. Nord - nml Central-Amerikil.

75. N. mesolepta Ehrenbg. (T. VI. F. 72.) Bis $\frac{-6}{100}$ Mm. lang, die Enden fast kopfförnig hervortetend. Frankreich, Savoyen, (rujana.

76. N. limosa Rabenh. (T. VI. F. 31. c.) Länglich, gegen die Enden erweitert und plötzlich ziemlich spitz zugerundet, bis $\frac{2}{100}$ Mn. lang. Sachsen.

77. N. persica Rabeuh. (T. VI. F. 55.) $\frac{i-8}{100} \mathrm{Mm}$. lang, grösste Breite $\frac{2-21 / 2}{100} \mathrm{Mm}$., ans stark banchiger Mitte beiderseits dureh zwei Wellenlinien in die sturk verdünnten und gerundeten Enden verlanfend, beiderseits der Hanptrippen nit vier wellenfürmigen Nebenrippen. sürlpersien.

78. N. undosa Ehrenbg. (T. VI. F. 56.) an Gestalt der N. persica sehr ähnlich, aber kanm 1/3 der Grösse erreichend, ohne Nebenrippen mu mu mit einer Wellenlinie in die stark verdümnten Enden verlanfend. Surnam, Frankreich. 


\section{PINNELARTA EIIRENBG. (T. VI.,}

Eine Navicula mil guerriflen ober gmerstreifen.

Wir finden in dieser Gattung eine Wiederholung sämmtlicher Navieula-Formen, und wo noch einzehe (ilierler fehlen. lässt sich mit sicherheit ammehnen. dass sie noch entdeckt werden: ebenso rephält es sich ungekeht. d. H. wo isolirte Fommen unter Pinmlaria anftreten. wird. man sie anch noch als glatte, morerippte Navicula entlecken. Dies Prinzip hat mich geleitet zur Annahme der Ehrenbergischen Gattumg.

† Arten von uachenfïmigrp Gestalt. mit stumpfen oder zugerundeten Endeu.

1. P. Iridis Ehrenbg. (T. VI. F. 1.) $\frac{18-25}{100} \mathrm{Mm}$. lang. kanm ïber $\frac{2}{100}$ Mm. breit,

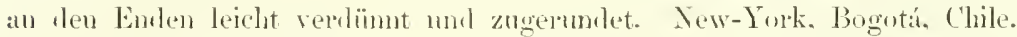

2. P. major Rabenh. P. viridis Ehrenbg.) (T. VT. F. 万. mat T. X. suppl. F. 4.) $\frac{10-12}{100} \mathrm{Mm}$. lang. längheh-elliptisch, gegen die Enden leicht verdünnt und zugermolet. Dureh ganz kiropa mol Amerika.

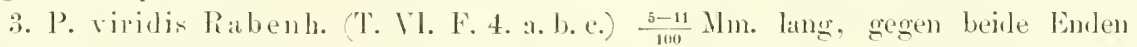
stäker verdünnt, als bxi major, und zugermulet. Ebentalls durch ganz Europa und Amerika verheitet. in südpersien. anch im Meteorstanbe.

4. P. Dactylus Elurenbg. (T. VI. F. 8.) $\frac{8-10}{100} M$ M. lang, bis $\frac{2}{100}$ Mm. breit. gegen die Enden schwach rerdünnt, breit abgemudet, anf $\frac{1}{100}$ Mus. 9 (Snerripen. Nord- und Central-Amerika.

5. P. costata Ehrenbg. Länglich-cifirmig. nit sehr breit abgermudeten Enden, anf $\frac{1}{100}$ Mm. 4 hreite Qnerrippen. Anerikil, Sit. Kitts.

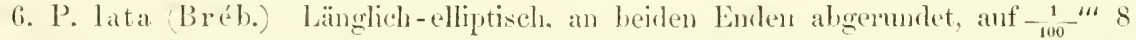
kräftige, in der Mitte zusammengencigte Querripen. Bei Falaise von de Brélrisson entdeckt.

7. P. chilensis Ehrenhg. (T. VI. F. 13.) $-\frac{5}{100}$ Hm. und dariber lang, $-\frac{11 / 2}{100} M \mathrm{H}$. breit, auf $\frac{1}{100}$ Mnı, $7-8$ kräftige Quemipen. (Gile, Bogotá.

8. 1'. suecica Ehrenbg. (T. VI. F. 14.) Länglich-elliptisch, an beiden Einden zugermolet, $\frac{5}{100} \mathrm{Mm}$. lang. fast $\frac{2}{100} \mathrm{Mm}$. breit, anf $\frac{1}{100}$ Mn. 7 querippen. Schwerlen.

9. P. borealis Ehrenbg. (T. VT. F. 19.) $\frac{2}{100}$ Mn. lang, linealinch, mit abgemuleten Enden. Sehr verbeitet: anch in Meteorstanbe wiederholt und in Magen der. Fhosifische beobachtet.

10. P. caraceana Ehrenbg. ist länger und in der Mitte gedunsen. Auf Bammstämmen in Venezuela.

11. P. bemiptera Rabenl. (T. VI. F. 17.) Bis-2 Mm. lang. anf $\frac{1}{100} 1 \mathrm{~m}$. $9-10$ Qnerripuen. Antillen. St. Kitts. Eine schlankere. etwas längere Form entreckte de Brébisson bei Falaise, v. Cesati fand sie bei Vercelli in Piemonterischen.

12. P. alliptica liabenh. (T. VI. F. 28.) Elliptisch, mit mehr oder minler abgerundeten Emben. anf $\frac{1}{100} \mathrm{Hm}$. 9-10 Querrippen. Frankreich, Italieu.

13. P. italiea Rabenl. (T. YT. F. 23. e.) Elliptisch, bir gegen $\frac{4}{100}$ Mm. lang umd halb so breit, anf $\frac{1}{100} M m .11$ zarte Querrippen, die in ein hnötchen enden. In den ästlichen Provinzen Italiens.

14. P. disciformis labenh. (T. V1. F. 23. d.) Fast kreisrund, scheibenlörmig, fast so breit als lang, anf $\frac{1}{\text { ino }}$ Mn. 6 lneite, nach der Mitte geneigte Rippen. In Tümpeh an Sabst-Buschom (Nï̈persien). 
15. P. coceoneoides Rabenh. (1. VI. F. 18.) Iänglich-ruml, kamm bis $\frac{1}{100} \mathrm{Nm}$. lang. $2 / 3$ so breit, aut $\frac{1}{100}$ Nm. $11-13$ gerale, dentliche, aber zarte Querripen. Stoekholm, unter couf. Ategagropila.

16. P. Utriculus Ehrenbg. Länglich, an den Enden kum zugerumlet. Mexiko.

$\dagger+$ Arten mit stark verdünuten, fast zugespitzten Enden.

17. P. viridula Rabent. (T. VI. F. 39.) $\frac{3-5}{100}$ Mn. lang, nit convergirenden, zarten Rippen. Durch ganz Europa, Amerika, Südpersien.

18. P. radiosa Ralenh. (T. VI. F. 9.) Schlanker und lie Ripren stäker, als bei der P. viridula. In Dentschland. Oberitalien.

19. P. lancenlata Ehrenbg. (T. VI. F. 20.) Elliptisch-lanzettiömig. $\frac{4-5}{100} \mathrm{Mm}$. lang, grösste Breite $\frac{11 / 2}{100} \mathrm{Mm}$. . nit 2 -3 Seitempipen und auf $-\frac{1}{110} \mathrm{~lm} .7-8$ dicke Querrippen. Durch Dentsehlaurl, Frankeich, Italien, Central-Anerika mud bei schiras in siidpersien.

20. P. Ehrenbergii Rabeuh. (T. VI. F. 21.) Lanzettlich, $\frac{3-4}{100}$ Mlm., selten darüber lang. mit convergiremlen, zarten Querrippen. Durch ganz Dentschlanul.

21. P. vulpina Rabenh. (T. VI. F. 38.) Lanzettfömig, ziemlich scharf zngespitzt, bis $\frac{5}{100} \mathrm{~lm}$. lang, Nebenseiten breit linealisch, ann liande nit klemen, punktförmigen Knötchen (lie Ansgangsknoten rer Querrippen der Hauptseiten). In Dentschland sehr verbreitet; ant St. Kitts in einer sehr fenchten Schlucht in Moospolstern.

2.2. P. Schomburgkii Ehrenbg. Lanzettförmig, dreinal so lang als breit, mit fast spitzigen knden, anf $\frac{1}{96} " 25$ Qnerrippen.

23. P. Iatinscula Rabenh. repräsentipt unter den Pimnularien die glatte Navicula latiuseula (T. V'T. F. 61.).

24. P. disphenia Ehreubg. (T. Vr. F. 25.) Länglich-linealisch, mit schart keilförmigen Euden.

25. P. Amphigomplus Ehrenbg. repräsentirt in dieser Formenreihe die Navicula Ampligomphus ('T. VI. F. 47.). Anerika, Frankreich.

26. P. peregrina Ehrenbg. (T. VI. F. 10.) Schlank, lineal-lanzettlich, $\frac{4-5}{100} \mathrm{Mm}$. lang. Nordamerika, Falklands-Inseln, Cuba, St. Doming", St. Jan, Sürdpersien.

27. P. gracilis Ehrenbg. Schlank Ianzettförmig, mit zugespitzten Enden und zarten, convergirenden Querippen. Sehr verbreitet, anch fossil.

28. P. inacqualis (Ehrenbg. (T. VI. F. 12.) Breit lanzettföruig, ungleichschenklich. nit stmupflichen Enden, $\frac{3-5}{100} 17 \mathrm{~m}$. lang. Durch ganz Europa, in Italien anch fossil.

29. P. amphioxys Ehreubg. Lineal-lanzettlich, schlank, an heiden Euden spitz, mit gerarlen Qucrstreifen. Islani, New-York.

30. 1'. libyca Ehrenbg. Ei-lanzettförmig, nit spitzen Enden, anf $\frac{1}{100}{ }^{\prime \prime} 14$ Quenrippen. Oase Siwah.

\section{$+\div \dagger$ Arten mit nicht ausgeschweiftem Rande, aber mit kopfürmig gestreckten oder eingeschnürten Enden.}

31. P. Amphirhynchus Rabenh. Wie Naviena Amphrhynchus, aber etwas gestreckter. In sïdlichen Italien.

32. P. pachycephala Rabenh. (T. VI. F. 40.) $\frac{3-4}{100}$ Mm. lang, sehlank lanzettlich, mit eingeschnïrten, dicken, gerundeten Enden und convergirenden Querrippen, 
stanken Centralknoten und muleutlichem Enclknoten. In einem Graben bei Rodi im Gargano.

33. P. grarganica liabenh. (T. V1. F. 41.) Bis $\frac{3}{100}$ Mn. lang, lanzettförmig, nit gestreckten mal abgerumleten Enden, in der Mitte nit 6 kräftigen querriplen, denen sich anf $\frac{1}{100}$ Mn. 10-12 habb so dicke anschliessen. In (iargano (Lago di s. Egirlio).

34. l'. capitata Rabenh. (T. V. F. 3.) Kurz ei-lanzettfömig, nit schabelfömig verdüunten, stump, zugerundeten Eurlen, $\frac{1-3}{100}$ Mn. lang. In Dentschland, Selhweden, Italien, sü̈lpersien; anch in Meteorstanbe.

35. P. Sillimanorum Elırenba. Lanzettförnig. grösser als die vorigen, in der Mitte stark erweitert, mit schabelfümig rorgestreckten, breit zugermoteten Enden. New-Tork.

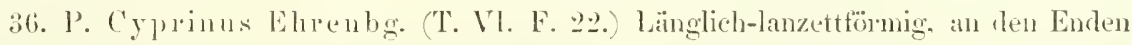
sehwach verdïnnt und breit zugerumlet. ('hile.

37. P. diomplata Ehrenbg. (T. Vl. F. :37.) Breit ei-lanzettförnig, mit kurz rorgestreckten mul gestutzten Enden, gegen $\frac{5}{100} \mathrm{Mm}$. lang, $\frac{2}{100}$ Mn. breil. Mexiko, Bogrotí.

38. P. dicephala lihrenbg. (T. VT. F. 44.) Linealisch, mit kurz rorgestreckten, stumpfen Enden, $\frac{11 / 2-3}{100}$ Mur. lang. Amerikil, Nest- und süideuropa; anch fossil.

39. 1’. aequalis Ehrenbg. Lanzetförmig-länglich, mit zusanmengesehnïrten, stumpfen Enden und zarten Querripen. Istand.

40. P. Placentula Ehrenbg. (T. VT. F. 16.) Bir gegen $\frac{5}{100}$ Mn. lang, gegen $\frac{2}{100}$ Mm. Jreit, gegen die Euden stark veroünnt umb stumpt abgerumlet. Amerika.

41. P. (rastrum Ehrenbge. (T. VI. F. 15.) Breit lanzettfïrmig, $\frac{2}{100}$ Mhn. und darïber lang, $\frac{1}{100}$ Mn. breit, nit wenigg vorgestreakten, stumpfen Enden. Norl- und Central-Ancrika, in Sïdpersien: anch in Meteorstaule und in banstein.

4\%. P. ot loutina Rabenh. (T. VI. F. 4\%.) Lanzettfömig, his $\frac{5}{100}$ Mhr. und dar-

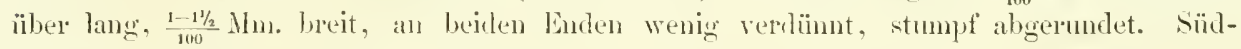
italien (terra li Otranto).

43. P. Pisciculus Eluenlg. (T. VI. F. 43.) Linealisch, bis $\frac{3}{100}$ Mnt. lang, nit leicht verdünnten, gestutzten Enden. Amerika, Sürpersien, Frankreich, Italien, Sicilien.

44. P. rostellat a Kंz. (T. VT. F. 46.) Lineal-länglich, mit rorgestreckten, stumpflich-spitzen Eurlen. In Salzwasser ant rler Insel Wangerooge.

45. P. amplaiceros Ktz. (T. VI. F. 45.) $\frac{1-1 \frac{1}{100}}{100}$ Mn. lang, breit lanzettlich, mit rorgestreckten mind gerundeten Enden. Dentschland.

46. P. inflata Rabenh. (T. V. F. 10. c.) ist die gestreifte Navieula intlata Kitz. In Deutschland, Bogotá in Amerika.

$\div+\div \dagger$ Arten mit bauchig- oder bucklig-aufgetriebener Mitte.

47. P. nobilis Ehrenbg. (T. VI. F. 2.) Sehr gross, bis $\frac{1}{4}$ Mm. lang bis gegen $\frac{3}{100}$ Mn. breit, mit erweiterten und breit zngermudeten Enden. Amerika, Frankreich, Italien, Bosnien; in Italien anch fossil.

48. P'. interrupta Rabenh. (T. VI. F. 3.) Eine schlanke P. nobilis mit zarten, unterbrochenen Querrippen. In der terra di Otranta (Sïditalien).

49. P. Tabellaria Ehrenbg. (T. VI. F. 24.) $\frac{3-6}{100}$ Mn. lang, mit stark gedun_ sener Nitte und mehr oder minder erweiterten und breit zugermoten Enden. Centralund Nordamerika. 
50. P. Legumen Ehrenbg. (T. VI. F. 34.) $\frac{4-5}{100}$ Mm. lang, dreiwellig, mit leicht verdüunten und stmmpfen Enden. Repräsentirt die Nav. nodusa nnter den Pinmularien. Durch Enropa und Amerika.

51. P. Monile Ehrenbg. $\frac{1}{72}{ }^{2}$ lang, viermal eingeselmïrt und ladurch in fünf fust kugelige Glierler getheilt. Berlin.

52. P. gibba Ehrenbg. (T. VI. F. 27.) $\frac{5-10}{100}$ Mm. Jang, miter den erweiterten und breit zugernndeten Euden zusammengeschnïrt. Durch Emopa und Amerika.

53. P. gibberular Ktz. (T. VI. F. 30.) $\frac{1-5}{100}$ Mm. langr, breit lineulisch, aus der banchig gedunsenen Mitte durch eine leichte Linschnïmng in die erweiterten, breit angerumleten Enden verlanfend. Nordhasen, Chemnitz, Dresden.

5. P. oblonga Rabenl. (P. macilenta Ehrenbg.) (T. VI. F. 6.) $\frac{10-15}{100}$ Mm. lang, circa $\frac{1}{100} \mathrm{Mm}$. breit, gegen die Enden verdïnot, stmpf zugerundet, Qmerrippen breit, etwas convergirend, anf $\frac{1}{100}$ Mm. 6-7. Durch Dentschland, Italien, Frankreich, Ameriki.

55. P. acrosphaeria liabeuh. (T. V1. F. 36.) Linealisch-länglich, in der Nitte leicht gednusen, an den Enden zugerundet, mit kurzen, dicken, die Mittehippe nicht beröhrenden Grerrippen. Frankreich.

56. P. Kefringensis Ehrenbg. Lanzettfirmig, kleiner als P. acrosphaeria, mit convergirenden und dünnern Qnerrippen. Schweden (Stockholmi).

57. P. Esox Ehrenbg. (T. V'1. F. 7.) Schmal lanzettlich, mit stark erweiterter Witte, gegen die Enden verlümt nnd zngerundet. mit zarten Querrippen. ('hile.

58. P. pachyptera Ehrenbg. (T. V1. F. 11.) Kmz und dick, nnter den sehr

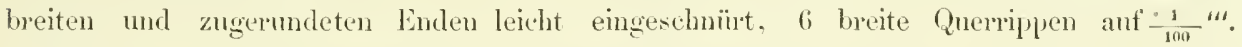
Labrador.

59. P. Gigas Ehrenbg. Gross, der P. nobilis ähnlich, 9 heite Querrippen anf $\frac{1}{100}{ }^{\prime \prime}$. Nordamerika.

60. P. Parmula Bréb. Länghich-elliptisch, mit stmmpfen Enden, sehr zarten Querpippen und 2 Längsrippen. $\frac{1}{80}-\frac{1}{60}{ }^{\prime \prime} \operatorname{lang}, \frac{1}{200}-\frac{1}{160} "$ "Ireit. Bei Falaise.

61. P. mesogongyla Ehreubg. Der P'. nobilis ähnlich, gegen die Enden rerdïnnt und olme Erweitermg zngerundet. Nordamerika.

62. P. porrecta Ehreubg. Lanzettfönig. verïngert, ans breiter Hitte nach unr nach in die breit zugermudeten Enden verdïunt, mit convergirenden Rippen. Nordamerika.

6.3. P. decnrreus Ehrenbg. (T. VI. F. 25.) Länglich, mit stark erweiterter Nitte nud breit zngerundeten Enden. Nord- und Central-xlmerika.

64. P. Trabecula Ehrenbg. ist mu schlanker als P. decurens. Amerika.

65. P. limosa Rabenl. (T. VI. F. 31.) Bis $\frac{3}{100}$ Mn. lang, an den Enden spitz zugermotet. Dentschland.

\section{$\leftarrow+\leftarrow \div \div$ Arten mit ausgeschweifter oder zusammengeschnürter Mitte, daher geigenfürmig.}

66. P. dissimilis Rabenh. (T, V. F. 32.) $\frac{8-10}{100}$ Mm. lang, in der Mitte bis anf $\frac{1^{1 / 2}}{100} \mathrm{M} / \mathrm{m}$. eingeschnïrt, gegen die breit zngermadeten Enden bis gegen $\frac{3}{100} \mathrm{Mm}$. erweitert, mit breiten, fast sichelförmig gebogenen, convergirenden, gegen die Mittelrippe verschwin- 
denden Querippen, 4 anf $\frac{1}{100}$ Mm.: Nebenseiten in rer Mitte bauchig anfgetrieben, gegen die breiten, stumpfen Enden nach und nach rerdünnt. sï̈lersien.

67. P. didyma Ehrenbg. (T. VT. F. 26.) Kurz geigenförmig, in der Mitte leicht zusanmengeschn̈̈rt, an den Enden breit zugerundet, mit breiten, geraden, die Mittelripue berïhrenden Querripuen. Amerika; anch in den Lagnnen der (Otranto im sïllichen Italien.

68. P. Apis Ehrenbg. (T. VI. F. 28.) Länglieh, in der Mitte lejebt zusammengesehnürt, mit stumpflich-zugerundeten Enden und geraden, körnig-knotigen Querripen. Vera ('ruz.

69. P. Conops Ehrenbg. (T. V1. F. 29.) Kleiner als die rorigen und mit gespitzten Euden, zarten Querippen. Tera C'mz.

70. P. Bombus Ehrenbg. $\frac{1}{32} "$ lang, mit farst gespitzten Enden und gekörntkuntigen, dieken Querrippen (21 auf $\left.\frac{1}{100}{ }^{\prime \prime \prime}\right)$. Aegina.

71. P. Crabro Ehrenbg. $\frac{1}{23}$ “" lang, mit stmupflich-spitzen Enden mud glatten, dicken Querriplen $\left(11-12\right.$ anf $\left.-\frac{1}{100} “{ }^{23}\right)$. Aegina.

72. P. Amphiprora Ehrenher. Gross, schmal lanzetförmig, mit breiten, stumj,en Enden. Nordanerika.

\section{FALCATELLA RABENH. (T. V.)}

Eine sichelförmig gekrümute Naviunla mit gestutzten oder stumpfen Eurlen, glatt oder quergestreift, mit dentlich entwickeltem Sabel, obne knotige Verdickung an den Enden. Nur eine Art ist uns bis jetat bekamn, die einen starken, pulstertimmigen Fuss entwickelt.

\section{a. GLATTE NICHT QUERGESTREIFTE FORMEx, \\ t auf einem gelatinösen, polsterfurmigen Fuss.}

1. F. romana Rabenh. (F. 1.) $\frac{6-8}{100}$ Mn. lang, gegen $\frac{1}{100}$ Mm. breit, linealisch, mit rechtwinklig abgestutzten Enden. In der Solfatara bei liom. F. a. zeigt schwärmzellen in danmen der \%elle.

tt freie, nicht aufgewachsene Formen.

2. F. I unata Rabenl. (Naricula lunata litz.) (F. 2.) $\frac{2}{100}$ Mn. mol auch darriber lang, sehnal linealiseh, mit stumpf abgerundeten Enden. In den warmen (huellen Italiens.

3. F. delieatula Rabenl. (Achantilimm delicat. Ktz.) (F. 4.) $\frac{1 / 2-1}{100}$ Mm. lang, stark bauchig. mit gestreckten nud gerundeten Eurlen. In Gräben Dentschlands, anch im Brackwasser an den Küsten, der Insel Wangerooge.

\section{b. QUERGESTREIFTE FORMEN.}

4. F. neapolitana Rabenh. (F. 3.) $\frac{2-4}{100}$ Mm. lang, an beiden Enden rechtwinklig abgestutzt. Bei Neapel, z. B. im Lago d’Agnano.

\section{XXYl. GYROSIGMA HASSAL. (T. V.)}

Eine Navicula mit Sförmig gekı̈̈mmten Hauptseiten; anf den Nebenseiten linealisch-schlank-lanzettförmig, mit stumpfen oder zugerundeten Enden, meist ohne Endknoten. 
1. G. Hassallii Rabenh. (Navic. Sigma Ehrenbg.) (F. 1.) $\frac{10-15}{100}$ Mm. lang. schlank sförmig, mit abgerunteten Enden. anf den Nebenseiten sehnal lanzettförmig, simnut: Durelı ganz Europa rerbieitet.

2. (6. acuminata liabenh. (F. 5. a.) Selten ïber $\frac{6-7}{100}$ Mn. Iang, robust, zugespitzt strumpflich. Durch šanz Europa, Bogotá.

3. G. attenuata liabenh. (F. 2.) $\frac{5-18}{100}$ Mn. lang, $\frac{1-3}{100}$ Mu. Ineit, gegen die Euden

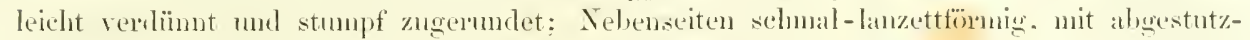
ten Enden. Dnreh Dentschlaurl, Frankieieh, Italien.

4. G. Hippocampus llassal. (F. 3.) $\frac{14-15}{100}$ Mn. lang, $\frac{3-4}{100}$ Mm. breit, lamzettlich zngespitzt, an ren Enden stumpf: Nebenseiten linealisch, nit stmupt zugerundeten Enden. Eigentlich Meerestrewohner, fiulet sich aber durch astuz Italien, sicilien und den benachbarten Inseln längs den Küsten in hagunen nur halbsalzigen Pfützen.

5. (r. Scalpellum Rabenh. (F. 10.) Gegen $-\frac{5-b}{100}$ Mun. lang, leicht gekrünut, an den Euden schwach verdïnnt und stump,f, olme Endknoten: Nebenseiten lineal-lanzettlich, stumpt'-abgestutzt. Antillen, $\beta$. persical, eine rerlängerte mul schlankere Form. im Salzsee - Nenek-Derja" hei schiras in sïdpersien.

6. G. (1urvala liabenh. (F. 8.) Lineal-lanzettlich, 4-8 Mus. lang, schlank, mit verdümnten, stumpfen Enden, auf den Nebenseiten lineal-lanzettlich, gestreckt. Durch ganz Enrola, in Amerika.

7. G. lamproeampa kabenh. (F. 9.) Schlank, lis $\frac{6}{100}$ Mn. lang, lineal-lanzettlich, mit stmupflichen Linden. Heeresbewohner: abel nicht selten in Brackwasser Norddentschlands.

8. (6. thuringica liabenl. (F. 4.) $\frac{8-10}{100}$ Mn. Ianğ, lanzettfürmig, zienlich scharf zugespitzt, in der Mitte wie eingeknickt. Im Śoolwasser bei Arten in Thin̈ngen.

9. G. a estuarii Bréb. Kleiner als G. thungica und nit geradem, nicht eingeknicktem Rande. Norifrankreich.

10. G. apula Rabenh. (F. 7.) $\frac{5-6}{100}$ Mm. lang, schlauk lanzettfömig. stark zuröckgekrïmmt, nit stumpliehen Enden: Nebenseiten breit linealisch. quergestreift, gegen die Enden verelümut mor ziemlich breit zugermudet. In ('apitanat (Ostitalien).

11. G. cuspidata líalienh. (F. 5. b.) $\frac{\text { s-10 }}{100}$ Nu. lang, schlank lanzettförmig, stark geklümms, mit lang zugespitzten, stumpflichen Enden. Europa, Amerika. Ist immer mit der acminata remiseht worlen.

12. G. Agellus (Ehrenbg.) mit zarten Längsstreifen. Salzburg.

13. (G. baltica (Ehrenbg.) (F. 6.) Breit linealisch, sehr gross, gerade, $\frac{20-25}{100}$ Mm. lang, kurz vor den verdünnten, stmmpf zugerundeten Enden gekrümmt. Meeresbewolncr: anch an der Küste des Arliatischen Meeres, z. B. in den Lagunen der terra di Otranto.

14. G. dubia Rabenh. $\frac{10-11}{100} \mathrm{Mm}$. lang, Störmig gekrümmt und um die eigene Axe gredreht. Bogotí. Scheint nur Bruchstïck zu sein.

\section{XXYI. STAURONEIS EHRENIGG. (T. IX.)}

Wie Novicula, aher statt des Mittelknotens eine (Querbinde.

1. St. Phoenicenteron Ehrenbg. (F. 1.) Von sehr rerschiedener Grösse $\left(\frac{8-20}{100} \mathrm{Mm}\right.$.) lanzettö̈mig, gegen die stumpfen Enden nach und nach rerdünnt, auf den 
Nebenseiten linealisch, mit fast rechtwinklig ahgestntzten Enlen. Durch ganz Europa umd Amerika: anch in sïdpersien.

2. St. lanceolata Ktz. (F. 9.) Bis $\frac{10}{100} \mathrm{Mm}$. lang, schlank lanzettfömig, mit stark rerdiunten, etwas vorgestreckten Enden. Frankreich, im Salzburgischen.

3. St. gratilis Elrenbg. (F. 2.) Kanm halb so gross als 2., schmal lanzettfömig. an den Enden breit abgestutzt. Amerika.

4. St. amphilepta Ehrenbg. (F. 7.) $\frac{5-6}{100}$ Mn. Iang, lanzettfömig, zugespitzt, mit stmmpfabgerumleten Enden. Chile, Bogotá, sachsen.

5. At. Baileyi Ehrenbg. Breit lanzettfömig, gross, mit leicht wellig gebogener ()berfläche, gegen die stmmpfen Enden nach nud nach verdïnnt. Sordamerika.

6. St. pteroidea Ehrenbg. Gross, heit - mol scharf lanzettförmig, mit zanten und punktirten Qnerstreifen, an den Enden stmmpf. Nordamerika.

7. St. stamophatena Ehrenbg. Lanzettëmigng, glatt, in der Mitte mit einer lichten, nicht domehgehenten Guerbinde, an den Enden etwas zusammengeschnürt und ziemlich spitz. Nordamerika.

S. St. Fenestra Ehrenbg. (F. 10.) Länglich, ghatt, an den keilförmig verdïnnten Enden gestntzt, am Sande mit parallelen Iimien. Cayenne.

9. St. linearis Ehrenbg. (F. S.) Wie die rorige, aber kleiner und nit fist schnabelfömigen Enden. In Amerika; anch in Dentschland.

10. St. exilis Ktz. (F. H1.) (iegen $\frac{1}{100}$ Mm. lang, batuchig, mit kurzrorgestreckten, fast kopffömigen Enden. Auf den Antillen; F. 6. von Bogotá.

11. Nt. phyllodes Ehrenbg. (F. 6.) Elliptisch-lanzettfömign, zngespitzt, nit spitzen Enden. Sïlameriki.

12. St. platystoma (Ehrenbg.) Ktz. (F. 2.) $\frac{5}{100}$ Mm. mul darïber lang. schmal lanzettlich, mit erweiterten, breit abgestutzten Enden. In Dentischland an mehrem Orten, Imerikiı.

13. Sit. amphicephala Kiz. (F. 12.) $\frac{4}{100} \mathrm{Mm}$. lang, lünglich, schlank, mit rorgezogenen. sehmabelfirmigen Enden. In Dentsehland. Frankreieh.

14. St. birostris (F. 13.) Schmal lanzettfömig, zugespitzt, mit schmabelförmigen, stmmptlichen Euden. Surinam, Mexiko.

15. Sit. anceps Ehrenbgr. (F. 14.) Lineal-lanzettlich, mit fast kopffömigen, gestutzten Enden. Cayeme, Californien.

16. St. monogramma Ehrenbg. Länglich, in der Mitte gedunsen, an den Enden zusammengeschmït, mit.gedunsenen und kopförmig zugerundeten Enden. Surinam.

17. St. Sieboldii Ehrenbg. Lanzettörnig, fast 6 mal länger als breit, mit langgestreekten, schmabelförmigen, stmmpfen Enden. In Japan.

18. St. acrocephala Rabenl. (F. 19.) $\frac{4-6}{100} \mathrm{Mm}$. lang, breit lanzettförmig, in der Mitte stark gedmsen, scharf zugespitzt, mit punktirten Querstreifen (10 auf $\frac{1}{100}$ Mm.). Siachsen.

19. St. polygramma Ehrenbg. (F. 18.) Elliptisch, mit stark erweiterter Querbinde, zugermudeten Enden md punktirten Längsstreifen. (uba.

20. St. lineolata Ehrenbg. (F. 17.) Elliptisch-lanzettfömig, mit stump,fen Enden md punktirten Längsstreifen. Cayenne.

21. St. inflata Ktz. (F. 15.) Kanm ïber $\frac{2}{100}$ Mn. lang, lïnglich, in der Mitte und an den breit zugerundeten Enden stark gedunsen. Anf den Antillen, Trinitat. 
22. St. ventricosa Kt\%. (F. 16.) Sehr klein, gegen $\frac{1}{100}-$ Mm. lang, in der Mitte stark bauchig gednusen, mit nicht durchgehender Qnerbinde; Enden stark eingesehnürt, kopfförnig. Bei Nordhansen, in sächsischen Erzgebirge, in Frankreich.

23. St. dilatata Ehrenbg. (F. 4.) Länghich, einmal länger als breit, an den Enden zusammengeschnürt, stumpf, kurz und breit zngernudet. Amerika.

24. St. constricta Ehrenbg. (F. 5.) Länglich, in der Mitte und gegen die rorgestreckten, stmmpfen Enden eingeschmürt. Chile.

\section{S'TAUROPTERA EHRENBG. ('T. IX.)}

Eine Stauroneis mit Querleisten.

1. St. aspera Ehrenbg. (F. 1.) $\frac{7-14}{100} \mathrm{Mm}$. lang, elliptisch-lanzettförmig, mit stmmpfen Enden; Querstreifen convergirend, mit spitzig-scharfen Punkten besetzt. In Frankreich F. c. nach Kü̈zing, dieselben anch in Piemont, Norwegen, Sipitzbergen, lsland, Amerika und den benachbarten Inseh.

2. St. A chuanthes Ehrenbg. (F. 2.) Schmal lanzettfömig, mit nach nnd nach verdünnten, stmmpfen Enden und convergirenden Qnerstreifen. Mexiko, New-Fomdland, in Frankreich.

3. St. Icostauron Ehrenbg. (F. 5.) Lünglich, fast elliptisch, mit wenig verdümnten, breit zugerumdeten Enden. Labrador.

4. St. cardinalis Ehrenbg. (F. 9.) Breit linealisch, an den Enden zugerundet; Querleisten wenig convergirend. In Amerika, Island.

5. St. parra Ehrenbg. (F. 6.) Lineal-lanzettlich, mehr oder minder schlank, an den Euden ger'undet-abgestutzt. Mexiko, Frankreich.

6. St. truncat a Rabenh. (F. 12.) $\frac{1}{100}$ Mm. und kanm darïber lang, lanzettlieh, mit abgestutzten knden; Querleisten fein gekörnt, convergirend, $14-15$ anf $\frac{1}{100}$ Mm. Unter Cladophora glomerata in Bosnien (v. Sendtner gesammelt).

7. St. microstauron Eluenbg. (F. 7.) Linealisch, vor den breit zugerundeten Euden eingeschnürt. Amerika.

8. St. pancicostata Rabenh. (F. 15.) $\frac{4-5}{100} \mathrm{Mm}$. lang, linealisch, in der Mitte stark, an den breit zugerundeten Enden schwach gedunsen: Querleisten entfernt, 4-.5 anf $\frac{1}{100}$ Mn., stark geneigt. Lichtenstein in Erzgebirge, nnter Fadenalgen.

9. St. gibba Ehreubg. (F. 3.) Linealiseh, in der Mitte und an den zugerundeten Enrlen gedunsen. Chile.

10. St. Legumen Ehrenbg. (F. 4.) Länglich-linealisch, dreiwellig, an den stumpfen Enden stark zusammengeschnürt. Chile.

11. St. macrocephala Ktz. Linealisch, schlank, unter den kopffömigen Enden zusammengeschürt, mit sehr dichten Querstreifen. In Frankreich.

12. St. dendrobates Ehrenbg. Schmal linealisch, an den Enden stumpf, am Rande mit dichten, schiefen Querstreifen; $\frac{1}{41} "$ lang. Auf Baumstämmen in den Urwäldern von Veneznela.

13. St. scalaris Ehrenbg. (F. 8.) Länglich-elliptisch, an den Enden germot, mit geraden, ziemlich entfernten Querleisten. Labrador.

14. St. Peckii Rabenh. (F. 13.) $\frac{2}{100}$ Mm. lang, kaum darïber, elliptisch-eiförmig, mit zugermndeten Enden; Querleisten dieht, 11-12 anf $\frac{1}{100} \mathrm{Mm}$. In der Lausitz. 
15. St. punctata Ktz. Breit lanzettörmig, $\frac{2}{100}-\mathrm{Mm}$. und darüber lang, ans der banchigen Mitte plïtzlich in die schlanken, schmabelförmig vorgestreckten Enden verlanfend: Querleisten punktirt-kuotig, 14-15 auf $\frac{1}{100} \mathrm{Mm}$. An dem Ufer der Tronto auf der östlichen Kïiste Italiens lebend, fossil im Bergmehl zn Santafiora.

16. St. coustricta Rabenl. (F. 10.) $\frac{3}{100} \mathrm{Mm}$. nnd dariber lang, breit linealisch, in der Mlitte buchtig zusammengezogen, an den Enden erweitert und breit zngerundet-gestutat: Querleisten convergirent, 8 anf $\frac{1}{100} \mathrm{Mm}$. In einem Bach bei Macerata (Italieni).

17. St. monogramma Ehrenbg. ist die gerippte Stamroneis monogramma, die anch der Achnanthes ventricosa ïhnlich ist. Amerika.

\section{S'TAUROGRAIIIA RABENH. (l. IX.)}

Eine Stauroneis mit starken, nach Innen vorspringenden linoten, die durch zarte streifen kreuzweise verbunden sind.

1. St. persicum Rahenh. Bis $\frac{5}{100}$ Mn. lang, grösste Breite $\frac{2}{100}$ Mm., ei-lanzettförmig, zugespitzt, aber gestutzt, mit breiter (Jner - nud etwas sehmälerer längsbinde. Siidpersien.

\section{FliU'TULLA AG. (T. V11.)}

Naviculae mit Längsrippe (auf den Hauptseiten), die in der Nilte unterbrochen ist, ohme Ccntralknoten, nistend in einer gestaltlosen Gallertmasse (Hüllmembran).

\section{a) ohne Streifen.}

1. F. torfaceal A. Brann in litt. c. jc. (F. 2.) $\frac{5-8}{100} \mathrm{Mm}$. lang, grösste Breite bis über $\frac{1}{100} \mathrm{Mm}$. nit stmmpfen, gerundeten Enden. $\ln$ Torfmon an Titisee, in Lachen an den Wämden und die Stengel und Wurzeln verschiedener Pflanzen, besonders der Menyanthes trifoliata, ïberzichend als schmutzig gelbliche, ziemlich feste, flache oder höckerige Gallertmasse.

2. F. saxonica liabenh. (F. 1.) Schlanker als die rorige, an den Enden der Hanptseiten mehr gespritzt: Nebenseiten linealisch, an den Enden breit zugerundet. Bildet schmutzig olivenbräunliche, zitternde Gallertmassen in kleinen Vertiefungen oder Höhlungen fenchtel Felsen in der sächsischen Shehweiz.

3. F. Hateckeriana Rabenh. (T. X. suppl. F. 14.) $\frac{1-1 \frac{1}{10}}{100}$ Mm. lang. spindelförnig, mit scharf zugespitzten Enden: Nehenseiten schmal lanzettlich, mit stumpfen knden. Bildet schmutzige Gallertklïmpchen an Moosen in einem Bach am Ratzeburger See, gesellig mit Cylindrospermum macrospermum. Mitgetheilt ron Herrn Apotheker R. Haecker in Läbeck.

4. F. Kïtzingiana liabenh. (Synedra nucicola Kitz.) (T. VII. F. 3.) 1 bis gegen $\frac{2}{100}$ Mm. lang, schmal lanzettlich, an den Enden abgestutzt. Anf Steinen in Bächen bei Nordhausen.

5. F. minuta Rabenh. (Synedra Frustulium Ktz.) (F. 4.) Kamm $\frac{1}{100}$ Mm. lang, schlank zugespitzt, mit stumpflichen Enden; Nebenseiten linealisch, mit abgestutzten Enden. Billet olivenbrame Gallertmassen an Steinen und andern Gegenständen in Bäehen. Dentschland, Italien. 
b) mit Querstreifen.

6. F. salina Ehrenbg. $\frac{1}{192}-\frac{1}{7^{2}}{ }^{\prime \prime}$ lang, sehw schmal linealiseh, scharf zugespitzt. Im Soolwasser bei Königsborn, anch in Thüringen.

\section{NAUNEMA EHRENBG. (T. VIl.)}

Eine Frustulia ınit sogenannter Deffnung in der Mitte. Die Gallerthülle gestaltet sich scheidenartig.

1. N. amphioxys Ehrenbg. (F. 1.) Lanzettfömig, scharf zugespitzt, glatt; Nebenseiten linealisch, reehtwinklig abgestutzt. Nexiko.

2. N. americannm Ehrenbg. Sehr gross, bis $\frac{1}{16}{ }^{\prime \prime}$, linealisch, mit ziemlich spitzen Enden; Querstreifen 18 anf $\frac{1}{96}{ }^{\prime \prime}$. Nordanerika in dem Hudsonfluss bei Westpoint.

\section{Xxivil. COLLeTONEMA BRÉB.}

Die Naviculae liegen in einer gestaltlosen Gallertmasse reihenweise. (Eine Abbildung ist uns nicht bekannt!)

1. C. viridnlum Bréb. Die Naviculae-Reihen bilden Spiralen. In Frankreich.

2. C. lacustre (Ag.) Ktz. Die Naviculae liegen in einfacher oder doppelter. Reihe. Im Mälarsee in Schweden.

3. C. eximinm (Thwaites) Ktz. Die Nariculae sitzen paarweise und schief anf einem Stiel und sind leicht Sförmig gekrïmmt.

\section{XXXYII. DHADESMIS KTZ. (T. IX.)}

Die Naviculae sind zu bandförmigen Fäden verbundeı.

1. D. confervacea Kitz. Lanzettförmig, glatt, an beiden Enden zugespitzt. Auf den Antillen und Trinitat.

Gleicht den Fragitarien, die Hauptseiten haben aber in der Mitte eine knotenförmige Verdickung.

\section{FAM. IX. SYNEDREAE.}

Panzer stab- oder nadelfürmig, bisweilen Sfïrmig gekrümmt, ohne Centralknoten, öfters mil durchgehenden oder in der Mitte unterbrochenen Querrippen oder Streifen; Nebenseiten meist genau linealisch; festsitzend und dann meist strahlig gruppirt oder frei und isolirt schwimmend.

Die Synedreen schliessen sich einerseits den Surirellen, anderseits den Navicnleen an: von beiden Formenreihen unterscheiden sie sich dureh ihren Grundtypus. Die klemern Formen, die bald den erstern, bald den letztern täuschend ähnlich sinł, unterscheiden sich von erstern durch den Mangel der Rippen oder Streifen, anch sind sie gewöhnlich festsitzend, während die Surrellen sich niemals ansetzen; von den Naviculis entfernen sie sich ganz besonders durch den Mangel des Centralknotens in den vordern Seiten. 
Viele Arten leben isolirt (wenigstens eine Zeit lang bis zmm Akt ihrer Theilung), sie tremen sich nach dem Theilmgsakte vollständig, viele jedoch setzen sich an, entwickeh einen stiel, der in den meisten Fällen mu eine polsterförmige, dicke, leicht gewölbte Unterlage bildet, nur in sehr vereinzelten Fällen wird diese Unterlage wirklich stielartig, sie verlängert sich. In beiden Fällen trägt der Stiel orler die Unterlage mehrere Individnen büschelartig, die mit ihner Basis eng verbunden, an den obern Enden strahlig anseinander weichen.

Wir kennen 106 Arten: 65 gehören dem siisswasser, 88 dem Meere an, , md 5 simd fossil gefunden. Einzehe Arten sind überall verbreitet, z. li. Syn. Uha lebt, wie die Meerbewohnenden $\mathrm{S}$. laevis und gracilis, unter allen Zonen: andere scheinen auf gewisse Lokalitätu beschü̈nt zu sein.

\section{SYNEDRA EIIRENBG. (T. IT. mu I.)}

Panzer prismatisch-rechtwinlilig, stabfïrmig, frei oder mit einem Ende angewaehsen; Ilauptseiten den Nebenseiten gleichgestaltig oder sclumäler und an den Enden gestutzt, stumpf oder spitz, glatl oder querrippig und dann gewöhnlich mit einem durchgehenden Lïngsstreifen gezeichnet.

Sie zertallen nach der Art und Weise ihres Anftretens in 4 Grmpen oder Untergattumgen, welche fïglich zu besonderen Gattmgen, gleich so vielen andern gleichwerthigen, erhoben werden können.

\section{a. SCAPULARIA KTZ. (T. IV.)}

Sehr kleine, freie oter aufgewachsene Formen, deren Haupt- und Nebenseiten ohne Rippen sind.

1. S. Atomus Naeg. (F. 32.) Aemserst klein. $\frac{1}{150}-\frac{1}{100}$ Mm. lang, Hauptseiten elliptiseh. mit grerumbeten Enden; Nebenseiten linealisch, gestutzt. Erzengt sich in Wassergefïssen, worin Wasser längere Zeit stelt: linclet sich awh in Freien zwischen Algen und ptlegt mit einer der Hanptseiten anfzuliegren: su sah anch A. Bram EntomostracaSchalen damit besetzt, mul sie kömte daher wohl anch eine Cocconeis sein.

‥ S. minntissima Ktz. (F. 33.) Selu klein, kamm $\frac{1}{100}$ Mm. lang, Hanptseiten lanzettförmig. stumpthich; Xelsenseiten sehr schms] linealisch. In Dentschland, Jtalien in stehendem Wasser. Ptïtzen, zumal muter Oscillarien.

3. S. pusilla litz. (F. 3t.) Gegen $\frac{1}{100}$ Mm. lang, lanzettlich, nit stmmpfen Enden; Tebenseiten lineal-länglich. Wie die vorigge.

4. S. perpusilla Kitz. (F. 35.) (regen $\frac{1}{100}$ Mm. lanğ, lanzettlieh, an den stmmpfen Euden zusammengeschnürt: Nebenseiten sehr sehmal linealisch. In hotanisehen Giurten zu Venedig.

5. S. ventricasa Rabenh. (F. 36.) $\frac{1}{200}$ Mn. lang. in der Mitte meist stark hanchig gedmsen, an den stmupten Enden stark znsammengeschnït; Nebenseiten schmal linealiseh, gestutzt. In Bäehen der Apenninen.

6. S. Biasolettiana Ktz. (F. 37.) Ders. ventrieosa ähnlich, aber mit gekrïmmten Nebenseiten. Bei Triest, mer Oscillarien.

7. S. acicularis Ktz. (F. 31.) $\frac{4-5}{100} \mathrm{Mm}$. lang, lineal-lanzettlich, mit sehr verlängerten, nadelfömigen Enden; Nebenseiten sehr schmal linealisch. Dureh ganz Europa.

8. S. angustata Kitz. (F. 80.) Kam über $\frac{2}{100} \mathrm{Mm}$. lang, länglich-lanzettfömig schmal-elliptisch, an den Enden stumptlich: Nebenseiten schmal linealisch. Unter verschiedenen Algen in den süssen Wässern Italiens. 


\section{b. ECHINELLA. (T. IV. und V.)}

Meist auf einem polsterförmigen oder stielförmig - verłängerten Fuss festsilzende und strahlig geordnete, öfters sichelförmig gekrümmte Formen, ohne (ouerrippen, ganz glatt; auf den Hauptseiten mit scharf zugespitzten oder stumpfen Enden.

9. S. palea Ktz. (F. 29.) Gegen $\frac{3}{100}$ Mm. lang, schmal lanzettlich, zugespitzt; Nebenseiten schunal linealisch. In Deutschland, den südlichen mo ötlichen Enropa, bei Bogotá in Amerika; in Meteorstaube und auf Dächern in Dresten.

10. S. dissipata Ktz. (fasciculata Ehrenbg.) (F. 38.) $\frac{1}{100}$ Mm. lang, schmal lanzettlich. In Dentschland, Frankreich, Italien, Bosnien. Lebt einzehn orler bïschlichstrahlig gruppirt.

11. S. fameliea Ktz. ist eine etwas grössere Form der S. dissipara. Wie jene dureh ganz Deutselıland.

12. S. parvula Ktz. (F. 39.) Bis $\frac{1}{100}$ Mm. lang, breit lanzettförmig, spitz. Gruppenweise anfsitzent, bisweilen anch frei schwinmend. Durch das mittlere, westliche und südliche Europa.

13. S. Fusidium Ktz. (F. 46.) Kaum iiber $\frac{1}{100}$ Mm. lang, schlank lanzettfömig, ziemlich spitz: Nebenseiten fast gleichgestaltig, linealisch, gegen die stmmpflichen Enden verdünnt. In Deutschland, Frankreich; erzeugt sich anch im Trinkwasser, wenn es einige Tage im Zimmer gestanden hat; anch in feuchten Moospolstern an Bämmen und auf Steinen, also wahrscheinlich auch im Meteorstaube.

14. S. fusidioides Rabenh. (F. 47.) Wie S. Fusidium, aber etwas robuster und anf den Nebenseiten an den Enden gestutzt. In Bächen und Gnellen, zmmal an Moos; anch auf Bäumen wiederholt und eimmal in dem stanbe anf dem 'Thurm des grossen Winterberges beobachtet.

15. S. radians Ktz. (F. 40.) $\frac{3-4}{100}$ Mn. laug, selı dicht zu strahligen Gruppen gehünt, linealisch, fast zugespitzt, auf den Nebenseiten (a) gestutzt. Durch ganz Europa.

16. S. gracilis Ktz. (F. 45.) $\frac{3-5}{100} \mathrm{Mm}$. lang, sehlank linzettfömig, seharf zugespitzt, auf den Vebenseiten an den Enden gestutzt. Ein Bewohner des Meeres, findet sich aber anch in dem Brackwasser der Küsten. F. 45. +. val. italica Rabenh., eine kräftigere, minder schlauke Form. In Lagunen der Ostkïste Italiens.

17. S. amplicephala Ktz. (F. 28.) $\frac{2-3}{100} \mathrm{Mm}$. lang, schlank, vor den kopfförmig erweiterten Enden zusammengeschü̈rt. In Dentschland, sïdpersien.

18. S. gracillima Rabenh. (F. 20. d. e.) Bis $-\frac{10}{100}$ Mn. lang, äusserst schlank und scharf zugespitzt. Dresden, in dem Schlamm der heissen Ablanfwässer bei der ,Trockne Ilefen-Fabrik"

19. S. subtilis Ktz. (Acus Eluenbg.) (F. 44.) $\frac{5-6}{100}$ Mm. lang, schlank lineallanzettlich. scharf zugespitzt; Sebenseiten an den Enden stumpflich-gestutzt. Im Soolgraben bei Artern in Thüringen, bei Dresden an Potamogeton erispus.

20. S. tenuissima Ktz. (T. V. F. 2.) $\frac{6-8}{100}$ Mm. lang, äusserst schlank und scharf zugespitzt. In Deutsehland und Frankreich. Sie ist für ein ungeübtes Ange selwwer und kaum von der S. gracillima zu unterseheiden, ilıe Enden sind jedoch länger ausgezogen und bei einer stets geringern Länge ist sie immer breiter als jene.

21. S. tenuis Ktz. (F. 3.) Bis $\frac{12}{100} \mathrm{Mm}$. lang, lineal-lanzettlich, nach und nach in die stumpflichen Enden verdünnt; Tebenseiten ziemlich breit, genau linealisch. Durch ganz Dentschland. 
22. S. Acula Kitz. (F. 1.) $\frac{18-24}{100} \mathrm{Mm}$. lang, scharf zugespitzt: Tebenseiten gegen die gestutzten buden leicht verdïnnt. Im südlichen und westlichen Enropa.

23. S. Laevis Ehrenbg. (T. IV. F. 43.) Bis $\frac{1}{10}$ Hn. lang. lanzettlich, gegen die gerundeten Enden leicht verdünt; Nebenseiten linealisch, gegen die gestutzten Enden meist verschmälert. Ein Meeresbewohner, aber anch in den Brackwasser der Küsten.

24. S. gibba Ehrenbg. ist in der Nitte stark gedmsen und lebt in büschligen Gruppen. In Nordameriki.

25. S. curvula Ktz. (T. V. F. 4.) Bogig gekrümnt, zngespitzt: Nebenseiten linealisch, an den stmmpf-gestutzten Enden leicht verdïnnt. b) punctata (F. F. 4. b.) mit einer lieihe punktförmiger linoteu. Bei Tordhausen.

26. S. alpina Naeg. Sehlank, sehr schmal lanzettförmig, gekrïmmt, mit kopfförmig vorgestreckten Enden: $\frac{1}{50}-\frac{1}{28} \cdot{ }^{\prime}$ lang. In der sichweiz.

27. S. subarenata Nateg. Wie die S. alpina, aber nur mol kaum halb so gross In der sichweiz.

28. S. alduata Naeg. Beiderseits linealiseh, die Hanptseiten bogig-gekrümmt und mit gerundeten Eurlen. In der Sehweiz.

29. S. Lunaris Ehrenbg. (T. V. F. 6.) Sichelfürmig gekrümmt, $\frac{5}{100}$ Mm. und darüber lang, mit verdünnten, stumptlichen Enden, anf einem polsterförnigen Fuss. Durch ganz Europa, bei Bogrotá in Amerika, in Nordafika.

30. s. bihunaris Ehrenbg. (F. 5.) $\frac{2-3}{100} \mathrm{Mm}$. dang, zweimal sichelförmig gekrümmt, mit stumpflichen Enden. Auf Conferven bei Berlin, in Sachsen, England.

31. S. falcata Ktz. et Bréb. Linealisch, gekrïmnt, am innern Raunde zweimal leicht wellenfömig gebogen; $\frac{1}{60}$ " lang. Bei Paris.

32. S. saxonica Ktz. ('T. IT. F. 13.) $\frac{4-7}{100}$ Mm. lang, lanzettförmig, mit stumpfen Enden, anf polsterförmigem sticke. In salzigen see bei Mansfelil.

33. S. Ehrenbergii litz. (T. T. F. 10.) Lineal-länglich. büschlig gehäuft an der Spitze eines verlängerten Stieles. Bei Berlin.

\section{c. ULNARIA KTZ.}

Aufgewachsen, Hauptseiten mit Querrippen, welche in der Mitte unterbrochen sind, bisweilen (scheinbar) durchgehen.

34. s. Ulna Ehreubg. (T. IV. F. 4.) $\frac{12-15}{100} \mathrm{Mm}$. lang, linealisch, an den Enden leicht verdümt und stmmpf-zugerundet, $11-12$ Querripren anf $\frac{1}{100}$ Mm.; Yebenseiten genan linealisch. Ueberall.

35. S. splendens Ktz. (F. 4. e. f.) unterscheidet sich nur durch die gegen ihre Enden erweiterten Nebenseiten.

36. S. danica Kitz. ist nur eine schlankere Form ron S. splendens. Alle drei Formen sind sehr verbreitet, sie finden sich durch ganz Europa, Amerika, Afrika, südpersien: im Passatstaube, anf Bäumen, Felsen und Bergspitzen.

37. S. mesocampa Bréb. ist anch eine S. Ulua, die Vitte anf den Hanptseiten ist aber etwas ansgeschweift.

38. S. a equalis Ktz. (F. 25.) Linealisch, an den Enden zusanmengeschnürt und zugerundet, $\frac{8-10}{100} \mathrm{Mm}$. lang: Nebensciten gegen die gestutzten Enden erweitert. Durch Dentschland. 
39. S. mesolepta Ktz. (T. V. F. 7.) Bis $\frac{1}{10} \mathrm{Mm}$. lang, schlank, gekrïmmt oder leicht Sförmig gekrümmt; Nebenseiten gegen die Enden etwas erweitert. Anf der Insel Trinitat.

40. S. amphirhynchus Ehrenbg. (F. 5. md 7.) Sehr gross, his $\frac{1}{1}$ Mur. lang, breit linealisch, an den Enden etwas zusammengeschü̈rt und stumpt, $9-11$ Querippen anf $\frac{1}{100}-\mathrm{Mm}$. In Dentschland, Italien, Frankreich. Amerika und Afriki.

41. S. acuta Ehrenbg. (F. 23. a-e.) $\frac{5-10}{100}$ Mn. lang, linealisch, an den Enden pötzlich zugespitzt, 8-9 Querippen anf $\frac{1}{100}$ Mu. In Californien, bei Bogotá, in Mexiko, Chile und Peru anfgefunden, wahrscheinhich durch ganz Amerika verbreitet: anf st. Kitts und in siidpersien.

42. S. oxylhyuchus Ktz. (F. 29. f. g.) ist ron S. aenta kum und uur durch die zusammengeschnürten Enden verschieden. In Dentschland.

43. S. vitrea Ktz. (F. 24.) schhiesst sich wieder durch die stark znsammengeschürten Enden der Hauptseiten an S. oxydyychus an. von der sie mur durch die an den Enden erweiterten Hauptseiten zn unterscheilen i.st. In Deutschland, Frankreich.

44. S. praturas Ehrenbg. (F. 19.) Linealisch, an den germdeten Enden keilförmig verdünnt; Nebenseiten an den Enden keilförnig nnd gestutzt. Mexiko.

45. s. lanceolata Ktz. (F. 14. und 18.) lineal-lanzettlich, nach mnd nach in die stumpflichen Enden verlaufend. Im Asphaltsee anf Trinitat.

46. S. debilis Ktz. (F. 26.) $\frac{2}{100} \mathrm{Mm}$. lang, limzettlich, mit stumpflichen, vorgestreckten Enden; Nebenseiten gegen die Enden leicht verdïnut und gestutzt. Durch ganz Europa.

47. S. porrecta Rabenh. (F. 27.) Gestreckt, schlank linealisch, bis über $\frac{2}{100}$ Mm. lang; Enden stark zusanmengeschnïrt und rorgestreckt; Nebenseiten fast wie bei s. debilis, mur schlanker. Südpersien (bei Gere).

48. S. notata Ktz. (F. 16.) - $-\frac{1}{100}$ bis gegen $\frac{2}{100}$ Mn. lang, schlank-elliptisch, mit fast gerundeten Enden, undentlich quergestreift; Nebenseiten länglich-quadratisch. In Dentschland, bei Stockhohm, in Holstein, Italien.

49. S. Vancheriae Ktz. (F. 15.) $\frac{1}{100}$ Mm. und darüher lang, lanzettlich, mit stark verdünnten und zugespitzten Enden; Nelenseiten genau linealisch. Durch ganz Europil.

50. S. capitata Ehrenbg. (F. 6.) $\frac{1}{8}-\frac{1}{5}$ Mu. lang. hinealisch, an den Euden kopfförnig erweitert, dreiseitig, stumpflich zugespitzt; Tebenseiten linealiseh, gegen die Enden fast mmerklich erweitert. Durch ganz Enroja.

51. S. longiceps Ehrenbg. Eine S. capitata mit stielförnig vorgestreckten Enden. In Nordamerika.

52. S. biceps Ktz. (T. V. F. 9. $\frac{1}{10}$ Mn. und daüiber lang, sichelförmigg gekrïnmt, nach um nach bis nuter die kopfförmig-erweiterten Euden verdünnt. $11-12$ Querrippen anf $\frac{1}{100} \mathrm{Mm}$.: Nebenseiten gegen die Enden erweitert. Varüt mit sehr stark gerlunsenen Enden (v. Arus) und anch mit ziemhich gestreckten Haupt- und fast genan linealischen Nebenseiten (r. recta). Durch Dentschland, Frankreich, die Schweiz, Oberitalien; auch fossil in der Lïnelumrer Heide.

53. S. valens Ehrenbg. (T. IV. F. 9.) Sehr gross, breit linealisch, an den Enden abgerundet, am Rande zart quergestreift. In Amerika.

54. S. scalaris Ehrenbgr. (F. 10.) Ëne S. valens mit breiterem Samm und gerippt. In Surinam und Kurdistan; auch fossil in Böhmen und Ungarn. 
55. S. spectabilis Ehrenbg. F. 8.) $\frac{8-10}{100}$ Mur. lang, linealisch, mit keilförmigen und gestutzten Enclen, 10 kräftigen Querstreifen anf $\frac{1}{100}-\mathrm{Mm}$. In Amerika, Italien, Siidpersien.

\section{d. TABULARIA KTZ.}

Durch unvollständige Theilung tafelfürmig verbunden, meist horizontal auf einem polsterfïmigen Fuss festsitzend.

56. S. parva Ktz. (F. 41.) Gegen $\frac{2}{100}$ Mm. lang, schmal lanzettförmig, glatt; Nebenseiten linealisch, an den Eulen gestutzt. In Brackwasser auf der Ostkïste Italiens.

57. S. pulchella (Ralfs) Ktz. (F. 17.) $\frac{3-4}{-100}$ Mm. lang, sehmal lanzettförmig: Nebenseiten gegen die gestutzten Enden nach und nach verschmälert. In England, Frankreich.

58. S. faniliaris litz. (F. 21.) Etwas grösser und schlanker, als die s. pulchella. In Frankreich.

59. S. socialis Rabenh. (F. 22.) $\frac{3-1}{100}$ Mm. lang, lanzettförmig, stmmpflich zngespitzt, quergestreift: Kebenseiten linealisch, an den gestutzten Enden keilfümig verdïnnt. Italien, anf Cladophora glomerata iu Gräben.

60. S. Acus K K. (F. 42.) $\frac{6-8}{100} \mathrm{Mm}$. lang, sehr schlank, nadelförmig zugespitzt, glatt; Nelsenseiten linealisch, gegen die gestntzten Enden verdünnt. Bei IJamburg: in Sachsen.

61. S. apiculata Rabenh. (F. 20. a.b.c.) $\frac{5-7}{100}$ Mm. lang, sehr sehlank, zart gestreift, linealisch nud an den Enden kurz zngespitzt. In Gräben und Tümpeln bei Dresden. 62. S. rumpens Kítz. (T. V. F. 8.) Klein, tafelförmig rerbunden, später anf Art der Gattung Diatoma sich lösend: 1lanptseiten schmal linealisch. an den Enden etwas gedunsen. Im Brackwasser (auf Wangerooge).

\section{SIGUATELLA KTZ. (T. IV.)}

Hauptseiten gerade, selten gekrümmt, mit durchgehenden Querrippen; Nebenseiten immer Sförmig gekrümmt.

$$
+ \text { Hauptseiten gekrümmt. }
$$

1. S. italica Rabenh. (F. 12.) $\frac{8-16}{100}$ Mm. lang, breit linealisch, leicht sförmig gekrïmmt, 9 Qnerrippen ant $-\frac{1}{j 00}-11 n$. In den Tïmpeln bei Sam ('ataldo moveit Lecte in der terra di Otranto.

2. S. vernicularis $\mathrm{K} t z$. (F. 3.) $\frac{6-8}{100} \mathrm{Mm}$. lang, schmal linealisch, glatt, an den Enden gestutzt. In Dentschland, Frankreich.

$\div+$ Haptseiten gestreckt gerade.

3. S. Nitzschii Kitz. (F. 1.) $\frac{1}{20}-\frac{1}{5}$ Mm. lang, gegen die stmmpflichen Enden nach und nach verdïnnt, 9 Querriplen auf $\frac{1}{100}$ Mm. Durch ganz Europa.

4. S. Brébissonii Kitz. (F. 2.) Bis $\frac{1}{10}$ Mm. lang, linealisel, an den Enden plötzlich stumptlich zugespitzt, 6 Querrippen anf $\frac{1}{100} \mathrm{Mm}$. In Frankreich bei Falaise.

5. S. tergestina Rabenh. (F. 12.) $\frac{8-12}{100} \mathrm{Mm}$. lang, linealisch, an den Enden zusammengeschnürt und stmmpflich, 11 Qnerrippen auf- $\frac{1}{100} \mathrm{Mm}$. Bei Triest, Vercelli, Ancona; auch in Frankreich. 


\section{FAM. X. GOMPHONEMEAE.}

Panzer länglich-keilförmig, an obern Ende sehr verschieden gestaltig, із ('entrum mit einer knotenförmigen Verdiekung; Nebenseiten meist genau keillïrnig, an der liasis stumpf oder abgerundet, oben geradtinig ibgestutat und zweiknolig; stiellos oder gestielt.

Die Gomphonemeen sind durch ihre keilförmige Gestalt sehr leicht zu erkennen und stehen als solche unter den Sïsswasser-Bewolnern fast isolirt da. Eine gleiche Gestalt besitzen nur die Merilieen, die sich aber durch ihre Entwicklung zu spiraligen Bändern leicht unterscheiden. Trift' man die Individnen isolint, so ist es schwieriger': man kam dann die Gomphonemeen nur an dem Centralkuoten erkemen. der den Meridieen fehlt. Im Meere kommt eine Gruppe vor. limophoreen genannt, deren Gestalt und Entwicklung den Gomphonemeen filst ganz gleich ist, sie besitzen aber keinen (entralknoten und haben Längsstriemen.

Die isolirt und anseheinend nackt lebenden Arten hat Kürzing als besondere Gattung getrennt und Sphenella genamnt. Die Gattung Gomphonema entwickelt einen Sticl auf dieselbe Weise, wie die Cymbellen, welcher je nach seiner ungestörten Entwicklung regelmässig oder unregelmässig, einfach oder wiederholt tichotom erscheint. Derselbe schwindet aber oder löst sich früher oder später, zum Herbst allemal, anf, die Individuen sint dann auch stiellos, und es ist alsdann fraglich, wohin sie gehören. Wollte man ganz consequent verfahren, so mïssten die Formen der Gattung Gomphomema auch als Sphenellen aufgefïhrt werden. Wir glauben aber, es wird genügen, hier wenigstens darauf aufmerksam gemacht zu haben.

Die dritte Gattung Gomphonella haben wir anfgestellt. Sie entwickelt ausser dem äusserst zarten Stiel noch so viel Hüllmembran, dass die Individuen wie die Frustulien haufenweise daron umhïllt sind und wie jene kleine, abgeschlossene Colonien bilden. Die Ehrenherg'sche Gattung Sphenosira entwickelt keinen Stiel, die Individuen bleiben durch unvollkommene Theilung in bandförmigen Fäden verbunden; ihre Nebenseiten sind anch nicht keilförnig und nur ihre Hauptseiten tragen den Charakter der Gomphonemeen.

Als Fortpflanzungsweise ist nur die einfiche Theilnng mit Sicherbeit bekannt; wahrscheinlich erfolgt sie auch durch Copulation, doch sind die Beobachtungen noch nicht constatirt.

Die Gomphonemeen leben fast alle im sïssen Wasser: von etwa 58 Arten (einige sind noch zweifelhaft) gehören nur 6 dem Meere an und 8 hat man fossil gefunden. Die meisten Arten sind unter allen Zonen gleichmässig vertheilt, nur wenige Arten und die Gattung Sphenosira sind bisher nur unter den Tropen gefunden worden und scheinen ihnen ansschliesslich anzugehören.

\section{SPHENELLA KTZ. ('T. VIII.)}

Schliesst die freien, stiellosen, nicht an- und aufgewachsenen Formen ein, deren Hauptseiten lanzettlich, deren Yebenseiten genau keilförmig sind.

1. Sph. obtusata Ktz. (F. 1.) Ueber $\frac{1}{100} \mathrm{Mm}$. lang, fast verkehrt ei-lanzettförmig; an den Enden gerundet, ganz glatt. In Gräben in Thüringen, Sachsen, bei Driesen in der Neumark. 
2. S. italicar Rabenh. (F. 8.) $\frac{1}{100}$ Mm. lamg, verkehrt eiförmig, oben breit zugermete, menten verschnälert, stmmpf, undentlich gekörnt oder gestreift. Unter Conferven bei Ancona (Ostkiiste Italiens). Ist wahrschenlich ein echtes Gomphonema, dessen Stiel geschwumlen ist.

3. s. rostellata Ktz. (F. 2.) Kaum $\frac{1}{100}$ Mm. lang, in Uer Mitte erweitert, gegen die Enden selnabelfürmig verschmälert, stmmpf. In Thïringen, Saehsen.

4. S. elongata Kt\% $\frac{2-3}{100} \mathrm{Mm}$. lang, ans erweiterter Mitte in die schlanken, schnabelförmigen Enden verlanfend; Nebenseiten schlank keilförmig. Thüringen.

5. S. vulgaris Kitz. (F. 4.) Bis $\frac{1}{100}$ Mm. lang, kam darüber, in der Mitte banchig erweitert, an den stmm,flich-gestutzten Enden stark verschmälert, änsserst zart gestreift. Durch ganz Deutsehlaud, Frankreich.

6. ‥ gla cialis Ktz. (F. 5.) Gegen $\frac{1}{100}$ Mn. lang, lanzettlich, mit ziemlich spitzen Enden, sehr zart gestreift. In (iletscherbächen.

7. S. angustata Kt\%. (F. 6.) Veist füchelförmig verbunden, lanzettlich, am obern Encle stumpf zugerundet, am untern stmmpflich: Nebenseiten seln schmal, lineal-keilförmig. Dureh Deutschland.

8. S. parvula Ktz. (F. 7.) Bis $\frac{1}{100}$ Mm. lang, glatt, lanzettförmig, zugespitzt und am Ende leicht kopfförmig gedunsen. Olme Ansicht der keilförmigen Tebenseiten von gewissen Navienlis nicht zu mterscheiden. In Frankreich, bei Bogotá in Amerika.

\section{GOMPHONEMA AG. (T. VIII.)}

Die Individuen sitzen auf einem einfachen, meist aber regehmïssigr dichotom - getheilten Stiele.

1. G. sphenelloides liabenh. (F. 1.) Ueber $\frac{1}{100}-M m$. ling, rerkehrt ei-lanzettfömigg, glatt, am obern Emle breit zugerundet: Nebenseiten keilförmig, stmmpfeekig gestutzt; Stiel einfich, stark. lion (bei Ariccio).

2. G. micropus Ktz. (F. 6.) Fast wie G. sphenelloiles, aber kleiner und schlanker: Stiel zart, dïm, bisweilen fadenförmig verlïngert und getheilt. In Dentschland, Frankreich.

3. G. tenellum Kitz. (F. 5.) $\frac{1}{200}$ Mm. lang, glatt, verkehrt ei-lanzettförmig, bisweilen fächelfömig rerbunden: Stiel mehr oder minder deutlich und entwickelt. Durch ganz Dentschland, Oberitalien, Frankreich, Schweden: bei Bogrotá in Amerika.

4. G. rotundatum Ehrenbg. (F. 17.) Bis $\frac{2}{100}$ Mm. lang, verkehrt eiförmig, oben breit zugermudet, gestreift (F.e.); Nebenseiten breit keilfömig; Stiel verlüngert dichotom. In südöstlichen liussland 1829 von Ehrenberg entdeckt, seheint dureh ganz Europa verbreitet: von Bogotá erhielten wir es lurch Herrn Lindig.

5. G. abbreviatum Ag. (F. 20.) So gross wie G. rotundatum, aber schlanker und ganz glatt, oft auch fächelförmig verbunden, bald anf knrzem dicken, bald anf verlängertem, schlankem und getheiltem Stiele. Durch ganz Europa.

6. G. pulvinatum A. Branu in litt. e. icone. (F. 16.) Bis $\frac{2}{100}$ Mm. lang, mach oben wenig verbreitert, an der Basis sehmäler als der sehr dicke, geschlïngelte, hie ınd da zweitheilige Stiel. Bildet kleine, sehr dichte Polster, scheinbar glatte Hügelehen, in dem alle Köpfe gleich hoch sink. Im Sihlwalde bei Zïrich, im septenber 1850.

7. G. clavatum Ehrenbg. (F. 23.) Länglich-kenlig, $\frac{1}{100} \mathrm{Mm}$. lang, zart quergestreift. Dureh ganz Euroja; auch fossil im Kieselguhr zu Franzensbad, im Bergmehl zil Santafiora. 
8. G. discolor Ehreubg. (F. 21.) Bis $\frac{1}{100}$ Mm. lang, schlank keilförnig, glatt, am obern Ende etwas ansgeschnitten. Durch Europa, in sibirien, Amerika.

9. G. erosum Rabenh. (T. X. suppl. F. 12.) Bis $\frac{2}{100} \mathrm{Mm}$. lang, länglich-eiförnig, mit gestutztem, ansgerandetem obern Encle; Tebenseiten schlank keilförmig; Stiel schön dichotom verzweigt. Un Dresden.

10. G. persicum Rabenh. (T. VIII. F. 4.) $\frac{3}{100}$ Mn. lang, gegen $\frac{1}{100} \mathrm{Mm}$. breit, verkehrt eiförmig, breit zngerundet, qnergestreift; Nebenseiten breit keilförmig. Bei schiras in Sïdpersien.

11. G. curvatum litz. (F. 18.) $\frac{11 / 2-4}{100}$ Mn. lang, verkehrt-ei-lanzettförmig: Nebenseiten keilförmig, gekrümut. Durch ganz Europa, Amerika, Nordafrika.

12. (G. crassum Rabenh. (T. X. suppl. F. 13.) Bis $\frac{5}{100}$ Mm. lang. grösste lireite $\frac{2}{100}$ Mn., dick keilförmig, oben gestutzt. nuten abgermdet, an Rande zart quergestreift. Sïdpersien.

13. G. hereynicum Rabenh. (T. VIll. F. 28.) Bis $\frac{4}{100}$ Mm. lang, nach oben und unten keilförmig rerschmïlert, stumpf abgerundet, quergestreift. Bei Ballenstedt im Harz, durch Herru Peck.

14. G. gracile Ehrenbg. (F. 26.) - -300 Mm. lang, selten darüber, lanzettförnig, schlank, an den Enden stumpf, mit zarten Querstreifen. Meist auf schön entwickeltem, dichotom getheiltem Stiele: fundet sich anch stiellos, durch ganz Europa, Anerika. Bildet brännliche Schleimüberzüge an Wasserpflanzen. Auch im Meteorstanbe.

15. G. anritum A. Braun in litt. c. ic. (F. 3.) $\frac{2-3 \frac{1}{2}}{100} \mathrm{Mm}$. lang, lanzettförmig, an den Enden stumpf, olne Querstreifen; Nebenseiten breit keilförnig, an der Basis abgerundet, oben gestntzt und an den Ecken mit wasserhellen, gallertartigen, leicht biegsamen, hormartigen Spitzen. Gestielt oder stiellos. Baden, in Titisee auf Nuphar spennerianum; anf Myriophyllum alternifolinm: in Wiesengräben bei Giessen. NB. F. c. sah ans, als sei es oben offen, wahrscheinlich aber mor optische 'Täuschung.

16. G. lanceolatum Ehrenbg. (F. 10.) Lanzettförmig, zugespitzt, stmmpflich, gestreift: Nebenseiten schlank keilförmig. Amerika.

17. G. affine Ktz. (F. 11.) Schlanker als G. lanceolatum, kaum specifisch rerschieden. Auf der Insel Trinitat.

18. (․ Vibrio Ehrenbg. (F. 9.) Schlank, lineal-lanzettförmig, nach und nach in die stumpfen Enden verdünnt. Amerika: anch im Neteorstanbe.

19. G. Cygnus Ehrenbg. Schmal lineal-lanzettlich, in der Nitte gedunsen, mit verlängertem stumpfen Kopfende. Nordamerika.

20. G. cuspidatum Rabenh. (F. 22.) Kraum über $\frac{1}{100} \mathrm{Hm}$. lang, ei-lanzettförnig, scharf zugespitzt, glatt: Tebenseiten keilförmig, öfters leicht gekrümmt; mit und ohne stiel. Bildet einen olivenbräunlichen Ueberzug an Wasserpflanizen bei Moritzburg in Sachsen.

21. (i. intricatun Kitz. (F. 27.) Linealisch, mit stark gedunsener Witte, gestreift, an den Enden stmmpf: Stiele verschlmngen. Bildet feste Schleinüberzïge an fenchten Gypsfelsen bei Nordhansen.

2.2. (G. Lageunla Ktz. (F. 24.) Gegen $\frac{2}{100}$ Mm. lang, schlank-keilförmig, gestreift, mit einem stumpfen kopfförmigen Ende. In Frankreich, anf den Antillen, im Niagara: auch fossil.

23. (i. cristatum Ralfs (F. 19. a. b. c. e.) $\frac{3-4}{100}$ Mn. lang. gegen das obere Ende 
sehr erweitert und mit einem (gleichsam) anfgesetzten Spitzchen gekrönt. In England, Sachsen (F. e.): fossil in Frankreich.

24. (i. Augur Ehrenlig. (F. 19. d.) Schlanker und mit schärferer spitze, als G. cristatum. In Amerika.

25. fr. nasutum Ehrenbg. Kürzer mul gedrungener, als G. Angur, eiförnig, mit einem kleinen anfgesetzten Spitzehen. New-York.

26. (․ geminatum Ag. (herenleamum Ehrenbgg.) (F. 14.) $\frac{6-5}{100}$ Mm. lang, gestreift, in der Mitte stark gedmsen, vor dem obern und untern Ende zusammengeschnürt, an beiden breit zugernudet. Auf Steinen in den Appächen Seandinaviens, Sehottlands, Irlands: in Oregonien, im see mitehigan", im Niagara in Amerika.

27. (1. gigantenm Ehrenbg. Grösser als (x. genmatum, lanzettförnig, in der Mitte stark gedunsen, ziemlich spitz, am obern Ende etwas spitzer als an der Basis. In Californien.

28. (․ anglienm Ehrenbg. (F. 2.) Längliels, gestreift, vor dem obern, kopfförmig zngerundeten Ende znsammengesehnïrt, gegen die Basis linealisch, stielfürnig verschmälert. In Jrland, Mexiko.

29. (6. subtile Ehrenbg. Schlank, durch einen dïnn verlängerten Hals in einen kleinen stmmpfen, fast gestutzten kopf erweitert. In Nordamerika.

30. G. capitatnm Ehrenbg. (F. 15.) $\frac{3-8}{\frac{3-8}{100}}$ Mrn. lang, gestreift, verkehrt ei-lanzettförmig, in der Mitte erweitert, gegen die Basis stielfürnig verdïnnt, an obern Ende rerschmälert, etwas vorgestreckt und breit zugermulet. In Dentschland, Frankreich, Italien, hei Bogotí in Amerika: anch fossil.

31. (4. constrictum Ehrenbg. (F. 12.) $\frac{3-4}{100}$ Mn. lang, gestreift, ans breiter Nitte gegen die Basis keilfömig verschn̈̈lert, vor dem breiten, fast gestutzten obern Ende eingeschnïr. Inrch ganz Emopa, Sïdpersien: anch fossil in Böhmen und Italien.

32. (i. acuminatum Elureubg. (F. 13.) - $\frac{4-5}{100} \mathrm{Mm}$. lang, gestreift, mehr oder minder schlank, gegen die Basis stielförnig verdïnnt, ïber der gedmsenen Mlitte stark eingeschnürt, daranf knpförmig erweitert und in ein zugespitztes Ende verlanfent. Durch ganz Europa, Amerika; anch fossil.

33. G. Brebissonii Ktz. Schlank, gestreift, $\frac{1}{35}$ “' lang. in der Mitte banchig, gegen die Basi: verdünnt, oberhalb ler Nitte zusinmengeschnïrt, mit keilförmig verdïnntem, stımpflichen Kopfe. Frankreich.

34. (i. coronatum Ehrenhg. (F. 7.) Schlank, grestreift, in der Mitte banchig, ïber und nnter dersellen leicht eingeschnïrt, gegen die Basis kolbig verdickt, am obern Ende herzörmig erweitert und mit vortretender spitze. In Nordamerika: fossil in ltalien.

35. G. Sceptrum Rabenh. (F. 8.) Fast wie G. coronatum, aber grösser und robuster, die Mitte stärker gedunsen, der Kopf nehr erweitert und die Basis nicht kolbig, sondern verdïnnt, fist zugespitzt. Lebend bei Bogotá in Amerikit.

36. G. laticeps Ehrenbg. Wie G. coronatum, aber kürzer und der Kopt stärker erweitert, als die Mitte. Auf Island.

37. G.? contractum ktz. (F. 25.) Sehr klein, in der Mitte zusammengeschnïrt, gegen die Basis rerdümnt, nach oben sehr elweitert und breit zugermulet. Bei Aschersleben am Harz. 


\section{XliI. GOMPHONELLA RABENH. (T. IX.)}

Eine gestielte Gomphonema in einer gestaltlosen fallertmasse.

1. (. olivacea Rabenh. (F. 1.) Bis $\frac{2}{100}$ Mm. lang, verkehrt- eiförmig-lanzettlich: Nebenseiten breit keilförmig, an Rande mit zarten Querstreifen. Durch ganz Europa. 2. G. angusta Rabenh. (F. 2.) Bis $\frac{11 / 2}{100} \mathrm{Nm}$. lang und stets schmäler als die vorige. Dureh ganz Europa.

3. (4. Lenormandi Rabenl. (F. 3.) $\frac{1}{100}$ Mm. lang, lanzettlich-spitz: Nebenseiten linealisch, fast keilförmig, glatt, an den Enden gestutzt. In Frankreich.

4. G. parvula Rabenl. Wie Sphenella parvula (T. VIII. F. 7.), gestielt und in einer Schleimmasse. In Dentschland, Frankreich.

\section{SPHENOSIRA EHRENBG. (T. VIJI.)}

Verkehrt ei-lanzettförmig, nach dem einen Ende keilfürmig versehmälert, an andern kopffïrmig zusammengeschnürt, durch unvollkommene Theilung zu bandfürmigen, biconvexen Fäden verbunden.

S. Catena Ehrenbg. ln Mexiko.

\section{FAM. XI. MERIDIEAE.}

Panzer länglich, plati, nit durehgehenden Querrippen, gegen die Basis keilförmig versehmälert, oben meist abgerundet, auf den Nebenseiten keilförmig. Einzeln oder zu Fäden verbunden.

Wie wir schon bei den Gomphonemeen bemerkt laben, herrscht in Bezug auf Gestalt unter beiden Familien grosse Verwandtschaft. Die Meridieen miterscheiden sich ansser den durehgehenden Querrippen, welche bei jenen weit zarter und in der Mitte nuterbrochen sind, besonders dureh ilnre Entwicklung zu bandförmigen Fäden, welche sich spiralig horizontal oder tutenfürmig vertikal einrollen. Diese Erscheinumg ist eine natïrliche Folge ilırer keilförnigen Gestalt und der unvollkommenen Theilung. So wie die Individuen familienweise sich rertikal erheben, so pflegt in der Regeł an der Basis sich ein polsterförmiger Fuss zu bilden, der für die ganzen Generationen als eine allgemeine Unterlage dient. Bisher ist diese lirscheimung nur bei M. constrictum beobachtet.

Diese Fanilie ist mur durch 5 Arten reprësentirt, die alle in Europa zu Hause sind. M. circulare ist die einzige, die wir anch ans Amerika und Südpersien besitzen. Im Meere hat man bisher noch keine gefunden.

\section{ONCOSPHENIA EHRENBG.}

Isolirt lebend, mit uugleichen Enden; am obern kopfförmig gerundet, an der Basis keilförmig verdünnt und lakenförmig.

1. O. carpathica Ehrenbg. $\frac{1}{66}$ “' lang, mit 11 Querrippen. In den Karpathen. 


\section{XIVI. MERIDION AG. (T. I.)}

Fächelförnig verbunden und spiralige Bänder darstellend.

1. M. circulare Ag. (F. 1.) Von sehr verschiedener Grösse, $\frac{1-4}{100}$ Mm. lang, verkehrt ei-lanzettfömigr (keilförmig), oben unł unten zugerundet; Nebenseiten ohne Striemen, am Rande gezahnt. Durch ganz Europa, Amerika, Südpersien.

2. M. Zinckeni Ktz. (F. 3.) Dem vorigen ähnlich, die Nebenseiten haben aber gebogene Striemen. In Dentschland.

3. M. constrictum Ralfs. (F. 2.) Hauptseiten unter dem obern Ende kopfförmig eingeschnïrt; Nebenseiten an der Basis sehr verschmälert und dadurch bisweilen tutenförmig sich eimrollend, damn mit der Basis sich ansetzend und einen gelatinösen Stiel entwickehud. Durch ganz Euroja.

4.? M. pandnriforme Ehrenbg. (F. 4.) Fast geigen-keilfömig, mit zugespitztem obern Enke. Eine zweifellafte, nicht genügend erkannte Form, die Ehrenberg in der Iset bei Catharinenburg im Ural Asiens 1829 fand, aber schon $18: 7$ bei Berlin beobachtet zu haben angiebt.

\section{FAM. XII. 'TABELLARIEAE.}

Pauzer linealisch, in der Nitle und an beiden Enden bauchig aufgetrieben und dadurch dreiknolig; Nebenseiten schmal- oder breit-tafelfürmig, nnit durchgehenden oder in der llitte unterbrochenen Längs- oder Querstriemen. Einzeln oder in bandförmigen Fäden, die sich zickzachförmig auflüsen.

Wir nehmen diese Familie nicht im Sinne Küitzing's. weleher Antor anch die meerbewohnende Grammatophora hierherzieht, eine Formenreihe, die weit davon versehierlen ist, sondern zählen mu und aussehliesslich diejenigen hierher, deren Hauptseiten rhureh drei Verdickungen ilreiknotig erscheinen und deren Centralknoten einen trichterförnigen Eindruck zeigt, welehen die Antoren mit Oeffung bezeichnen. Die Nebenseiten sind quadratisch: bei 'Tabellaria bald länger bald kürzer, bald breiter bald schnäler', erreichen aber" niemals die eigentliehe Tafelform, wie sie Tetracyelus, zumal aber Terpsinoë zeigt. Für diese Gattungen bieten die Striemen rler Tebenseiten die wesentlichsten Charaktere: sie sind entweder schmal linealisch, fast rinnenförmig und versehwinden gegen lie Mitte, so bei Tabellaria: sie gehen durch, so bei Tetracyelus: oder sie sind gegen die Mitte seitwärts gekrïmmt und kenlig verdickt, bei Terpsinoë.

In Betracht der Nebenseiten wïrde mol müsste sich die nene Bram'sche Gattung Gamphogramma hier anschliessen, doch sind ihre Hauptseiten zu wesentlich rerschieden.

Die Fortptlanzung der Tabellarien geschieht durch einfache Theihug. Sie leben frei orter entwiekeln einen gelatinösen Stiel, mit dem sie sich ansetzen. Ihre Theilung ist meist unvollkommen: Tetracychs bleibt in Bändern verbunden, Tabellaria nnd Terpsinoë bleiben nach der Theilung hurch Hüllmembran an einer der Ecken, gewïhnlich abwechsehd verbunden und bilden so zickzackförmige Fäden. 
Diese Familie ist im süssen Wasser nur durch 5 Glieder repräsentirt, eine grössere Zahl gehört dem Neere ansschliesslich an, und eine noch grössere (27) kommt nur fossil vor.

\section{ILVII. TETRACYCLUS RALFS. (T', IX.)}

Nehenseiten breit tafelfürmig, mit durchgehenden Striemen.

1. T. lacustris Ralfs. In stehenden Wässern Englands, Islands.

\section{TABELLARIA EHRENBG. (T. X.)}

Nebenseiten schmal talelförmig, mit unterbrochenen Striemen. lie zu Bändern verbundenen Individuen trennen sich, bleiben aber durch die llüllmembran an den Ecken verbunden und bilden so zickzackförmige Füden.

1. T. fenestrata Kitz. (F. 1.) $\frac{3-4}{100}$ Mm. lang, schlank, mit genau gegenüberstehenden Striemen. Durch gauz Europ) gemein.

2. T. floceulosa (Roth) Kt\%. (F. 2.) $\frac{1-2}{100}$ Mm. lang, länglich oder quadratisch, mit abwechselnden Striemen. Dureh ganz Europa, Amerika; auch anf Bämmen in den Urwäldern ron Venezuela.

3. T. ventricosa Ktz. (F. 5.) Wie T. floceulosa, aber in der Mitte weit stärker gedunsen, als an den Enden. In Frankreich.

NB. Die von Ehrenberg noch als lebend anfigeführten Arten, wie T. sculpta, laevis, Taenia, bleiben zweifelhaft und sind nach dem von E. selbst gegebenen Gattungsbegriff keinen Falls Tabellarien.

\section{TERPSINOË EHRENBG. (T. X.)}

Nebensciten breit und gross tafelfürmig, mit unterbrochenen, nach Innen keulig verdickten striemen.

Die Gattung erimnert lebhaft an Gomphogramma, sie unterseheidet sich aber dureh die Gestalt der Hauptseiten sehr wesentlich; zu dem kommt, dass Terpsinoë sich zwar vollkommen theilt, aber durch Hüllmembran, welche ein Zwischenglied bildet, an den Ecken abwechselnd verbunden bleibt.

T. musica Ehrenbg. Nebenseiten sehr feinknotig-punktirt. Die einzige bekannte Art lebt im tropischen Anrerika. 


\section{RECAPITULATION.}

\begin{tabular}{|c|c|c|c|c|}
\hline \multirow{2}{*}{$\begin{array}{l}\text { Nane } \\
\text { der Fanilien. }\end{array}$} & \multicolumn{2}{|c|}{$\begin{array}{c}\text { Zahl der lebend } \\
\text { beobachteten Arten im }\end{array}$} & \multirow{2}{*}{$\begin{array}{l}\text { Sind fossil } \\
\text { gefunden. }\end{array}$} & \multirow{2}{*}{$\begin{array}{c}\text { Summa } \\
\text { der bekannten Arten. }\end{array}$} \\
\hline & Süsswasser. & Meere. & & \\
\hline I. Melosireae .. & 31 & 37 & 89 & 163 \\
\hline II. Eunotieae. . . & 69 & 4 & 42 & 95 \\
\hline III. Cymbelleae. . & 40 & 4 & 9 & 43 \\
\hline IV. Achnantheae. & 8 & 11 & 1 & 19 \\
\hline V. Cocconeideae. & 14 & 20 & 6 & 38 \\
\hline VI. Snrirelleae . . & 43 & 34 & 15 & 92 \\
\hline VIl. Fragilarieate. . & 38 & 8 & 33 & 76 \\
\hline VIIl. Naviculaceae. & 216 & 131 & 37 & 383 \\
\hline IX. Synedreac . . & 65 & 38 & 5 & 106 \\
\hline X. Gomphonemeae & 50 & 6 & 8 & 58 \\
\hline XI. Meridieze. . . & 5 & 0 & 0 & 5 \\
\hline X11. Tabellarieae . & 5 & $1 j$ & 27 & 46 \\
\hline Summa & 582 & 308 & 272 & 1124 \\
\hline Licmophoreae . . & 0 & 34 & 2 & 35 \\
\hline Striatelleae ... & 0 & 10 & 0 & 10 \\
\hline C'oscinodisceae . . & 0 & 96 & $6 ?$ & 126 \\
\hline Anguliferae... & 0 & 4 & 3 & 6 \\
\hline Eupodiseeae . . . & 0 & 34 & 8 & 42 \\
\hline Augnlatae .... & 0 & 47 & 36 & 76 \\
\hline Summa Summarum & 582 & 533 & 383 & 1419 \\
\hline
\end{tabular}




\section{SYNONYMEN-REGISTER.}

Achnanthes adnata Bory Dict. cl.: Achnanthes brevipes. - arcuata Kítz. Synops. Diat. (Linn. 1833): Rhabdonema marit.).

- bacillarioides Bory Dict. cl.: Achnanthes brevipes.

- bijuga Turpin mémoir. du Mus. d'hist. nat.: Scenodesmus (Desmidiee).

- bilunata Turpin 1. 1.: (Desmidiee).

- dimorpha Turpin 1. 1.: (Desmidiee).

- dubia Bory Dict. cl.: Achnantbes brevipes.

- Leibleini Ag. Consp. Diat.: Achnanthes exilis.

- macropus Ktz. in litt.: Achnanthes Carmichaelii (marit).

- multiarticulata Ag. Consp. Diat.: Achnanthes brevipes.

- obliqua Turpin mémoir. du Mus. d'hist, nat.: (Desmidiee).

- octalterna Turpin 1. 1.: (Desmidiee).

- parvula Ktz. Act. 1836: Hyalosira (marit.).

- quadralterna Turpin mémoir. du Mus. d'hist. nat.: Sicenodesmus (Desmidiee).

- quadricanda Turpin 1. I.: Scenodesmus (Desmidiee).

- quadrijuga Turpin 1. 1.: (Desmidiee).

- seriata Ag. consp. Diat.: Cymbosira (marit.).

- stomatomorpha Turpin mémoir. du Mlus.: Spondylosium (Desmidiee).

- turgens Ehrenbg. Verb. in Amer.: Achnanthes subsessilis.

- unipunctata Carmich. sec. Grev. Sc. Flor.: Striatella uripunctata (marit.)

Achanthidium delicatulum Ktz. spec. Alg.: Falcatella delicatula.

— flexellum de Bréb. in Ǩtz. spec. Alg.: Cymbella flexella.

Aulacoeystis pellucila Ilassal. Freshwat. Alg.: Auphipleura pellucida.

Bacillaria Acus Sichrank (1 823 ): Euglena Acus (Infus.?)

- acerosa Schrank: Desmidiee.

- adriatica Lobarz. in Linn. 1840: Grammatophora marina.

- bipunctata Selurank (1823): Synedra Ulna.

- bipunctata Hempr. et Ehrenbg. Aymbol. phys. (1828): Fragilaria bipunctata (virescens).

- Cistula Hempr. et Ehrenbg. 1. I.: Cocconema Cistula.
Bacillaria Cleopatrae Itempr. et Ehrenbg. 1. 1.: Grammatophora marina.

- communis Bory Dict. cl.: Synedra Ulna.

- conjugata Turpin ménoir. du Mus. d'hist. nat.: Pinnularia major.

- crassa Bory Encyclop. méthod.: ? Pinnularia major.

- cuneata Ehrenbg. Infus.: Diatoma mesodon.

- diophthalma Hempr. et Ehrenbg. Symbol. phys.: Fragilaria diophthalma.

- elongata Ehrenbg. Infus.: Diatoma Ehrenbergii.

- flocculosa Ehrenbg. Infus.: Diatoma pectinale.

- fulva Nitzsch Beitr. zur Infus. ex parte: Cymbella truucata.

- fulva Nitzsch 1. 1. ex p.: Navicula fulva.

- fulva Nitzsch 1. 1. ex p.: Pinnularia major.

- fusiformis Hempr. et Ehrenbg. Symbol. phys.: Gyrosigma acuminata.

- IIystrix Bory Encyclop. méthod.: Synedra Gallionii (marit.).

- Lunula Sichrank Act. Ac. Leop. Car. Nat. cur.: Closterium (Desmidiee).

- Lyngbyi Bury Eneyclop. méthod.: Synedra Ulna.

- Meneghini Lobarzewsky in Linn. 1840: Grammatophora marina.

- Mülleri Bory Encyclop. méthod.: Bacillaria paradoxa (marit.).

- multipunctata Ehrenbg. Symbol. phys.: Fragilaria capucina.

- multistriata 1lempr. et Elrenbg. Symbol. phys: Closterium (Desmidiee).

- palea Nitzsch Beitr. zur Infus.: Navicula gracilis, Denticula tenuis ete.

- Paxillum Bory Encyclop. méthod.: Synedra Ulna.

- pectinalis Nitzsch. l. l.: Fragilaria rhabdosoma, Diatoma pectinale.

- pectinalis Ehrenbg. Infus.: Diatoma tenue.

- phoenicenteron Nitzsch 1. l. ex p.: Stauroncis Phoenicenteron.

- phoenicenteron Nitzsch 1. I. ex p.: Navicula fulva.

- pho nuceuteron Nitzsch 1. I. ex p.: Navicula gracilis.

- phwenicenteron Nitzsch 1. l. ex p.: Pinnularia major. 
Bacillarta P’olematei I Iempr. et khrenhg. Symbol. phys. et Infus.: liatoma pectinale.

— seriata Ehrenlog. Infus.: Diatoma pectinale.

— signoidea Nitжrch lkitr. zur Tulu*.: Sigmatella Nitzsilii.

- tabrllarjis Ehrenbg. Infus:: 'Tabellaria floceulosa.

- Clua Nitzsch Beitr. zur Inlus.: Synedra [Tna.

- viridis Nitzsch Bejtr.: l'imnularia viridula.

- vitrea Bory Euczelon. méthod.: Śynedra Ulna.

- volgaris Ehrenbg. Infus.: Diatoma rulgare.

Brachyoira aponiua Ktz. Alg. Decad.: Navicula aponina var. brachysira.

Ceramium vermcosum Roth Cat. bot.: Achuanthes brecipes (marit.).

Chaos infusorium Schrank Beitr.: Navienla fulva.

Coceneis Amphiceros Elrenbg. Ber. d. Berl. Ak. $(1 \$ \neq 0)$ : Dory]liora (marit.).

- Clypens Ehrenlig. Infus.: Campylodiseus Clypens (fosisil).

- Kützingii Brél. sec. Ktz. spece. Alg.: Cucconeis Pediculus.

- leptoceros Ehrenlog. Verb. in Amer.: Rhaphoneis (marit.).

- nidulans Lobarzewsky in Linn. (1840): Cocconeis limbatiı.

- patavina Menegh. sec. Ktz. spec. Alg.: Cocconeis Prediculus.

- Rhombus Ehrenbg. Ber. A. Berl. Ak. (18t0): Doryphora (mart.).

Coccounema Cistula llassitl Freshwat. Alg.: Coceonema cymbilinme.

- Crotae Lihrenlgg. Kreidef.: Eunotia Cretae (fossil).

- Fuxidium Elrenhg. Inliss.: Cymbella Fusidiun.

- gilum $\beta$. K1z. spec. Alg.: Cymbella Orsiniana.

- gracile Ehrentig. Vert. in Amer.: Cymbella gracilis.

- lepteceros Ehrenhg. I. 1.: Cymbella leptoceros.

- Lunula Ehrenlog. l. 1.: Cymbella Lumula.

- ventricosum Ilassall Freshwat Alg.: Cucounema gibbum.

Conferva armillaris Mäll. Nov. Act. IIolm.: Achnanthes longipes (marit.).

- biddulphiana Simith Engl. bot.: Tabellaria focenlosa.

- bipartita Bory Dict. cl.: Englena virdis (Infusorimm?).

- dissiliens Dillw. British Conferv.: (Desmidiee).

- divergens Roth Cat. bot.: ?

- faseiata Dillw. British Conferv: Mclosira varians.

- focculosa 1)illw. British Conferv.: Diatoma rulgare.

- Aoceulosa Simith Engl. bot.: Tabellaria floceulosa.

- foetida Dillw. British Conferv.: Schizonema (marit.)

- hirta Müller Boschält. d. Berl. naturl: Ges.: Achnanthes brevipes.

- hyemalis Roth Cat. bot.: Melosira varians.

- inflexa Roth. Cat. bot.: Melosira (Gallionella). (marit.)

- lineata Dillw. British Conferv.: Melosira (Gallionella). (marit.)
Confersa moniliformis Flor. Danica: Melosira (Gallionella). (urarit.)

- nmmuloides Smith Engl. But.: Mosira (Gallionella). (marit.)

- nummuloides Ag. syst. Alg.: Mlelosira (Gallionella). (marit.)

- nummuloides Lyngb. IIydropliyt.: Melosira (Gallionella). (marit.)

- olliqua simith Engl. Bot.: Istlmia (nuarit.).

- ochracea Roth, Schum., Dillw.: ? Velosira (Gallionella) orichalcea.

- orichalcea (Mert. apud Jurgens) Ag. syst. Alg: Melosira orichalees.

- pectinalis Mäller. Act. nor. Ac. P'etropol. ex p.: Frisilaria capueina.

- pertinalis Dilkw. British Confers.: Himantidinm peetinale.

- rhomboidalis Bory mémoir. dı Mus. d'hist. nat.: Tahellaria floceulosa.

- rutilans Trentepold in Roth, Cat. bot.: Schizonema rutilans (marit.).

- stipitita Smith Engl. Bot.: Achnanthes longipes (marit.).

- taeniaeformis Smith 1. 1.: Grammatophora marina.

- upon Conferva Dillen. list. musc.: ? Aehnanthes (marit.).

Crystallia pulvinata Sommerf, sec. Ag.: Gomphonema constrictum.

Cyclotella ovalis Bréb. Considerat.: Amploord oralis.

Cymbella acuta Ag. consp. Diat.: Aciculae Spongillae lacustris.

- adnata Bréb. Alg. Falais.: Epithemia Zchra.

— appenliculata Ag. Consp. Diat.: Navieula appenticulata.

- appendiculata Godey et Bréb.: Navioula amplishaena.

- avenacea findey et Bréb.: Pinnularia gracilis.

- Areus Massall Freshwa1. Ag.: Ceratoneis Areus.

- copulata Bréb. Alg. Fatais.: Cocconema Cistula.

- cymbitormis 13réb. Alg. Falais.: Cocconema eymbiforme.

- fulva Ag. Consp. Diat.: Navicula fulva.

- gastrojdes $\mu$, Ktz. Bacill. et spec. Alg.: Cymbella truncata.

- geminata Brél. Alg. Falais.: Cymbella Lunula.

- Ilopkirkii Noore, IIassal Freslowat. Alg.: ? Pinnuburia gracilis.

- lyalina $\mathrm{dg}$. consp. Diat.: Pinnularia grarilis.

- inerassata Bréb. Ng. Falais.: Epithemia gibha.

- laetevirens Harv. sec. Kit. spec. Alg.: Pinudaria viridula.

- lacvis Nacgeli sec. Ktz. spec. Alg.: Cymbellae gracilis forma obsolete striata.

- lanceolata Agr? sec. Ktz. l. l.: Pinnularia Ehrenbergii.

- lanceolata Ag. consp. Diat.: Navicula lanceolata.

- late fasciata $\mathrm{Ig}$. l. 1.: Navicula lizlva.

- lineata IIarvey sec. Ktz. spec. Alg.: Coceonema cymbiforme. 
Cymbella maculata Kíz. Bacill. et spee. Alg.: Cymbella Lunula.

- minor. Ag. Consp. Diat.: Navicula fulva.

- operculata Ag. consp. Diat.: Cyclotella operculata.

- Pediculus Kitz. Bacill. et spec. Alg.: Cocconeis Pediculus.

- phoenicenteron Ag. l. 1.: Stauroneis Phoenieenteron.

- pieta Bréb. Alg. Falai.s.: Epithemia turgida.

- reniformis Ag. 1. 1.: (Desmidiee.)

- Scalprum Ag. consp. Diat.: Gyrosigma Scalprum. (marit.)

- sigmoides Ag. 1. 1.: Sigmatella Nitzschii.

- turgida Hassall Freshwat. Alg.: Epithema turgida.

- Zebra Ilassail 1. 1.: Epithemia Zebra.

Cymbophora fulva Bréb. sec. Kitz. spee. Alg.: Cocconema cymbiforme.

- maculata Bréb. sec. Kítz. I. I.: Cymbella leptucerus.

Cystopleura alpestris Bréls. .1g. Falais.: Epithemia alpestris.

- ocellata Bréb. l. I.: Epithemia ocellata.

Dendrella geminata Bory Encyclop. méthod.: Gomphonema geminatum.

- Lynglyei Bory 1. 1.: Gomplonema geminatum.

- olivacea Bory 1. 1.: Gomphonella olivacea.

- styllarioides Bory l. 1.: Gomphonema geminatum.

Denticellae spec, Ehrenlug. Ber. d. Berl. Ak.: 1) dontella et Biddnlphia (marit.).

Denticula thermalis $\beta$. rupentris Ktz. spec. Alg.: Gomphogramma rupestre.

Diatoma arcuatum Lyngb. Ilydrophyt.: Rhabdonema (marit.).

- arcuatum Hoffinann - Bang sec. Kitz. spec.: Striatella (marit.).

- auritum Lyngb. Hydroplyyt.: Odontella (marit.).

- Biddulphianum Ag. Consp. Diat.: Bid\}ulphia (marit.)

- brachygonum Carnich. sec. Kítz.: Grammatophora marina.

- erystallinunı Ag. Consp. Diat.: Synedra erystallina (marit.).

danica Bory Dict. cl.: Diatoma temue var.

- dissiliens Ag. Consp. Diat.: Desmidiee.

- fasciculatum Ag. I. 1.: Synedra Fallionii (marit.).

- fenestratun Lyngb. Hydrophyt.: Tabellaria fenestrata.

- fenestratum lítz. Alg. Decad.: Diatoma vulgare.

- flabellatum dürgens $\mathbf{1 g}$. exs.: Rhipidophora (marit.).

- Hoceulosum Ag. syst.: Lyngb. Iydropl..: Tabellaria Hoeculosa.

- flocezosum DeC. Flor. lranc.: Diatoma vulgare.

- interstitiale Ag. Consp. Diat.: Biddulphia (marit.).

- latruncularium .Ig. 1. 1.: Grammatophora marina.

- liberum $\mathrm{Ig}$. Consp. Diat.: Biddulphia (marit.).

- Lyugbyei Ag. 1. 1.: Grammatophora marina.

- marinum .g. I. 1.: Grammatophora marina.

- minimum Ralfs sec. litz.: Diatoma vitreum (marit.)-
Diatoma Navicula Coda Almanac de Carlshad: Fragilaria diuphthalma.

— obliqnatum Lyngb. Ilydrophyt.: Isthmia (marit.).

- obliquatum IImk. British Flora: Isthmia (marit.).

- parasiticum Ig. Consp. Jiat.: Synedra ITha.

- pectinale Ag. Disp. Alg.: I Iimanticlium pectinale.

- ramosum Ag. (onsp. Diat.; Licmophora (marit.).

- rigidum DeC. Flor. franc.: ? Achanthes longipes (marit.).

- scalaris (Xrateloup, list. de la Soc. med. Montp.: Synedra I'lna.

— stipitatum Ig. syst.: ? Achnanthes (marit.).

— striatulum bingl. Bot.: Rhabdomenat (marit.).

- sulphurascens Ig. syst. Alg.: Fragilarin virescens.

- Swartzii Ag. Swenkk. but., łỵngl. et Turp. l. l.: Desmidiee.

- tabulatum Ig. Consp. Diat.: Symedlat Gallioni (marit.).

- taeniaeforme $\mathbf{g}$. l. l.: Grammatspluera marina.

- variegatmo Ig. Comsp. Diat.: Synedra laevin.

- Vexillum Jürgens Mlg. exs.: Achnantlies (marit.).

Diploueis Bombus Ehrenbg. Ber. d. Berl. Ak. (1841): Piunularia Bombus.

- Crabro Ehrenbg. I. l.: Pinularia Crabro.

- Faba Ehrenbg. 1. 1.: Navieula Faba.

Discoplea atmosphaerica Elıenbg. Ber. d. Berl. Ak. Cyclotella.

- Kützingii Ehrenlog. Ber. der Berl. Ak. (1840): Cyclotella operculata.

- venusta Ehrenbg. 1. 1. (1852): Cyclotella venusta.

Echinella ablureviata Ehrenbg. Infus.: Gomphonema abbreviata.

- acuta Lyngh. IIydrophyt.: Aciculae Spongillae.

- capitata Ehrenlog. Infus.: Synedra Ehrenbergii.

- Chauvini Duly 13ot. gall.: Synedra amphirhynchus.

- circularis Grer. Se. flor.: Merilion circulare.

- crenulata Conda, Nnanac de Carlsbad: Cromphonema abbreviatum.

- cuneata Lyngl. Iydrophyt.: Podosphenia (marit.).

- lasciculata Lyngl. 1. 1.: Synedra Gallionii (marit.).

- - p. truncata Grev. Sc. er. Flor.: Synedra Clna.

- Halellata Grev. I. I., Ehrenbg. Infus.: Liemophora (marit.).

- geminata Lyngh. Iyylrophyt.: Gomphonema geminatum.

- oblonga (Frev. Se. er. Flor.: Desmisliee.

— olitusa Lyngl). Iydropli.: Synedra LIna.

- obtusa Jirgens .lyg. exs.: Epithenia turgida.

- olivacea Lyngh. 1. 1.: Gomphonellar ulivacea.

- paradoxa Lyngl. l. 1.: Rhipidophora (marit.)

- splendisla Ehrenbg. Infus.: Licmoplora (marit.)

- stipitata Lyngl. Iydroplyyt.: Achnanthes brevipes (marina).

- striata Turpin Dict. d'list. natur.: Podosphenia gracilis (marina).

- stricta Bory Dict. cl.: Fodosphenia gracilis (marina). 9 * 
Echinella ventilatoria Bury l. I.: Podosphenia gracilis (marina).

- ventilatoria Desmaz. (sec. Ehrenbg.): Meridion cirenlare.

versatilis Ag. syst. Algar.: Oplurydium versatile (Prototyj. s. Inim.).

- vitrea Bory Dict. A.: Syuedra vitrea.

Epithema adnatum Bréb. Considerat. sur les Diat.: Epithemia Zebra.

Eumericlion constrictum Ktz. Bacill. et spec. Algar.: Meridion constrictum.

Eunotia Argus Elurenbg. Verb. in Amer.: Epithemia Argus.

- Faba Ehrenbg. Infus.: Epithenia Faha (fossil).

- gilba Ehrenbg. Verb. in Aner.: Epithemia gibba.

- gibberula Ehrenbg. I. 1.: Epithemia gibberula.

- granulata Ehrenbg. in Pogrgend. Annal.: Epithemia granulata.

- Lilorile Ehrenlog. Verb. in Amer.: Epithemia Librile.

- ocellata Ehrenbg. Nachricht über Infus.: Epithenia ocellata.

- textricula Ehrenlog. Verh. in Amer.: Epithemia textricula.

- turgida Ehrenlyg. Infus.: Ephithemia turgida.

- Westermanni Ehreulg. Infus.: Epithemia Westermanni.

- Zebra Elirenheg. l. l.: Epithenia Zebra.

- zebrina Elırenlog. Verb. in Amer.: Epithemia zelorina.

Exilaria Arens Bréb. Alg. Falais.: Synedra biceps.

- capitata Ilassall Freshwat. Alg.: Synedra capitata.

- crystallina Kiz. Algen Decad.: Synedra biecps.

- curvata Ktz. Algen Decal.: Synedra lunaris.

- fasciculata Kítz. Actien 1836: Synedra affinis.

- fasciculata Kitz. Algen Decad.: Synedra saxonica.

- flabellata Elırenlig. Infus.: Licmophora (marit.).

- Flabellum Elrenlg. Beitr.: Veridion circulare.

- flexa Bréb. Alg. Falais.: Ilimantidium biceps.

- fulgens Grev. Sc, cr. Flor.: Licmophora (marit.).

- lunaris Jenner, in Flora of Tunbrilge Wells: Synedia lunaris.

- minutissina Berkel. Glean. of Brit. Alg.: Gomphonellat olivacea.

- notata sulur herb. sec. Ktz.: Synedra fuscienlata (urarit.).

- panduriformis Elurenhg. Abh. d. Berl. Ak.: Meridion panduriforme.

- pulchella Ralfs sec. Kïutz.: Syuedra pulchella.

- rul,iginea Bréb. Alg. Falais.: Gomphonema curvatum.

- tenuissima Bréb. l. l.: Synedra tenuissima.

- truncata Ktz. Syn. Diat.: Gomphonema gracile.

- Ulna IJassall Freshwat. Alg.: Synedra Ulna.

- Vaucheriae Ktz. Syu. Diat.: Synedra Vaucheriae.

— viridescens Bréb. Alg. Falais.: Synedra amphirhynchus.

Fragilaria Amphiceros Elurenbg. Ber. d. Akad. 1844: Odontidium Amphiceros.

-. usgnata Ehrenbg. Infus.: Fragilaria eapucina.
Fragilaria aurea Carmich. sec. Ktz.: Desmidiee.

- binodis Ehrenbg. Verb. in Amer.: Navicula binodis.

- eoufervoides Grev. in Honk. British Flor.: Fragilaria virescens.

- diatomoides Grev. I. 1.: Wesmidiee.

- fasciata Lyngb. Hydrophyt.: Grammatophora marina.

- fissa Ehrenbg. Infus.: Fragilaria capucina.

- grandis Elurenbg. Infus.: Odontidium grande.

- granulata Ehrenbg. Ber. der Berl. Ak. (1844): Odontidium granulatum.

- hiemalis Lynglo. Hydrophyt.: Odontidium hiemale.

- hicmalis Duby Bot. gallic.: Himantidinm Soleirolii.

-. Iatruncularia Lyngb. Ilydrophyt.: Grammatophora inarina.

- lineata Lyngb. 1. 1.: Melosira lineata (marit.).

- mesudon Ehrenbg. Netenrp.: Odontidium mesodon.

- multipunctata lihrenbg. Infus.: Fragilaria capucina.

- nodulosa Ehrenbg. Verb. in Amer.: Odontidium nodulessum.

- nummuloides Lyngb. Iydrophyt.: Melosira nummuloides (marit.).

- pectinalis Lyngb., Ag., Ktz., Elurenbg.: Himantidium pectinale.

- pinnata Elurenbg. Verb. in Amer.: Odontidium pinnatum.

- pinnulata Ehrenbg. l. 1.: Odontidium pinnulatum.

- rotmdata Ehrenhg. l. l.: Odontidium rotundatum.

- salina Kítz. in Linn. 1833: Achnanthes brevipes.

- scalaris Ehronlog. Infus.: Fragilaria rhabdosoma.

- striata Elırenlig. Verb. in Amer.: Odontidium hiemale.

- striatula Lyngb. Hydrophyt.: Grammatonema striatulum.

- striolata Ehrenlog. Meteorp.: Odontidium striolatum.

- syriaca Ehreubg. Ber. d. Akad.: Odontidinm syriacum.

- tenuis Ag. Comsp. Diat.: Fragilaria capucina.

- turgidula Elırenbg. Infus.: Odontidiun turgidulum.

- unipunctata Lyngb. IIydrophyt.: Striatella 'unipun(tata marit.).

Frustulia aerusphaeria Bréb. Consp.: Pimularia acrosphaeria.

- acmminata Kitz. Syn. Diat.: Gyrosigma acuminata.

- adnata Ktz. Nlgen Decad.: Epithenia Zebra.

- agrestis Corda Alnanae de Carlsbad: ? Pinnularai viridis.

- anceps Ktz. Syn. Diat.: Synedra parvula.

- apprendiculata Ig. Jeon. Alg., Kitz. in Limn., Ehrenlg. Infus.: Navicula appendiculata.

- asbestina Leiblein in I Har. Ratislı: Aciculae Spongillae!

- attenuata Ktz. Syn. Biat.: Gyrosigma attenuata.

- arenacea Bréb. Consp.: Pinuularia gracilis.

- lipunctata Bréb. Consp.: Navicula Brébissonii.

- circularis Duby Bot. gall.: Meridion circulare.

- coffeaeformis $\Lambda \mathrm{g}$. in Diar. Ratisb.: Amphora coffeaeformis. 
Frustulia cofteaeformis Ktz. Algen Decad.: Cocconema। cymbiforme.

- eonspurcans Ag. Comsp. Diat.: Pinnularia gracilis.

- copulata Ktz. Syn. Diat.: Anpliora ovalis.

- costata Lobarzewsky in Linn 1840: Rhaphidogloea (marit.).

- cuneata Ag. syst.: Podosphenia (marit.).

- cuspidata Ktz. Syn. Diat.: Navicula fulva.

- cyubiformis Ktz. 1. 1.: Cocconema eymbiforme.

- depressa Kłz. l. l.: Navicula amplisbaena.

- dilatatil Bréb. cousp.: Synedra capitata.

- elliptica Ag. Syst. Alg.: Amphora elliptica.

- fasciata Alenegh. see. Ktz.: Synedra Vlna.

- fulva Bréb. sec. Kítz.: Navicula microstoma.

- fulva Kitz. Syn. Diat.: Cymbella truncata.

- gastroides Kít. Syn. Miat.: Cymbelia gastroides.

- gracilis Jenner in Flora of Tunbridge Wells: Piunularia gracilis.

- iucrassata Ktz. Syn. Diat.: Epithemia gibba.

- inflata Ktz. Syn. Diat.: Navicula inflata.

- Jürgensï Ag. Consp. Diat.: Epithemia turgida.

- lanceolata Ktz. Syn. Diat.: Navicula lanceolata.

- Lens Bréb. consp.: Cocconeis Pediculus.

- librilis Jenner in Fiora of Tunbridge Wells: Surireila Solea.

- Lyngbyei Kłz. Syn. Diat.: Podosphenia (marit.).

- maculata Ḱtz. Alg. Dec.: Cymbella Lunula.

- major Ktz. Syn. Diat.: Pinnularia major.

- maritima Ehrenbg. Infus.: Phlyctaenia (usarit.).

- minor $\Lambda$ g. Syst. Alg.: Navicula fulva.

- multifasciata Ktz. Syn. Diat.: Surirella multifasciata.

- nidulans Bréb. consp.: Cocconeis nidulans.

- Nitzschii Kótz. Syu. Diat.: Sigmatella Nitzschii.

- nodosa Jenner in Flora of Tunbridge Wells: Navicula nodosa.

- nodulosa Bréb. Considerat.: Pimularia Termes.

- oblonga Kitz. Algen Decad.: Pinnularia oblonga.

- obtusa Ag. Consp.: Denticula obtusi.

- ocellata Bréb. Alg. Falais.: Pinnularia ohlonga.

- olivacea Kitz. Syn. Diat.: Gomphonella olivacea.

- operculata Ag. Consp. Diat.: Cyclotella operculata.

- Orsiniana Menegh. sec. Kítz. spec. Alg.: Cymbella Orsiniana.

- ovalis Ktz. Syn. Diat.: Amphora ovalis.

- Palea Kítz. Syn. Diat.: Pinnularia gracilis.

- parrula Kítz. Syn. Diat.: Synedra parvula.

- parasitica Ag. Syst. Alg.: Synedra Ulna.

- pellucida Ḱtz. Algen - Decad.: Amplipleura pellucida.

- picta Kiz. Syn. Diat.: Epithemia turgida.

- punctata Ktz. Syn. Diat.: Denticula obtusa.

- quadrangula Ag. Consp. Diat.: Synedra Llna.

- quinquepunctata Kítz. l. l.: Surirella solea.

- Scalprum Kít. Syn. Diat.: Gyrosigma (marit.).

- Scaphidium Brél. Alg. Falais.: Eunotia amphioxys.
Frustulia sigmoidea Jemner in Flora of Tunbridge Wells: Sigmatella Nitzschii.

- spleutens Kit\%. Syn. Diat.: Synedra splendens.

- subquadrata Bréb. Alg. Falais.: Surirella minuta.

- subtilis Ktz. Syu. Diat.: Synedra subtilis.

- tenuissima Ktr. Syn. Diat.: Synedra tenuissima.

- Turpinï Bréb. Consil.: P'innularia najor.

- Ulna Kitz. Alg. Decad.: Synedra Ulna.

- ventrieosa lítz. Syn. Alg.: Cymbella ventricosa.

- vermicularis Ktz. Syn. Diat.: Sigmatella vermicularis.

- viridis Ǩ́z. Syn. Diat.: Pinnularia.

- viridula Kiz. Syn. Diat.: Pinularia viridula.

Gallionella aurichalcen Elırenbg. Infus.: Melosira orichalces.

- ? californica Ehrenbg. Ber. der Berl. Ak. (1852):

Melosira ? ealifornica.

- calligera Elirenbs. Ber. der Berl. Ak. (1844): Melosira calligera (fossil).

- coarctata Ehrenbg. Verl. in Amer.: Melosira oriclualcen.

- coronata Elırenbg. Ber. der Berl. Ak. (1844): Melosira coronata (fossil).

- crenulata Ehrenbg. Verb. in Amer.: Melosira crenulata.

- decussata Ebrenbg. Ber. der Berl. Ak. (184I): Melosira decussata (fossil).

- distans Elırenlug. in Poggend. Annal. (1836): Melosira distaus.

- ferruginea Ehrenl,g. Infus.: Gloeotila ferruginea (Alge).

- granulata Elırenlog. Ber. der Berl. Ak.: Melosira granulati.

- itilica Elırenbg. Infus.: Melosira italica (fossil).

- laris Ehrenbg. Ber. der Berl. Ak. (1850): Melosira laevis.

- lineata Elırenbg. Infus.: Melosira lineata (marit.).

- lirata Elrenbg. Verb. in Amer.: Melosira lirata.

- marelica Ehreubg. l. l.: Nelosira grauulata.

- moniliformis Bailey Wyatt Alg. Dammon.: Melosira unnmoloides.

- monilifurmis Bory Dict. el.: Melosira moniliformis (marit.).

- nummuloides Bory 1. l. et Ehrenbg. Infus.: Melosira salina.

- Oculus Elurenbg. Ber. der Berl. Ak. (1944): Melosira Oculus.

- operculata Ehrenbg. 1.1. (1 $\$ 33)$ : Cyelotella operculata.

- pileata Elirenbg. l. l. (18t4): Nelosira pileata.

- plana Ehrenhg. I. 1. (1\$45): Melosira plana.

- procera Ehrenlog. I. I. (1850): Melosira procera.

- senlpta Ehrenlog. I. i.: Melosira sculpta.

- Sol Ehrenlig. I. I. (1844): Nelosira Sol.

- spiralis Elırenbg. 1. 1.: Melosira spiralis.

- sulcata Elırenbg 1. 1. (1940): Melosira sulcata.

- tenerrima Elirenbg. l. I. (1850): Melosira tenerrima.

- Tympanum Ehrenbg. I. 1. (1844): Melosira Tympanum (uarit.). 
Gallionella undulata Ehrenbg. 1. 1. $(18+0)$ : Melosira | undulata (fossil).

- varians Bhrenbg. Infus. ex parte: Melosira varians.

- varian kihrenbg. I. l. ex parte: Melosira arenaria.

- vermicularis Bréb. Alg. Falais.: Melosira arenaria.

Gloeonemat. spee. Ehrenlyg. Ber. der Berl. Ak.: Formae dubiate.

Gloeonema paradoxum Ehrenbg. Infus. (nec Ag.): Eneyonema paradoxum.

Gloionema globiferum $\Lambda \mathrm{g}$. consp. Diat.: ?

— Ilenfleri Menegh. ex Kitz.: Diatoma Threnbergii.

- Leibloini Ag. consp. Diat.: Eneyonena paradoxum.

- vermiculare $\Lambda \mathrm{g}$. comsp. Diat.: ?

Gomphonema ampullaceum (Hrev. in J Iook. British Flor.: Gomphonema geminatum.

- angustmu Ktz. Bacill. et spee. Alg. exel. Siyn.: Gomphonellir augusta.

- angustum Ag. Consp. Diat.: Gomplonena gracile.

- apiculatum Rabenl. Bacill. Fascikel: Gomphonema eristatum.

- urgentescens Kitz. Syn. Diat.: Lienophora (marit.).

- Berkeleyi Grev. in Ilook. Brit. Flora: Gomphonella olivacea.

- brevipes Ktz. Syn. Diat.: Gomphonema abbreviatum.

- Clavus Bréb. sec. K̇tz.: Gomphonema acuminatum.

- cristatum Ralfs in Anual. and Magaz. of Nat. llist.: Gomplionema Angur.

- dichotomum Ktz. Bacill. et spee. Alg.: Gomphonema gracile.

- dichotonum fossile Bréb. sec. Ḱtz.: Gomphonema Brebissonii.

- geminatum Ktz. Algen-Dacad.: Gomphonella olivacea.

- herculeum Ehrenbg. Ber. der Berl. Ak. (1845): fromplonema geminatum.

- lanceslatum Ag. Consp. Diat.: Coceonema lanceolatnm.

- Leib]einï Ag. Consp. Iiat.: Gomphonella olivacea.

- Lenormandi Chanvin, Ktz. spec. Alg.: Gomphonella Lenormandi.

- minntissimum Bréb. see. Ktz.: Spbenella parvula.

_- minutissimm Kt\%. Algen Decad.: Gomphonema curvatum.

- minutum Ag. Consp. Diat.: Gomplonema acuminatum.

- oculatum Kitz. Syn. Diat.: ( 'omplonema clavatum.

- olivicea Ktz. Bacill. (t Sipec. Alg.: Gomphonella olivacea.

- pachycladium Bréb. sec. Ktz.: (romphonema abbreviatum.

- paradoxum Ag.Syst.: Rhipidophora paradoxa (marit.).

- parvulum Ktz. Spec. Algar.: Gomphonella parvula.

- pohliacforme lítz. Algen Decad.: Gomphonema constrictum.

- pyriferum Suhr sec. Kitz.: Gomphonema geminatum.

- Radicula Suhr sec. Ktz.: Gomphonema geminatuin.
Gomphonema ramosisximum Naegeli in Kíz. spec. Alg. Gomphonella olivacea var.

- semielliptieum Ag. Consp. Diat.: Cocennema Cistula.

- septatum Ag. Consp. Diat.: Gomphonema discolor.

- simplex Ktz. Syn. Diat.: Cocconema Cistula.

- sphaerophorum Elırenbg. Ber. Jer Berl. Ak. (1845) Gomphonema Lagenula.

- subramosum Ag. Consp. Diat.: Gomphonema discolor.

- sulramosum Ktz. Bacill. et Fpee. Alg.: Gomplonemal clavatum.

- tinctum Ag. Consp. Diat.: Rlipidophora elongata (marit.).

- truncatum Ehrenbg. Infus.: (romplonema constrictum.

Isthmia catenata Menegh. sec. Ktz.: Encyonema paradoxum.

Licmophora minuti Ktz. Algen-Decad.: Gomphonema abbreviatum.

Lysigonium lineatum Link, IJorac physic. berol.: Melosira lineata (marit.).

- moniliforme Link 1. 1.: Melusira (marit.).

- taenoides Stiebel in Mus. Senkenb.: (Oscillarie).

Meloseira Ig. Consp.: Melosira.

Melosira Borreri Wyatt Alg. Danmon: Melosira (marit.).

- Borreri Grev. in IJook. Brit. Flor.: Mclosira (marit.).

- diseigera Ag. syst. Alg.: Melosira (marit.).

- fragilis Kız. in Linnaea (1833): ?

- Heufleri Menegh. sec. Kitz.: Odontidium hiemale.

- hormoides Montagne Flor. Boliv.: Podosira (marit.).

- lentigera IIarr. Man. of British Alg.: ?

- minutula Bréb. Alg. Falais.: (iloeotila (Alge).

- Thompsoni IJav. Man. of Britislı Alg.: Melosira orichaleea.

Neridion cordatum Corda Almanac de Carlsbad: Mcridion cirenlare.

- Flabellum Ehrenlig. Ber. der Berl. Ik. (1833): Meridion circulare.

— ovatum Ag. Syst. Ag.: ?

— radians $\Lambda$ g. Syst. Ag. ex part.: Liemophora (marit.).

- vernale Ehrenbg. Infus.: Meridion circulare.

Monema prostratum Berkeley Gleanings of Brit. Alg.: Euryonema prostratum.

Navieula acrospluaeria Ktz. Bacill. et Spec. Alg.: Pinnularia acrophlacia.

- acuminata kitz. Bacill.: Gyrosigma acuminata.

- Acus Elurenbg. Ber. der Berl. Ak. (183-1): Synedra sultilis.

- acuta Bory Dict. el.: Nadeln der Spongillen.

- Agellus Ehrenbg. Ber. der Berl. Ak. (1840): Gy. rosigma Agellus.

- Amphigomphus $\beta$. Litz. Bacill.: Pinnularia Amphigomplus.

- Amphora Ehrenhg. Ber. der Berl. Ak. (1831): Amphora ovalis.

- Amphiprora Ktz. Bacill.: Pinnularia Ampliprora. 
Navicula A pis Kitz. Bacill.: Pinnularia Apis.

- Arens Elirenlog. Infus.: ('eratumeis Areus.

_- attenuata Ǩ́z. Bacill.: Gyrosigma attenuata.

- baltica Ehrenbg. Infus.: Gyrosigma baltica.

- bifuns Ehrenbg. Infus.: Surirclla biseriata.

- bipunetata Bory Encyclop. métlod.: Pinnularia gracilis.

- bipunctata Turpin Dict. des sc. natur.: Pinularia viriclis.

- bitruncata Turpin 1. l.: Navicula amphisbaena.

- Bomlus Kitz. spec. Alg.: Pinnularia Bombus.

- borealis Kitz. Bacill. of Sipec. Alg.: Pinnularia borealis.

- eapitata Elnenbg. Infus.: Pinnularia capitata.

- (P'innularia) eardinalis Elurenbg. Ber. der Berl. Ak.: Stauroptera cardinalis.

- duilensis Kíz. Bacill.: Pinnularia chilensis.

- ciliata Corda Nmanac de Carlsbad: Coceonema gibbum.

- Conops K1z. Baeill.: Pinmularia Conops.

Navicula? eonstrieta Ehrenbg. Infus.: Denticula constricta.

- Cosmaria Tréb. sec. Kiz.: Navicula undosa.

- costata Corda Almanac de Carlsbad: Cocconena Cistula.

- Crabro Kiz. Spec. Alg.: I'innularia Crabro.

- curvula Ehrenbg. Infus.: Gyrosigma curvula.

- Cyprinus Kitz. Bacill.: Pinnularia Cyprinus.

- Dactylus Kiz. Bacill.: Pinnularia Dactylus.

- decurrens lítz. Bacill.: Pinnnlaria deemrens.

- decurrens var. ". Ktz. Spec. Alg.: Pinularia Trabecula.

- decurrens var. f. Kitz. l. l.: Navicula Trabecula.

- depressa Kiz. in Linnaea (1833): Navicula fulva.

- dicephala Ehrenbg. Infus.: Pinnularia dicephala.

- didyma Kítz. Bacill.: Pinmularia didyma.

- Disphenia Ktz. Bacill. Pinnularia Disphenia.

- Ehrenbergii Ḱtz. Bacill.: Pinuularia Ehrenbergii.

- elliptica Ktz. Bacill.: P'innularia elliptica.

- Esox Kítz. 1. 1.: l’innularia Emox.

- Hexnosa Ehrenlgg. Ber. der Berl. Ak. (1831): Gyrosigma acuminata.

- Follis Ehrenbg. lufus.: Navicula inflata.

- fusiformic Ehrenlig. Ber. der Berl. Ak. (1s-9): Grrosigma alcuminata.

- Gallionii Bory Encyel. méthoul.: Synedra Gallionii (marit.).

- Gastrum Kitz. l. l.: Pinnularia Gastrum.

- gibba Ehrenbg. Beitr. (Abh. d. Akad. 1830): Epithemia gibba.

- gibba litz. Bacill.: P'innularia gibba.

- Gigas Kíz. Bacill.: Pinnularia Gigas.

- granulata Ehrenbg. Ber. der Berl. Ak. (1836): Ejithemia granulata.

- hemiptera Ktz. l. 1.: Pinnularia hem:ptera.

- Mippocampus Elırenbg. Infus.: Gyrosigma Hippoeampus.
Navicula inaequalis Elurenbg. Infus.: I'innularia inaequalin.

- inflata var. $\beta$. Kitz. Bacill.: Pinnularia inflata.

- lamprocampa liluenbg. Ber. der Berl, Ak. (1sto): Gyrosigna lamprocampa.

- lanceolata Elurenbg. Infus.: P'imularia Eluenhergii.

- lata Ki\%. Bacill.: Navirula microstoma.

- lata Bréb. Comsiderat.: Pinnularia lata.

- latiuseula s. Kiz. spee. Alg.: J'imularia latinseula.

- Librilis Ehrenbg. Infus.: Surirella Solea.

- Librile jusenilis Ebrenbg. Indiss.: Navienla binodis.

- libyea Ehrenbg. Ber. der Berl. Ak. (184(1): Pinnularia libyea.

- lineolata Ehrenbg. Verb. in Amer.: Navieula serians.

- lunata Kítz. Bacill. et Sipec. Alg.: Faleatella lunata.

- macilenta Elurenbg. Intus.: Pimmlaria oblonga.

- major İ:\%. Bacill. et Spee. Alg.: Pinnularia viridis.

- major var. $\beta$. conjugata Ktz. Apee. Alg.: P'inuularia major.

- mesogongyla Kitz. Batill.: Pinnularia mesogongyla.

- mesotyla lítz. Bacill.: Navienla seopulorum.

- ninor Bréb. sec. Kítz. Śynedra parvula.

- mixta Brél. sec. Kítz.: Pinnularia P'isciculus.

- neglecta K'tz. Bacill, et spec. Alg.: Pinnularia lanceolata.

- nobilis Ktz. Bacill.: Pinnularia nobilis.

- nodusa var. ß. Kiz. Bacill.: Pinnularia Legumen.

- uodulosa Kitz. Bacill. et Spec. Alg.: Pinularia Termes.

- obliqua Turpin Diet. d. sc. nat.: Cocconema Cistula.

- oblonga Ehrenhg. Terb. in Amer.: Navicula velox.

- oblonga Kiz. Bacill.: Pinnularia oblonga.

- obtusa Bory Eneycl. method. et Turpin Dict. d. sc. nat.: Navicula fulva.

- ordinata Bríd). sec. Kłz.: Tavicula aponina v. brachysira.

- uxyptera Ǩtz. Bacill. et spec. Alg.: Pinnularia oxyptera.

- pachyptera Ktz. Bacill.: Pinnularia pachyptera.

- palea Masuall Freshwat. Alg.: Pimularia gracilis.

- Pamula Bréb. in Kiz. Sipec. Alg.: Pimnularia Parmula.

- parvula Kitz. in Linnaca (1\$33): Navicula fulva.

- pellucida Ełhrenbg. Infus.: Amphipleura pellucida.

- peregrina Kłz. l. 1.: Pimmlaria peregrina.

- Ihwenicenteron Ehrenbg. Infus.: Stauroneis Phoenicenteron.

-. Pinciculus Kit. Bacill.: Pinnularia Piscicnlus.

- Placentula Kiz. l. l.: Pimularia Placentula.

- platystomat Ehrenbg. Infus.: Stauroneis platystoma.

- pleurophora Ktz. l. l.: Pinnularia costata.

- porrecta Kítz. Bacill.: Pinnularia porrecta.

- producta Bréb. sec. Ktz.: Synedra acieularis.

- quadricostata Elurenbg. Infus.: Amphora quadricostata. 
Navieula Sealpellum Kítz. Spee. Alg.: Gyrosigma Scalpellum.

- Sealprum Ktz. Bacill, ex parte: Gyrosigma Sealpellum.

- Schomburgkii Kítz. Spece. Alg.: Pinnularia Schomburgkii.

- Sigma Elırenbg. Ber. ler Berl. Ak. (1834): Gyrosigna Hassallii.

- sigmoidea Elırenbg. Ber. der Berl. Ak. (1830): Gyrosigma acuminata.

- sigmudea Ehreubg. Infus.: Sigmatella Nitzschii.

- Sillimanorum Kì. l. l.: Pinnularia Sillimanorum.

- ? splendida Ehreubg. Infus.: Surirella splendida.

— ? striatula Ehrenbg. Infus.: Surirella striatula.

- suecica Ehrenhg. Infus.: Piunularia suecica.

- Tabellaria Ktz. Bacill.: Piunularia Tabellaria.

- thuringica KKtz. Bacill.: Gyrosigma thuringiaca.

- thuringiaca Rabenh. Bacill.: Denticula constricta.

- transversa Bory, Encyel. méthod.: Pinnunalia gracilis.

— trinodis Ehrenbg. Ber. der Berl. Ak.: ? Tabellaria flocculosa.

— turgida Ehrenbg. Beitr. 1833: Epithemia turgida.

- umbonata Ehrenlıg. Infus.: Surirella thermalis.

- uncinata Ehrenbg. Beitr. 1830: Epithemia gibba.

- nndulata Ehrenbg. Infus.: Denticula undulata.

- Utriculus Kitz. Bacill.: Pinuularia Ctriculus.

- ventricosa Ehrenlog. Ber. der Berl. Ak. (1530): Navicula amphisbaena.

— viridis Ehreulog. Infus.: Pinnularia viridis.

_ viridis Kítz. Baeill. et Śpec. Alg.: Pinnularia viridula.

- Westermanni Ehrenbg. Ber. der Berl. Ak. (1833): Epithemia Westermanni.

- Zebra Ehrenbg. Beitr. 1834: Epithenuia Zebra.

Nematoplata argentea Bory Dict. el.: Fragilaria capucina.

- bronchialis Bory 1. 1.: Jlimantidium pectinale.

- capucina Bory 1. 1.: Fragilaria capucina.

- peetinalis Bory 1. 1.: Himantidium pectinale.

- quadrata Bory 1. 1.: Melosira varians.

Nitzschia elongata Hassall Freshwat. Alg.: Sigmatella Nitzschii.

Pyxidicula opereulata Elırenbg. Ber. der Berl. Ak. (1834): Cyelotella opereulata.

Rhabdium obtusum Wallr. Flor. erypt.: Synedra Ulua. Sphenella olivacea Kitz. Syu. Diat.: Gomphonclla olivacea. - Lenomandi Kiz. Bacill.: Gomphonella oliracea. Styllaria cuneata Bory Dict. el.: Podosplsenia (marit.). - minutissina Ilarr. British Alg.: Gomplonema tenellum.
Styllaria olivacea Bory Dict. cl.: Gomphonella olivacea. - palutusir Ag. Consp. Diat.: ? Sphenella vulgaris.

- paradoxa Bory Dict. cl.: Rbipidophora (marit.).

Surirella bifrons Ehrenbg. Verb. in Amer.: Surirella biseriata.

- bifrons Jenner in Flor. of Tunbridge Wells: Surirella Jenneri.

- contorta Bréb. see. Kitz.: Surirella flexuosa.

- crumena Bréb. sec. Ktz.: Cyclotella Meneghiana var.

- cuneata Bréb. sec. Kłz.: Surirella striatula.

- melosiroides Menegh. in litt. sec. Ktz.: Cyclotella Meneghiniana.

- ovata Kîtz. Bacill.: Surirella minuta.

— viridis Ehrenbg. Ber. der Berl. Ak. (1836): Pinnularia viridis.

Synedra armoricana Ktz. Bacill.: Sigmatella Brebissonii.

- australis Ehrenbg. Ber. der Berl. Ak. (1840): Entopyla australis (fossil).

- curvata Ktz. in litt.: Synedra lunaris.

- exilis Kiz. in litt. (1843): Synedra parvula.

- fasciculata Ehrenbg. Infus.: Synedra dissipata.

- flexuosa Bréb. sec. Ktz. Spec. Alg.: Eunotia flexuosa.

- var. angusta Bréb, 1. 1.: Eunotia paclaycephala.

- Fusidium Kíz. Bacill. et Spec. Algar.: Frustulia minuta.

— minutissima $\beta$. Ḱtz. Spee. Alg.: Frustulia pelliculosa.

- mucicola Ktz. Bacill. et Spee. Ilg.: Frustulia Küitzingiana.

- oxyrhynelus Kí. Bacill. ex max. parte: Synedra acuta.

- sigmoidea Kt\%. Bacill. : Sigmatella Nitzsehii.

- tergestina Kítz. Bacill. et Spec. Alg.: Sigmatella tergestina.

- verunicularis Kîtz. Bacill.: Sigmatella vermicularis.

Tenachinm hyemale Wall. Flor. erypt.: Odontidium hiemale.

- pectinale Wallr. 1. 1.: Himantidiun pectinale.

- striatulum Wallr. l. 1.: (Desmidiee.)

Vesicularia composita llassall in Amnal. and Mlagaz. of Nat. Ilist.: Melosira varians.

Vibrio Fusus Schrank Samml. naturh. Aufsätze: Navicula fulva.

- paxillifer Nü̈ller Anim. infus.: Bacillaria paradoxa (marit.).

- paxillifer Schrank Fauna boica: Diatoma tenue.

Vorticella pyraria Müll. Verm. hist.: Gomplıonema geminatum. 



\section{Eunctia}

$\int_{a}^{a} \int_{0}^{b} \frac{1}{c}$

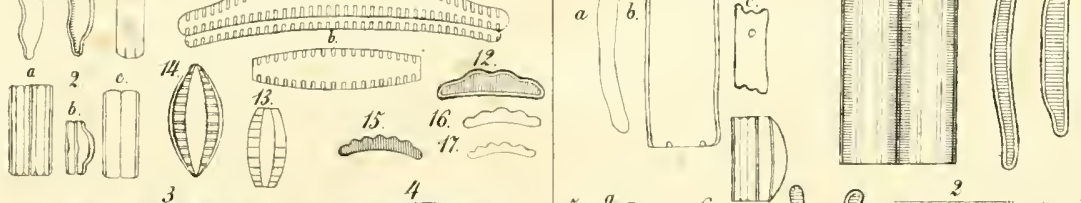
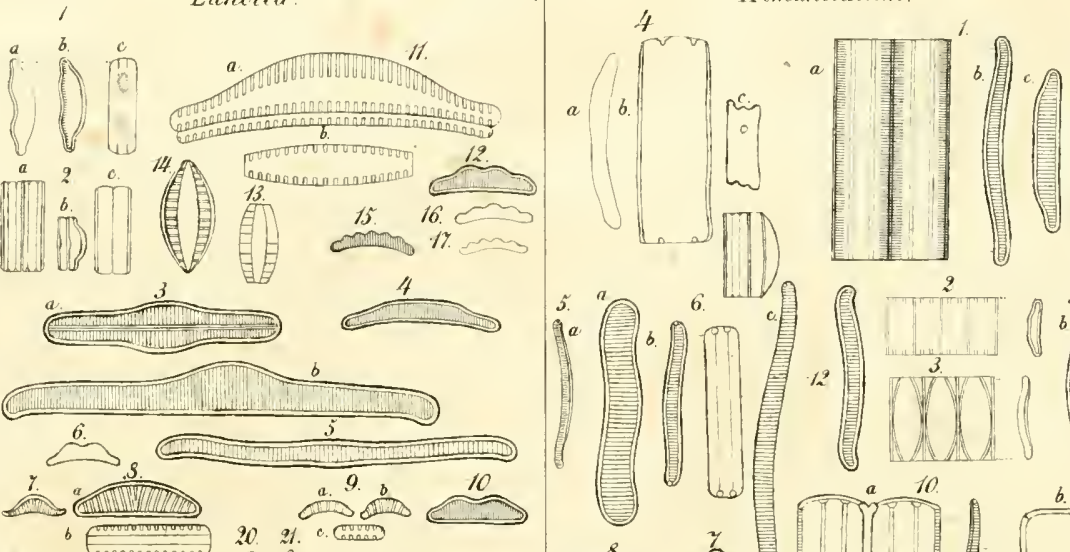

20. 21. C. Gum
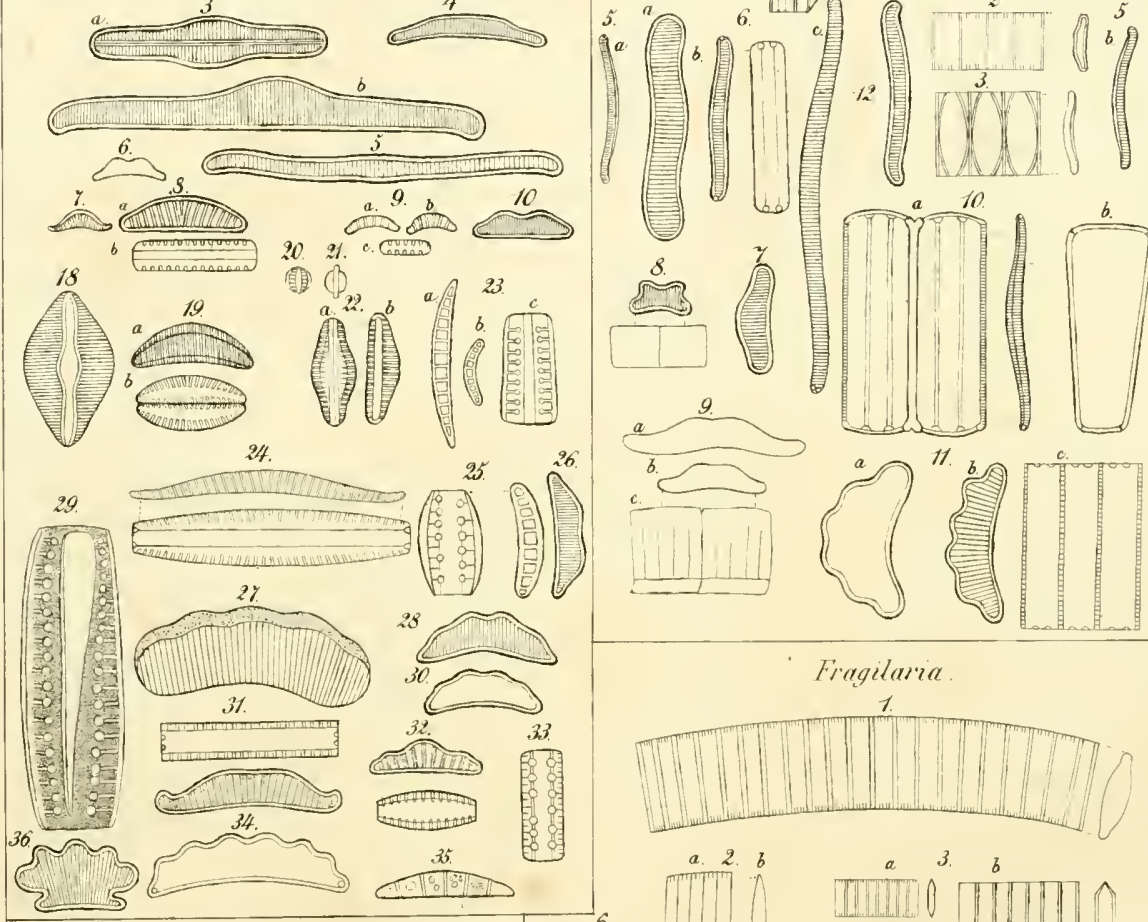

Fragilaria
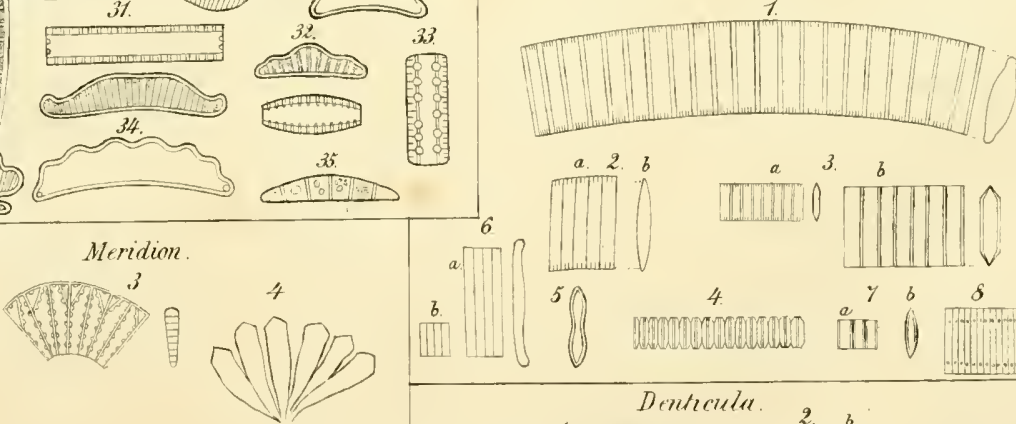

(

s

4

Y 68

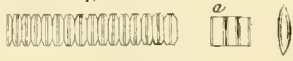

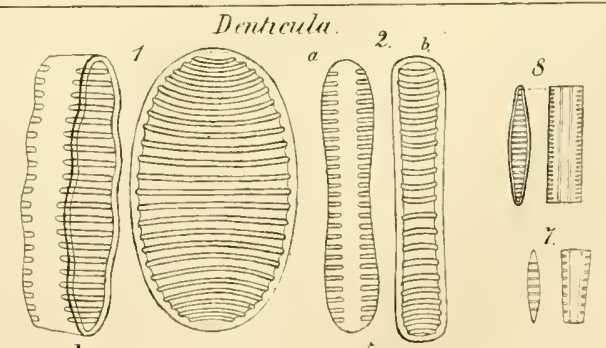

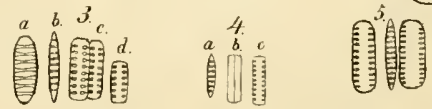

I 


\section{Tab. I.}

EUNOTIA.

Fig. I. E. amphioxys.

2. - alpina.

3. - (Epilliemia) gibba.

4. - - depressa.

j. - - nodosa.

6. - Camelus.

7. - (Epith.) Sorex.

8. - Zebra.

9. - - savonica.

10. - lliodon.

11. - (Epith.) turgida.

12. - Zygodon.

13. - (Epith.) Textricula.

14. - - gibberula.

1:3. - quinaria.

16. - tridentula.

17. - quaternaria.

18. - (Epith.) angulosa.

19. - - Westermanni.

20. - - lindigii.

21. - cingulala.

22. - (Epitl.) ventricosa.

23. - - alpestris.

24. - - adnata (Vertagus).

25. - - oceilata.

26. - declivis.

27. - Elephas.

28. - Sella.

29. - (Epith.) otrantina.

30. - dizyga.

31. - (Epith.) Librile.

32. - margaritifera.

33. - Argus.

34. - Djadema.

33. - (Epith.) quinquecostata.

36. - Corona.

\section{HIMANTIDIUM.}

Fig. I. Il. pectinale, c. strictum. 2. - ininus.
Fig. 3. H. Soleirolii.

4. - Halcyonellate.

5. - gracile.

6. - Arcus.

7. - monodon.

8. - Papilio.

9. - gujanense.

10. - attemuatum.

11. . Telraudon.

12. - bicęıs.

13. - veneris. (Ans Versehen ist die Nummer nicht beigesetz1, die Figur steht nnmittelbar uster N. i. c.)

\section{FRAGILARIA.}

Fig. 1. F, virescens.

2. - capucina.

3 - acuta.

4. - corrugata.

j. - constricta.

6. - rhabdosoma.

7. - dioplinhulma.

8. - bijunctata.

DENTICHLA.

Fig. 1. D. undulata.

2. constricta.

3. - thermalis.

4. - tenuis.

5. - elegans.

6. - frigida.

7. - acuta.

8. - obtusa.

MEtiLION.

Fig. 1. M. circulare.

2. - constrictum.

3. - Zinckenii.

4. - ? panduriforme. 


\section{Tab. II.}

ODONTHMLII.

Fig. 1. O. grande.

2. - Mesodon.

3. - pinnatum.

t. - a. b, d, liemale.

i. - c, rotundatum.

.̈. - glaciale.

6. - turgidulum.

7. - salislurgense.

8. - bugotanum.

9. - striolatum.

\section{CYCLOTELLA.}

Fig. 1. C. operculata.

2. Menegliniana.

PIXIDICULA.

P. major.

MELOSIRA.

Fig. 1. M. salina.

2. - orichalcea.

3. - crenulata.

i. - rarians.
Fig. 3. II. arenaria.

6. - subflexilis.

7. Jürgensii.

8. - garganica.

9. - distans.

10. - aequalis.

11. - americana.

12. - Binderiana.

\section{CAMPYLOIISCLS.}

Fig. 1. c. radiosus.

2. ? striatus.

DIATOMA.

Fig. 1. 1). elongatum.

2. - pectinale.

3. - mesodon.

i. - cuneatum.

ə. - tenue: a) intermediun, b) cuneatum, c) normale, d) moniliforme, e) dimotum.

6. - vulgare.

7. - Ehrenbergii.

8. - mesoleptum. 




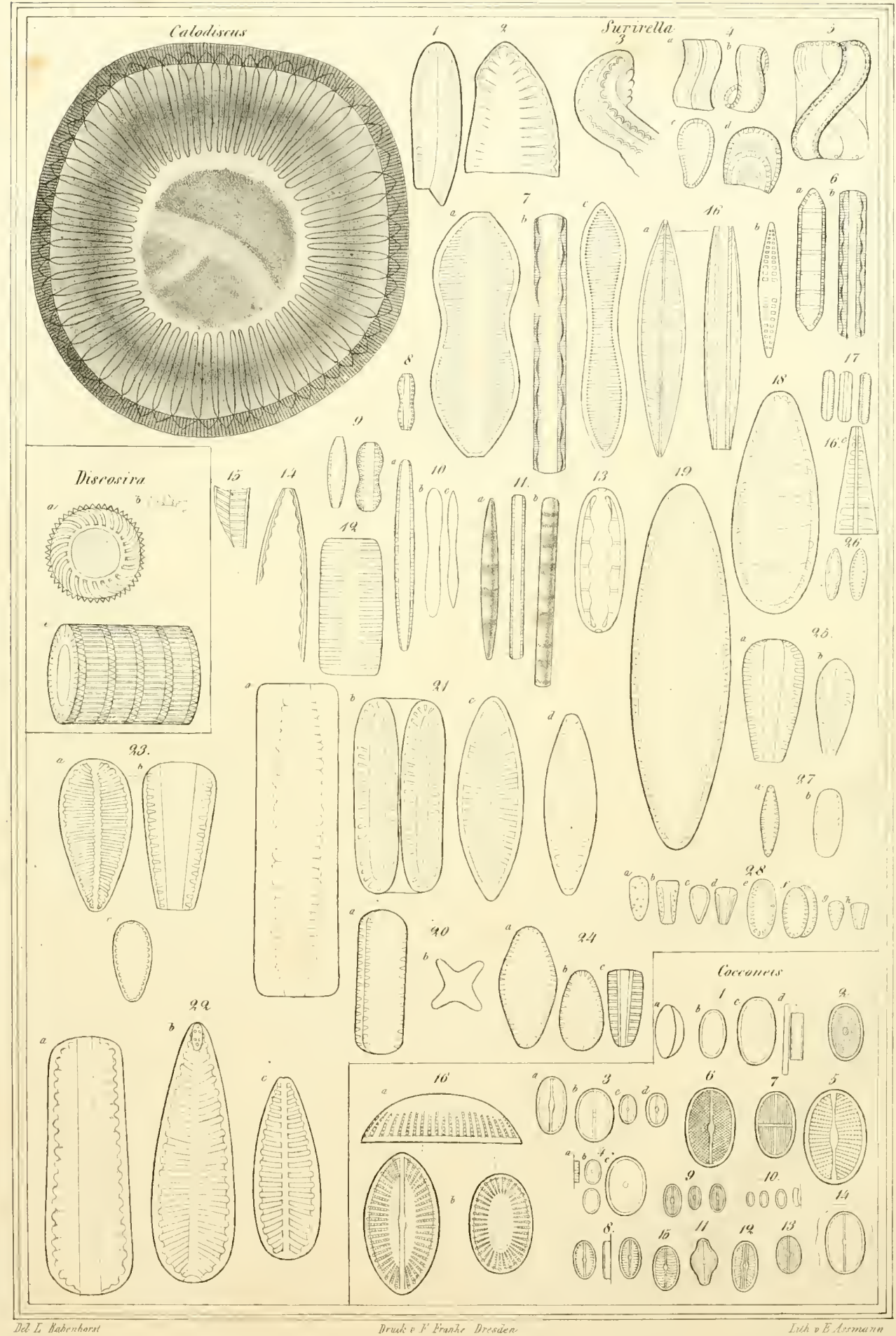


Tab. III.

CALODISCUS superbus.

DISCOSIRA sulcata.

SURIRELLA.

Fig. I. S. Myodon.

2. - elegans.

3. - flexuosa.

4. . Campylodiscus.

5. - spiralis.

6. - regula.

7. - Solea (Librilis Ehbg.)

8. - didyma.

9 - panduriformis.

10. - umbonata.

11. - multifasciata.

12. - ambigua.

13. - Breuteliana.

14. - oblonga.

1.5. - ? australis.

16. - Craticula b) chilensis.

1\%. angusta.

18. - elliptica.

19. - peruviana.

20. - Jenneri.

จ1. - biseriata (bifrons).
Fig. 22. S. splendida.

23. - striatula.

24. - ovalis.

23. - euclypta a) Vorderfliiche, b) Seitenlliiche.

26. - microcora.

27. - obtusangula.

28. - minuta.

\section{COCCONEIS.}

Fig. 1. C. Pediculus.

2. - punctata.

3. - Placentulia.

4. - Scutellum.

5. - persica.

6. - decussati.

7. - fasciata.

8. - salinia.

9. - minor.

10. - pumila.

11. - mexicana.

12. - striata.

13. - concentrica.

14. - limbata.

15. - Scutellum (Legumen).

16. - brundusiaca. 


\section{Tab. IV.}

\section{SYNEIRA.}

Fig. 1. S. Sigmatella) Nitzschii.
2. - Brébissonii.
3. - - vermicularis.
4. - Ulna e) splendens.
5. - amphirhynchus v. otrantina.
6. - capitata.
7. - amphirhynchus.
8. - spectabilis.
9. - valens.
10. - scalaris.
11. - tergestina.
12. - italica.
13. - saxonica.
14. - lanceolata.
1:. - Vaucheriae.
16. - notatu.
17. - pulchella.
18. - lanceolata.
19. - praemorsa.
20. - a. b. c. atpiculata. d. e. gracillima.
21. - familiaris.
2.2. - socialis.
23. ; acuta f. g. oxyrhynchus.

Fig. 24. S. vitrea.

25. - aequalis.

26. - debilis.

27. - porrecta.

28. - amplicephala.

29. - palea.

30 . - angustata.

31. - acicularis.

32. - Atomus.

33. - minutissima.

34. - pusilla.

3.3. - perpusilla.

36 . - rentricosa.

$37 . \quad$ - Biasolletiana.

38. - dissifrata (fasciculata).

34. - parvula.

40. - rudians.

1. - parva.

42. - Acus.

i3. - laevis.

4f. - subtilis.

45. - gracilis $\div$ forma italica.

46. - Fusidium.

47. - fusidioides. 


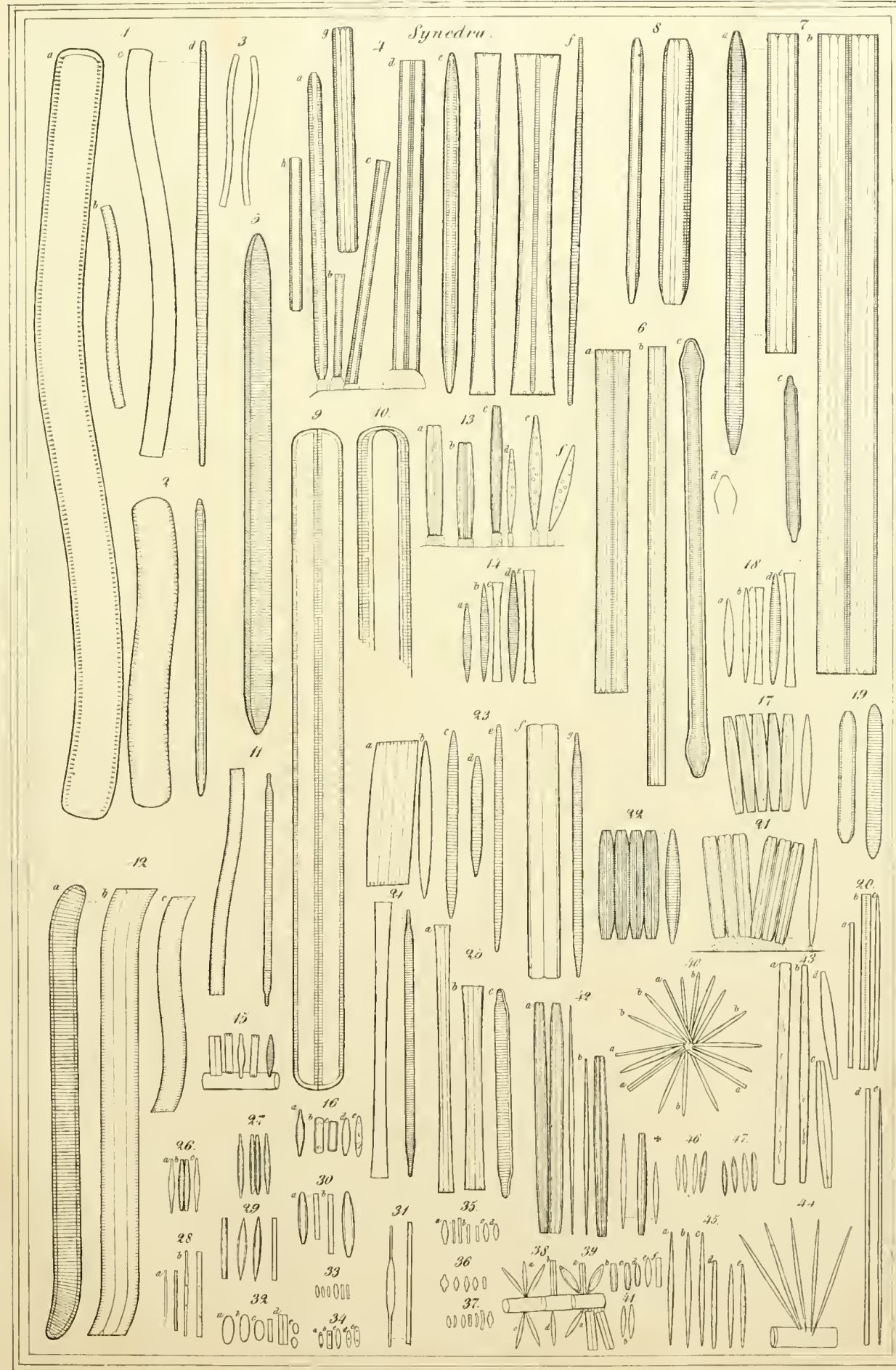




Tif. 1.

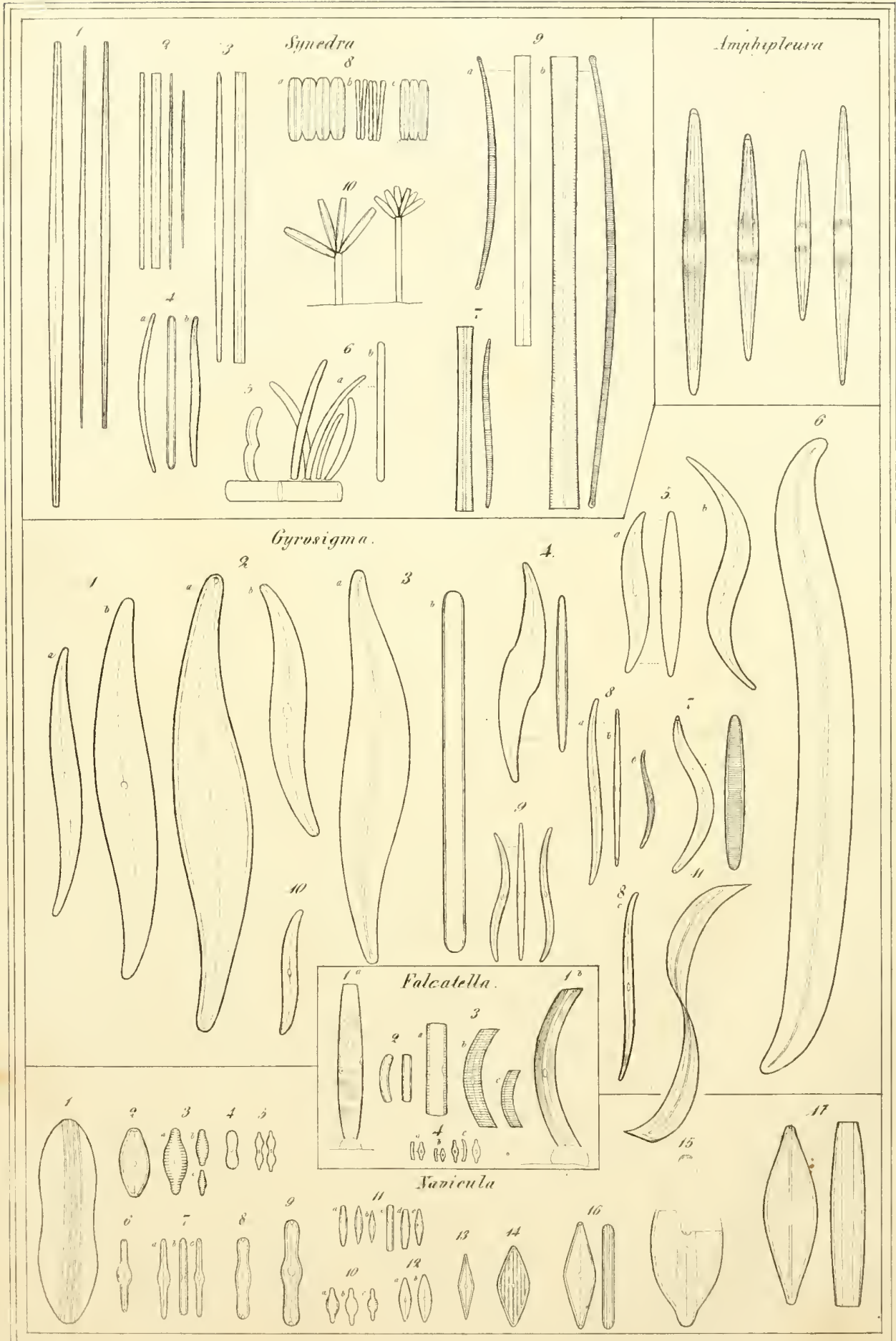




\section{Tab. V.}

\section{SYNEDRA.}

Fig. 1. S. Aeula.

2. - tenuissima.

3. - tenuis.

4. - $\alpha$. curvula, $\beta$. punctata.

5. - bilunaris.

6. - lumaris.

7. - mesolepta.

8. - rumpens.

9 . bicens.

10. - Ehrentiergii.

AMPHIPLEURA.

Fig. 1. A. pellueida.

\section{GYROSIGIA.}

Fig. !. G. Hassallii.

פ. - attemuata.

3. - Hippocampa.

4. - thuringica.

ว. - acuminata, b. cuspidata.

6. - baltica.

7. - apula.

8. - eurvula.

9. - lamprocampa.

10. - Scalpellum.

11. - dubia.

\section{FALCATELLA.}

Fig. 4. a. b. F. romana.

2. F. lunata.

3. - neapolitana.

4. - delicatula.

\section{NAVICULA.}

Fig. 1. N. paradoxa.

2. - Semen.

3. - (Pimnularia) capitata.

4. - duplicata.

3. - binodis.

6. - mesotyla.

7. - seopulorum.

8. - leptogongyla.

9. - tumidula.

10. - a. b. intlata, e. Pinnularia intlata.

11. - a. b. aponina, c. d. e. braclysira.

12. - Velox (oblonga).

13. - rhomboides.

14. - nombea.

15. - Lyra.

16. - cuspidata.

17. - fulva. 


\section{PINNULARIA.}

Fig. 1. P. Iridis.

2. - nobilis.

3. - interrupti.

4. - viridis.

5. - majol.

6. - oblonga.

7. - Esox.

8. - Vactylus.

9. - radiosa.

10. - peregrinat.

11. - pachypterit.

12. - inctequalis.

13. - chileusis.

1i. - sueciea.

1\%. - Gastrum.

16. Placentula.

17. - hemiptera.

48. - cocconeoides.

19. - borealis.

20. - lanceulata.

21. - khrenbergii.

2. - Cyprinus.

23. - elliptica. c. italica. d. disciformis.

2i. - Tahellaria.

2:). - decurrens.

26. - didyma.

27. - gibba.

28. - Apis.

๑9. - Cynops.

30. - gibberula.

31. - limosa.

32. - dissinilis.

33. - Termes.

31. - Legunen.

3.3. - disphenia.

36. - acrosphaeria

$3 \%$ - diamphola.

38. - vulpina.

39 . viridula.

40. - pachycephala.

4. - garranica.

42. - otrantiua.

43. - Piscjculus.

44. - dicephina.

43. - amphiceros.

46. - rostellata.
NAVICLIA.

Fig. 47. N. Ampligumplus.

4x. - Dirhynchus.

49. - biceps.

̋0. - Amphirbynehus.

引̈. - serians.

52. - rostrata.

33. - microstoma.

54. - Brebissonii.

5.. - persica.

56. - undosa.

ij. - Carassius.

fis. - altinis.

59. - ambigua.

60. - dubia.

61. - latiuscula.

62. - fulva.

63. - amphioxys.

64. - gracilis.

6.j. - sphaerophora.

66. - amplisbaena.

6i. - truncata.

68. - rhynchreeplata.

69. - leptocephala.

70. - eurycephala.

71. - cryptocephala.

7.. - mesulepta.

73. - acuta.

7i. - guttulifera.

7. - limbata.

76. - Bacillum.

7. - lauceolata.

78. - appendicula.

79. - Jurgensii.

so. - ninutissima.

81 . mutica.

४2. - Pupula.

8:3. veneta.

84. - exilis.

8.j. - lineolata.

86 . - nodosa.

87. - appendiculata.

88. - aponina.

89. - Cesatii. 


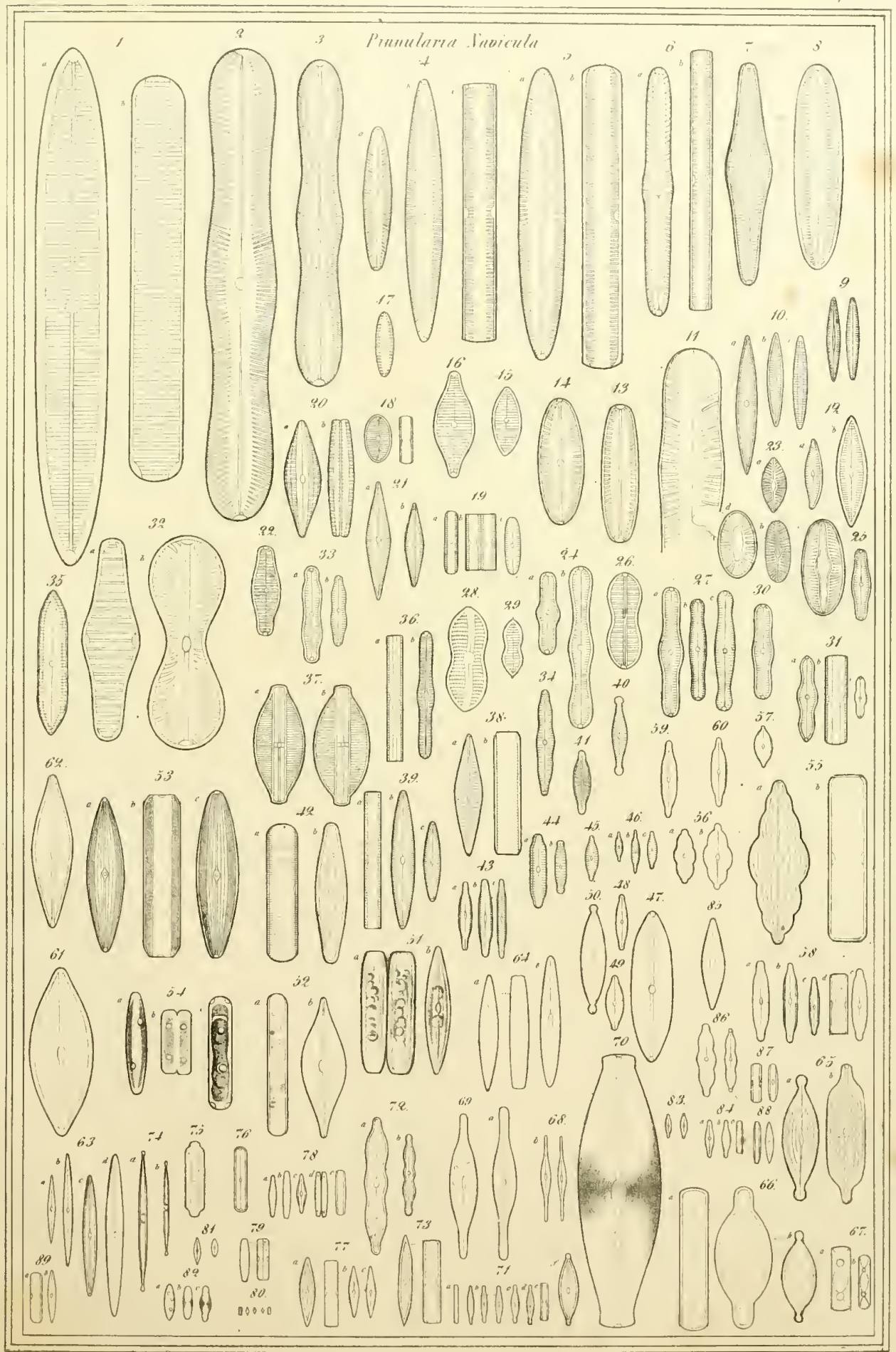





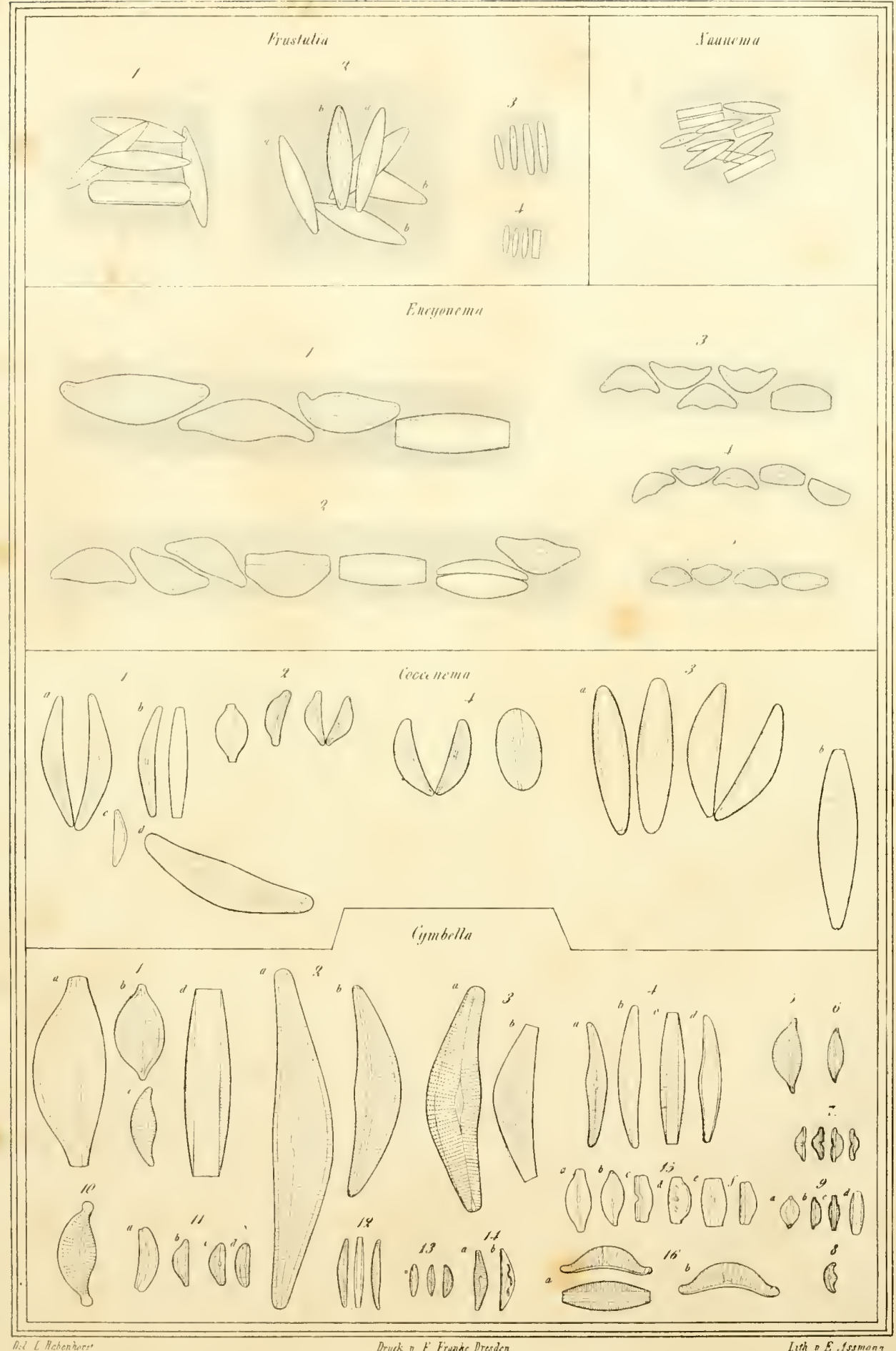




\section{Tab. VII.}

FRUSTULIA.

Fỉg, 1. F. saxonica.

2. - torfacea.

3. - Kützingiana.

4. - minuta.

NALINEIA.

Fig. 1. N. amplioxys.

ENCYONEIIA.

Fig. 1. E. prostratum.

2. - Auerswaldii.

3. paradoxum.

4. - idem (Copie!).

5. - caespitosum.

COCCONEMA.

Fig. 1. C. cyubiforme.

2. - gibbum.

3. - Ianceolatum.

4. - Cistula.
CYMBELLA.

Fig. 1. C. Ehrenbergij.

2. - gastroides.

3. - fulva (truncata).

4. - beIvetica.

i. - rostrata.

6. - obtusiuscula.

7. excisa.

8. - Fusidium.

9. - ventricosa.

10. - eurycephala.

11. - Lunula.

12. - gracilis.

13. - affinis.

1i. - a. leptoceras.

b. curvata.

1.3. - Hlexella.

16. - costata. 


\section{Tab. VIII.}

\section{ACIINANTHES.}

Fig. 1. A. exilis.

2. - minutissima.

3. - subsessilis.

1. brevipes.

5. - intermedia.

6. - turgens.

7. - cristata.

\section{ACHNANTHIDIUN.}

Fig. 1. A. Otrantinum.

2. - microcephalum.

SPHENELLA.

Fig. 1. S. oblusata.
2. - rostellata.
3. - elongata.
4. - vulgaris.
5. - glacialis.
6. - angustata.
7. - parvula.
8. - italica.

\section{SPHENOSIRA.}

Fig. 1. S. Catena.

\section{GOMPHONEMA.}

Fig. 1. G. sphenelloides.
2. - anglicum.
3. - auritum.
4. - perficum.
5. - tenellum.
6. - micropus.
7. - coronatum.
8. - Sceptrum.
9. Vibrio.

10. - lanceolatum.

11. - aftine,

19. - constrictum.

13. - acuminatum.

14. - geminatum.

Ḧ. - capitalun.

16. - pulvinatum.

17. - rotundatum.

18. - curvatum, b. und c. salinum.

19. - cristatum d. Argur, e. saxonicum.

20. - abbreviatum a. brevipes, b. longipes.

21. - discolor.

22. - cuspidatum.

23. - clavatum.

21. - Lagenula.

2:. - ? contractum.

26. - gracile (dichotomum) b. nach Ralfs.

27. - intricatum.

28. - hercynicum. 


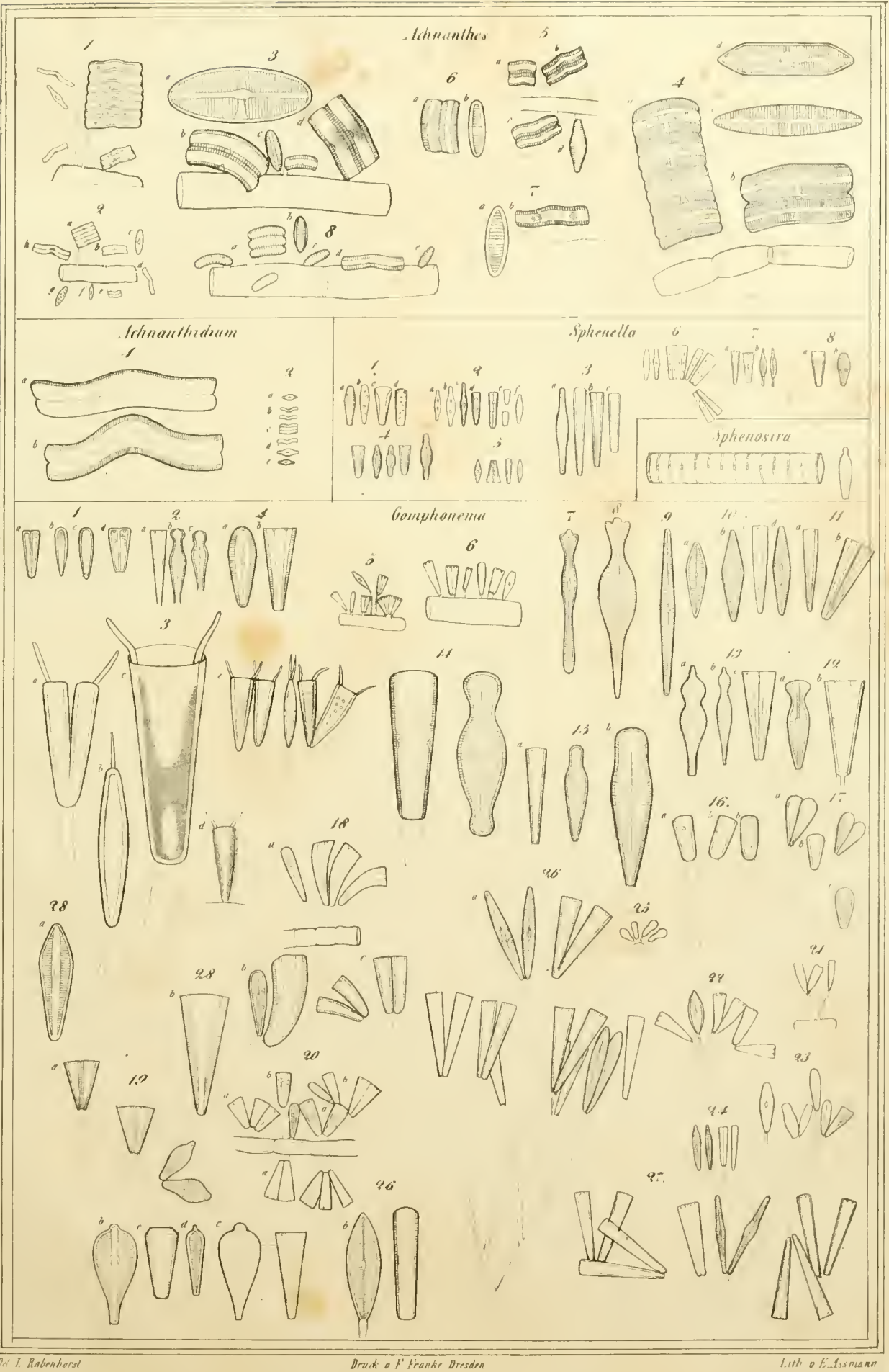




Till 1

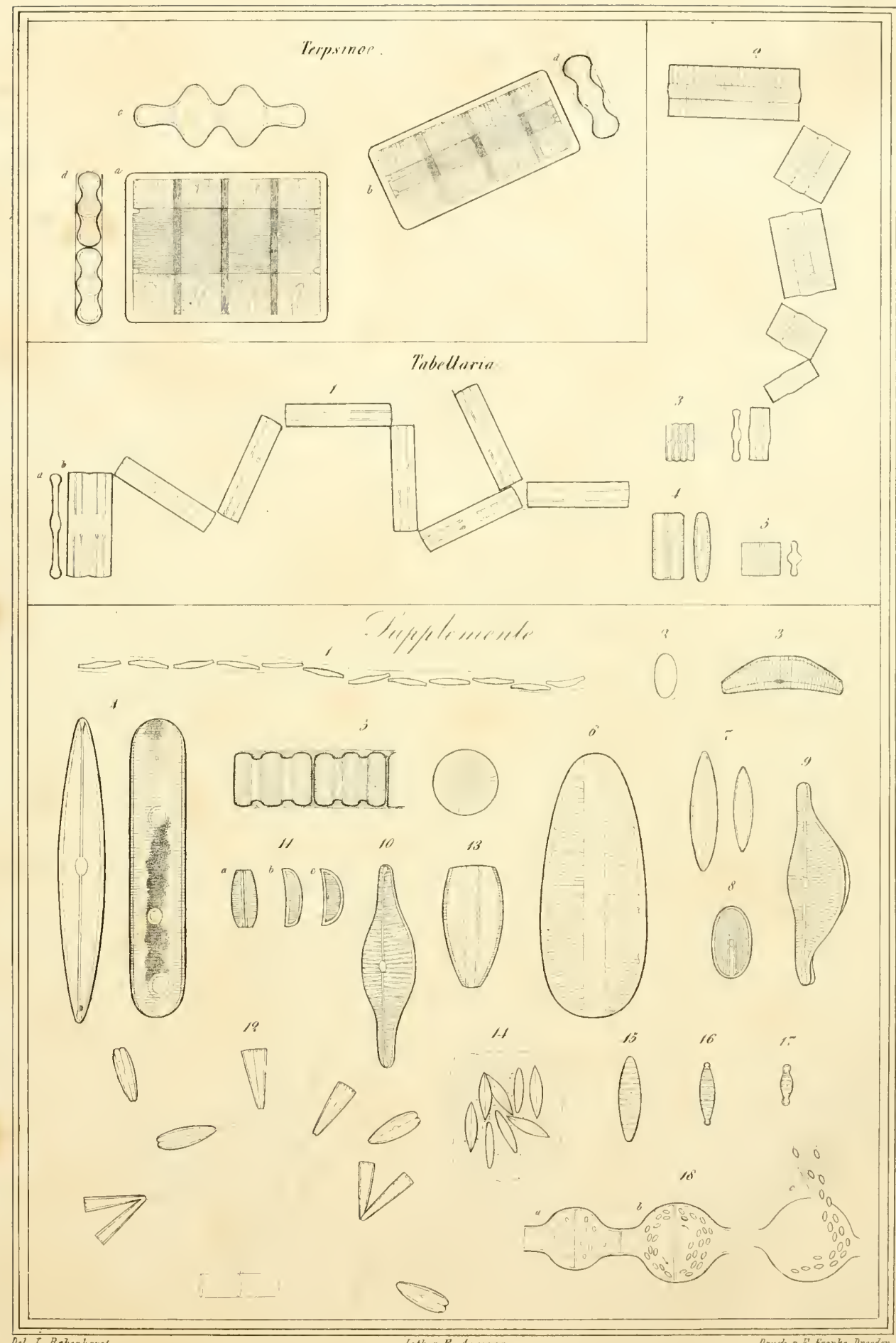




\title{
Tab. X.
}

\author{
TERPSINOE.
}

Fig. 1. T. musica.

TABELLAPIA.

Fig. 1. T, fenestrati.

2. - flocculosa.

3. - laevis.

4. - seulpta.

5. - ventricosa.

\section{SUPPLEMENTE.}

Fig. I. Encyouema gracile.

2. Cocconeis limbati.

3. Cymbella microstoma.

i. Pinnularia major. (Selianke Form aus Sachsen, die runden Zellen nit derber Zellhaut, ohne körnigen luhalt, gelb gefärbt.

5. Melosira Roeseana.

6. Surirella ichthyocephala.

\%. Stauroneis amplitepta (aus Thüringen!).

8 . Cocconeis striolata.

9. Cymbella fornicata.
Fig. 10. Cymbella porrecta.

11. Cocconenua saxonicuu.

12. Gomphonema erosum.

13. crassullu.

11. Frustulia ratzeburgensis Hanckeriana).

15. Odontidium liemale.

16. - clamocephalum.

17. - capitatum.

18. Fruchtzellen vou Melosira varians, b. Strimung des Zellinhaltes, c. das Ausströmen der Bruten. 


\section{Tab. IX.}

GONPHONELLA.

Fig. 1. G. olivacea.

2. - angustala.

3. - Lenormandi.

\section{CERATONEIS}

Fig. I. C. Arcus.

9. Fasciola.

3. - laminaris.

4. - amplhioxys.

\section{STAURONEIS.}

Fig. I. S. Phoenicenteron.
2. - platystoma,
3. - gracilis.
f. dilatata.
3. - constricta
6. - phyllodes.
7. - amphilepta.
8. - linearis.
9. - lanceolalis.
10. - Fenestri.
11. - exilis.
12. - amphiceplala.
I3. - birostris.
14. - ancejs.
15. - inflata.
16. - ventricosa.
17. - lineolata
18. - polygramma.
19. - acrocephala.

\section{STAUROPTERA}

Fig. I. S. aspera.
2. - Achnauthes.
3. - gibba.
4. - Legumen.
i. - Icostanron.
6. - parva.
7. - microstauron.
8. - scalaris.
9. - cardinalis.
10. - constricta.
11. - punctata.
12. - truncata.
13. - Peckii.
1i. - (Staurogramma) decussata.
1:. - paucicostatit.

\section{ANPIIORA.}

Fig. 1. A. oralis.

2. - gracilis.

3. - libyca.

4. - aftinis.

3. - quadricostata.

6. coffeaeformis.

7. - Fischeri.

8. - aponina.

9. - lineolata (nach Elureuberg).

10. - dieselbe aus Sachsen.

11. - Hohenackicri.

\section{GOMPHOGRAMIIA.}

Fig. 1. G. rupestre.

\section{TETRACYCLUS.}

Fig. I. T. lacnstris. 
Tiif III

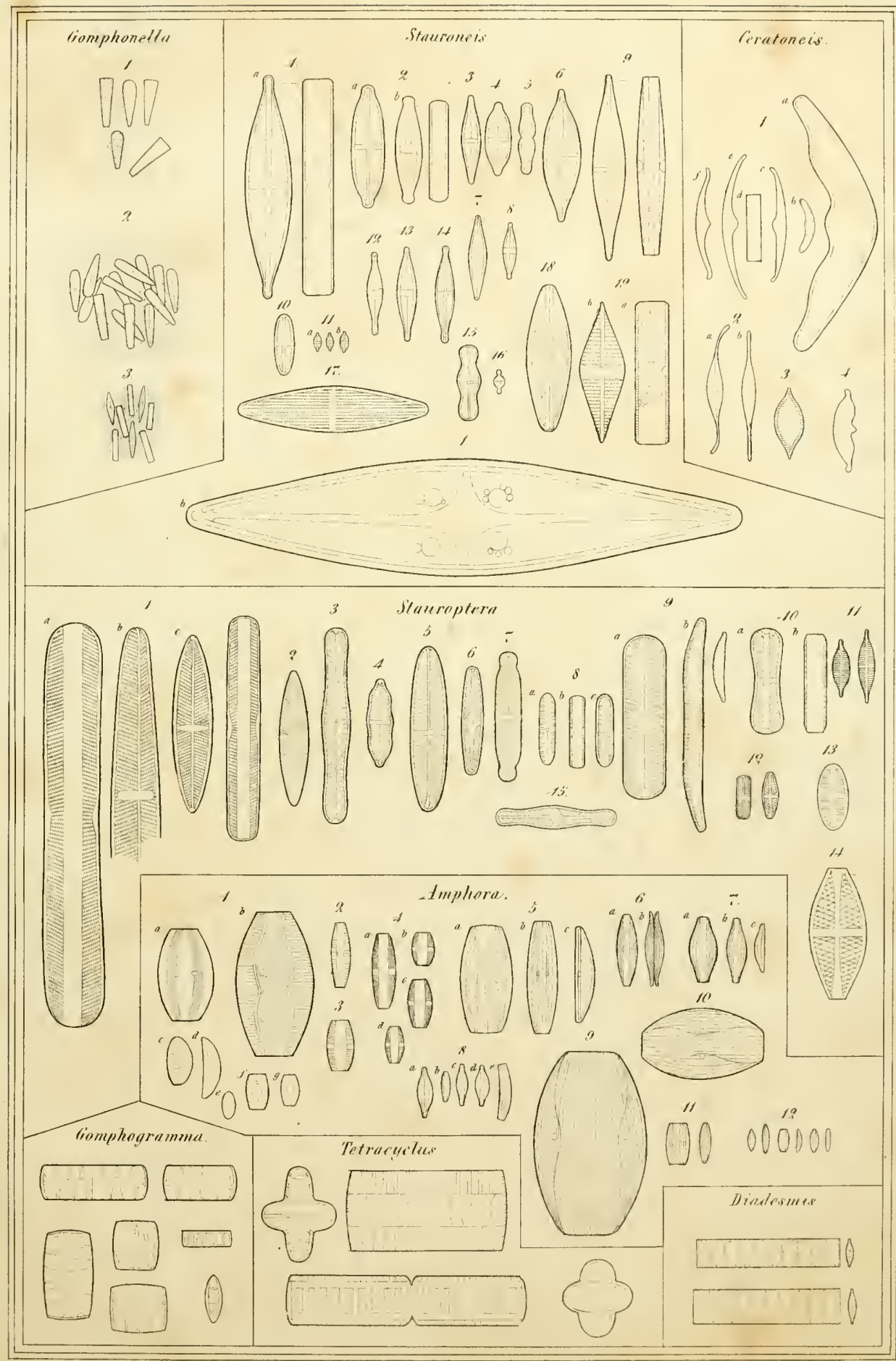



$-$ 




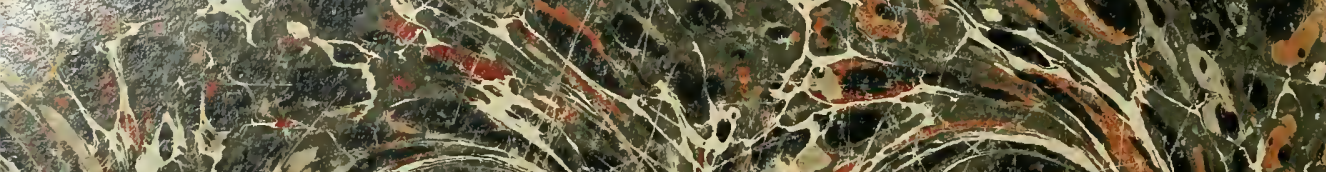

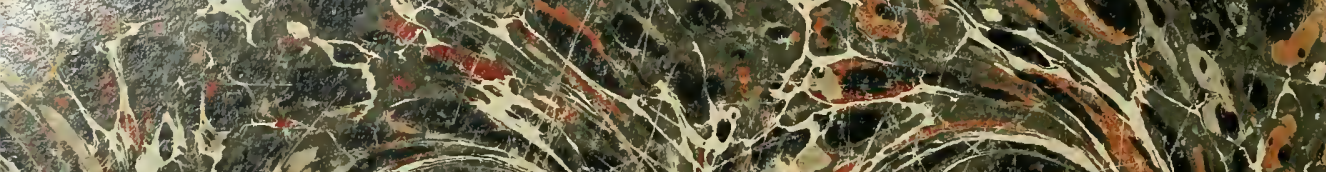
1) $27=0$

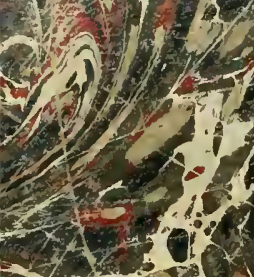
(1) $M(-1,25)$
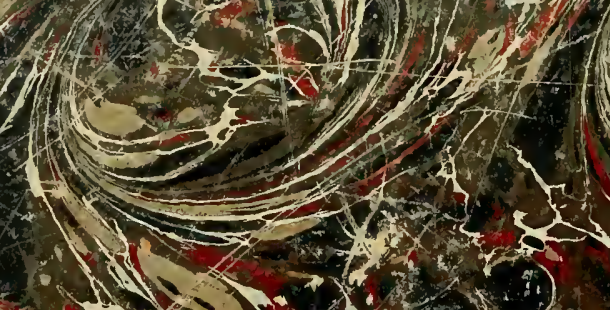

e

(2) กix.

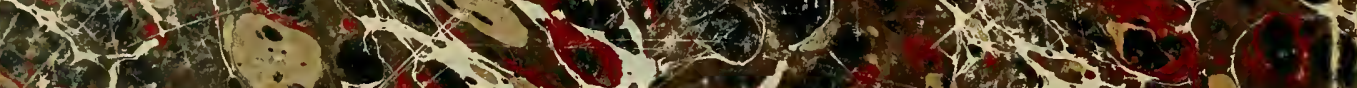

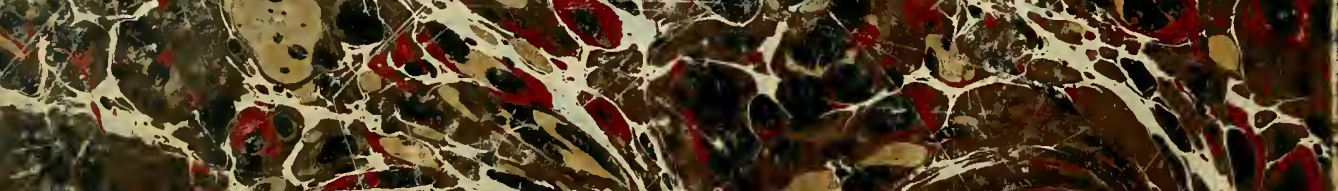

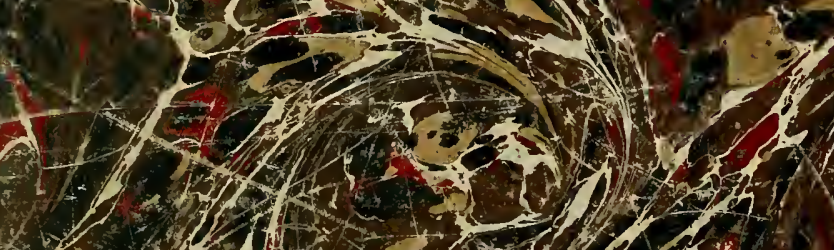

$\frac{2}{3}$

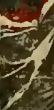

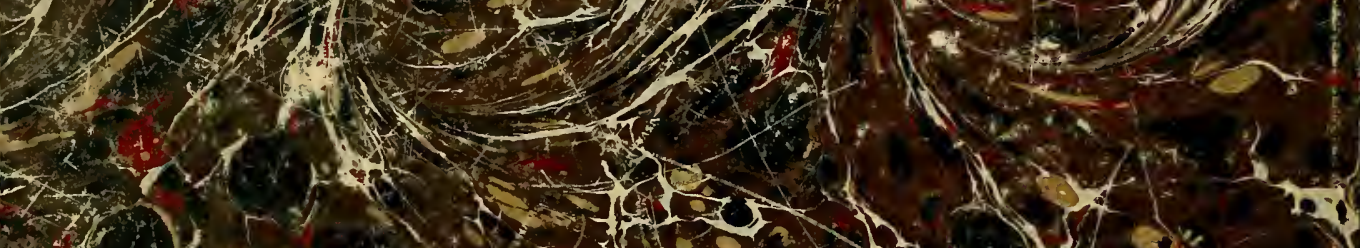
$+2$

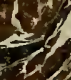

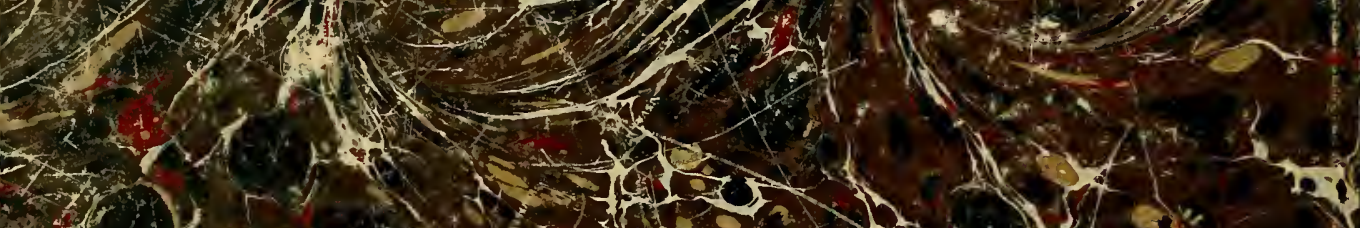

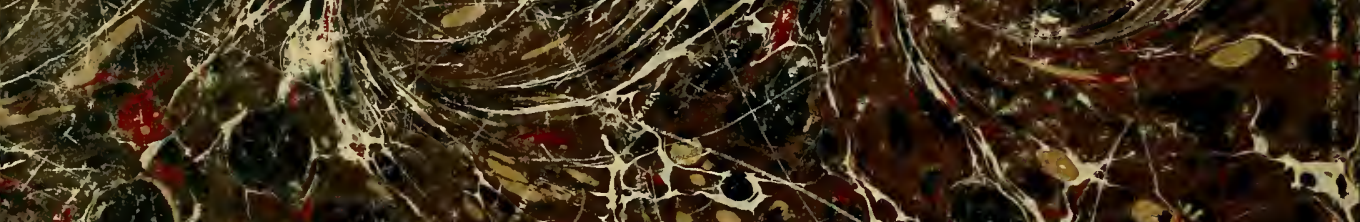

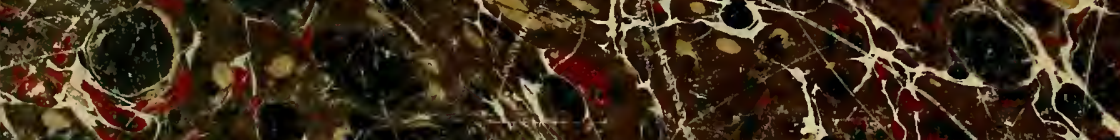

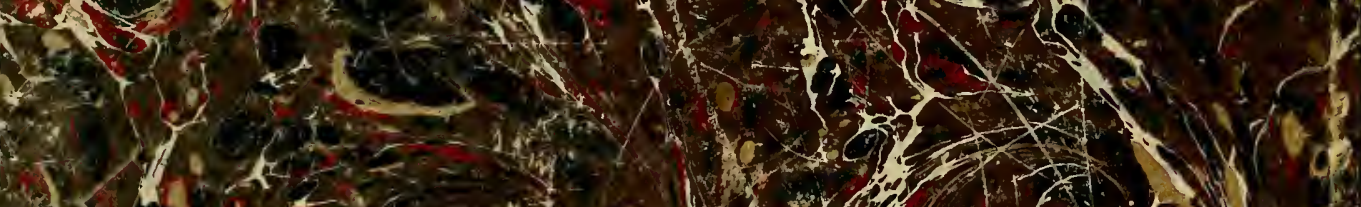

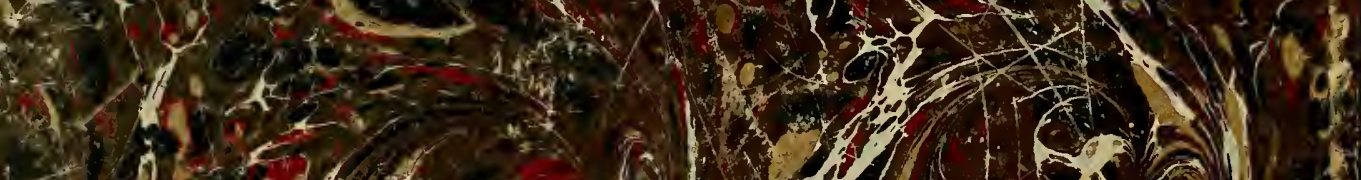
3) 2. $14=2$ -1

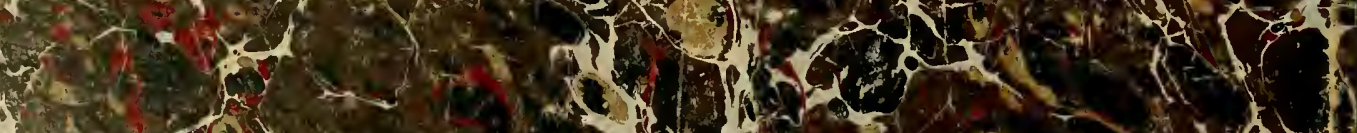

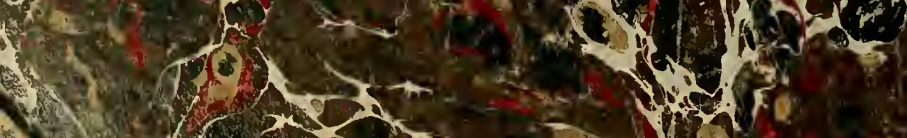
$1+x+y^{2}$

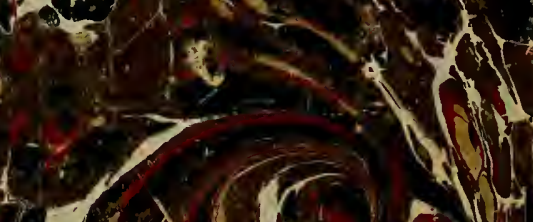

